

Tendencias actuales de los Derechos

Humanos y el Derecho Internacional

Humanitario en Colombia 



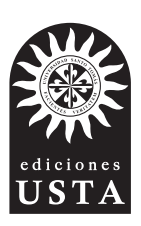

\section{Tendencias actuales de los Derechos Humanos y el Derecho Internacional Humanitario en Colombia}

Jorge Enrique Carvajal Martínez COMPILADOR ACADÉMICO

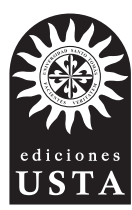




\section{Alfonso Camelo, Heyder}

Tendencias actuales de los Derechos Humanos y el Derecho Internacional Humanitario en Colombia/ Heyder Alfonso Camelo, (y otros diecisiete), Bogotá: Universidad Santo Tomás, 2018.

347 páginas; cuadros, gráficos e ilustraciones

Incluye referencias bibliográficas

ISBN 978-958-782-133-8

E-ISBN: 978-958-782-134-5

1. Derechos humanos-Colombia. 2. Protección de los derechos humanos-Colombia. 3. Pobreza-Colombia. 4. Posconflicto-Colombia. 5. Conflicto armado-Colombia. 6. Desplazamiento forzado-Colombia-Investigaciones 7. Reparación (Justicia penal) 8. Derecho internacional humanitario I. Universidad Santo Tomás (Colombia).

CDD 341.04 CO-BoUST

(C) Heyder Alfonso Camelo, Ana María Jimenez, Jorge Carvajal, Helber Noguera, Iván Darío Valderrama Romero, Román Francisco Téllez Navarro, Carolina Blanco Alvarado, Alejandro Ramelli Arteaga, Alejandro Valencia Villa, Liliana Rocío Chaparro Moreno, María Constanza Ballesteros Moreno, Álvaro Moreno Duran, Cecilia Barraza Morelle, Lucía Gómez Castro, Juan Andrés Amador, David Valencia, Elsa Bonilla Piratova y Sandra Milena Molina Peláez

(C) Compilador académico: Jorge Enrique Carvajal Martínez

Comité científico: Omar Huertas Díaz, doctor en Ciencias de la Educación, docente de la Universidad Nacional de Colombia; Eduardo Rodríguez, doctor en Sociología jurídica, docente de la Universidad Nacional de Colombia; Misael Tirado Acero, doctor en Sociología Jurídica, docente de la Universidad Católica de Colombia; José Manuel Gual Acosta, doctor en Derecho Privado, profesor de la Universidad Libre; y German Burgos Silva, doctor en Derecho, docente de la Universidad Nacional de Colombia

Comité editorial: Rodolfo Torregrosa Jiménez., doctor en Sociología Jurídica, docente de la Universidad Libre; David Echeverry Botero, magíster en Derecho Económico, docente de la Universidad Javeriana; Joaquín Acosta Rodríguez, Doctor en Derecho Privado. Docente e Investigador de la Universidad Militar Nueva Granada; Mónica Lucia Fernández, doctora en Derecho Privado, profesora de la Universidad Católica; y Rodrigo Plazas Estepa, magíster en Derecho, docente de la Fundación Universitaria Republicana.

Pares académicos: Henry Bocanegra, doctor en Sociología jurídica, docente e Investigador de la Universidad Libre, y Andrés Mauricio Guzmán Rincón., doctor en Derecho, docente e Investigador de la Universidad Libre.

(C) Universidad Santo Tomás, 2018

Ediciones USTA

Bogotá, D. C., Colombia

Carrera 9 n. ${ }^{\circ} 51-11$

Teléfono: (+571) 587 8797, Ext. 2991

editorial@usantotomas.edu.co

http://ediciones.usta.edu.co

Hecho el depósito que establece la ley
ISBN: 978-958-782-133-8

E-ISBN: 978-958-782-134-5

Primera edición, 2018

Se prohíbe la reproducción total o parcial de esta obra, por cualquier medio, sin la autorización autorización expresa del titular de los derechos.

Impreso en Colombia • Printed in Colombia 


\section{Tabla de contenido}

INTRODUCCIÓN

Jorge Carvajal

PRIMERA PARTE. TEMAS Y DEBATES DEL POSCONFLICTO

ESTADOS EN PERIODOS DE POSCONFLICTO: ELEMENTOS

PARA LA COMPRENSIÓN DE LOS RETOS LUEGO DE

LA SUPERACIÓN DE UN CONFLICTO ARMADO

Heyder Alfonso Camelo

INTERPRETACIÓN DE LA LEY DE VÍCTIMAS Y DE RESTITUCIÓN DE TIERRAS A FAVOR DE LOS NIÑOS, NIÑAS Y ADOLESCENTES

QUE HAN SIDO RECLUTADOS POR GRUPOS ARMADOS

en Colombia.

Ana María Jimenez

El Movimiento de víctimas en América Latina y una APROXIMACIÓN A UNA CARACTERIZACIÓN DE ORGANIZACIONES DEFENSORAS DE DERECHOS HUMANOS EN COLOMBIA

JoRge CARVAJAL

Helber Noguera

LA INCERTIDUMBRE DE LAS VICTIMAS DENTRO DEL ACUERDO PARA LA CONSTRUCCIÓN DE UNA PAZ ESTABLE Y DURADERA

Iván Darío Valderrama Romero

Román Francisco Téllez Navarro

Carolina Blanco Alvarado

REFLEXIONES SOBRE LA NATURALEZA JURÍDICA DEL I03 ACUerdo Final

Alejandro Ramelli Arteaga 
Preguntas Y ReSPUESTAS SOBRE EL DERECHO A LA VERDAD Y LA FUTURA COMISIÓN QUE SOBRE EL PARTICULAR HABRÁ EN COLOMbia

Alejandro Valencia Villa

SEGUNDA PARTE. GÉNERO Y DERECHOS HUMANOS

EL PRINCIPIO DE IGUALDAD Y NO DISCRIMINACIÓN

Y LOS ENFOQUES DIFERENCIALES COMO HERRAMIENTA

Liliana Rocío Chaparro Moreno

Violencia de GÉNero InSTITUCiOnal

I 8 I

María Constanza Ballesteros Moreno

Álvaro Moreno Duran

EL GÉNERO: UNA HERRAMIENTA A FAVOR DE LOS DERECHOS

$20 I$ HUMANOS DE LAS MUJERES Y DE LAS MINORÍAS CON GÉNERO NO HEGEMÓNICO

Cecilia Barraza Morelle

TERCERA PARTE. LAS REDES SOCIALES Y PRIVACIDAD, EDUCACIÓN EN DERECHOS HUMANOS Y DEFENSA DEL ESTADO

“CHOOSE LIFE”: PRIVACIDAD, REDES SOCIALES Y BIG DATA. 235

Lucía Gómez Castro JUAN ANDRÉS AMADOR

David Valencia

CONSIDERACIONES SOBRE LA PERTINENCIA DE LA 277 EDUCACIÓN EN DERECHOS HUMANOS

Elsa Bonilla Piratova

INSTITUCIONES EN LA DEFENSA JURIDICA INTERNACIONAL DEL ESTADO

Sandra Milena Molina Peláez 


\section{Introducción}

$\mathrm{D}$ esde finales del siglo XX el Estado Social de Derecho se constituyó como la guía a seguir en le ordenamiento político, social y jurídico en la mayoría de países de occidente. Este modelo fortaleció los derechos y libertades de las personas, a demás se propuso mejorar las necesidades materiales sociales de la sociedad. Para ello se incorporó al interior de las constituciones un amplio catálogo de derechos y garantías en el ámbito individual, así como de corte social, económico y cultural. También el nuevo constitucionalismo dio un importante reconocimiento a los tratados internacionales en el ordenamiento jurídico interno.

Con la ampliación de titularidades en el marco nacional y su desarrollo en lo internacional, se ha generado nuevas discusiones sobre los derechos humanos en particular los niveles de exigibilidad de los derechos civiles y políticos, así como las garantías para la materialización de los derechos económicos, sociales y culturales. Al rededor del tema emergen diferentes posiciones acerca del grado de relación existente entre los diferentes pactos de derechos humanos y el nivel de materialización por vía legislativa o jurídica al interior delos Estados. En particular este debate se da entre los derechos civiles y políticos con relación a los derechos económicos, sociales y culturales. Algunos sectores consideran que los derechos civiles y políticos son derecho fundamentales esto se refleja en el grado de exigibilidad jurídica ya que son de obligatorio cumplimiento en todo momento y lugar, el juez está obligado a hacer cumplir y respetar estos los derechos fundamentales. Mientras que los derechos sociales son de orden prestacional y programático atados a la regla fiscal, por lo tanto no exigibles por vía jurídica. Existe también el enfoque de la interdependencia, indivisibilidad y universalidad de los derechos, de tal manera que entendemos los derechos humanos tanto los civiles y políticos como los económicos y sociales son derechos humanos exigibles por vía judicial. 
Por otro lado, en el actual orden constitucional, existe un reconocimiento amplio de los sujetos de derechos. Se ha creado una estructura legal que otorga titularidades de reconocimiento a grupos sociales antes excluidos como las mujeres, las comunidades étnicas, o grupos por razón de su edad o su identidad sexual, entre otros. Por este motivos, los movimientos sociales y los grupos han incrementado sus accionar frente al derecho y reclaman la realización efectiva de lo social, es decir, el cumplimiento de los derechos sociales para la realización de condiciones materiales, para superar los desequilibrios y las desigualdades materiales.

Para materializar los derechos de los grupos y movimientos sociales, han utilizado las acciones constitucionales como medio para la realización de los derechos. En términos generales podemos señalar que a través de estas acciones se brinda el garantismo jurídico, el cual consiste en el desarrollo de un sistema de principios, normas e instituciones jurídicas, que tienen como función sujetar los poderes públicos a la ley y a la constitución y materializar las derechos humanos. El sistema de garantías que hoy en día tiene un valor supremo en el Estado constitucional se caracteriza por el sistema de garantías adquiere su máxima expresión al incorporar en norma constitucional los tratados internacionales de derechos humanos y con ello ampliar el rango de protección y de tutela de derechos y promover la justicia constitucional al interior de los tribunales de justicia quienes serían los garantes al momento en el cual un ciudadano accionará el sistema de garantías.

A pesar de que el discurso de los derecho humanos se ha consolidado existen importantes retos para su materialización, por ejemplo, a nivel global la disputa entre los derechos y la seguridad (Ramírez; Guecha \& otros 2017) ${ }^{1}$ y en el contexto latinoamericano se presentan innumerables conflictos de orden político, social y económico aún no superados. Para el caso colombiano, a demás de los temas anteriores es

1 Ramírez; Guecha \& otros, (2017), Las tensiones entre libertad y seguridad, Ed. Grupo Editorial Ibáñez y Universidad Santo Tomás de Aquino, Bogotá, Colombia. Castillo; Nino \& otros (2017), Nociones sobre seguridad y paz en las Relaciones Internacionales Contemporánea, Ediciones USTA, Bogotá, Colombia. 
necesario reflexionar sobre la paz. Esta situación impone nuevos retos al Estado social de derecho y al constitucionalismo contemporáneo.

El texto que presentamos y que hemos titulado: Tendencias actuales de los Derechos Humanos y el Derecho Internacional Humanitario en Colombia, incorpora desde diversas perspectivas teóricas y problemáticas relacionados con los derechos humanos y el Estado social de derecho. El objetivo de la investigación era de estudiar algunos de los conflictos presentes en el país, para ello decidimos hacer estudios interdisciplinarios reuniendo a investigadores de derecho de nuestra facultad. A partir diversas reuniones se establecieron discutir sobre tres temas que pueden a portar a pensar un pensar un mejor país, estos fueron: en primer lugar, se analizan temas y debates del posconflicto, de los innumerables aspectos que podemos analizar se privilegiaron problemas de los derechos de las víctimas y el marco jurídico del pos acuerdo, aspectos que sin duda son relevante para consolidar la paz. Un segundo grupo de investigaciones se enfocaron a los debates sobre derechos humanos y género, enfocado principalmente en los derechos de las mujeres analizando aspectos tan importantes como no discriminación y violencia. Por último, un grupo de investigadores propusieron trabajar temas que a veces por la coyuntura social o políticas son dejados al margen, en este sentido este grupo analizó los siguientes aspectos, las redes sociales y privacidad, educación en derechos humanos y defensa del estado.

Agradecemos el apoyo dado por la decanatura y la dirección del centro de investigaciones sociojurídicas "Francisco de Vitoria" quienes nos alentaron en todo momento para el desarrollo de este trabajo.

Jorge EnriQue Carvajal Martínez DOCTOR EN SOCIOLOGÍA JURÍDICA E INSTITUCIONES POLÍTICAS 



\section{PRIMERA PARTE \\ LOS TEMAS Y DEBATES \\ DEL POSCONFLICTO}





\section{Estados en periodos de posconflicto: Elementos para la comprensión de los retos luego de la superación de un conflicto armado}

Heyder Alfonso Camelo

\section{Introducción}

$\mathrm{F}^{1 \text { fin de un conflicto armado suele alcanzarse, en términos genera- }}$ Cles, a través de dos vías: por medio de una negociación política llevada a cabo por las partes en confrontación, o por la victoria militar de uno de los actores. De cualquier forma, este periodo que inicia con el cese de hostilidades entre las partes enfrentadas es entendido como posconflicto (Rettberg, Guizado, 2002, p. 19), y los Estados, al igual que la sociedad en su conjunto, acostumbran encaminar esfuerzos en fortalecer sus instituciones con miras a iniciar un proceso de reconstrucción de confianza con la ciudadanía.

Frente a este escenario la recuperación económica desempeña un papel central en la esfera pública (Collier, 1994; Collier, Hoeffler, Söderbom, 2008); en el ámbito político y social se implementan estrategias de inclusión de actores políticos o sancionan a aquellos que estuvieron una vez involucrados en la guerra (Hartzell, 2007); pero también se hace relevante la posibilidad de implementar los acuerdos alcanzados (Fortna, 2004, 2008; Walter, 2002). En otras palabras, se inicia una reconstrucción de la sociedad que permita superar las consecuencias dejadas por el conflicto y logre la normalización del país afectado. 
Un conflicto armado afecta algunos de los propósitos fundamentales de un Estado, como lo es mantener el orden y evitar la violencia, la hostilidad y las agresiones entre los diversos actores que lo conforman. En este orden de ideas, dentro de un conflicto armado, la hostilidad se configura en un escenario en el cual los individuos y los colectivos pueden resolver sus tensiones y los conflictos cotidianos; recurriendo a la violencia como una estrategia válida para esta finalidad ${ }^{2}$.

Como consecuencia de esto se observa cierta fragilidad del Estado en dos aspectos fundamentales. El primero de ellos reside en que la capacidad de regulación del orden social del Estado es afectado por los actores que le compiten, tanto en términos institucionales, de ejercicio de la violencia, como de recursos. El segundo planteamiento, a su vez, reconoce la pérdida de legitimidad del Estado en dicha regulación que afecta tanto a las poblaciones en las cuales se experimentó con mayor fuerza el conflicto armado como en las que no. Esto, al entrar en un periodo de posconflicto, afecta directamente la capacidad del Estado para regular el orden social, trayendo como consecuencia, entre otras, variaciones en la violencia que es desplegada.

Para comprender los retos de los Estados en un periodo de posconflicto el presente artículo se encuentra estructurado en tres secciones. La primera de ellas se encuentra encaminada a delimitar el concepto de posconflicto, determinando sus características y alcances analíticos. La segunda sección gira en torno a los efectos de los conflictos armados sobre la capacidad y legitimidad de los Estados, reconociendo los elementos clave para ser atendidos en un posconflicto. Por último, en la tercera, se presentan de manera sucinta los retos a tener en cuenta en el momento de entrar a un periodo de posconflicto.

\section{Acerca de los periodos de posconflicto}

Este artículo se centra, ante todo, en el concepto de posconflicto sobre otros como lo son el de posguerra o posacuerdo, principalmente por

2 Esta idea ha sido tomada del concepto de estado de guerra que trabaja Uribe (1999), y que posteriormente es retomada por Gonzalez, Bolivar, \& Vasquez (2003) 
dos razones. La primera de ellas debido a su origen. A partir de la década de los noventa ${ }^{3}$, la consolidación de la paz después de los conflictos es tratada como aquellas medidas destinadas a individualizar y fortalecer estructuras que tiendan a reforzar y afianzar la paz a fin de evitar una reanudación del conflicto (Boutros-Ghali, 1992. 11). Y, en ese contexto, la idea de guerra fue reemplazada por la de conflicto, con un claro propósito de diferenciarlo del periodo de la Guerra Fría; reconociendo a través de este cambio las emergentes dinámicas de confrontación, donde lo que predominaba no era la guerra entre Estados sino los conflictos internos.

Esta fundamentación toma distancia de la idea de posguerra sustentada por Suhrke \& Berdal (2011), quienes hacen referencia al posconflicto como un oxímoron; hecho por el cual no recurren a esta categoría. De hecho explicitan la dificultad, en términos cualitativos, de definir la duración de este periodo "pos”, aunque en términos cuantitativos reconocen que el punto de quiebre es un periodo de cinco años. O el de Darby (2005) y Steenkamp (2011) quienes centran su atención en los retos de posacuerdo, y la dificultad de concretar un escenario de paz luego de un conflicto.

La segunda razón reside en que esta división, con base en los desarrollos descritos, llega a ser enteramente semántica. El concepto de posconflicto, siendo relacional y performativo, entendido como un campo de "lucha" que puede ser marcado menos por la ruptura o por un nuevo y diferente periodo, que por una continuación de procesos que se encontraban en marcha durante los periodos de preguerra y guerra (Gagnon \& Brown, 2014), aporta en mayor grado a la construcción teórica, que los pocos desarrollos de los conceptos de posguerra y posacuerdo.

Ahora bien, hablar de un periodo posconflicto, dado su desarrollo teórico, no está desprovisto de tensiones y controversias. La categoría, como lo señalan Gagnon \& Brown (2014), desde su concepción en la década de los años noventa es altamente política. De hecho, es

3 Este cambio es resultado del documento "Una agenda para la paz", del entonces Secretario General de las Naciones Unidas, Boutros Boutros-Ghali. 
un concepto que se ha "propagado" desde aquel entonces y aún no se ha constituido un campo sólido que integre los hallazgos de distintas disciplinas en una comprensión integral y teorética de los periodos posconflicto (Gagnon \& Brown, 2014).

Sin embargo, como lo demuestran estudios como los de Vicent Chetail, quien ofrece cuatro explicaciones a estos fenómenos: "emergiendo de un conflicto", “en las secuelas del conflicto”, “en riesgo de recaer en el conflicto" y "estancamiento en un área gris donde no hay paz ni guerra” (citado por Gagnon \& Brown, 2014); Charles T. Call, quien ofrece una definición de facto, entendiendo este periodo como de "sociedades que han experimentado conflicto y un alto al fuego, bien sea a través de una victoria o una negociación"(Call, 2012); al igual que Virginia Gamba, quien centra la atención en la provisión de ley y orden, la creación de infraestructura, la desmilitarización de la sociedad, y el desarrollo sostenible (Darby, 2005), existen características en común que permiten la construcción de una categoría teórica para el análisis. Por tanto, con miras a la construcción teórica del concepto de posconflicto, a continuación se profundiza en sus principales características.

\section{Construcción del concepto de posconflicto}

Como se indicó anteriormente, definir un periodo posconflicto en el que se encuentra inmerso un Estado, no está desprovisto de tensiones. Sin embargo, con base en el trabajo desarrollado por Michael Boyle (2014), se tomarán en cuenta cuatro aspectos fundamentales para su delimitación, a saber: 1). El Estado tuvo que haber experimentado un conflicto armado entre al menos dos partes; 2). La guerra tuvo que haber sido conducida en el territorio de dicho Estado; 3). Hubo una terminación explícita y formal de la guerra; y 4). Los acuerdos de paz deben durar por lo menos un año (Pág. 48). Estos aspectos pueden ser clasificados en dos categorías: aquellos que hacen referencia al conflicto en sí mismo, y los que tratan directamente con la superación de dicho conflicto. 
En cuanto a la primera categoría, los aspectos que hacen referencia al conflicto en sí mismo, tanto el criterio de territorio, pero también, la participación de al menos dos partes en las confrontaciones, lleva a tener presente el escenario en el que se desarrollaron las hostilidades y el cual se espera superar. Ante todo, el criterio señalado se encuentra directamente relacionado con la definición que brinda en un primer momento Nicholas Sambanis (2004), quien señala que una guerra civil se determina porque sea desarrollada en un territorio de un Estado, donde las partes se encuentren militar y políticamente organizadas, siendo el Estado una parte de ellas. El año de inicio se determina por el primer año en el que el conflicto causa entre 500 y 1000 muertes, y, a lo largo de su duración, debe ser caracterizado por una violencia sostenida, la cual, no puede causar menos de 500 muertes en un periodo de tres años (Pág. 830).

Sin embargo, aunque útil la definición de Sambanis, el Uppsala Conflict Data Program y el International Peace Research Institute, definen conflicto como una contienda que involucra asuntos de gobierno y/o territorio donde se hace uso de la fuerza armada entre dos partes, donde al menos una es el gobierno de un Estado, que resulta en al menos 25 muertes relacionadas con el combate (UCD \& PRIO, 2009. Pág. 1). Clasificando como conflicto armado menor aquel escenario que produce entre 25 y 999 muertes; mientras que las guerras civiles, operacionalmente, presentan mil muertes relacionadas con el combate en un año dado. Esta definición permite realizar un mejor seguimiento a las dinámicas de las guerras, pues toma también en cuenta los periodos en que la intensidad de la violencia disminuye. Logrando de esta manera la comprensión del fenómeno de la guerra en un largo periodo, pues en tanto dinámicas, la intensidad de la violencia es variable.

En resumen, la construcción de la categoría posconflicto demanda, en un primer momento, la delimitación de una situación de conflicto armado que haya experimentado un Estado; se configura en pre-condición la existencia de este. Y, como se aprecia en ambos abordajes, es de importancia reconocer que dicho conflicto se desarrolle en el territorio de un Estado (Sambanis) y que el uso de la fuerza armada se llevara a cabo por al menos dos partes (UCD \& PRIO). Esto, adicional, permite entablar la diferencia entre la situación de conflicto armado 
que se espera superar, y las dinámicas del escenario posterior a su finalización. Entablando con esto vasos comunicantes con la segunda categoría, donde se encuentran los aspectos dirigidos a determinar la superación del conflicto.

Si bien existen consensos, no exentos de algunas divergencias, entorno a la definición de conflicto armado, la finalización de éste se configura en el inicio del periodo posconflicto; de ahí la relevancia de reconocer el momento en que termina. Boyle (2014, Pág. 48) determina que uno de los aspectos en cuanto a la finalización del conflicto está relacionado con una terminación explícita y formal de la guerra. En este sentido, la base de datos de terminación de conflictos de Uppsala ${ }^{4}$ (UCDP Conflict Termination Dataset, 2010) anota que los conflictos terminan cuando los criterios de al menos 25 muertes relacionadas con el combate en un año, el nivel organizativo básico de los actores armados, y la incompatibilidad, dejan de cumplirse; definiendo así cuatro tipos de terminación (UCDP, 2010. Pág. 244):

1. Victoria: hace referencia a cuando una de las partes involucradas en el conflicto armado es derrotada o eliminada, o de otra manera sucumbe a través de una capitulación, rendición o un anuncio público similar.

2. Acuerdo de paz: es definido como un acuerdo que se ocupa de la resolución de la incompatibilidad firmada y/o aceptada públicamente por todos, o por los principales, actores en un conflicto.

4 La base de datos de terminación de conflictos de Uppsala permite también superar el debate del uso del concepto de posconflicto. Este debate reside en el hecho que, en situaciones complejas de violencia en las que participan varios actores con presencia diferenciada en el territorio de un Estado, ejerciendo diferentes formas de violencia, el fin del conflicto puede ser escalonado. Sostiene que el número de actores participantes puede reducirse como consecuencia de negociaciones parciales en las cuales deponen sus armas, mientras que otros continúan inmersos en las hostilidades; por tanto, se argumenta, no es recomendable hablar de posconflicto pues no se ha superado en su totalidad el conflicto armado. Sin embargo, en este documento, un conflicto finaliza de acuerdo a los criterios que estipula la base datos, en la cual es tratado como un sólo conflicto, y no como varios en un mismo país. 
3. Acuerdo de cese al fuego: es un acuerdo entre los principales actores de un conflicto que da por terminadas las operaciones militares.

4. Otros resultados: consiste en aquellos casos donde el conflicto cesa sin una victoria o algún tipo de acuerdo.

Por tanto, la finalización de un conflicto está determinada por la cesación de las dinámicas de confrontación en las que se encontraba inmerso el Estado. Permitiendo de esta manera especificar el momento en el cual inicia un periodo posterior al conflicto, un escenario de posconflicto, que permite temporalmente la implementación de unos acuerdos o el cambio en las dinámicas sociales que se encontraban permeadas por la violencia.

Por esto Boyle, implementa el cuarto aspecto que determina que los acuerdos de paz deben durar por lo menos un año, siendo estos reconocidos por las partes involucradas en las hostilidades, así, luego de un año, retomen las acciones bélicas. Ahora bien, este aspecto, se encamina a excluir aquellos casos en los que existen ceses de fuego interrumpidos con algún grado de violencia temporal, sin embargo, esta definición excluiría los dos últimos tipos de terminación, acuerdo de cese al fuego y otros resultados, construidos por la base de datos de Uppsala. Para solventar esta delimitación, debe tomarse en cuenta el criterio de implementación de un año de los acuerdos de paz alcanzados, pero también la medición de terminación ofrecida por el UCPD, donde determina, como se señaló anteriormente, que si no se presentan al menos 25 muertes por combate en un año se da por finalizado el conflicto 5 . Este enfoque permite delimitar la categoría posconflicto,haciendo uso de características que se relacionan con el tipo

5 Cabe aclarar que uno de los autores que ha debatido este criterio es Nicholas Sambanis. Para este autor la terminación de la guerra se presenta si en un periodo de tres años el promedio de muertes no asciende a 500. En ese caso, según él, se puede se puede codificar el fin de la guerra a pesar que el último año de esta alcance las 100 muertes. Sin embargo es recomendable el uso de los criterios determinados por la base de datos de Uppsala que permiten la comprensión de los cambios en las dinámicas de los niveles de violencia en los conflictos armados. 
de confrontación armada que está experimentando un Estado, pero también, los mecanismos a través de los cuales esta se termina. De esta manera se configura un concepto que logra brindar elementos de análisis que se encuentran directamente relacionados con las experiencias de Estados que han soportado violentos conflictos armados.

Cabe aclarar que el concepto de posconflicto no es indefinida en el tiempo ${ }^{6}$. Mientras que los Estados pueden sufrir efectos prolongados provenientes del conflicto armado por años después de la guerra, muchos de los traumas inmediatos de la violencia ${ }^{7}$ organizada en el territorio duran tan sólo un corto periodo de tiempo después del fin de las hostilidades (Boyle, 2014. Pág. 51). Por tanto, de acuerdo con Boyle (2014), un Estado es clasificado como posconflicto durante cinco años después del final forma del conflicto a menos que la guerra reinicie antes del periodo que ha sido señalado anteriormente. Hartzell (2001) coincide con esta delimitación temporal pues a lo largo de esos cinco años algunos de los efectos del conflicto se van a atenuar, además, los efectos de los arreglos institucionales que se hayan propuesto pueden lograr algún impacto a través de los años, logran que la naturaleza del conflicto civil cambie (Pág. 184).

El status de posconflicto puede durar menos de los cinco años si la confrontaciones se reanudan y las bajas, resultado de estas, vuelven a generarse. Por tanto, los Estados pueden perder el status de posconflicto si otra guerra estalla, bien sea entre los mismos combatientes o entre una nueva serie de actores. En algunos casos, señala Boyle, la finalización formal de un conflicto armado puede durar poco más de un año pero rápidamente re-emerge con nuevos actores.

6 Un Estado puede dejar de estar en un periodo de posconflicto si inicia otra guerra, bien sea con los mismos actores u otros nuevos. Por tanto, se tomará en cuenta la definición brindada anteriormente por el Uppsala Conflict Data Program para determinar si, la magnitud de la violencia, permite hablar de un reinicio de las hostilidades o el inicio de una nueva guerra.

7 Para conocer el debate en torno a las diferentes lecturas de la violencia en periodos posconflicto puede consultarse mi artículo "Aportes para la comprensión de la violencia en periodos de posconflicto" en revista Ciudad Paz- ando, edición No 15 (Vol 8, Num 1, primer semestre de 2015). 
Es importante aclarar con base en los aportes de Gagnon \& Brown (2014), que, como se señaló al inicio, el concepto de posconflicto es relacional y performativo, en otras palabras, que depende en gran medida del contexto en el cual se desarrolle, y aunque pueden hallarse variados escenarios, existen variables que deben ser tenidas en cuenta con miras a la reflexión teórica. Por tanto, se debe otorgar cierto grado de flexibilidad que permita dar cuenta de la manera en que los países entran y superan un periodo de posconflicto. Pretendiendo con esto una comprensión fluida del fenómeno en el tiempo, que tal vez las delimitaciones estrictas impedirían. Si bien el periodo de cinco años es tomado como un punto de referencia temporal, la categorización de los países que se encuentran dentro de un periodo de posconflicto debe permitir fronteras dúctiles que resulten de las particularidades que experimentan.

Ahora bien, como se ha señalado, resultado del fin de la guerra ${ }^{8}$ un país entra en un periodo de posconflicto, durante el cual inicia un proceso de construcción de paz y reconstrucción del Estado que ha sido afectado por la violencia desplegada por las partes en confrontación. La experiencia y las dinámicas de dicho periodo no son iguales para todos los países, particularmente en la violencia que es ejercida mientras dura. Los países inmersos en un posconflicto bien deben hacer frente a una violencia que se encuentra directamente relacionada con el conflicto armado que se ha superado, siendo usada como un mecanismo para estropear los acuerdos de paz, sabotear lo términos alcanzados, u obtener ganancias adicionales con la renovación de dicho conflicto.

Capacidad de regulación del orden social por parte del Estado El desarrollo que han tenido los análisis en relación con las dinámicas de los grupos armados dan cuenta de la competencia en términos de regulación que estos ejercen frente al Estado; en este sentido los grupos armados determinan el orden social, interviniendo en la vida local

8 Como se anotó anteriormente el fin de una guerra, de acuerdo al UCPD de la Universidad de Uppsala, puede darse a través de cuatro tipos: victoria, acuerdo de paz, acuerdo de cese al fuego y otros resultados. 
(Arjona, 2010). Los señores de la guerra, individuos que controlan pequeñas partes de territorio usando una combinación de fuerza y patronato, son los actores más representativos de estas lógicas (Marten, 2012). A su vez, otras formas de regulación, como las pandillas, proporcionan micro-regímenes de orden, así como formas comunales de pertenecer a determinadas, si bien delimitadas, entidades colectivas, en un contexto más amplio de la inseguridad crónica y de exclusión (Rodgers, 2009). O las mafias, siendo una empresa económica específica, una empresa que produce, promueve y vende protección privada (Mosca, 2003; Gambetta, 2007).

Esta formas de organización, que compiten con el Estado en cuanto a su capacidad de regulación de la vida social, no se encuentran exclusivamente relacionadas con un escenario de conflicto armado. Ahora bien, la existencia de este exacerba la competencia que determinados grupos realizan a través de la escisión de la soberanía (Kalyvas, 2010), como es el caso de los grupos armados, que están en contienda contra el Estado. Sin embargo, muchas otras formas paralelas de regulación local existen durante y subsisten luego de la finalización del conflicto armado, tanto en zonas en las cuales se experimentó con mayor intensidad el conflicto, como en otras que pudieron estar al margen. Dicha competencia en cuanto a la capacidad del Estado se refleja en tres aspectos: 1. La presencia institucional, 2. Monopolio de la violencia, y 3. Recursos.

Estos tres aspectos se encuentran ínter-relacionados entre sí, pues en conjunto determinan en gran medida la capacidad de los Estados de ejercer una regulación efectiva de la vida social de los ciudadanos. Ahora bien, en cuanto a la primera, la presencia institucional, ésta no debe limitarse tan sólo a la existencia o no de instituciones, sino también debe abarcar la posibilidad que tiene el Estado de hacer garantizar la vigencia de la ley, constituyéndose como una autoridad razonablemente acatada. La presencia del Estado en el territorio es diferenciada (Gonzalez, Bolivar, \& Vasquez, 2005), no es homogénea, lo cual puede llevar a la existencia de un vacío de poder que, tanto en el marco de un conflicto armado como en ausencia de este, implica la competencia que realizan diversos grupos para proveer servicios y dar respuesta, de acuerdo al orden implementado, a las necesidades ciudadanas. 
El monopolio de la violencia, como segundo aspecto, refiere a la definición clásica otorgada por Weber (2004) en cuanto a que el Estado es una comunidad humana que (de manera exitosa) reclama el monopolio del uso legítimo de la fuerza física dentro de un territorio. Ahora bien, el Estado, como se señaló anteriormente, tanto en el marco de un conflicto armado como fuera de este tiene una competencia constante de otros grupos por el ejercicio de la violencia. En una guerra es evidente dicha disputa, especialmente por figuras como la de los señores de la guerra ${ }^{9}$; pero también por otras organizaciones como las mafias o las pandillas, al igual que las comunidades, como lo señala Godoy (2006) para el caso de Guatemala, que pueden hacer uso de la violencia como forma de resolver sus conflictos o para obtener intereses privados. Realizando ofertas de seguridad, vigilancia y cumplimiento del orden a través de la coerción que, claramente, discrepa del Estado.

Por último, en términos de recursos, desde las primeras fases de construcción del Estado la posibilidad de recaudar impuestos y de hacerse de medios que les permita la acumulación de capital ha sido uno de sus objetivos prioritarios (Tilly, 1985). Sin embargo esta tarea siempre se ha encontrado rodeada de dificultades, en especial, por la competencia que diversas organizaciones realizan al Estado. En un escenario de guerra es usual el control de los recursos como mecanismo de financiación de las acciones o de beneficio de quienes participan en las confrontaciones, pero a su vez como la posibilidad de controlar las población a través de la recaudación de impuestos (Ballentine \& Sherman, 2003). Ahora bien, esta lucha por los recursos no sólo se presenta en las guerras, también otros grupos como las mafias o las pandillas pueden competir al Estado con miras a llevar a cabo sus transacciones; de hecho consolidan mercados en los que las líneas entre sectores criminales, informales y formales son borrosas.

La capacidad de regulación del orden social por parte de los Estados abarca estos tres aspectos anotados; los cuales, en muchos casos, hacen

9 Quienes son "señores" (en el sentido feudal) que amenazan o usan la "guerra" (violencia desatada por sus milicias) para retener su poder (Marten, 2012). 
frente a una competencia que bien puede darse tanto en el marco de un conflicto armado como fuere de este. Sin embargo, un conflicto armado exacerba las manifestaciones y los escenarios de competencia en esta regulación como resultado de la escisión de la soberanía y el control que obtienen los grupos armados. Una vez finalizado, demanda esfuerzos por parte del Estado para retomar la regulación del orden social, en el cual existan unos principios predecibles ${ }^{10}$ para el comportamiento de los individuos y el colectivo que se alejen de la violencia, al tiempo que debe enfrentar las competencias resultantes en dicha regulación que pueden llevar a la variación de la violencia en un escenario posconflicto.

\section{Legitimidad en la regulación del orden social por parte del Estado}

La regulación del orden social por parte del Estado no está sujeta tan sólo a la capacidad que tenga de hacer presencia, implementar la ley o responder a las necesidades de la ciudadanía. Estos aspectos, sin duda alguna, son fundamentales; pero a la par, es necesaria la legitimidad ${ }^{11}$ en sus actuaciones, en cuanto que lo ciudadanos reconozcan en éstas cierto grado de autoridad.

Esta legitimidad, como lo señala Tilly (1985), ha sido un factor determinante en la construcción del Estado. Al hacerse de la guerra como un instrumento de expansión y consolidación del territorio, los Estados implementaron dos estrategias: (a) extender su burocracia a la comunidad local y (b) fomentar la creación de fuerzas policiales, subordinadas al gobierno y no a individuos, diferentes de las fuerzas empleadas en la guerra y, por tanto, menos útiles para ser utilizadas como instrumentos por sus rivales (Pág. 9).

10 La idea de conducta predecible es tomada de Elster (1991).

11 La legitimidad debe comprenderse como el merecimiento de reconocimiento con el que cuenta un orden político". De acuerdo a Habermas, esta se sostiene desde las satisfacciones que conlleve el sistema que se quiera legitimar y la fuerza justificativa de tal legitimación. 
Sin embargo, además de centralizar el ejercicio de la violencia, era necesario que los ciudadanos reconocieran que dicho acto era generado por una entidad que gozaba de una autoridad. Por esta razón, la resistencia popular a la guerra fue determinante en la construcción del Estado; pues cuando la gente de la calle se resistió tenazmente, las autoridades hicieron concesiones: garantía de derechos, instituciones representativas, tribunales de apelación. (Tilly, 1985. Pág. 21) En otras palabras, a la par de brindar protección a los individuos, se implementaron estrategias dirigidas a la configuración de autoridad de las instituciones del Estado en la regulación de la vida social ${ }^{12}$.

Dicha legitimación depende del reconocimiento del orden que brinda el Estado, el cual le otorga la probabilidad de encontrar obediencia de los ciudadanos. Sin embargo, esta legitimidad, en el territorio, es disputada por diferentes actores. En el marco de un conflicto armado los grupos en confrontación, como lo anota Kalyvas (2006) y Arjona (2010), procuran, a través de la influencia en los asuntos civiles, obtener mayor cooperación, que a su vez, refuerza el control territorial. Las acciones que realizan por convertirse en el nuevo proveedor de la justicia es un paso esencial hacia la obtención de este tipo de cooperación, ya que ayuda al grupo a centralizar el poder y darle un aura de legitimidad.

Ahora bien, esta disputa no sólo es llevada a cabo por los grupos armados, existen otras organizaciones que, al ofrecer algunos servicios, también constituyen procesos de legitimación por medio de la instauración de un orden social. Tal es el caso de las mafias, quienes a través de la protección, lograron hacerse de funciones judiciales y de intermediación que les confirió legitimidad en las comunidades (Skaperdas, 2001; Varese, 2001; Gambetta, 2007), o de las pandillas, quienes al establecer un orden, permiten definir la pertenencia de los individuos en comunidades marginadas (Rodgers, 2009. Pág.12).

No obstante, como se ha indicado con anterioridad, la existencia de un conflicto armado potencia estas disputas que se ven reflejadas en la capacidad del Estado en hacer frente a los riesgos que implican

12 Esta discusión acerca de la legitimación también es referenciada por Habermas (1999) en cuanto a las estrategias del Estado nacional para afrontar el problema de la integración social. 
la instauración de ordenes paralelos, además de no contar, en muchas zonas, con la legitimidad de los ciudadanos en relación con las acciones que toma y los servicios que presta. Al superar un conflicto armado, en el periodo de posconflicto, un Estado debe reconstruir la legitimidad que ha perdido tanto en zonas en las cuales la disputa por la legitimidad de la organizaciones fue evidente, como en aquellas que no. La recuperación de la legitimidad no sólo se centra en las zonas devastadas por la guerra, sino también en otras que, aunque pudieron no ser afectadas directamente por la violencia, requieren acciones que fortalezcan el papel del Estado como regulador de la vida social.

El fortalecimiento de la legitimidad una vez finalizado el conflicto se enfrenta no sólo a la percepción de un "vacío de protección” por parte de la población como lo han señalado Nussio \& Howe (2013), en el cual muchos crímenes que eran controlados por un sistema de protección ilegal pueden surgir, y a los cuales el Estado debe hacer frente, sino que también debe competir con variadas organizaciones que pretenden obtener réditos de la desestructuración de organizaciones que ostentaban el control social en determinados territorios. De hecho, la legitimidad es un aspecto relevante en cuanto a la capacidad del Estado en el restablecimiento del orden social del país que ha superado un conflicto armado.

En este orden de ideas, tanto las variaciones de la violencia en un periodo posconflicto, como los retos institucionales, pueden ser explicados además de la capacidad de la regulación del orden social por parte del Estado, a través de la legitimidad que dichas acciones tienen en la población. La posibilidad que tiene el Estado de determinar dicho orden, de regular las relaciones sociales, y de imponerse a otros órdenes paralelos que le compiten, permite la comprensión de los cambios en el ejercicio de la violencia, de los objetivos que persiguen y de los actores que hacen uso de esta.

\section{Retos de los Estados en un periodo de posconflicto (a manera de conclusión)}

Luego del recorrido realizado tanto por el concepto de posconflicto, como de las características de los Estados que lo afrontan, se puede 
sostener, tal como lo afirma Sisk (2013), que un rasgo particular es la fragilidad con la que estos Estados emergen de un conflicto armado. Esta se caracteriza en términos sociales por la vulnerabilidad de grupos poblaciones; en lo económico por la pobreza e inequidad; en cuanto a la gobernanza por la dificultad de brindar bienes públicos; y por los obstáculos al brindar seguridad (pág. 37).

Todos estos factores deben ser afrontados por los Estados una vez finalizado un conflicto armado. El recobrar la capacidad, entendida desde lo institucional pero también en cuanto autoridad, es fundamental para lograr instaurar no sólo una regulación efectiva del orden social, y a su vez la reconstrucción de la legitimidad de los Estados; especialmente en zonas donde la violencia del conflicto armado fue mucho más evidente.

El lograr ocupar el "vacío de seguridad" que se presenta después de un conflicto armado es fundamental para el Estado. Presentarse como el ente que provee de servicios públicos a las poblaciones, que rinde cuentas por su acciones públicas, que permite la participación pluralista, y que salvaguarda la seguridad de cada miembro dentro de sus fronteras, es indispensable para retomar un camino alejado de la violencia. Pero también esto ayuda a prevenir la reanudación del conflicto, pues reconstruye canales a través de los cuales los ciudadanos pueden tramitar sus conflictos, y a su vez el Estado obtiene legitimidad en su accionar.

\section{Referencias}

Archer, D., \& Gartner, R. (1976). Violent Acts and Violent Times: A Comparative Approach to Postwar Homicide Rates. American Sociological Review, 41(6), 937.

Arjona, A. M. (2010). Social Order in Civil War. YALE UNIVERSITY.

Azam, J.-P., Collier, P., Bevan, D., Dercon, S., Gunning, J. W., \& Pradhan, S. (1995). Some Economic Consequences of the Transition from Civil War to Peace (SSRN Scholarly Paper No. ID 1149065). Rochester, NY: Social Science Research Network.

Ballentine, K., \& Sherman, J. (2003). The Political Economy of Armed Conflict: Beyond Greed and Grievance. Lynne Rienner Publishers. 
Boutros- Ghali, B. (1992). Un Programa para la Paz (Asamblea General No. A/47/277). Naciones Unidas.

Boyle, M. J. (2014). Violence after War: Explaining Instability in Post-Conflict States. Baltimore: Johns Hopkins University Press.

Call, C. T. (2012). Why Peace Fails: The Causes and Prevention of Civil War Recurrence. Georgetown University Press.

Collier, P. (1994). Demobilization and insecurity: A study in the economics of the transition from war to peace. Journal of International Development, 6(3), 343-351.

Collier, P., Elliott, V. L., Hegre, H., Hoeffler, A., Reynal-Querol, M., \& Sambanis, N. (2003). Breaking the Conflict Trap: Civil War and Development Policy. Washington, DC : New York: World Bank Publications.

Collier, P., Hoeffler, A., \& Söderbom, M. (2008). Post-Conflict Risks. Journal of Peace Research, 45(4), 461-478.

Darby, J. (Ed.). (2005). Violence and Reconstruction (1 edition). Notre Dame, Ind: University of Notre Dame Press.

Eck, Kristine, \& Hultman, Lisa. (2007). One-sided violence against civilians in war: insights from new fatality data, 233-246.

Elster, J. (1991). El cemento de la sociedad: las paradojas del orden social. Gedisa.

Espinal, M. A. A., \& Rendón, J. C. V. (1998). Guerra, soberanía y órdenes alternos. Estudios Políticos, 0(13).

Fortna, V. P. (2004). Peace Time: Cease-Fire Agreements and the Durability of Peace. Princeton, N.J: Princeton University Press.

Fortna, V. P. (2008). Does Peacekeeping Work?: Shaping Belligerents' Choices after Civil War. Princeton: Princeton University Press.

Gagnon, C., \& Brown, K. (Eds.). (2014). Post-Conflict Studies: An Interdisciplinary Approach (1 edition). London ; New York, NY: Routledge.

Gambetta, D. (2007). La mafia siciliana: el negocio de la protección privada. Fondo de Cultura Económica.

Girod, D. M. (2014). Reducing postconflict coup risk: The low windfall coup-proofing hypothesis. Conflict Management and Peace Science,

Glassmyer, K., \& Sambanis, N. (2008). Rebel-Military Integration and Civil War Termination. Journal of Peace Research, 45(3), 365-384. 
González, F. E., Bolívar, I. J., \& Vásquez, T. (2003). Violencia política en Colombia. De la nación fragmentada a la construcción del Estado. CINEP.

Gurr, T. R. (2011). Why Men Rebel: Fortieth Anniversary Edition (Anv edition). Boulder, Colo.: Paradigm Publishers.

Gurses, M., \& Rost, N. (2013). Sustaining the peace after ethnic civil wars. Conflict Management and Peace Science, 30(5), 469-491.

Habermas, J. (1999). La inclusión del otro: estudios de teoría política. Paidós.

Hartzell, C. A. (2007). Crafting Peace: Power-Sharing Institutions and the Negotiated Settlement of Civil Wars. Penn State University Press.

Hartzell, C., Hoddie, M., \& Rothchild, D. (2001). Stabilizing the Peace After Civil War: An Investigation of Some Key Variables. International Organization, 55(01), 183-208.

Hechter, M. (1995). Explaining Nationalist Violence. Nations and Nationalism, 1(1), 53-68.

Höglund, K., \& Orjuela, C. (2011). Winning the peace: conflict prevention after a victor's peace in Sri Lanka. Contemporary Social Science, 6(1), 19-37.

Horowitz, D. (2008). Conciliatory Institutions and Constitutional Processes in Post-conflict States. William \& Mary Law Review, 49(4), 1213.

Kalyvas, S. N. (2010). La lógica de la violencia en la Guerra Civil. Ediciones AKAL.

Kathman, J. D., \& Wood, R. M. (2014). Stopping the Killing During the "Peace": Peacekeeping and the Severity of Postconflict Civilian Victimization. Foreign Policy Analysis,

Kreutz, J. (2010). How and when armed conflicts end: Introducing the UCDP Conflict Termination dataset. Journal of Peace Research, 47(2), 243-250.

M.van, D. (2009). Cocaleros. Violence, drugs and social mobilization in the post-conflict Upper Huallaga Valley, Peru. Rozenberg Publishers.

Mann, M. (1991). El poder autónomo del Estado: sus orígenes, mecanismos y resultados. Zona Abierta, (57), 15-50.

Marten, K. (2012). Warlords: Strong-arm Brokers in Weak States. Ithaca, NY: Cornell University Press. 
Monk, D. B., \& Mundy, J. (2014). The Post-Conflict Environment: Investigation and Critique. Ann Arbor: University of Michigan Press.

Mosca, G., Caselli, G. C., \& Ingroia, A. (2003). ¿Qué es la mafia?. Fondo de Cultura Económica.

Moser, C., \& Mcllwaine, C. (2000). Violence in a Post-Conflict Context: Urban Poor Perceptions from Guatemala. Washington, D.C: World Bank Publications.

Nasi, C. (2007). Cuando callan los fusiles: impacto de la paz negociada en Colombia y en Centroamérica. Editorial Norma.

Nussio, E., \& Howe, K. (2013). When Illegal Protection Collapses: Pathways to Increased Post-Demobilization Violence (SSRN Scholarly Paper No. ID 2277954).

Rochester, NY: Social Science Research Network.

O'Donnell, G. (1993). On the state, democratization and some conceptual problems: A Latin American view with glances at some postcommunist countries. World Development, 21(8), 1355-1369.

Peacock, S. C., \& Beltrán, A. (2003). Hidden Powers in Post-conflict Guatemala: Illegal Armed Groups and the Forces Behind Them. Washington Office on Latin America.

Proksik, J. J. (2013). Organized Crime and the Dilemmas of Democratic Peace-Building in Kosovo. International Peacekeeping, 20(3), 280-298.

Raeymaekers, T. (2013). Post-war Conflict and the Market for Protection: The Challenges to Congo's Hybrid Peace. International Peacekeeping, 20(5), 600-617.

Rettberg, A., \& Guizado, Á. C. (2002). Preparar el Futuro: Conflicto y Post-Conflicto en Colombia. Alfaomega.

Rodgers, D. (2009). Slum wars of the 21st century: gangs, mano dura and the new urban geography of conflict in Central America.

Russett, B. (2003). Civil Wars Kill and Maim People - Long after the Shooting Stops. American Political Science Review, 97(1), 189-202.

Sambanis, N. (2004). What Is Civil War? Conceptual and Empirical Complexities of an Operational Definition. Journal of Conflict Resolution, 48(6), 814-858.

Scheper-Hughes, N., \& Bourgois, P. I. (2003). Violence in War and Peace: An Anthology (1st edition). Malden, Mass.: Blackwell Publishing. 
Schuld, M. (2013). The Prevalence of Violence in Post-Conflict Societies: A Case Study of Kwazulu-Natal, South Africa. Journal of Peacebuilding \&amp; Development, $8(1), 60-73$.

Sisk, T. (2013). Statebuilding (1 edition). Cambridge: Polity.

Skaperdas, S. (2001). The political economy of organized crime: providing protection when the state does not. Economics of Governance, 2(3), 173-202.

Stedman, S. J., \& Rothchild, D. (1996). Peace operations: From short-term to longterm commitment. International Peacekeeping, 3(2), 17-35.

Stedman, S. J., Rothchild, D., \& Cousens, E. M. (Eds.). (2002). Ending Civil Wars: The Implementation of Peace Agreements. Boulder, Colo: Lynne Rienner Pub.

Steenkamp, C. (2005). The Legacy of War: Conceptualizing a "Culture of Violence" to Explain Violence after Peace Accords. The Round Table, 94(379), 253-267.

Steenkamp, C. (2009). Violence and Post-war Reconstruction: Managing Insecurity in the Aftermath of Peace Accords. London; New York; New York: I. B. Tauris.

Steenkamp, C. (2011). In the shadows of war and peace: making sense of violence after peace accords. Conflict, Security oramp; Development, 11(3), 357-383.

Suhrke, A., \& Berdal, M. (2011). The Peace In Between: Post-War Violence and Peacebuilding (1 edition). Routledge.

Theidon, K. (2012). Intimate Enemies: Violence and Reconciliation in Peru. Philadelphia: University of Pennsylvania Press.

Tilly, C. (1985). War Making and State Making as Organized Crime. In Bringing the State Back In. Cambridge University Press.

Uppsala Conflict Data Program, \& International Peace Research Institute. (2009). UCD/PRIO Armed Conflict Dataset Codebook Version 4-2009.

Uribe, M. T. (1999). Las soberanías en disputa: ¿conflicto de identidades o de derechos? Estudios Políticos,

Varese, F. (2001). The Russian Mafia: Private Protection in a New Market Economy. Oxford University Press.

Walter, B. F. (1997). The Critical Barrier to Civil War Settlement. International Organization, 51(03), 335-364.

Walter, B. F. (2002). Committing to Peace: The Successful Settlement of Civil Wars. Princeton, N.J: Princeton University Press. 
Walter, B. F. (2004). Does Conflict Beget Conflict? Explaining Recurring Civil War.

Journal of Peace Research, 41(3), 371-388.

Weber, M., \& Owen, D. S. (2004). The Vocation Lectures. Hackett Publishing.

Zahar, M.-J. (2006). Political Violence in Peace Processes. In Violence and reconstruction. 


\section{Interpretación de la Ley}

de víctimas y de restitución de tierras a favor de los niños, niñas y adolescentes que han sido reclutados por grupos armados en Colombia ${ }^{13}$

ANA MARÍA JiMÉNEZ ${ }^{14}$

\section{Introducción}

T a Ley de víctimas y de restitución de tierras (Ley 1448 de 2011) _fue adoptada por el gobierno colombiano como una herramienta de justicia transicional, con el objetivo de establecer un conjunto de medidas judiciales, administrativas, sociales y económicas, individuales y colectivas, en beneficio de las víctimas del conflicto armado, que posibiliten hacer efectivo el goce de sus derechos a la verdad, la justicia y

13 Articulo resultado producto de investigación del proyecto denominado "Procesos de exigibilidad y justiciabilidad de los Derechos Humanos y el Derecho Internacional Humanitario, en el contexto nacional e internacional.” Adscrito al grupo de investigación Sociohumanistico Categoría A en Colciencias de la Facultad de Derecho de la Universidad Santo Tomás Bogotá.

* Abogada, Magister en Investigación docente de la Maestría en defensa de los derechos humanos y el derecho internacional humanitario ante Cortes y tribunales internacionales de la Universidad Santo Tomás. Email anijipa75@ gmail.com 
la reparación. Así, esta ley abre la posibilidad de que el Estado, de manera solidaria, concurra en la reparación de las víctimas del conflicto armado y de la violencia socio política en Colombia. Si bien esta ley a primera vista cobija a todas las víctimas del conflicto armado por hechos causados a partir del primero de enero de 1985, esta plantea varios criterios de exclusión dentro de los cuales se encuentran: i) el tipo de grupo que comete los hechos victimizantes (exclusión de grupos de delincuencia común); ii) la pertenencia de las víctimas a los grupos armados al margen de la ley, y iii) en el caso de las víctimas de reclutamiento ilícito, se excluye a quienes no hayan sido desvinculados del grupo armado antes de cumplir los 18 años, con la excepción de los niños y niñas pertenecientes a comunidades indígenas.

En particular, la exclusión de las víctimas de reclutamiento ilícito que no se desvinculen de los grupos armados antes de cumplir la mayoría de edad ha generado amplios debates. Para algunos, esta exclusión iría en contra del principio de igualdad y no discriminación y el principio del interés superior del niño, ambos de rango constitucional, y establecidos en los tratados internacionales de derechos humanos firmados por el Estado colombiano. Además, podría suponer la violación del derecho a la reparación de las víctimas de reclutamiento ya que, en la práctica, son mínimos los casos que han logrado condenas a los perpetradores por vía judicial y menos aún los casos que efectivamente han dispuesto reparación para las víctimas.

Así, en este documento se analizan los argumentos legales que sustentan la exclusión de la Ley 1448 de 2011 (en adelante Ley de víctimas) de las víctimas de reclutamiento ilícito que no se hayan desvinculado de los grupos armados antes de cumplir los 18 años. Para ello, se realiza un pormenorizado estudio del articulado de la ley y de sus decretos reglamentarios, así como también de los pronunciamientos de la Corte Constitucional sobre la exequibilidad de algunos apartes de la ley de víctimas relevantes para este debate. Además, se plantean algunas alternativas para la interpretación sistemática de la ley de víctimas conforme al principio del interés superior de los niños y las niñas, el principio de favorabilidad y el principio de igualdad y no discriminación. Finalmente, se concluye que la ley de víctimas debe ser interpretada de manera tal que garantice el más alto nivel de protección a 
las víctimas de uso y reclutamiento ilícito para hacer efectivo su derecho a la reparación integral sin importar si estas han cumplido o no la mayoría de edad (Sentencia C-253 de 2012).

\section{La reparación administrativa de las víctimas de reclutamiento ilícito conforme a la Ley 1448 de 2011}

\section{La reparación como un derecho de las víctimas de reclutamiento ilícito y una obligación del Estado colombiano}

La Ley de víctimas en su articulado dio prevalencia a la reparación de las víctimas menores de edad en el proceso de reparación administrativa. Así, incluyó por ejemplo, en el artículo 13, el enfoque diferencial, con el objeto de que se adopten criterios que respondan a las particularidades y grado de vulnerabilidad de los grupos poblacionales históricamente discriminados como lo son los niños, niñas y adolescentes. Igualmente, dispuso la creación de un encargo fiduciario con el fin de garantizar que la indemnización llegue directamente a las víctimas niños y niñas al cumplir la mayoría de edad. Además, en su título VII, la Ley prevé medidas especiales para la reparación de los niños y niñas huérfanos, víctimas de minas antipersona, o que han nacido como resultado de la violencia sexual sufrida por sus madres dentro del conflicto armado. En materia de reclutamiento ilícito señala que todas las víctimas de este delito tienen derecho a la reparación (artículo 190).

No obstante, el parágrafo 2 del artículo 3 de la ley de víctimas establece que: Los miembros de los grupos armados organizados al margen de la ley no serán considerados víctimas, salvo en los casos en que los niños, niñas o adolescentes hubieren sido desvinculados del grupo armado organizado al margen de la ley siendo menores de edad.

Lo primero que hay que precisar en relación a la citada norma es que, de acuerdo con la Constitución política de Colombia, la Ley de infancia y adolescencia (Ley 1098 de 2006) y la Convención de los derechos del niño, la categoría niño o niña comprende a todas las personas 
menores de 18 años, sin distinción alguna por razones de raza, sexo, género, etnia entre otros factores. Así las cosas, podría afirmarse entonces que la edad universalmente aceptada y reconocida en Colombia es la de 18 años. Lo anterior fue así plasmado, en la ley 1448 de 2011 en su artículo 181.

En segundo lugar, es importante señalar que el artículo 3 reconoce que, a excepción de los demás miembros de los grupos armados no estatales, los niños, niñas y adolescentes reclutados por estos grupos son víctimas de reclutamiento, el cual es, según los estándares internacionales, un crimen de guerra (Estatuto de Roma, artículo 8 xxvi), una grave violación de derechos humanos (Convención de los derechos del niño, artículo 48 y 49), una de las peores formas de explotación infantil (OIT, Convenio 182, artículo 3), y una infracción al derecho internacional humanitario -DIH- (Protocolos adicionales de 1977 a los Convenios de Ginebra). Igualmente, el reclutamiento ilícito constituye un delito en Colombia conforme al Código Penal (Ley 599 de 2000).

La Corte Constitucional colombiana ha observado al respecto que "es un hecho comprobado que el reclutamiento forzado de menores de edad-niños, niñas y adolescentes- es una práctica criminal en la que incurren en forma extensiva, sistemática y habitual los grupos armados ilegales que toman parte del conflicto armado en Colombia, tanto guerrillas como paramilitares”. Agrega que, durante el reclutamiento los niños y niñas son expuestos a los riesgos frecuentes de la guerra y cumplen tareas que constituyen una violación compleja de derechos humanos. Además, el reclutamiento genera graves impactos que trascienden en el tiempo, incluso con graves efectos transgeneracionales ${ }^{15}$, como la pérdida de la infancia, los daños sicosociales, el desarraigo y la ruptura de vínculos con las familias y comunidades entre otros impactos (Tribunal Superior de Bogotá, 2011). Estos daños tienen efectos

14 El daño "producido por las experiencias traumáticas es multigeneracional, al ser simultáneamente varias generaciones; intergeneracional, en tanto se tradujo en conflictos entre generaciones y transgeneracional, pues sus efectos reaparecen de diversos modos en las generaciones siguientes" (Kordon et al., 1999: 51), tomado de: CINTRAS, EATIP y otros (2009). Daño transgeneracional: Consecuencias de la represión política en el cono Sur, Santiago de Chile. 
a nivel individual, familiar y colectivo ya que suponen la ruptura del niño o la niña con su entorno e involucra otras violencias en contra de sus familias y comunidades las cuales pueden ser sujeto de presión, amenaza y/o desplazamientos forzados (Molano, H; Jiménez, A. Arévalo, L. y otras, 2014).

En consecuencia, el Estado tiene la obligación legal de crear los mecanismos necesarios para materializar el derecho a la verdad y a la justicia de las víctimas y repáralas por los perjuicios materiales y morales sufridos durante el reclutamiento ilícito (artículo transitorio 66 de la Constitución Política), ya sea para lograr la reparación por parte de los victimarios (a través de la jurisdicción ordinaria o la de Justicia Transicional) o la reparación solidaria por del Estado (mediante la reparación administrativa establecida en la Ley de víctimas).

Sobre el particular la Corte Interamericana de Derechos Humanos -CorteIdh-, en reiterada jurisprudencia desde el caso Velázquez Rodríguez, ha señalado que "es un principio de Derecho Internacional, que la jurisprudencia ha considerado 'incluso una concepción general de derecho', que toda violación a una obligación internacional que haya producido un daño comporta el deber de repararlo adecuadamente. La indemnización, por su parte, constituye la forma más usual de hacerlo"16 (CorteIdh, 1989, párr. 25). Dicha indemnización no solo debe cobijar a la víctima sino también a sus familiares quienes pudieron haber sufrido a su vez daños por lo ocurrido a esta y por lo tanto estos deben ser debidamente reparados (CorteIdh, 2002).

Con base en lo anteriormente expuesto se concluye que, siendo el reclutamiento ilícito una grave violación de los derechos humanos de los niños y niñas, que genera graves daños a nivel individual y colectivo, el Estado Colombiano tiene la obligación de garantizar el acceso

15 Otros tribunales internacionales se han pronunciado en igual sentido: CPJI, Caso Fábrica Chorzów (1927), párr. 21, y Caso Fábrica Chorzów (1928), párr. 29, y Corte Internacional de Justicia (CIJ), Reparation for injuries suffered in the service of the United Nations (1949), párr. 184. Tomado de: Nash C. (2009). Las Reparaciones ante la Corte Interamericana de Derechos Humanos (1988 - 2007). 
a la justicia de las víctimas para que sean reparadas integralmente ya sea a través de la vía judicial o la administrativa.

\section{Acceso a la reparación administrativa y judicial de las víctimas de reclutamiento ilícito}

Como se señaló previamente, el artículo 3, parágrafo 2 bajo análisis, plantea que solo se reconocerán como víctimas para efectos de la Ley 1448 de 2011, a los niños y niñas reclutados por los grupos armados no estatales mientras estos ostenten la condición de personas menores de edad, es decir, que se hayan desvinculado antes de cumplir los 18 años. Una vez cumplan la mayoría de edad estos no pueden acceder, como sujetos de reparación, a las medidas establecidas en la Ley de víctimas, ya que han dejado de ser niños y niñas.

Sobe el particular la Corte Constitucional en el análisis de exequibilidad de la norma en mención, en la sentencia C - 253A de 2012, consideró que:

...quienes hayan sufrido un daño como consecuencia de infracciones al DIH o de violaciones graves y manifiestas a las normas internacionales de Derechos Humanos en condiciones distintas de las allí contempladas, no pierden su reconocimiento como víctimas, ni quedan privados de la posibilidad de acudir a los mecanismos ordinarios que se han establecido en la legislación ordinaria para que se investiguen y persigan los delitos, se establezca la verdad, se sancione a los responsables y se repare de manera integral a las víctimas, y que el sentido de la disposición es el de que, en razón de los límites o exclusiones que ella contiene, esas personas no tienen acceso a las medidas especiales de protección que se han adoptado en la ley, en el marco de un proceso de justicia transicional (CC, p. 60).

En el caso particular de las víctimas de reclutamiento ilícito no desvinculadas antes de cumplir la mayoría de edad, la Corte Constitucional en la Sentencia C-253ª de 2012 señaló que 
(...) una vez los niños, niñas y adolescentes cumplan la mayoría de edad, podrán ingresar al proceso de reintegración social y económica (...) Por otra parte, al margen de esas previsiones, quienes se vincularon a los grupos armados siendo menores de edad, pueden, cuando sean adultos, acceder a los mecanismo ordinarios de verdad justicia y reparación, así como a los programas especiales de reinserción y de integración social que ha previsto el Estado.

(...) el alcance de la ley es el de que los menores desmovilizados en condición de tales son reconocidos per se cómo víctimas. Cuando la desmovilización sea posterior a la mayoría de edad, no se pierde la condición de víctima, derivada, en primer lugar, de la circunstancia del reclutamiento forzado, pero en ese caso se impone acreditar ese hecho y acceder a los programas especiales de desmovilización y de reinserción, en los cuales será preciso que se adelante una política diferencial, que tenga en cuenta la situación de los menores y las limitaciones que tienen para abandonar los grupos al margen de la ley.

Conforme al razonamiento de la Corte Constitucional, la disposición que excluye a las víctimas de reclutamiento ilícito que han cumplido la mayoría de edad sin desvincularse del grupo armado es exequible, no desconoce su condición de víctimas y tampoco niega la reparación a las víctimas puesto que estas pueden acceder a la vía judicial para obtener la reparación de los daños causados. Así, los delitos cometidos en contra de estas víctimas deben ser investigados por la jurisdicción penal ordinaria o la de justicia transicional puesto que persiste la obligación del Estado de investigar y sancionar a los responsables.

Sin embargo, partiendo de un enfoque de realidad del acceso a la justicia de las víctimas de reclutamiento ilícito y de la experiencia en Colombia frente a la reparación judicial, se encuentra que, son pocas las sentencias de la jurisdicción penal ordinaria que han establecido reparaciones para las víctimas de reclutamiento de manera integral, reconociendo los daños materiales y morales, y que disponen algún tipo de reparación para los familiares. 
En un estudio realizado por UNICEF en 2015 acerca del abordaje de la reparación judicial en sentencias de la jurisdicción de justicia transicional y de la ordinaria $(\mathrm{JPO})^{17}$, se encontró que En relación al daño moral, la mayoría de las sentencias de JPO mencionan de manera superficial que el reclutamiento ilícito genera impactos en los niños y niñas. Sin embargo, en estas no se analiza el impacto sicosocial, los efectos de la pérdida de la infancia, de los lazos familiares o la afectación de otros derechos fundamentales mencionados anteriormente como el derecho a la familia, la educación y la libertad sexual entre otros. Tampoco hay reconocimiento de otras formas de reparación tales como las garantías de no repetición, la restitución y la rehabilitación. En los únicos fallos que se abordan este tipo de medidas son en los casos relacionados con la desaparición de dos niñas que fueron reclutadas, para exigir colaboración del condenado para la ubicación de los restos. En la mayoría de las sentencias no es reconocido el daño moral a los familiares de las víctimas, a pesar de haber comparecido y haber narrado el dolor sufrido por el reclutamiento de sus hijos e hijas (UNICEF, 2015, p. 28).

Además, el estudio encontró que la mayoría de sentencias por el delito de reclutamiento ilícito tanto de la jurisdicción penal ordinaria como de la de justicia transicional, niegan la reparación de daños materiales a los niños y niñas, basándose en argumentos, como por ejemplo, que los niños y niñas tienen restricciones para trabajar, que no pueden ganar un salario mínimo completo y que indemnizar los daños materiales como el lucro cesante podría incentivar el trabajo infantil (Tribunal Superior de Bogotá, 2011). Además, no se reconoce dentro de los daños inmateriales el daño al proyecto de vida de las víctimas

17 El estudio analizó dieciséis sentencias condenatorias proferidas por la JPO por hechos de reclutamiento ilícito cometidos entre los años 2009 y 2012. Seis sentencias corresponden a hechos cometidos por el frente 47 de las FARC-EP, una por el Ejército de Liberación Nacional (ELN) y nueve por los bloques Norte, Puerto Boyacá y Tayrona de las AUC. Igualmente, se estudiaron cinco sentencias proferidas por la Jurisdicción de justicia transicional entre los años 2011 y 2014, en contra de miembros de los Bloques Bananero, Norte, Elmer Cárdenas y Vencedores de Arauca y el Frente José Pablo Díaz de las AUC (Unicef, 2011). 
de reclutamiento, a pesar de que hay suficiente evidencia para demostrar los impactos que este delito genera en todas las esferas individual, familia y colectiva de los niños y niñas.

A partir de lo expuesto previamente se concluye que, si bien el Estado colombiano está obligado a reparar a las víctimas de reclutamiento ilícito, ya sea a través de la vía judicial o la administrativa, y que la Corte Constitucional declaró exequible el apartado del artículo 3 parágrafo 2 de la Ley 1448, por considerar que el recurso adecuado que deben agotar las víctimas mayores de edad es el de la reparación judicial, la realidad pone de presente que, son pocas las personas desvinculadas que a través de la vía judicial han podido obtener reparación integral por los daños sufridos en razón de su reclutamiento, al igual que sus familiares.

\section{El reclutamiento ilícito como restricción a la libertad personal}

Por otro lado, el artículo bajo estudio pone una carga excesiva sobre las víctimas de reclutamiento ilícito al establecer como condición el haberse desvinculado antes de cumplir los 18 años. Esta disposición supone que los niños y niñas vinculados a un grupo armado tienen la libertad de abandonar el grupo voluntariamente. Dicho supuesto plantea a las víctimas una disyuntiva que puede poner en riesgo su vida puesto que, si quieren acceder a la reparación por la vía de la Ley 1448 de 2011, deberán entonces hacer todo lo posible para salir del grupo armado antes de cumplir los 18 años. Sobre el particular la Coalición contra la vinculación de niños, niñas y jóvenes al conflicto armado en Colombia - Coalico- en su intervención ciudadana en el proceso de constitucionalidad que culminó con la Sentencia C-253A de 2012 observó que

la coerción a la que son sometidas las víctimas de reclutamiento forzado hace que el intento de fuga de los grupos armados se constituya en un acto heroico que compromete sus vidas, ya que de fallar serán castigados inclusive con la muerte. Así por ejemplo, entre las infracciones más graves del código militar de las FARC-EP que se consideren delitos capitales sancionables con 
una ejecución sumaria, independientemente de la edad del que la haya cometido, se encuentra el intentar escapar, en particular si llevan un arma consigo.

Como se ha constatado a partir de los testimonios de niños y niñas reclutados recopilados en diferentes estudios y procesos judiciales y administrativos, los niños y niñas reclutados ingresan la mayoría de las veces al grupo armado bajo coacción o amenaza y, una vez adentro, quedan bajo la estructura de mando del grupo armado, siendo sujetos del régimen disciplinario y de sanciones, dentro de las cuales se encuentran los consejos de guerra. Para la Defensoría del Pueblo (2005), escaparse supone particulares riesgos para su vida e integridad física, dadas las posibles retaliaciones que devienen de un egreso de ésta naturaleza por parte de las organizaciones armadas, de manera que, no sólo ésta, sino también sus redes familiares se ven expuestas a las sanciones impuestas con frecuencia por estos grupos a las personas que se niegan a seguir perteneciendo a ellos y que pueden expresarse en castigos, amenazas, persecuciones, destierros e incluso la muerte. Esto demuestra que los niños y niñas reclutados no disponen de voluntad para permanecer o dejar de pertenecer al grupo armado, ya que esta decisión está en cabeza de los superiores y comandantes quienes podrían atentar contra su integridad personal y su vida.

\section{Reparación de víctimas de reclutamiento que cumplen la mayoría de edad}

El condicionamiento que plantea el parágrafo 2 del artículo 3 de la Ley de víctimas, abre el debate respecto a la reparación de las víctimas de reclutamiento que cumplen la mayoría de edad. En principio, a partir de los argumentos antes expuestos, está claro que las personas reclutadas ilícitamente son víctimas y por tanto los daños que se les han causados deben ser reparados, ya sea por el perpetrador o el Estado. Igualmente, se ha demostrado que dichos daños trascienden en el tiempo e incluso pueden tener efectos transgeneracionales que no se agotan con su desvinculación del grupo armado o su ingreso al 
programa de restablecimiento de derechos. No obstante, falta establecer si otros hechos victimizantes análogos al reclutamiento tienen condicionantes similares relacionados con la edad de las víctimas. Para ello se realizará un ejercicio comparativo entre el reclutamiento ilícito y la desaparición forzada.

El reclutamiento es "la conscripción o alistamiento obligatorio, forzado y voluntario de niños y niñas a cualquier tipo de grupo o fuerza armada" (Principios de París, 2007) el cual, al realizarse frente a personas que están por debajo de la edad estipulada en los tratados internacionales y las normas nacionales, resulta ilícito (Principios de París, 2007). Para el caso de Colombia la edad de referencia es la de 18 años ${ }^{18}$.

Por su parte la desaparición forzada es, conforme al artículo 2 de la Convención Internacional para la protección de todas las personas contra las desapariciones forzadas: "el arresto, la detención, el secuestro o cualquier otra forma de privación de libertad que sean obra de agentes del Estado o por personas o grupos de personas que actúan con la autorización, el apoyo o la aquiescencia del Estado, seguida de la negativa a reconocer dicha privación de libertad o del ocultamiento de la suerte o el paradero de la persona desaparecida, sustrayéndola a la protección de la ley".

A partir de dichas definiciones se encuentra que ambos son delitos de ejecución permanente o continuada, es decir, que la vulneración o puesta en riesgo del bien jurídico se mantiene en el tiempo sin solución de continuidad, hasta cuando el autor, por voluntad propia, deja de lesionarlo, o hasta cuando por otra razón, por ejemplo, la muerte de la víctima o su huida, desaparece el daño o el peligro al interés o valor tutelado ${ }^{19}$. Además, en ambos casos se desconoce el paradero de la víctima y tampoco se sabe si esta se encuentra viva o muerta. Por otro lado, en ambos casos, los familiares de las víctimas son amenazados para que no interpongan denuncia de los hechos o se desplacen.

18 Colombia al firmar la Convención de los Derechos del Niño hizo una reserva elevando la edad de prohibición de reclutamiento a 18 años. Este mismo estándar fue plasmado en la Ley de infancia y adolescencia.

19 Corte Suprema de Justicia, Cas. Penal, Sentencia 30/2006, Rad. 22813. M.P. Álvaro Orlando Pérez Pinzón. 
En relación a lo que dispone la Ley de víctimas respecto a la desaparición forzada se puede decir que esta es incluida como un hecho victimizante que amerita reparación al igual que el reclutamiento ilícito y para ambos se dispone un monto de 40 SMLV de indemnización. No obstante, dicha Ley no plantea ningún condicionamiento respecto a la edad de las víctimas de desaparición forzada para reclamar la reparación como si lo hace en el caso de reclutamiento.

Dicha distinción frente a delitos que presentan gran similitud plantea la siguiente pregunta: ¿cuál es la trascendía del cumplimiento de la mayoría de edad en términos de la reparación de los impactos causados a las víctimas de reclutamiento ilícito?

Para la Corte Constitucional el factor crucial es la edad de la víctima. "Cuando se sobrepase el límite de la minoría de edad, cambian las circunstancias que le imponen al Estado el deber de especial protección y por ello, resulta admisible que la ley de víctimas establezca como límite para acceder a las medidas de protección en ella consagradas el hecho de que la desmovilización haya ocurrido mientras las personas sean menores de edad" (Corte Constitucional Sentencia C-253ª de 2012).

Si bien está claro que, el Estado ha previsto un conjunto de políticas y medidas de reintegración y restablecimiento de derechos diferenciales para quienes son menores de 18 años, por su condición de niños y niñas, lo cierto es que, en términos de reconocer y otorgar la indemnización, no existe ninguna diferencia sustancial entre las víctimas para acceder a esta en términos de procedimientos, recursos etc. ${ }^{20}$. Así, se considera que, en principio, en términos de otorgar indemnización, no debería haber condicionamientos para unas víctimas distintos a los de las demás, en términos de la edad puesto que, esta no tiene ninguna relevancia al momento de reclamar la indemnización.

Otras posturas plantean que el condicionamiento de haberse desvinculado antes de cumplir la mayoría de edad, se introdujo motivado

20 La única distinción para reclamar la indemnización entre menores de 18 y adultos es que a los primeros se les constituye un encargo fiduciario que pueden reclamar al cumplir la mayoría de edad, mientras que los segundos, pueden reclamarla a través de una carta cheque. 
en el polémico debate acerca de la doble condición que pueden tener las niñas y niños reclutados como víctimas y victimarios. Esta doble condición supone que aunque se reconozca que estos niños y niñas fueron víctimas del accionar de un grupo armado y que ingresaron a este bajo coacción o amenaza, estos también pudieron haber perpetrado delitos. Sobre el particular en la sentencia C-203 de 2005 la Corte Constitucional señaló que "si bien los niños, niñas y adolescentes desvinculados "son considerados víctimas del conflicto (...) dicha condición no los exime per se de toda responsabilidad penal”.

Mientras las víctimas son menores de edad existen suficientes argumentos para atenderlos y repararlos como víctimas, puesto que el Estado ha dispuesto una normativa que le da prevalencia a dicha condición sobre la de victimarios. Pero al cumplir la mayoría de edad su situación se complejiza. Como lo ha señalado el Instituto Internacional para la Justicia Transicional -ICTJ-:

El tránsito del ICBF a la ACR representa el paso de ser desvinculado a desmovilizado, el paso de la niñez a la edad adulta, de ser entendido como víctima a una nueva y ambigua categoría más cercana a la de victimario... Actualmente, estos jóvenes pasan directamente a la ACR donde reciben el trato de desmovilizados al igual que los adultos que ingresan al programa de reintegración. Al no haber en la actualidad ninguna distinción o programa diferencial en la ACR para quienes han sido ya reconocidos como víctimas de reclutamiento ilícito, los desvinculados acaban haciendo parte del mismo programa en el cual participan los responsables de su vinculación a la guerra. Además, este tránsito pierde de vista la especificidad de los impactos generados por el reclutamiento ilícito, los cuales ameritan una atención diferencial que permita su superación (ICTJ, 2015:20).

De acuerdo con lo anterior, el cumplimiento de la mayoría de edad de las víctimas de reclutamiento ilícito cambia radicalmente su percepción social y su estatus jurídico frente a los hechos que hayan cometido siendo adultos, mas no siendo niños. Y es en este tránsito en el que la 
sociedad y el Estado se encuentran con la faceta del "victimario", del adulto desmovilizado, la cual sale del marco general de protección de la infancia y genera tensión en cuanto a la respuesta del Estado frente a estos sujetos.

Esto se ve reforzado por el hecho de que, al considerar la posibilidad de que las victimas de reclutamiento que cumplen la mayoría de edad puedan acceder a la indemnización, se aumente dramáticamente el universo de víctimas a quienes el Estado, con sus recursos, debería reparar. Muestra de lo anterior es que más de 2.198 paramilitares y guerrilleros declararon durante el proceso de desmovilización haber sido reclutados siendo niños (Coalico, 2011). Lo anterior plantea que el número de personas víctimas de reclutamiento ilícito en Colombia podría entonces superar los estimados hechos por Human Rights Watch en 2003 (6.000), la Oficina del Alto Comisionado de las Naciones Unidas para Colombia -OACNUDH- en 2003 (14.000) y Natalia Springuer en 2011 (18.000).

Conforme a este análisis, adultos desmovilizados podrían ser beneficiarios de la reparación por el reclutamiento sufrido cuando eran niños, reparación a la cual tienen derecho conforme a la Constitución y los tratados internacionales, como se afirmó previamente. Esto es totalmente probable y jurídicamente sustentable en el escenario de la reparación judicial en donde, muchas de las víctimas de reclutamiento cumplieron la mayoría de edad durante el trámite de los procesos penales y fueron reparadas siendo adultas.

Llama la atención el caso particular de la Jurisdicción de justicia transicional en la cual se han emitido alrededor de ocho sentencias que incluyen cargos de reclutamiento ilícito. En la sentencia de Freddy Rendón Herrera, alias “el Alemán”, por ejemplo, las víctimas de reclutamiento no fueron entregadas oportunamente al Estado, razón por la cual estas cumplieron la mayoría de edad y se presentaron a rendir testimonio siendo adultas. Este proceso tuvo como resultado la reparación de alrededor de 300 personas reclutadas ilícitamente cuando eran niños, que en su mayoría al momento del juicio eran adultas. Otro caso es el de la sentencia contra Salvatore Mancuso en la cual, el Tribunal Superior de Bogotá encontró que, el 55\% o 49 de los niños víctimas de reclutamiento "ingresó siendo menor de edad y 
se desmovilizó siendo mayor de edad" (Tribunal Superior de Bogotá, 2014). Esto quiere decir que a través de la Ley 975 de 2005, modificada por la Ley 1592 de 2012, se ha otorgado reparación judicial a personas adultas por las violencias que sufrieron siendo niños y niñas.

En suma, en el escenario de la reparación judicial es factible que las victimas de reclutamiento reclamen la reparación a que tienen derecho por las violaciones de sus derechos siendo niños y niñas, por causa del reclutamiento ilegal por actores armados mientras que, en el ámbito de la reparación administrativa, no es factible ya que, existe un condicionamiento que restringe el universo de victimas que pueden reclamar indemnización, basado en la edad de las víctimas.

\section{La prescripción de la acción penal como límite para reclamar la reparación administrativa}

Habiendo establecido que la Ley de víctimas condiciona la reparación de las víctimas de reclutamiento a que hayan cumplido la mayoría de edad, es importante pasar a determinar cómo opera la prescripción de la acción penal en casos de reclutamiento ilícito, ya que, el artículo 190 de la Ley de víctimas hace referencia a dicho término.

Conforme al Código Penal Colombiano (Ley 599 de 2000) artículo $83^{21}$, la acción penal frente al del delito de reclutamiento ilícito tiene, en principio, una prescripción de 20 años $^{22}$. Esto significa que hasta antes del vencimiento de dicho plazo, se puede interponer una denuncia o realizar una investigación de oficio por estos hechos.

No obstante, es importante recordar que, como se explicó previamente, el delito de reclutamiento ilícito por su naturaleza es de ejecución permanente o continuada, por lo que la vulneración al

21 El artículo 83 del Código Penal dispone: “la acción penal prescribirá en un tiempo igual al máximo de la pena fijada en la ley, si fuere privativa de la libertad, pero en ningún caso será inferior a cinco (5) años, ni excederá de veinte $(20)$ ".

22 Si el artículo 162 establece que la pena máxima de privación de la libertad es de 10 años de prisión, y se dice que la prescripción de la acción penal se da en el doble del tiempo previsto para la pena (entre 5 y 10 años) entonces la prescripción tiene lugar en un plazo de 20 años. 
bien jurídico tutelado se mantiene en el tiempo hasta que esta cesa. Este elemento es fundamental para comprender el límite de prescripción de la acción penal del delito de reclutamiento ilícito ya que, el artículo 84 del código penal establece que: "En las conductas punibles de ejecución permanente o en las que solo alcancen el grado de tentativa, el término comenzará a correr desde la perpetración del último acto".

Por su parte, el artículo 90 de la ley 1448 de 2001, dispone al respecto que:

\begin{abstract}
ARTÍCULO 190. NIÑOS, NIÑAS Y ADOLESCENTES VÍCTIMAS DEL RECLUTAMIENTO ILÍCITO. Todos los niños, niñas y adolescentes víctimas del reclutamiento, tendrán derecho a la reparación integral en los términos de la presente ley. Los niños, niñas y adolescentes víctimas del delito de reclutamiento ilícito podrán reclamar la reparación del daño, de acuerdo con la prescripción del delito consagrada en el artículo 83 del Código Penal (negrilla fuera del texto).
\end{abstract}

Entendiendo que el artículo 90 de la Ley de víctimas remite a la prescripción penal del delito de reclutamiento, lo planteado en dicho artículo supone, en principio, que las víctimas de uso y/o reclutamiento ilícito, puedan reclamar la reparación dentro de un plazo mínimo el de 5 años y máximo el de 10 años, contados desde la perpetración del último acto (artículo 84 C.P), que puede ser por ejemplo la liberación, la captura o la muerte del niño o niña).

No obstante, como se ha reiterado previamente, la misma Ley de víctimas en su artículo 3, parágrafo 2, ha impuesto como condicionante que la víctima se haya desvinculado del grupo armado antes de cumplir los 18 años. Entonces, la pregunta que surge es: ¿qué plazo debe tener en cuenta la Unidad para las Víctimas -UARIV- al momento de valorar la declaración hecha por las víctimas de reclutamiento para ser considerado beneficiario de la reparación administrativa? Y ¿si ésta cumplió la mayoría de edad pero no obstante aún no ha prescrito la acción penal, podría reclamar la reparación? 
A primera vista la respuesta a dichos interrogantes es no podrían reclamar la reparación si cumplieron la mayoría de edad pero aún no ha prescrito el delito, ya que el condicionante del artículo 3, parágrafo 2, excluye de plano a las víctimas de reclutamiento que hayan alcanzado la mayoría de edad. Sin embargo, existen argumentos para demostrar que conforme al principio del interés superior del niño y el principio de favorabilidad, las víctimas de reclutamiento podrían reclamar la indemnización dentro del plazo previsto por la prescripción de la acción penal, sin importar su edad, como se expondrá más adelante.

\section{Situación de las y los niños y jóvenes indígenas víctimas de reclutamiento}

Conforme a la Convención de los Derechos del niño (artículo 30) y la Observación general número 11 del Comité de los derechos del niño (2009), los niños, niñas y adolescentes pertenecientes a pueblos indígenas necesitan medidas especiales para el pleno disfrute de sus derechos, con el objeto de superar las barreras y la discriminación que dificultan su acceso a estos en igualdad de condiciones a los otros niños y niñas.

Por su parte el artículo 48 del Decreto ley 4633 de 2011, que reglamenta la reparación administrativa para pueblos indígenas, señala que "los derechos de los niños, niñas y jóvenes indígenas víctimas son prevalentes de conformidad con la Ley de Origen, Ley Natural, el Derecho Mayor, el Derecho Propio, la Constitución Política y las Normas de Derechos Humanos y, dado el carácter inadmisible y apremiante de su situación, y su importancia para la permanencia y pervivencia física y cultural de los Pueblos Indígenas a que pertenecen”.

Dicho Decreto además, en su artículo 51, reconoce como uno de los hechos victimizantes que gravemente afecta a la niñez indígena el reclutamiento ilícito, en los mismos términos que lo establece la Ley 1448 de 2011. No obstante, el artículo 3 parágrafo 2 de dicho Decreto, dispone frente a los niños y niñas indígenas víctimas de reclutamiento lo siguiente:

Los niños, niñas y adolescentes de los pueblos y comunidades indígenas vinculados a los diferentes actores armados son víctimas 
y deben ser reparados individualmente y colectivamente la comunidad. Los pueblos y comunidades indígenas son víctimas de toda forma de reclutamiento forzado, por lo tanto, deben ser reparados colectivamente.

En otras palabras, el Decreto en mención no plantea ninguna restricción de edad para otorgar reparación administrativa a las víctimas de reclutamiento pertenecientes a pueblos indígenas y por lo tanto, conforme al artículo 3, incluso las víctimas que han cumplido la mayoría de edad podrían ser beneficiarias de dicha reparación.

Así, este Decreto plantea una excepción a la regla establecida en los artículos, 3 y 184 de La ley de víctimas por cuanto a los niños y niñas indígenas no se les exige haberse desvinculado antes de cumplir los 18 años y, siendo adultos, pueden reclamar la indemnización. Esto naturalmente suscita una pregunta: ¿por qué se autoriza la reparación a las víctimas de reclutamiento ilícito pertenecientes a comunidades indígenas que han cumplido la mayoría de edad, mientras que a las víctimas pertenecientes a otros grupos étnicos o a comunidades campesinas no?

En principio, no se encuentran argumentos que sustenten dicho trato diferencial ya que, tanto las víctimas pertenecientes a grupos étnicos como los raizales o los afrodescendientes ${ }^{23}$ como aquellas pertenecientes a pueblos indígenas gozan de protección especial y diferencial del Estado, tienen derecho tanto a la reparación individual y colectiva y han sufrido de manera desproporcionada los efectos del conflicto armado. Lo cierto es que, el Decreto 4633 de 2011 plantea una excepción a la regla prevista en el parágrafo 2 numeral 3 de la Ley de víctimas y autoriza la reparación de las víctimas de reclutamiento ilícito, indígenas, mayores de edad.

23 El artículo 3 parágrafo 1 del Decreto Ley 4635 de 2011, reglamentario de la Ley de víctimas, dispone: "Los miembros de los grupos armados organizados al margen de la ley no serán considerados víctimas, salvo en los casos en los que los niños, niñas o adolescentes hubieren sido desvinculados del grupo armado organizado al margen de la ley siendo menores de edad”. 


\section{Argumentos interpretativos de la ley 1448 de 2011 en favor de las víctimas de reclutamiento ilícito}

\section{La necesidad de una interpretación sistemática de ley}

Si bien previamente se ha advertido que el artículo 3 parágrafo 2 de la ley 1448 de 2011, plantea una exclusión de las víctimas de reclutamiento ilícito que no se hayan desvinculado antes de cumplir los 18 años, existen otras normas dentro de la misma ley que tendrían que analizarse en conjunto para llegar a una interpretación más favorable para las víctimas de reclutamiento ilícito.

Conforme a la jurisprudencia constitucional (Sentencia C-641 de 2001) "la interpretación sistemática es la lectura de la norma que se quiere interpretar, en conjunto con las demás que conforman el ordenamiento en el cual aquella está inserta". Lo anterior a la luz de la Ley 1448 significa que, hay que analizar los artículos específicos referentes a la reparación de las víctimas de reclutamiento ilícito en conjunto con otras normas generales aplicables a la niñez víctima del conflicto armado y los principios generales de la reparación entre otras disposiciones, con el objeto de realizar una interpretación acorde al espíritu del legislador y los parámetros constitucionales.

Lo primero que habría que hacer entonces es remitirse al artículo 1 de la Ley de víctimas, con el objeto de consultar el objetivo primario de dicha ley, el cual es

establecer un conjunto de medidas judiciales, administrativas, sociales y económicas, individuales y colectivas, en beneficio de las víctimas de las violaciones contempladas en el artículo $3^{\circ}$ de la presente ley, dentro de un marco de justicia transicional, que posibiliten hacer efectivo el goce de sus derechos a la verdad, la justicia y la reparación con garantía de no repetición, de modo que se reconozca su condición de víctimas y se dignifique a través de la materialización de sus derechos constitucionales (negrilla fuera del texto). 
Es decir que, uno de los objetivos primordiales de la ley es el reconocimiento de la condición de víctima de las personas que sufrieron algún daño a causa del conflicto armado y repararlas. Sumado a esto la ley establece que las víctimas menores de edad "gozarán de todos los derechos civiles, políticos, sociales, económicos y culturales, con el carácter de preferente" (artículo 181), razón por la cual tienen derecho a la reparación integral, derecho que incluye las medidas de indemnización, rehabilitación, satisfacción, restitución y garantías de no repetición (artículo 182).

Igualmente, la ley dentro de los principios generales incluye el enfoque diferencial el cual plantea en el artículo 13 que "el Estado ofrecerá especiales garantías y medidas de protección a los grupos expuestos a mayor riesgo de las violaciones contempladas en el artículo $3^{\circ}$ de la presente Ley tales como mujeres, jóvenes, niños y niñas" etc.

Otro principio reconocido por la ley es el de igualdad (artículo 6) según el cual "las medidas contempladas en la presente ley serán reconocidas sin distinción de género, respetando la libertad $u$ orientación sexual, raza, la condición social, la profesión, el origen nacional o familiar, la lengua, el credo religioso, la opinión política o filosófica”.

Los artículos en mención expresan el deseo del legislador de garantizar la reparación de las víctimas del conflicto armado dando prevalencia a los derechos de quienes hayan sufrido algún hecho victimizante siendo menores de 18 años, por su condición de sujetos de especial protección. No obstante, como se explicó previamente, el legislador quiso imponer una restricción para el acceso a la reparación de las víctimas de reclutamiento ilícito consistente en haberse desvinculado antes de cumplir los 18 años. A pesar de ello, dentro de la misma ley existe otra disposición que plantea la obligación del estado de reparar integralmente a todas las víctimas de reclutamiento ilícito sin excepción.

En particular, el artículo 190 de la Ley de víctimas establece que, todos los niños y niñas víctimas de reclutamiento son acreedores de la reparación integral en los términos de la presente ley. Dicho artículo se refiere de manera general a todas las personas que fueron reclutadas ilícitamente sin ninguna distinción por motivos de sexo, origen étnico o edad. Además, establece una obligación general para el Estado el cual, 
al comprobar el hecho victimizante de reclutamiento ilícito, debería otorgar la correspondiente reparación administrativa a las víctimas.

Dicha norma, dentro del articulado de la ley, se encuentra ubicada en el título VII sobre la protección integral a los niños, niñas y adolescentes víctimas, es decir, dentro del acápite que recoge las disposiciones especiales aplicables a la población menor de 18 años. Así, esta norma es posterior a aquellas que establecen de manera explícita el condicionamiento de la desvinculación antes de cumplir la mayoría de edad. No obstante, la Corte Constitucional en reiterada jurisprudencia

ha considerado obligatorio el respeto del principio de favorabilidad, de conformidad con el cual la ley permisiva o favorable, aun cuando sea posterior, se aplica de preferencia a la restrictiva o desfavorable. Frente a este punto, ha advertido que aun cuando el artículo 29 de la Constitución se refiere a la aplicación del principio en "materia penal”, ello “(...) no impide que el legislador lo extienda a otros ámbitos del derecho (...) Tampoco conduce a que el juez deba interpretar restrictivamente esta garantía, que tiene pleno sentido y especial relevancia dentro de un estado social de derecho en otros contextos punitivos diferentes al penal (negrilla fuera del texto) (Corte Constitucional, sentencia C692-08).

Así, lo primero que habría que decir es que el artículo 190 es una norma mucho más favorable que la establecida en el artículo 3 parágrafo 2 y el 184 ya que, cobija a todas las víctimas de reclutamiento sin hacer ninguna exclusión. Sobre el particular, la misma ley en su artículo 27 señala que

En lo dispuesto en la presente ley, prevalecerá lo establecido en los tratados y convenios internacionales ratificados por Colombia sobre Derecho Internacional Humanitario y Derechos Humanos que prohíban su limitación durante los estados de excepción, por formar parte del bloque de constitucionalidad. En los casos de reparación administrativa, el intérprete de las normas consagradas en la presente ley se encuentra en el deber de escoger y aplicar la 
regulación o la interpretación que más favorezca a la dignidad y libertad de persona humana, así como a la vigencia de los derechos humanos de las víctimas (negrilla fuera del texto).

Igualmente, en su artículo 191 ha establecido que: "Las normas del presente título se aplicarán sin perjuicio de lo dispuesto en otras disposiciones de esta ley. En caso de duda, en los procesos de reparación administrativa, se aplicará la disposición que sea más favorable para el niño, niña o adolescente, en consonancia con el interés superior del niño”.

Dicha disposición, retoma uno de los principios más importantes en materia de interpretación normativa en favor de la infancia, el principio del interés superior del niño y de la niña, establecido en la Convención de los derechos del niño (artículo 4), en la Constitución política nacional (artículo 13) y la ley de infancia y adolescencia (artículo 8). Según la jurisprudencia constitucional:

El principio del interés superior del menor se erige en definitiva como una norma de amplio reconocimiento en el ordenamiento jurídico interno y en el derecho internacional vinculante para Colombia. Representa un importante parámetro de interpretación para la solución de controversias en las que se puedan ver comprometidos los derechos de niños, niñas y adolescentes. En su análisis es preciso tomar en cuenta las condiciones jurídicas y fácticas para optar por aquella decisión que, en mejor medida, garantice sus derechos e intereses con miras a su desarrollo armónico e integral (Corte Constitucional, sentencia C-262 de 2016).

Con base en lo anteriormente expuesto se concluye que, el artículo 190 de la ley de víctimas es una norma más favorable para las víctimas de reclutamiento ilícito la cual, interpretada conforme a los principios de favorabilidad (para todas las víctimas sin importar la edad) e interés superior del niño (cuando las víctimas son menores de 18 años), autoriza a todas las víctimas de este delito a que presenten su solicitud de reparación administrativa y ser acreedoras de indemnización, sin 
importar si estas han cumplido o no la mayoría de edad. Con ello, se está reconociendo la importancia de que a todas las víctimas de reclutamiento se las repare integralmente debido a las graves consecuencias que este delito genera a nivel individual y colectivo, y que, a pesar de haber cumplido la mayoría de edad, siguen enfrentando los impactos que dejó este hecho en sus vidas.

\section{La fuerza mayor como un argumento para la ampliación de los términos de registro}

Una vez demostrado que conforme al principio de favorabilidad todas las víctimas de reclutamiento, sin importar su edad, pueden presentar su solicitud de registro, es preciso analizar aquellos casos en los cuales las víctimas pudieron haber enfrentado situaciones que les impidieron radicar dicha solicitud dentro de los plazos establecidos en la ley.

El Decreto 4800 de 2011, reglamentario de la ley de víctimas, establece en cuanto a la oportunidad de presentar la solicitud de registro lo siguiente:

Artículo 28.- Oportunidad del registro. De conformidad con lo establecido en el artículo 155 de la Ley 1448 de 2011, la solicitud de registro deberá presentarse en un término de 4 años contados a partir del 10 de junio de 2011, fecha de promulgación de la Ley, para quienes hayan sido victimizadas con anterioridad a ese momento; y de 2 años contados a partir de la ocurrencia del hecho para quienes hayan sido victimizados con posterioridad a esta fecha $(. .$.

En el evento de fuerza mayor que haya impedido a la víctima presentar la solicitud de registro en el término establecido en este artículo, se empezará a contar el mismo desde el momento en que cesen las circunstancias que motivaron tal impedimento, para lo cual deberá informar de ello al Ministerio Público al momento de la declaración, quien remitirá tal información a la Unidad Administrativa Especial para la Atención y Reparación Integral a las Víctimas. 
Dicha disposición establece un plazo perentorio, diferenciando dos situaciones, conforme a la fecha de ocurrencia de los hechos victimizantes. Además, plantea una excepción para los casos en los cuales las víctimas enfrentaron una situación de fuerza mayor que les impidió presentar su solicitud en tiempo.

Así, una víctima que logre demostrar que por razones de fuerza mayor no pudo presentar en tiempo su solicitud de registro, puede alegar dicha circunstancia con el objeto de que se acepte su solicitud a pesar de haberse vencido el plazo. En el caso de las víctimas de reclutamiento es claro que, como se demostró previamente, estas no disponen de su voluntad para dejar el grupo armado, aun siendo mayores de edad, debido a la coacción a la que están sometidos la mayoría de sus miembros.

Sumado a lo anterior, el artículo 184 de la ley de víctimas plantea que los padres, o en su defecto, el defensor de familia, están facultados para elevar la solicitud de registro, como representantes legales del niño, niña o adolescente, de la indemnización a la que estos tengan derecho. Esto significa que, si el niño o la niña aún se encuentran reclutados o desaparecidos, sus representantes legales pueden presentar la declaración y por ende tendría la UARIV que crear el encargo fiduciario para que el niño reclame la reparación una vez salga del grupo armado.

Por lo tanto, las víctimas de reclutamiento ilícito que no se desvincularon siendo menores de 18 pueden argumentar razones de fuerza mayor que les impidieron radicar su solicitud en tiempo y además, sus familiares podrían en su nombre radicar la solicitud en cualquier tiempo.

\section{Conclusión}

Como ha sido demostrado previamente, si bien la Ley 1448 de 2011 establece como hecho victimizante el reclutamiento ilícito y la prevalencia de los derechos de la infancia, esta plantea como condicionante, para que las víctimas de reclutamiento puedan acceder a la reparación administrativa, que se desvinculen antes de cumplir los 18 años. 
Además, se estableció que si bien la Corte Constitucional consideró que el recurso adecuado que deben agotar las víctimas mayores de edad, excluidas de la ley por no haberse desvinculado antes de cumplir los 18 años, es el de la reparación judicial, la realidad pone de presente que, son pocas las personas desvinculadas que a través de la vía judicial han podido obtener reparación integral por los daños sufridos en razón de su reclutamiento.

Por otro lado, se estableció que los niños y niñas víctimas de reclutamiento ilícito son sujetos de protección constitucional reforzada ya que, además de ser menores de edad, ostentan la condición de víctimas de una de las peores violencias que tiene lugar dentro del conflicto armado. Esto amerita que sean reparadas de manera integral, lo cual supone que el Estado garantice los mecanismos necesarios para que estas sean indemnizadas, ya sea por el victimario (a través de la vía judicial) o de manera subsidiaria por el Estado (mediante la reparación administrativa).

Aunado a lo anterior, se estableció que los niños y niñas reclutados ingresan la mayoría de las veces al grupo armado bajo coacción o amenaza y que, por tanto, no disponen de voluntad para permanecer o dejar de pertenecer al grupo armado. Así, la decisión está en cabeza de los superiores quienes podrían atentar contra la integridad personal del niño o la niña. Por lo tanto, estas personas no tienen la capacidad de decidir si permanecen o abandonan el grupo armado con el objeto de presentarse ante el Ministerio público, antes de cumplir los 18 años, para rendir declaración y ser reconocidas como beneficiarias de la ley.

Además, se señaló que en el caso de las víctimas de reclutamiento pertenecientes a pueblos indígenas el Decreto ley 4633 de 2011 no plantea la misma restricción de edad establecida en el artículo 3 de la Ley 1448 razón por la cual las victimas pertenecientes a estos grupos, a pesar de haber alcanzado la mayoría de edad pueden ser beneficiarias de la reparación administrativa, lo cual no se aplica a otros grupos étnicos como los raizales y afrodescendientes.

Igualmente, se demostró que realizando una interpretación sistemática de la Ley de víctimas se encuentra una disposición más favorable para las víctimas de reclutamiento la cual, no impone ningún condicionante de edad para reclamar la reparación administrativa. 
Esto significa que sin importar si han cumplido o no la mayoría de edad estas personas pueden ser acreedoras de la indemnización y demás medidas de reparación que dispone la Ley.

Aunado a lo anterior se estableció que los familiares de las víctimas de reclutamiento ilícito podrían presentar la solicitud de registro de sus hijos reclutados, en cualquier momento, alegando la imposibilidad de estos para hacerlo (fuerza mayor) o el desconocimiento de su paradero como víctimas de (desaparición forzada), pero siempre teniendo presente la prescripción de la acción penal conforme a lo dispuesto en el artículo 190 de la Ley de víctimas.

Finalmente, se concluye que teniendo en cuenta el objetivo primario del legislador al concebir la Ley de víctimas, las personas que fueron reclutadas ilícitamente, en su calidad de sujetos de especial protección y víctimas de una de las peores formas de explotación infantil dentro de los conflictos armados, merecen ser reconocidas como sujetos de reparación y, sin importar si se desvincularon antes o después de cumplir la mayoría de edad, deberían ser incluidas en el registro único de víctimas. Esto con el ánimo de recibir la indemnización y ser beneficiarias de las demás medidas de reparación establecidas en la ley.

\section{Bibiografía}

CINTRAS, EATIP y otros (2009). Daño transgeneracional: Consecuencias de la represión política en el cono Sur, Santiago de Chile.

Coalición contra la vinculación de niños, niñas y adolescentes al conflicto armado en Colombia (2011), "Desmovilización paramilitar: Obstáculos para el acceso a la justicia de las víctimas de reclutamiento ilícito", ponencia presentada por Ana María Jiménez en la conferencia organizada por el proyecto ProFis de la GIZ en julio de 2011, Bogotá, Colombia.

Constitución Política de Colombia de 1991 (1991) . Legis.

Comité de los derechos del niño (12 de febrero de 2009). Observación General No.11 Los niños indígenas y sus derechos en virtud de la Convención sobre los Derechos del Niño, documento de Naciones Unidas CRC/C/GC/11.

Organización Internacional del Trabajo -OIT-. (1999) Convenio 182.

Corte Constitucional de Colombia. (2012) Sentencia T-129 de 2012. M.P: Jorge Ignacio Pretelt Chaljub. 
Corte Constitucional de Colombia (2012), Sentencia C-781 de 2012. M.P. María Victoria Calle Correa.

Corte Constitucional de Colombia (2016), Sentencia C-262 de 2016. M.P: Jorge Iván Palacio Palacio.

Corte Constitucional de Colombia (2012), Sentencia C-253 de 2012, M.P: Gabriel Eduardo Mendoza Martelo.

Corte Interamericana de Derechos Humanos, (1989). Caso Velásquez Rodríguez Vs. Honduras, Sentencia de 21 de julio de 1989 (Reparaciones y Costas).

Corte Interamericana de Derechos Humanos Caso las Palmeras Vs. Colombia (2002) Reparaciones (Art. 63.1 Convención Americana sobre Derechos Humanos), sentencia de 26 noviembre de 2002.

Corte Penal Internacional. (1998)Estatuto de Roma.

Corte Suprema de Justicia, Sala de casación penal, (tresde abril de dos mil ocho 2008), M.P: Javier Zapata Ortiz, Bogotá, D.C.

Corte Suprema de Justicia, (2006) Sala de casación penal, Sentencia 30/2006, M.P: Álvaro Orlando Pérez Pinzón.

Human Rights Watch (2003). Aprenderás a no llorar: niños combatientes en Colombia, Washington D.C.

Instituto Internacional para la Justicia Transicional -ICTJ, (2014), Jiménez, Ana María, Ladish, Virginie, Correa, Cristian y otros. Reparación integradora para niños, niñas y jóvenes víctimas de reclutamiento ilícito en Colombia, Nueva York.

Instituto Colombiano de Bienestar Familiar -ICBF- (2013). CONCEPTO 99, Bogotá.

Arévalo L.; Molano H.; Jiménez A. y otras (2014). El delito invisible: criterios para la investigación de niños, niñas y adolescentes a grupos armados en Colombia, 2014.

Naciones Unidas.(1989) Convención Internacional sobre los derechos del niño.

Naciones Unidas (2007). Los Principios de Paris: Principios y guía sobre niñez vinculada con fuerzas o grupos armados, Paris.

Nash C. (2009). Las Reparaciones ante la Corte Interamericana de Derechos Humanos (1988 - 2007), Chile.

Oficina en Colombia del Alto Comisionado de las Naciones Unidas para los Derechos Humanos (2003). Informe sobre la situación de los derechos 
humanos en Colombia, documento de Naciones Unidas E/CN.4/2003/13, del 24 de febrero de 2003.

República de Colombia. (2011) Ley 1448 de 2011, Ley de víctimas y de restitución de tierras.

República de Colombia, Bases para el Plan Nacional de Desarrollo 20102014 "Prosperidad para todos".

República de Colombia, (2000) Ley 599 de 2000, Código Penal.

República de Colombia. (2012) Ley 1592 de 2012, "Por medio de la cual se introducen modificaciones a la ley 975 de 2005".

República de Colombia (2011) Decreto 4633 de 2011, Por medio del cual se dictan medidas de asistencia, atención, reparación integral y de restitución de derechos territoriales a las víctimas pertenecientes a los pueblos y comunidades indígenas.

República de Colombia, (2006) Ley 1098 de 2006, por la cual se expide el Código de la Infancia y la Adolescencia.

Sistema Interamericano de Derechos Humanos.(1969). Convención Americana sobre Derechos Humanos.

Springer, Natalia (2012). Como corderos entre lobos: del uso y reclutamiento de niños, niñas y adolescentes en el marco del conflicto armado y la criminalidad en Colombia, Bogotá.

Tribunal Superior de Bogotá, Sala de justicia y paz,(2011) sentencia del 16 de diciembre de 2011, contra Fredy Rendón Herrera, M.P: Uldi Teresa Jiménez López.

Tribunal Superior de Bogotá, Sala de justicia y paz (2014), sentencia contra Salvatore Mancuso, del 20 de noviembre de 2014, M.P: Léster M. González R.

UNICEF (2015). Análisis comparativo de procesos y sentencias proferidas en Justicia y Paz en materia de reclutamiento ilícito y violencia sexual contra niños y niñas. 


\section{El Movimiento de víctimas en América Latina y una aproximación a una caracterización de organizaciones defensoras de derechos humanos en Colombia ${ }^{24}$}

Jorge CarvajaL ${ }^{25}$

HeLber Noguera ${ }^{26}$

\section{Introducción}

Tas víctimas sobrevivientes de los campos de concentración de la Lsegunda guerra mundial empezaron a forjar el camino y abrir las

24 Articulo resultado producto de investigación del proyecto denominado "Procesos de exigibilidad y justiciabilidad de los Derechos Humanos y el Derecho Internacional Humanitario, en el contexto nacional e internacional." Adscrito al grupo de investigación Sociohumanistico Categoría A en Colciencias de la Facultad de Derecho de la Universidad Santo Tomás Bogotá.

25 Doctor en sociología jurídica e instituciones políticas, tesis con mención de reconocimiento, Universidad Externado de Colombia. Magister en Estudios Políticos del Instituto de Estudios Políticos y Relaciones Internacionales IEPRI de la Universidad Nacional. Especialista en sociología jurídica, Universidad Externado de Colombia. Abogado, Universidad Nacional y Licenciado en Ciencias Sociales, Universidad Distrital. docente e investigador en la Universidad Santo Tomás y Universidad. Código Orcid: 0002-4478-3575. Email: jorgecarvajal@usantotomas.edu.co

26 Abogado, docente e investigador en la Universidad Santo Tomás y Universidad Incca de Colombia. Magíster en Defensa de los Derechos Humanos y Derecho Internacional Humanitario ante Organismos y Tribunales Internacionales. Actualmente Asesor en el programa ProPaz de la GIZ. Email: helbernog@hotmail.com 
puertas para el reconocimiento de las víctimas de manera universal, este reconocimiento se ha visto materializado por la comunidad internacional con la expedición del Estatuto de Roma por parte la Corte Penal Internacional, entre otros instrumentos ${ }^{27}$.

América Latina se ha caracterizado por diferentes tipos de procesos violentos como lo son las dictaduras del cono sur, conflictos territoriales, conflictos armados y en general seudo democracias donde los ataques a la población civil han determinado la existencia de un número de víctimas en demasía significativo.

Es por esto que la visibilización de las víctimas de estos hechos cobra una vital importancia, está claro también que cada proceso de reivindicación de garantía y protección de derechos e incluso de memoria que han adelantado las víctimas es diferente en cada país debido a las diferentes situaciones de injusticia y a los procesos de trasformación de la realidad política, social y cultural. Estos procesos adelantados tienen como objeto hacer que se respeten sus derechos como víctimas, los cuales son el acceso efectivo en condiciones de igualdad a los diferentes organismos que imparten justicia; la reparación adecuada, efectiva y rápida del daño sufrido (Restitución, indemnización, rehabilitación, satisfacción y garantías de no repetición) y el derecho a acceder a la información pertinente sobre las violaciones de sus derechos y los diferentes mecanismos de reparación (ONU, 2005).

Los ciudadanos latinoamericanos han vivido en un escenario de conflictividad que hace que el ciudadano se sienta vulnerable e inseguro, entendiendo esto no solamente como la vulnerabilidad a ser víctimas de un hecho violento, sino también a no contar con un Estado Constitucional de derecho que brinde los estándares mínimos en satisfacción de los derechos fundamentales a los ciudadanos. (BriceñoLeón \& Zubillaga, 2001, p. 171).

27 Por ejemplo, Conjunto de principios actualizado para la protección y la promoción de los derechos humanos mediante la lucha contra la impunidad, los Principios y directrices básicos sobre el derecho de las víctimas de violaciones manifiestas de las normas internacionales de derechos humanos y de violaciones graves del derecho internacional humanitario a interponer recursos y obtener reparaciones, los Principios rectores de los desplazamiento internos y la Convención Internacional para la protección de todas las personas contra las desapariciones forzadas. 
Los periodos de transición de las democracias en América latina se han caracterizado por la creación de diferentes movimientos sociales que tuvieron lugar para evidenciar no solamente la violencia, sino las desigualdades económicas, sociales y políticas. Estos movimientos se han legitimado mediante el discurso de los derechos humanos y la democracia (Garza, 2017. p. 160).

Como lo manifiesta Garza (2017) estos movimientos nacen de la necesidad de encontrar soluciones a sus demandas de justicia, verdad y memoria frente a las autoridades que minimizaban u ocultaban los contextos de vulnerabilidad en los que estos se encontraban. Ya sean contextos de desigualdades en términos sociales o de satisfacción de necesidades básicas o de memoria frente a hechos violentos acontecidos en contra suya, de sus familiares o de su comunidad que pretendían ser minimizados u ocultado por las diferentes fuerzas estatales. Las organizaciones de derechos humanos como movimientos sociales se han encargado de la defensa de estos derechos en un marco de protección y promoción a la dignidad humana, la integridad, la libertad, las condiciones de igualdad, entre otros (Garza, 2017, p. 161)

Tanto las organizaciones de derechos humanos como los grupos organizados de luchas civiles en latinoamerica se funda en la protección de los derechos humanos basados en la defensa de la dignidad humana o de la vida digna, reconociendo derechos como la libertad, la integridad física, la igualdad, la vida y la justicia (Garza, 2017, Pp. 161). También, desde la perspectiva de la inteligencia social, autores como Schvarstein (2012) ven como objetivo de las organizaciones de víctimas el asegurarse de no ser cómplices en abusos contra los derechos humanos. Ello incluso desde el rol que adquirieron a partir de 1945 como actor internacional con estatus consultivo ${ }^{28}$ o como lo expresa Kennedy $(2007,250)$ grupos de presión ante la suscripción de tratados internacionales.

Ahora bien, después de considerar algunos aspectos generales, pasaremos a identificar características de algunos casos/país; esto es, Argentina, México y Colombia. Los criterios para plasmar en el presente

28 Artículo 71 de la Carta de las Naciones Unidas. 
texto tales países giran en torno a las características disímiles y variadas de los procesos de violencia, las relaciones con el estado en el pasado y en el presente las diferentes formas en que se han materializado sus reivindicaciones.

\section{Caso Argentina}

La dictadura Argentina comprendida entre 1976 y 1983 se caracterizó por las violaciones sistemáticas a los derechos humanos, enmarcado en el denominado terrorismo de Estado en contra de la población civil que se encontraba en oposición a las políticas de la junta militar. En este periodo cualquier persona que se encontrare en oposición era tildada de subversiva o de terrorista, en el marco del "Proceso de Reorganización Nacional”. (Ortiz, 2012)

En el contexto de violaciones de derechos humanos empezaron a surgir diferentes movimiento de políticos, intelectuales, religiosos, abogados que se organizaron para demandar y realizar acompañamiento a las víctimas y protestar en contra de la violencia de Estado que se ejercía en ese momento, es así como se fundó la Asamblea Permanente por los Derechos Humanos, la cual tenia como objetivo principal denunciar los actos de violencia política (Garza, 2017, Pp. 162).

Uno de los movimientos más visibles e importantes fue el movimiento de las Madres de la Plaza de Mayo el cual empezaron a surgir en los primeros años de la dictadura con la finalidad de expresar su descontento y reclamar por información de sus hijos, hijas, nietos y nietas que se encontraban desaparecidos o que se encontraban detenidos. La primera aparición de las madres de la plaza de mayo como tal fue el 30 de abril de 1977 con la presencia de 14 madres el primer día, número que fue aumentando con el paso del tiempo (Reyes, 2008).

Las madres de la plaza de mayo pasaron de ser un movimiento que se alzaba en protesta ante la represión, a ser víctimas directas de esta. Las violaciones de derechos humanos, la estigmatización de su labor, los secuestros y desaparición de sus miembros, un claro ejemplo fueron las desapariciones de tres de las fundadoras de este movimiento social: Esther de Balestrino, Azucena Villaflor y Mary Ponce de Bianco (Ortiz, 
2012. Pp. 167). Una de las estrategias de las visibilización de las madres eran conocido como la "ronda" en la cual las mujeres con un pañuelo blanco en la cabeza caminaban en circulo alrededor del obelisco de la Plazo de Mayo, a pesar de la orden que se encontraba vigente la cual impedía este tipo de concentraciones. (Garza, 2017, Pp. 162).

A pesar del proceso institucional de violencia en contra de las madres, estas mujeres lograron constituirse como una asociación en 1979. Ya como organización, se tuvieron que exponer a diferentes procesos los cuales hicieron fortalecer su labor como movimiento social. Estos procesos de visibilización y de fortalecimiento inician en 1979 en el marco del testimonio que tuvieron que realizar las madres sobre la situación de la dictadura Argentina ante la visita de la Comisión Interamericana de Derechos Humanos. (Ortiz, 2012. Pp. 167)

A las Madres de la Plaza de Mayo se unieron diferentes colectivos y diferentes movimientos sociales, como es el caso de movimientos artísticos, como el de Rodolfo Aguerreberry, Julio Flores y Guillermo Kexel, los cuales crearon siluetas de personas que colgaron alrededor de la ciudad como expresión de la violencia y en memoria a las personas desaparecidas. (Garza, 2017, Pp. 162).

Posteriormente, otro proceso de fortalecimiento se dio en 1981 cuando las madres realizaron las "Marchas de resistencia" en la cual ocupaban la Plaza de Mayo durante 24 horas seguidas en forma de protesta y visibilización. Uno de los acontecimientos más importantes en Argentina en esta época fue la confrontación militar con Gran Bretaña denominada la Guerra de las Malvinas, esta coyuntura impregno todos los aspectos de la vida cotidiana de los argentinos y las madres de la plaza de mayo no fueron la excepción, de esta manera las madres expresaban su postura con diferentes consignas, dentro de las cuales se encontraba "Las Malvinas son Argentinas, los desaparecidos también", de esta manera las madres no solamente luchaban por intereses particulares, sino por los intereses de la sociedad Argentina. (Ortiz, 2012. Pp. 168)

Una vez finalizada la época de la dictadura y la presidencia de Raúl Alfonsín las madres se vieron inmersas en diferentes procesos como los juicios de las juntas militares, la Comisión Nacional sobre 
Desaparición de Personas, las exhumaciones de cadáveres y las reparaciones a las víctimas. (Ortiz, 2012. Pp. 167)

Este proceso post dictadura trajo consigo la división de las Madres, las cuales quedaron en dos grupos 1) Las Madres de Plaza de MayoLínea Fundadora y la Asociación de Madres de Plaza de Mayo, esta decisión de separación se dio por diferencias políticas entre las integrantes del movimiento. (Ortiz, 2012. Pp. 167)

Las Madres de la Plaza de Mayo emitieron un fuerte mensaje político dentro de la dictadura militar, emitieron un juicio sobre la realidad social de Argentina en ese momento histórico. La lucha de las Madres reivindicó no solo diferentes derechos, sino su participación en diferentes escenarios que buscaban la verdad y la justicia de las víctimas.

Es así que para 1983, en el gobierno del presidente electo Raúl Alfonsi, este toma consignas de las Madres en el marco de los diferentes procesos que se estaban adelantando en contra de los hechos ocurridos en la dictadura, como lo fue "El juicio y castigo a los culpables". En este mismo sentido, fue el reclamo de satisfacción al derecho de justicia de los diferentes movimientos sociales lo que hizo que Alfonsi fuera un abanderado de los procesos penales adelantados en las Juntas Militares contra los responsables de las violaciones de derechos humanos en la dictadura (Ortiz, 2012. Pp 169).

Igualmente la participación activa de los familiares de las víctimas con la Comisión Nacional sobre la Desaparición de Personas (CONADEP), hizo que esta Comisión pudiera tomar 7.000 declaraciones donde se documentaban 8.960 casos de personas desaparecidas y la publicación del Informe "Nunca más", en el cual se documentaban los diferentes crímenes cometidos en el marco de la dictadura (Ortiz, 2012. Pp 169).

Los movimientos sociales de víctimas y derechos humanos en Argentina no terminan al finalizar la dictadura, en el proceso de transición democrática se seguían llevando a cabo movilizaciones sociales encabezadas por los diferentes colectivos de víctimas con la finalidad de realizar un ejercicio de memoria por las víctimas de la dictadura. Es en una de estas movilizaciones en 1976 en la Ciudad de la Plata cuando fueron secuestrados por su activismo social y su posición política 9 estudiantes, en lo que se denomino como la "noche de los lápices". 
En la actualidad el movimiento, con sus principales características y reivindicaciones, se mantiene latente. A pesar de que el periodo transicional parece estar lejano, el fortalecimiento de la democracia pasa por el movimiento de derechos humanos de Argentina, no tanto a través de la búsqueda de personas desaparecidas o raptadas e incluso de la judicialización de quienes fueron responsables de los hechos hace que no solamente las víctimas y las organizaciones conozcan la verdad, sino también que la sociedad civil construya colectivamente la memoria histórica para hacer veeduría a los procesos violentos desde el Estado para su garantizar su no repetición.

Hoy los debates incluyen análisis y reflexiones acerca de la "estatización” o "institucionalización” del movimiento a partir del año 2002 y las repercusiones de ello en la disminución de su "ethos participativo" y como agentes de cambio social. Para profundizar en la reflexión conceptual y pragmática de tal debate puede consultarse a Natalucci (2011).

\section{Caso México}

Históricamente el pueblo mexicano ha sido protagonista de grandes violaciones de derechos a los derechos humanos, han sido víctimas de desigualdad social, política y económica, pero en el mismo sentido han sido protagonistas de grandes movimientos sociales que ponen la cara en contra de los hechos victimizantes.

A lo largo de la historia se pueden identificar momentos claves en los cuales los movimientos sociales marcaron un precedente claro en la institucionalidad mexicana, algunos de los casos más emblemáticos de estas luchas sociales son por ejemplo la huelga de Refrescos Pascal de 1982, el surgimiento del Ejercito Zapatista de Liberación Nacional (EZLN) en 1994, la gran huelga de la Universidad Nacional Autónoma de México en 1999, el movimiento de San Salvador Atenco de 2011, el movimiento social surgido por la desaparición de los estudiantes de la Escuela Normal Rural de Ayotzinapa, entro muchos otros casos.

En lo últimos años uno de los movimientos sociales de víctimas que ha adquirido mayor trascendencia ha sido el Movimiento por la Paz 
con Justicia y Dignidad en México, el cual nace como respuesta de la sociedad civil mexicana a la violencia que se vive como consecuencia de la lucha institucional contra el narcotráfico. Este movimiento nace específicamente el 28 de mazo de 2011, luego de que Juan Francisco, hijo del poeta Javier Sicilia, fuera asesinado en compañía de sus amigos y de dos adultos que los acompañaban en la ciudad de Temixco (Azaola, 2012. Pp. 159).

En abril de 2011 Javier Sicilia publica en el semanario el Proceso una carta dirigida tanto a los políticos como a los criminales mexicanos y en general a todas las personas que se encuentran relacionadas con el crimen organizado. Dicha publicación se convierte en una Convocatoria a la sociedad mexicana y que con el apoyo de amigos, familiares y otros intelectuales logro que esta llegara al odio de muchos sectores de la sociedad civil. El 6 de abril de 2011 acudieron más de cuarenta mil personas vestidas de blanco al zócalo de la ciudad de Cuernavaca para exigir a las autoridades no solamente el esclarecimiento de los hechos y la búsqueda de los responsables de diferentes hechos de violencia, sino un desescalamiento de la violencia en todo México. (Jacinto, 2011, Pp.63).

Las convocatorias del Movimiento por la Paz con Justicia y Dignidad se fueron haciendo más grandes y de mayor trascendencia para la sociedad civil, a tal punto, que se convocó a una marcha desde el zócalo de la ciudad de Cuernavaca hasta el zócalo capitalino del 5 al 8 de mayo de 2011. El objetivo de esta movilización era la conformación de un Pacto Nacional por la Paz, el cual contenía 6 pilares 1) Verdad y Justicia; 2) poner fin a la estrategia de guerra y asumir un enfoque de seguridad ciudadana; 3) combatir la corrupción y la impunidad; 4) atención de emergencia a la juventud y acciones efectivas de recuperación del tejido social, y 6) democracia participativa y democratización en los medios de comunicación. (Azaola, 2012. Pp. 161).

Este Pacto Nacional tuvo un fuerte impacto en las diferentes esferas de poder mexicanas, lo que causó que el poder ejecutivo y judicial aceptaran a reunirse con los líderes del movimiento y la creación de mesas de trabajo para resolver los 6 pilares planteados. En el marco de estas acciones el Poder Ejecutivo creó la Procuraduría de Atención a las Víctimas del Delito, el Movimiento declaró su descontento por 
esta medida ya que esta contaba con escasas facultades y con escasos recursos (Azaola, 2012. Pp. 162).

A pesar de diferentes iniciativas legislativas, no se materializaron, en tanto en las discusiones y en los procesos de aprobación no se dio una gran participación del movimiento, buena parte de ello consecuencia de la institucionalidad y los diseños legislativos. El movimiento tuvo una gran e importante participación en la creación de la Ley General de Víctimas, esta Ley no solo reconoce los derechos y garantías de las víctimas de diferentes tipos de delitos, sino a las víctimas de violaciones de los derechos humanos, también protege a las víctimas indirectas o los familiares de víctimas y se crea el Registro Nacional de Víctimas y de un Sistema Nacional de Atención a Víctimas. Mediante esta Ley se pretenden salvaguardar los derechos a la justicia, la verdad y la reparación integral de las víctimas de violencia (Azaola, 2012. Pp. 162).

\section{Caso Colombia}

La violencia reciente en Colombia data de los años cincuenta, el conflicto armado colombiano ha afectado a 8.376 .463 víctimas, de las cuales 7.134.646 son casos de desplazamiento, 983.033 casos de homicidios, 165.927 casos de desapariciones forzadas, 10.237 casos de tortura, entre otros hechos delictivos (Portafolio, 2017).

A pesar de que este conflicto data de los años cincuenta, los primeros antecedentes de la formación de movimientos sociales de víctimas en territorio colombiano se encuentran de los años setenta, estos movimientos surgen de la oleada de represión y violencia desatada en el gobierno de Julio César Turbay, el conflicto armado colombiano, la violación sistemática de los derechos humanos, las condiciones de desigualdad, entre otras muchas razones. Estas reivindicaciones sociales surgen en el contexto del posicionamiento del discurso de la protección y promoción de los derechos humanos, la firma de los principales tratados de derechos humanos, las visitas de diferentes organizaciones de carácter internacional y el surgimiento de diferentes procesos de diálogos con los grupos guerrilleros en el marco de los gobiernos de los presidentes Belisario Betancour y Virgilio Barco, lo cual causó que 
se abrieran espacios en la agenda estatal y social para el florecimiento del discurso de estos movimientos (CNMH, 2015, Pp. 21).

Como se caracterizará en este texto, en Colombia existe un movimiento social de derechos humanos, en los términos de Leal (1991) en el entendido que "... Por movimientos sociales entendemos aquellas acciones sociales colectivas, más o menos permanentes, orientadas a enfrentar injusticias, desigualdades o exclusiones, es decir, que denotan conflictos y que tienden a ser propositivas. Todo ello en contextos históricos...”

Como lo expresa Múnera (1998) el movimiento de los Derechos Humanos comporta en su accionar los tres principios básicos de todo movimiento social: La identidad, es decir, la definición del actor por sí mismo; la oposición, en la cual su contradictor es el Estado y la totalidad, es decir, una actividad reivindicativa con proyección en el ámbito social. Según los tipos de relaciones, este movimiento sostiene relaciones de articulación, de oposición y de exclusión.

De articulación, en la medida en que en el transcurso de su historia ha creado formas progresivas de coordinación, interlocución y adhesión a otros movimientos, atrayendo especialmente a las organizaciones sindicales, a los grupos eclesiásticos o al movimiento popular. Véase en lo concerniente ejemplos como el MOVICE o en su defecto la Coordinación Colombia, Europa, EEUU, como plataforma de coordinación entre organizaciones. De oposición, porque define una postura indeclinable de rechazo a cualquier forma de abuso contra la vida humana, tanto frente al Estado como ante los particulares y los grupos armados. De exclusión, en cuanto a la actitud diferenciada de admisión de sus miembros, de aceptación de alianzas y de evitar provocaciones provenientes de sectores que pretenden silenciarlo.

Citando a López (2012), en el campo de los derechos humanos podemos distinguir cuatro tipos de actores y organizaciones que cumplen labores de promoción o defensa según sus "niveles y ámbitos de acción" (Landman, 2006, p. 21). Por un lado, una clara distinción entre organizaciones internacionales y nacionales/locales; por otro lado, entre organizaciones gubernamentales y no gubernamentales que se vinculan a la defensa especial de los derechos humanos (Tabla 1). 
Tabla 1. Tipo de organizaciones de promoción de defensa de derechos humanos

\begin{tabular}{|l|l|}
\hline \multicolumn{1}{|c|}{ Organizaciones públicas internacionales } & \multicolumn{1}{c|}{ ONG internacionales } \\
\hline $\begin{array}{l}\text { Naciones Unidas, Unión Europea, } \\
\text { Organización para la Seguridad y } \\
\begin{array}{l}\text { Cooperación en Europa, Organización } \\
\text { de Estados Americanos, Corte Penal } \\
\text { Internacional. }\end{array}\end{array}$ & $\begin{array}{l}\text { Amnistía Internacional, Asociación } \\
\text { Internacional Contra la Esclavitud, } \\
\text { Human Rights Watch, Human Rights } \\
\text { First, Liga Internaciones de Derechos } \\
\text { Humanos }\end{array}$ \\
\hline \multicolumn{1}{|c|}{$\begin{array}{l}\text { Organizaciones públicas locales/ } \\
\text { nacionales }\end{array}$} & \multicolumn{1}{c|}{ ONG locales/nacionales } \\
\hline $\begin{array}{l}\text { Gobiernos estatales, gobiernos sub- } \\
\text { nacionales, escuelas públicas e } \\
\text { instituciones estatales }\end{array}$ & $\begin{array}{l}\text { ONG de derechos humanos, } \\
\text { organizaciones de la sociedad } \\
\text { civil, movimientos sociales, grupos } \\
\text { políticos. }\end{array}$ \\
\hline
\end{tabular}

Fuente: elaboración de López (2012) con base en Landman, 2006

Los primeros miembros de los movimientos sociales de víctimas eran generalmente militantes de izquierda, profesionales sensibles a las casusas sociales, lideres sociales, sindicalistas y en general los grupos sociales víctimas de represión y violencia. Estos movimientos surgen no solamente para iniciar acciones de acompañamiento a las víctimas de la violencia socio política, sino también para oponerse a los políticos gubernamentales y a las desigualdades sociales bajo el discurso de la protección de los derechos humanos.

En 1973 nació el Comité de Solidaridad con los Presos Políticos $(\mathrm{CSPP})^{29}$, la primera Organización Gubernamental en Colombia, esta ONG es creada para dar protección y apoyo a las personas que han sido víctimas de persecución por motivos políticos, y nace de la mano de miembros de diferentes movimientos de víctimas como lo son la Asociación Nacional de Usuarios Campesinos (ANUC), el Movimiento de los barrios nororientales, entre otras organizaciones y diferentes académicos del orden nacional (CNMH, 2015, Pp. 20).

29 Se resalta que fue creado entre otras personas por, Gabriel García Márquez, Enrique Santos Calderón, líderes sociales como Noel Montenegro de la Asociación Nacional de Usuarios Campesinos, la señora Carmen de Rodríguez, del movimiento de los barrios nororientales y miembros de la academia como Jorge Villegas, Diego Arango y Nirma Zárate. 
El CSPP nace en el marco de una situación que estaban viviendo miembros de la Unión Sindical Obrera, que se encontraban participando en actividades de huelga en la industria petrolera. Debido a esto, los miembros del sindicato fueron capturados y procesados en un consejo verbal de guerra. (Escritores y Periodistas, 2013)

Los últimos años de la década de los 80 fueron años sombríos para la protección de los derechos humanos en Colombia, la violencia política se encontraba en ascenso y el ejercicio estatal no era los suficientemente fuerte para detener el ejercicio abusivo del poder. Esta situación dio inicio a la articulación de nuevos movimientos sociales de víctimas de esta violencia sistemática, quienes de la mano de líderes y lideresas sociales fueron abriéndose paso en el sistema jurídico colombiano de la protección de los derechos humanos (CNMH, 2015, Pp. 25).

Posteriormente en 1982 se creó la Asociación de Familiares de Detenidos- Desaparecidos (ASFADDES), la cual tenía como objetivo visibilizar los casos de personas desaparecidas en el territorio nacional, debido a que las autoridades tenían como practica sistemática desconocer la ocurrencia de estos hechos. ASFADDES contó con el apoyo del movimiento estudiantil, especialmente estudiantes de la Universidad Nacional y la Universidad Distrital, los cuales realzaban un acompañamiento permanente a las movilizaciones de ASFADDES, especialmente a las marchas conocidas como "Marchas de los claveles blancos” en las cuales los familiares de las víctimas marchaban con claveles blancos y con fotografías de los desaparecidos con el objetivo de visibilizarlos (Garza, 2017, Pp. 168).

En los años setenta surge un gran número de organizaciones que tienen como finalidad el acompañamiento a las víctimas del conflicto y la promoción y protección de los derechos humanos, la visibilización de las víctimas y la exigencia de justicia. Es así como surgen el Centro de Investigación y Educación Popular (CINEP) en 1972, la Comisión Andina de Juristas en 1988, el Colectivo de Abogados "José Alvear Restrepo" (CCAJAR) en 1980, la Comisión Colombiana de Juristas (CCJ) en 1988, entre muchas otras organizaciones. Todas las acciones encabezadas por las organizaciones defensoras de derechos humanos y movimientos sociales de víctimas fueron estigmatizadas y deslegitimadas por la institucionalidad, relacionando su labor con miembros 
al margen de la ley, realizando persecuciones políticas, amenazas, homicidios, entre muchas otras acciones para impedir el crecimiento y desarrollo de estas luchas sociales (CNMH, 2015, Pp. 28).

Del mismo modo que los hechos violentos aumentaban en todo el territorio nacional, también aumentaban los movimientos de víctimas que aclamaban justicia en nombre de sus víctimas. Es en este contexto que surgen organizaciones regionales como de las Madres de la Candelaria en la ciudad de Medellín, las cuales eran grupos de mujeres generalmente de origen campesino que realizaban plantones frente a la iglesia de Nuestra Señora de la Candelaria todos los miércoles o los viernes con la finalidad de exigir justicia por sus familiares desaparecidos (Garza, 2017, Pp. 168). De manera regional y en el mismo periodo de tiempo se resalta la creación de la Corporación Regional para la Defensa de los Derechos Humanos (Credhos) que fue creada en 1987 como un instrumento de sensibilización y apertura de espacios sociales para el trabajo humanitario y para la defensa de los derechos humanos de los pobladores de Barrancabermeja y el Magdalena Medio.

Igualmente existen movimientos de víctimas más recientes como el Movimiento Nacional de Víctimas de Crímenes de Estado (MOVICE) el cual surgió en el 2005 como respuesta a la expansión del paramilitarismo en el territorio colombiano y la militarización territorial en el marco de la Ley 975 de 2005. Este movimiento tiene como objetivo principal la reivindicación y la visualización de las víctimas de los crímenes cometidos por miembros de las fuerzas estatales o los grupos paramilitares (Garza, 2017, Pp. 170).

Las reivindicaciones sociales de estos movimientos de víctimas en Colombia han tenido diferentes matices a lo largo de la historia ${ }^{30}$, en parte debido precisamente a los diferentes y gran número de movimientos que han surgido no solamente por ser víctimas de la violencia socio-política, sino por las condiciones de desigualdad social.

Un ejemplo claro de la reivindicación de los derechos de las víctimas en Colombia debido al trabajo de los diferentes movimientos sociales es la tipificación del delito de desaparición forzada como un

30 Véase al respecto el artículo de Romero (2013) 
delito autónomo mediante la expedición de la Ley 589 de 2000. Antes de la expedición de dicha ley las desapariciones forzadas en Colombia eran investigadas y juzgadas en el marco de otros delitos (por ejemplo secuestro), lo que causaba una situación de impunidad generalizada para estos casos. Esta tipificación fue el resultado de 12 años de luchas de los familiares de las víctimas de este delito, ya que desde 1988 se habían presentado seis proyectos de Ley (ONU, 2009).

Pero el accionar de los movimientos sociales no se detuvo con la tipificación de este delito, sino que estos se convirtieron en los principales actores que fiscalizaban las diferentes herramientas que vinieron con dicha tipificación, como la creación de la Comisión Nacional de Búsqueda de Personas Desaparecidas, el Mecanismo de Búsqueda Urgente, entre otros.

El repertorio del movimiento en Colombia como lo expresó Aranguren (2009) tiene una dimensión nacional e internacional.

En la dimensión nacional son valiosos los aportes a la democracia que hacen las organizaciones. De ellas es dable resaltar el acopio de información, sistematización e investigación ${ }^{31}$ de graves violaciones a los derechos humanos e infracciones al $\mathrm{DIH}^{32}$, el ejercicio de difusión de las mismas y las labores de incidencia en el diseño, implementación y seguimiento a las políticas públicas; o en su defecto, el considerar tales documentos en procesos de investigación, juzgamiento y sanción de responsables de violaciones a través de entre otras elementos de prueba, el análisis de contexto. De lo anterior se puede consultar la labor que hace el equipo Nizkor, el Comité Permanente por la Defensa de los Derechos Humanos (CPDH), el Centro de Investigación y Educación Popular (Cinep), el Instituto Popular de Capacitación (IPC), el Instituto Latinoamericano de Servicios Legales Alternativos (ILSA) y más recientemente DeJusticia.

31 Esto es clave, por ejemplo el $85 \%$ de la información del Centro de Derechos Humanos de Naciones Unidas proviene de organizaciones de la sociedad civil. Cf. Menon, 2009

32 Un primer ejemplo de ello fue el Libro Negro de la Represión (1974), editado por el Comité de Solidaridad con los Presos Políticos. 
También puede resaltarse la manera en que las organizaciones hacen incidencia en varios Estados con presencia en Colombia o agencias de cooperación para ver en los propios territorios o hablando con los directamente involucrados los avances y retrocesos en materia de protección, garantía y respeto de los derechos humanos; un ejemplo de ello es la caravana de juristas que anualmente se promueve ${ }^{33}$. También las labores que desde los territorios se gestiona, entre otros los realizados por organizaciones como la Comisión de Justicia y Paz en el Chocó, Urabá, Putumayo, Magdalena Medio; la Corporación Integral para el Desarrollo Cultural y Social (Codecal), el Instituto Popular de Capacitación (IPC) en Antioquia, la ya referida Corporación Regional para la Defensa de los Derechos Humanos (Credhos) y la Organización Femenina Popular (OFP) en Santander y Magdalena Medio, el Colectivo de Abogados Luis Carlos Pérez, entre otros. (López, 2012).

De otro lado, y como lo expresa Peruzzotti (2010) es fundamental el rol de accountability social que realiza el movimiento, en tanto logran en muchas ocasiones activar las agencias de rendición de cuentas horizontales — cortes, instancias administrativas, ombudsman, entre otras- o ejerciendo una función de vigilancia y denuncia pública de los déficit institucionales. En esta categoría se pueden incluir aquellas organizaciones que consideran clave diseñar, llevar a cabo socializar y promover iniciativas de memoria histórica, de ellas por ejemplo Hijos e hijas por la memoria y contra la impunidad ${ }^{34}$ o Quinta por quinta de Norte de Santander.

Desde lo estrictamente jurídico el movimiento ha logrado (LÓPEZ, 2012) la especialización de un cuerpo de abogados que llevan las demandas y los casos contenciosos, un fuerte trabajo en red con cuerpos de abogados nacionales e internacionales y tener contacto directo con la Comisión Interamericana de Derechos Humanos. Muchos de los procesos contenciosos contra el Estado que llevan a cabo las ONG —como el Colectivo de Abogados José Alvear Restrepo, la Comisión

33 Puede ampliarse la información en: http://www.colombiancaravana.org.uk/ consultado el 12 de septiembre de 2017.

34 Para profundizar véase a Gómez, D y otros (2007) 
Colombiana de Juristas, Fundación Nydia Erika Bautista, SISMA Mujer, Humanas, Corporación Jurídica Humanidad Vigente, la Corporación Jurídica Libertad- en el sistema internacional, interamericano y nacional, son procesos que involucran temas de graves violaciones de derechos y sanciones con altos montos económicos. En dichos procesos, las ONG canalizan y atienden las demandas y denuncias de diversas organizaciones, activistas, víctimas y familiares de víctimas de las violaciones.

En el plano internacional, algunas organizaciones no solamente cuentan con estatus consultivo ante la ONU - como se dijo supra - , sino que tienen un poder de incidencia significativo en escenarios internacionales referidos a la suscripción de tratados internacionales o la verificación o monitoreo que se sigue al estado colombiano respecto al cumplimiento de sus obligaciones internacionales en materia de derechos humanos ${ }^{35}$. Por otra parte, en relaciones de bilateralidad entre los Estados, como el proceso de certificación al congreso de los Estados unidos por parte de la Secretaría de estado de ese mismo país, las organizaciones que trabajan y hacen seguimiento al cumplimiento de los compromisos colombianos en esta materia han venido realizando una incidencia periódica que posibilite mayores controles al Estado y apoyos a las organizaciones de la sociedad civil.

La discusión sobre la institucionalización del movimiento en Colombia no se ha dado de manera profunda en comparación con el caso argentino, en tanto se han posibilitado escenarios de colaboración a partir de iniciativas de algunas entidades, por ejemplo la Comisión de Derechos Humanos de la Procuraduría General de la Nación ${ }^{36}$ por iniciativa de Carlos Mauro Hoyos invitando al Comité Permanente por la Defensa de los Derechos Humanos y la Asociación de Familiares de Detenidos Desaparecidos -ASFADDES-. También en razón a que recientemente algunas personas que han hecho parte de las organizaciones

35 Por ejemplo el Examen Periódico Universal - EPU - y la posibilidad que tienen las organizaciones de presentar informes alternos a los presentados por los Estados.

36 ROMERO (2013) reseña la Resolución 035 del 9 de septiembre de 1986. 
pasaron a ser funcionarios públicos en entidades del estado que tienen por misión la garantía y protección de los derechos de las víctimas, entre otras la Unidad de Restitución de Tierras o el Centro Nacional de Memoria Histórica. Otro debate que se quiso posicionar fue la llamada despolitización de las organizaciones y el "centrarse" para tener una imagen más cercana a la opinión pública y tener mayor acceso a fuentes diversas de recursos, en términos de Gómez (2013).

Este conato de fotografía del movimiento es ello, solo un diagnostico que está en constante movimiento, donde las fronteras temáticas, territoriales o de énfasis de trabajo organizacional se cruzan, se mezclan y se difuminan. Buena parte de las organizaciones reseñadas trabajan en redes y complementan sus quehaceres investigativos, de denuncia y de incidencia en redes; otras discuten, posicionan argumentos, debaten y se transgreden en escenarios políticos y de movilización. Cada una tiene su propia agenda, pero se encuentran y desencuentran ante y con el estado o con las agencias de cooperación internacional. La búsqueda constante de fuentes de financiación y el tratar de mantener su autonomía es central.

Cada día se originan organizaciones que hacen que el movimiento se encuentre en constante cambio y que las características muten o sean otras. Las organizaciones de víctimas se han llegado a institucionalizar o las estructuras a través de la cuales el dialogo, la concertación o la reivindicación en algunas ocasiones es "jalonada" por entidades del Estado (como la defensoría del pueblo) o por agencias de cooperación internacional.

El Estado por su parte, ha entendido la relevancia de contar con las organizaciones como aliado para legitimar su labor, acercarse a la sociedad civil y mantener canales de diálogo que le permitan respetar y proteger los derechos de los ciudadanos de manera directa y participativa. En algunos escenarios, el Estado logra entender la relevancia de las organizaciones en el fortalecimiento de la democracia.

\section{Conclusiones}

En algunos países de América latina se puede manifestar la existencia de un movimiento de víctimas, derivado de pasados - o presentes 
- con periodos históricos de violencia que se han traducido en graves violaciones a los derechos humanos y/o infracciones al derecho internacional humanitario; bien sea por causa de dictaduras, conflictos armados internos y violencia generalizada. A partir de la caracterización histórica de los movimientos de victimas de Argentina y México se intentó abordar un repertorio del movimiento de víctimas en Colombia en lo nacional e internacional. El texto intenta hacer una geografía de organizaciones defensoras de derechos humanos que harían parte del movimiento ubicándolas desde una constelación jurídica, otra investigativa y de incidencia. De seguro este conato catastral es insuficiente y sesgado, deja por fuera de la narrativa a varias organizaciones que de manera valiente y con mucho esfuerzo en la cotidianidad y en la periferia busca reivindicar los derechos de las víctimas. A ellas nuestras sinceras disculpas.

\section{Referencias bibliográficas}

Aranguren, E. (2009). Oing y derechos humanos en Colombia. Un golpe ineludible y vigoroso de la sociedad civil. Colombia Internacional ISSN 0121-5612. No.69 Bogotá Enero - junio. 2009

AZAOLA, E. (2012). El movimiento por la Paz con Justicia y Dignidad. Revista Desacatos No. $40 \mathrm{sep} /$ dic de 2012. Centro de Investigaciones y Estudios Superiores en Antropología Social- Distrito Federal, México. Pps. 159-170.

BRICEÑO-LEÓN, R. \& ZUBILLAGA, V. (2001). Dimensiones y construcciones de la violencia en América Latina. Acta Científica Venezola, 52, 170-177. Caracas.

CENTRO NACIONAL DE MEMORIA HISTÓRICA. (2015). El Derecho a la Justicia como garantía de no repetición. Volumen 1. Graves violaciones de derechos humanos: Luchas sociales y cambios normativos e institucionales 1985- 2012. Imprenta Nacional de Colombia, Bogotá, D.C.

D' ALESSANDRO, M. (1998). Los movimientos sociales en la transición democrática. El caso de las Madres de Plaza de Mayo: sentimiento y discurso. Revista Gredos América Latina hoy, Vol. 20 Ediciones Universidad de Salamanca. 
Escritores y Periodistas. (2013) Comité de Solidaridad con los Presos Políticos. Revista "Bienvenidos a Villavivavive", No. 12, diciembre 15 de 2013.

GARZA, J. (2017). Actores y redes del movimiento por los derechos humanos en América Latina. En: Boletín de Antropología. Universidad de Antioquia, Medellín, vol. 32, N. ${ }^{\circ}$ 53, pp. $158-179$.

GÓMEZ, J. (2013). Organizaciones no gubernamentales y entidades sin ánimo de lucro en Colombia: Despolitización de la sociedad civil y tercerización del Estado. Gestión y política pública ISSN 1405-1079. Vol.23 No.2 México jul./dic. 2014

GÓMEZ, D; CHAPARRO, D; ANTEQUERA, J; PEDRAZA, O. (2007). Para no olvidar: hijos e hijas por la memoria y contra la impunidad. Antipoda Revista de Antropología y Arqueología. ISSN 1900-5407. No.4 Bogotá Jan./June 2007

JACINTO. L. (2011) Javier Sicilia: el Movimiento por la Paz con Justicia y Dignidad en México. Disponible en: https://www.imex-revista.com/ wp-content/uploads/Jacinto.pdf

KENNEDY, Paul. (2007). El parlamento de la humanidad. La historia de las Naciones Unidas. Bogotá: Random House Mondadori.

LEAL, F. (1991). "Los movimientos políticos y sociales. Un producto de la relación entre Estado y sociedad civil”, Revista Análisis Político, No.13, IEPRI, Universidad Nacional de Colombia, Bogotá, mayo agosto 1991, pp. 7-21.

LOPEZ, J. (2012). Las organizaciones no gubernamentales de derechos humanos en la democracia. Aproximaciones para el estudio de la politización de los derechos humanos en Colombia. Estudios Políticos, 41, ISSN 0121-5167. Medellín, julio-diciembre de 2012: pp. 103-123.

MENON, Ganesh. (2009). Genesis and Role of NGOs in Protecting Human Rights. iii vols. New Delhi: Dominant Publisher and Distributors

MÚNERA, L. (2008). "Rupturas y continuidades. Poder y movimiento popular en Colombia 1968-1988”, IEPRI, Facultad de Derecho, Universidad Nacional de Colombia, CEREC, Bogotá, 1998

Naciones Unidas, Oficina del Alto Comisionado para los Derechos Humanos. (2005). Resolución 2005/35 Principios y directrices básicos sobre el derecho de las víctimas de violaciones de las normas internacionales de derechos humanos y del derecho internacional humanitario a interponer recursos y obtener reparaciones. 
Naciones Unidas, Oficina del Alto Comisionado para los Derechos Humanos. (2009). La desaparición forzada de personas en Colombia. Guía de normas, mecanismos y procedimientos. Disponible en: http://www.hchr. org.co/publicaciones/libros/desaparicion_forzada_2009.pdf

Natalucci, A. (2011). Entre la movilización y la institucionalización: Los dilemas de los movimientos sociales (Argentina, 2001-2010). Polis (Santiago), 10(28), 193-219. http://www.scielo.cl/scielo.php?pid=S0718-6568 2011000100012\&script=sci_arttext\&tlng=pt

ORTIZ, K. (2012). Las madres de la plaza de mayo y su legado por la defensa de los derechos humanos. Revista Universidad Nacional, Trabajo Social No. 14, enero- diciembre 2012. Bogotá. D.C. Pp. 165-177.

PERUZZOTTI, Enrique. (2010). La política de accountability social en América Latina. En: Olvera, Alberto y Isunza, Ernesto (eds.). Democratización, rendición de cuentas y sociedad civil. Participación ciudadana y control social (pp. 245-264). México: Miguel Ángel Porrúa

PORTAFOLIO. (2017). 8.376.463 víctimas del conflicto armado en Colombia. Disponible en: http://www.portafolio.co/economia/gobierno/ el-numero-de-victimas-del-conflicto-armado-en-colombia-504833

REYES, M. (2008) Reflexiones sobre la justicia de las víctimas. Revista Estudios de Filosofía, No. 37 pp. 249-255

ROMERO, A. (2003). El movimiento de Derechos Humanos en Colombia. Boletín $N^{\circ}$ 5: Emergencia de los Movimientos Sociales en la Región Andina. Marzo 2003. http://www.uasb.edu.ec/padh

SCHVARSTEIN, Leonardo. Inteligencia social de las organizaciones. Transcripción: Francisco Torres Gómez. 2012. En: file://C:/Users/Administrador/ Downloads/677-1837-1- 


\title{
La incertidumbre de las víctimas dentro del Acuerdo para la Construcción de una Paz Estable y Duradera ${ }^{37}$
}

\author{
Iván Darío Valderrama Romero ${ }^{38}$ \\ Román Francisco Téllez Navarro ${ }^{39}$ \\ Carolina Blanco Alvarado ${ }^{40}$
}

\section{Introducción}

$\mathrm{C}_{\text {generada con posterioridad al plebiscito efectuado el } 2 \text { de octubre }}$

37 El presente manuscrito es producto del proyecto de investigación "el principio de reciprocidad de la contratación estatal en el marco de la Comunidad Andina (CAN), gestionado en el Centro de Investigaciones de la Facultad de Derecho de la Universidad Santo Tomas (Sede Bogotá).

38 Abogado Universidad Libre, especialista en Derecho Penal y Criminología, Magister en Derecho Penal, Exsecretario de la Sala Penal del Tribunal Superior de Quibdó-Chocó, Asesor y Litigante, docente Universidad Militar Nueva Granada, Correo electrónico: ivan.valderrama@unimilitar.edu.co.

39 Abogado de la Universidad Libre de Colombia, especialista en Derecho Constitucional de la misma casa de estudios y magíster en Derecho Procesal Penal de la Universidad Militar Nueva Granada. Docente del área de Derecho Público de la Universidad Militar Nueva Granada. Correo electrónico: roman. tellez@unimilitar.edu.co.

40 Abogado de la Universidad Externado de Colombia. PhD en Derecho Universidad Santo Tomas (Sede Bogotá). Docente e Investigadora del Centro de Investigaciones de la Facultad de Derecho de la Universidad Santo Tomas. Correo: carolinablancoalvarado@hotmail.com 
de 2016, por medio del cual se le preguntaba a los Colombianos ¿si estaba de acuerdo con un proceso de paz con las Farc Ep para la construcción de una paz estable y duradera? La respuesta democrática obtenida fue la negatoria a ese responsivo, a partir de allí e indiferente con el tema político, las víctimas del conflicto armado entraron en una llamada incertidumbre, de cara a lo dispuesto para las mismas en materia de reparación.

De esta forma, se debe tener claridad que independientemente de lo sucedido con el plebiscito, la realidad del país sigue siendo la misma y las víctimas continúan a la espera de dignificar su vida y teniendo en cuenta que Colombia se encuentra suscrita a los objetivos propuestos por la justicia transicional, que se mueve entre la verdad, justicia, reparación y no repetición.

El proceso de paz adelantado con las Farc Ep en la Habana, ha partido la historia de Colombia en dos, el primer capítulo se puede referir a la época de la violencia al margen de diversos grupos armados al margen de la ley y la segunda parte los devenires después de la suscripción del acuerdo final para la terminación del conflicto, esa transición implica la contraposición de la realidad de una sociedad y la norma como garantía y estabilidad jurídica no solo a nivel nacional sino su percepción a nivel internacional.

Después de instalada la mesa de conversación en la Habana el día 18 de octubre de 2012 en Noruega, Oslo, con el objetivo de buscar una solución al conflicto armado que azotaba al país por más de cuatro décadas, la sociedad colombiana asumió una posición diferente hacia el corto, mediano y largo plazo, en temas como la seguridad ciudadana, la intervención positivas en las zonas alejadas del país y que tradicionalmente habían estado en manos de los Grupos Armados Organizados al Margen de la Ley (GAOML) visiones mejores de educación y de progreso a diferentes sectores poblacionales entre otros.

Las víctimas eran uno de esos sectores poblacionales más interesados en las discusiones indiferentemente de su posición política al respecto, pues al fin sentían posible la construcción de una memoria que permitiera aclarar lo sucedido por largos años.

Después de cuatro largos años y algo más el día 24 de agosto las Farc Ep y el Gobierno colombiano suscribieron un Acuerdo Final Para 
la Terminación del Conflicto y la Construcción de una Paz Estable y Duradera; decisión está que fue objeto de consulta al pueblo colombiano en los términos de una figura jurídica denominada plebiscito acogido por las partes en su correspondiente momento y como tal se fijó para ese efecto el día 2 de octubre de 2016, donde luego de diversas discusiones de naturaleza propagandística los colombianos escogieron la opción NO a la pregunta ¿Apoya usted el acuerdo final para la terminación del conflicto y la construcción de una paz estable y duradera?.

Por supuesto esa respuesta replanteo el contexto de las discusiones que en torno a la paz se venían discutiendo hasta ese momento, uno de esos aspectos fue la percepción que las víctimas del conflicto armado tuvieron sobre ese particular, en los tiempos actuales podemos decir que la visión de las víctimas directas del conflicto armado es de incertidumbre. Por ende la palabra "incertidumbre" se ha convertido en un término fundamental, para describir la situación actual del país con posterioridad al inicio de la implementación del acuerdo redefinido de manera bilateral por las partes que dio como resultado documento final el día 24 de noviembre de 2016 con aval de la Corte Constitucional la cual manifiesta que indistintamente de los resultados el presidente de la república mantiene las competencias para preservar el orden público, más aún si se está haciendo referencia a un proceso para alcanzar la paz.

De allí parte este documento para establecer las consecuencias y el resultado del plebiscito referido e introducirnos en la evolución que ha tenido del acuerdo final para la construcción de una paz estable y duradera hasta el día de hoy.

Lo expuesto permite esgrimir el siguiente problema de investigación: ¿El resultado del plebiscito para la paz desmejoro o no los derechos y expectativas de las víctimas del conflicto armado en Colombia? Para desatar esa cuestión se adoptará un modelo de investigación de tipo jurídico y sociológico exploratorio, pues se abordará históricamente las llamadas leyes de transición en conflictos armados nacionales, tomando como referencia las teorías jurídicas y sociológicas estas últimas como resultado de escuchar a las víctimas y su percepción sobre lo sucedido, sumado a las conclusiones personales de los autores desde una perspectiva crítica constructiva. El método a utilizar es el 
documental, que permite la consulta y depuración del material pertinente para dar respuesta a la pregunta de investigación.

\section{Desarrollo}

Para entender el contexto que se pretende plantear debemos tener claro que es la "incertidumbre" y para ello debemos manifestar que es una figura conceptual que contribuye ostensiblemente al análisis de un objeto y en nuestro caso sobre la situación actual que se haga del país.

Es bueno delimitar como "La incertidumbre tiene su historia, incluso es un producto de la historia. Sería apasionante trazar una historia de la incertidumbre en el derecho, que necesariamente está muy relacionada con la situación social y política”Fuente especificada no válida..

Por lo anterior este aspecto, está estrechamente relacionado con la certeza del derecho, su eficiencia y a veces su problemática de aplicación y que supone necesariamente un sistema de derecho positivo basado en:

El principio convencionalista y iuspositivista de legalidad, se realiza al precio de la posible incoherencia; es decir, de la presencia simultánea de normas de las que no siempre puede decirse, con juicios verdaderos o falsos, ¿cuál de ellas es aplicable, y por lo tanto al precio de una incertidumbre acerca de la solución de sus posibles antinomias? Fuente especificada no válida..

De ahí que, la antinomia vista desde la incertidumbre, se comprende como aquella situación en la que se encuentran dos normas en posiciones diferenciales que llevan a conflictuar una situación, "debido a que una norma obliga y la otra prohíbe, o una obliga y la otra permite, o una prohíbe y la otra permite un mismo comportamiento"Fuente especificada no válida.. 
Así, la antinomia refleja el choque de dos proposiciones incompatibles, que permiten un sesgo a la incertidumbre; se podría decir que la antinomia le suma a la incertidumbre la falta de certeza de las normas y las circunstancias que rodean la situación actual del país, pues se aprueba una cosa por parte de los actores del conflicto Estado Farc Ep y de otra se desconoce por un sector de la población nacional en respuesta al plebiscito al que se ha hecho referencia.

Lo expuesto como abrebocas para demostrar que el a hoy inacabado proceso de paz entre las Farc Ep y el gobierno es un paso necesario e importante, pero es solo el comienzo de una enorme tarea colectiva para una paz duradera, expresión insigne del texto construcción de paz en Colombia, compilado por Rettberg (2012) que refleja la imperiosa necesidad de la paz en Colombia y que se consolida con lo propuesto por las partes en negociación, en cuanto, a la necesidad de la participación popular, hecha por la Farc Ep.

"Todos los sectores populares deben reclamar su participación dejando oír desde ya sus múltiples voces y propuestas. Necesitamos al pueblo, al constituyente primario, definiendo la ruta del diálogo desde " $y a$ "” Fuente especificada no válida.

Aspectos que reflejan los puntos de vistas claros y necesarios para el país; por un lado, que la paz sea duradera y por el otro la participación de todos, sin embargo, dentro de este objetivo propuesto no se puede dejar de lado a quienes de una u otra forma desean afectar este proceso, tal como lo afirma Acero (2014) que el proceso de paz "afortunadamente está llegando a un punto de no retorno. Sin embargo, es importante reconocer que una vez se firme el acuerdo final el país va a sufrir un incremento de la violencia y de la delincuencia, producto de una destorcida violenta" (pág. 8)

Se tiene entonces, que, en el proceso de paz, además de integrar una serie de acuerdos y compromisos, no se pueden dejar de lado, aquellos factores que lo entorpecen y que están presentes dentro y fuera de la negoción. Es así, que al buscar una percepción transparente y conforme a las necesidades específicas del país, es una lucha titánica y más 
aún si se tiene en cuenta que el conflicto ha afectado a todos los sectores económicos y a "todos". Por ello, tener una postura clara frente al tema de la paz resulta algo complejo.

En este orden de ideas, el presente manuscrito busca solamente hacer una mirada crítica de la incertidumbre de las víctimas en el acuerdo de paz de Colombia, en la Habana de cara a lo sucedido con el acuerdo de paz y lo dispuesto para las víctimas del conflicto. De esta forma, se debe tener claridad que independientemente de lo sucedido en el plebiscito, la realidad del país sigue siendo la misma y las víctimas continúan a la espera de dignificar su vida y teniendo en cuenta que Colombia se encuentra suscrita a los objetivos propuestos por la justicia transicional, que se mueve entre la verdad, justicia, reparación y no repetición.

Se podría afirmar que la incertidumbre, en el proceso de paz, resulta fundamental, hace parte de la atmosfera, debido a que esta circunstancia particular de Colombia dejado "una huella profunda e imborrable en la siquis de millones de colombianos y no solo víctimas mortales y heridas físicas" Fuente especificada no válida.. Entonces, se puede afirmar que Colombia, se ha comenzado a preocupar por sus víctimas, teniendo en cuenta que "paradójicamente, en un país que cumple más de 60 años de guerra no hay estudios serios que den cuenta de ese daño"Fuente especificada no válida.. De ahí que, se observa que a partir de la expedición de la ley 1448 de 2011 "Por la cual se dictan medidas de atención, asistencia y reparación integral a las víctimas del conflicto armado interno y se dictan otras disposiciones" que se comienza una tarea real para visibilizar las víctimas del conflicto, que en intentos anteriores no tuvieron la respuesta deseada, pues se observa que los intentos legislativos eran muy ligeros una prueba de ello es la ley 975 de 2005 "Por la cual se dictan disposiciones para la reincorporación de miembros de grupos armados organizados al margen de la ley, que contribuyan de manera efectiva a la consecución de la paz nacional y se dictan otras disposiciones para acuerdos humanitarios" es un esfuerzo incipiente frente a la realidad y participación de las mismas en la solución del conflicto armado nacional, a partir de allí hacia atrás existían leyes orientadas a la conminación al desarme 
pero que realmente no tuvieron impacto en la comunidad de víctimas de la nación colombiana.

Es así, como las víctimas constituyeron un factor determinante en la negociación de la Habana, debido a que resarcir a las víctimas está en el centro del acuerdo del Gobierno Nacional - Farc- Ep, en este sentido, se trataron los derechos humanos de las víctimas en el marco de la justicia transicional.

De esta forma, es importante destacar que el proceso de paz que se adelantó con las Farc-Ep, en la Habana, abarca seis aspectos trascendentales en la historia del conflicto, entre estos se tiene la política agraria integral, participación política, fin del conflicto, solución al problema de las drogas ilícitas, víctimas, y finalmente la implementación, verificación y refrendación.

Aspectos, que se diluyen en la incertidumbre que se tiene pues a hoy se ha convertido en una circunstancia recurrente, llegando a ser endémica; pues en ella, se aglomeran, no solamente las circunstancias de las víctimas, sino lo que el Estado les quiere ofrecer, a través de largos y significativos compromisos normativos, que sí se revisa a conciencia la capacidad del Estado para responder, con todo aquello que busca devolverles a las victimas su statu quo, se tiene que el Estado colombiano no posee, ni la capacidad administrativa, ni los recursos económicos para afrontar los compromisos adquiridos.

Pero, piénsese por un instante, que las circunstancias del país son benéficas para brindar el respaldo a lo propuesto en los acuerdos de paz. Entonces, ¿cómo se podría enfrentar la antinomia entre una norma y otra?, ¿cómo se daría la dinámica normativa de Colombia, frente a un problema que ha vivido con todos los colombianos por 53 años ininterrumpidos?

\section{La negociación en la Habana y la protección a las víctimas}

El proceso de paz en la Habana, con relación a las víctimas no ha dejado de lado la justicia transicional como eje fundamental, para emprender las acciones orientadas a mejorar la condición de las víctimas. 
El acuerdo establece diez principios bajo los cuales se dio la discusión de la Habana, que responden a los parámetros de la justicia transicional; a la necesidad de que las víctimas participen en las discusiones, y al criterio, clave, de que "los derechos de las víctimas no son negociables, sino que, como lo impone el derecho internacional, lo que se deberá acordar es como satisfacerlos"Fuente especificada no válida..

Así, los principios establecidos en la Habana para las víctimas se orientan al reconocimiento, responsabilidad y derechos de éstas, quedando claro que no son negociables, existiendo, además, la participación de las víctimas en las discusiones, esclarecimiento pleno de la verdad, la reparación, protección, acuerdos de no repetición, la reconciliación y, por último, el enfoque de derechos.

Aspectos todos que parten de la justicia transicional, y se apoyan en lo dispuesto por la Ley de Víctimas.

Así, el Estado requiere hacer uso de todas las herramientas con las que cuenta para enfrentar esta problemática; teniendo como eje fundamental, el aparato normativo, que permite la integración de normas que buscan solucionar de fondo situaciones adversas de las víctimas con ocasión de los grupos armados.

De este modo, la llamada Ley de Víctimas sancionada en 2011, constituye otra de las acciones a seguir por el Estado frente a situaciones socialmente problemáticas que llevan la solución o el control de las mismas.

En el marco de la justicia transicional la garantía que se les ofrece a las víctimas, a través del Sistema Integral de Verdad, Justicia, Reparación y No repetición -SIVJRNR-, sistema que integra diferentes mecanismos judiciales y extrajudiciales al servicio de quienes se han visto afectados con ocasión del conflicto armado, buscando con ello, lograr la mayor satisfacción posible de los derechos de las víctimas.

En este orden de ideas, existe en la actualidad un debate frente al alcance de los montos de la reparación administrativa, los cuales no han brindado una claridad frente al compendio de la reparación, generando con ello, un choque entre las diferentes vías legales - judicial y administrativa -, que pone de manifiesto el inconformismo de los afectados y genera además grandes interrogantes frente a la forma como el Estado ofrece la reparación. 
Entonces, existiendo un marco regulatorio para la reparación, ¿Cómo se manejaría lo propuesto por el Acuerdo final de la Habana, con relación a las víctimas? Máximo si se tiene en cuenta, que el Acuerdo para las víctimas, reafirma las cinco medidas establecidas en materia de reparación en pro de lograr la satisfacción de los derechos de las víctimas, que busca:

Asegurar la rendición de cuentas por lo ocurrido, garantizar la seguridad jurídica de quienes participen en él, y contribuir a garantizar la convivencia, la reconciliación y la no repetición, como elementos esenciales de la transición a la paz Fuente especificada no válida..

Establece el Acuerdo la rendición de cuenta. Entonces, un proceso tendiente a la terminación de un conflicto armado por vía de negociación política debe contemplar mecanismos de rendición de cuentas por los crímenes cometidos en el marco del conflicto y de satisfacción de los derechos de las víctimas.

Y esto no solo porque en los últimos veinte años han cambiado las condiciones para negociar la terminación del conflicto, sino también porque la existencia de estos mecanismos constituye un presupuesto para avanzar efectivamente en la transición hacia una sociedad más democrática y respetuosa de los derechosFuente especificada no válida..

De ahí que, dentro del proceso de rendición de cuentas y satisfacción de los derechos de las víctimas, existe a cargo del Estado un deber de investigar, juzgar y sancionar.

No, obstante este deber no puede ser absolutizado, sino más bien ponderado con otros deberes igualmente relevantes como el de alcanzar la paz, y debe además ser sopesado de cara a las limitaciones fácticas y de un análisis acerca de las mejores alternativas para satisfacer efectivamente de los derechos de las víctimasFuente especificada no válida.. 
Aspecto que lleva a establecer que el marco para la paz en el contexto actual no puede tener como referente los estándares de transiciones de la guerra a la paz que se dieron hace veinte años, tampoco debe utilizar los estándares sobre el alcance del deber de investigación y sanción en tiempos de normalidad, ni aquellos establecidos para transiciones de la dictadura a la democracia; esto debido a que los procesos tendientes a la superación de un conflicto armado plantean condiciones y limitaciones diferenciales y por eso los estándares no pueden ser simplemente equiparados.

Por esta razón, está bien orientada la idea nuclear del actual "Marco Jurídico para la Paz de establecer criterios de selección y priorización que permitan centrar los esfuerzos en la investigación y sanción de los máximos responsables de los crímenes más graves y representativos, admitir penas alternativas y combinar esto con mecanismos extrajudiciales"Fuente especificada no válida. de rendición de cuentas y garantía de derechos.

Es por ello, que el marco normativo dispuesto por la Ley de Víctimas y los planteamientos expuestos por el Acuerdo de la Habana, en materia de reparación a las víctimas, se ve intrincado en la rendición de cuentas, que pone en evidencia lo deseado, lo que tiene el Estado para responder y los lineamientos normativos de la Justicia Transicional.

No obstante, es necesario mencionar que la justicia transicional no es una forma especial de justicia, "sino una justicia adaptada a sociedades que se transforman a sí mismas después de un período de violación generalizada de los derechos humanos. En algunos casos, estas transformaciones suceden de un momento a otro; en otros, pueden tener lugar después de muchas décadas"Fuente especificada no válida..

Es por esto que, frente a la necesidad imperativa de paz, se ha asumido como una práctica normal de la política en situaciones de transición, y especialmente en aquellos aspectos relacionados con la reparación que integra el Derecho de las víctimas, de sus derechohabientes y de las colectividades a obtener reparación por los daños y perjuicios sufridos.

Es así, como en el maremágnum de situaciones que se han desprendido del conflicto interno que Colombia padece, han dejado claro, que el camino de la insurgencia supera los mecanismos y acciones que el 
Estado ha emprendido hasta la fecha, para combatirlos, al punto que las disímiles situaciones que se desprenden de tal situación han desbordado la estabilidad del Estado, enfrentando toda clase de problemas sociales, siendo uno de los más relevantes la situación de las víctimas.

A hoy esta abiertamente demostrado que las víctimas han sido parte integral de este proceso que según manifestaciones de las mismas no se ha concretizado con medidas efectivas que permitan el restablecimiento total de sus derechos pues hasta a hoy existe una implementación de esos acuerdos y esa situación tomara bastante tiempo para su consolidación no queriendo decir con ello que no sea posible, pero que tal vez la transición demore poco menos que el periodo de conflicto.

Para comprender los cambios por los cuales la ley de victimas ha pasado se hace necesaria devolverse a ver cuál fue el proceso de consecución de este cuerpo normativo ley, de esta forma, la "Ley 418 de 1997, prorrogada y modificada por las leyes 548 de 1999 y la 782 de 2002 y la 1106 de 2006, su rol fue facilitar acuerdos con grupos armados, aprueba medidas de asistencia humanitaria a víctimas. Así mismo Ley 387 de 1997 que regula acción del Estado para la prevención del desplazamiento forzado y para la atención humanitaria de emergencia y apoyo a la consolidación socioeconómica. No incluye reparación” (Los complejos debates de la Ley de Víctimas, 2013).

Dentro de este marco hace presencia en Colombia la justicia transicional, por medio del proyecto de ley de alternatividad penal en el 2003, que en su momento expreso lo siguiente:

La propuesta legislativa se orienta hacia una concepción restaurativa que supera la identificación de castigo con venganza, propia de un discurso en el que lo principal es reaccionar contra el delincuente con un dolor similar al que él produjo en la víctima y, sólo en segundo lugar, buscar la no repetición (prevención) y la reparación de las víctimas. Es importante tener en cuenta que al hacer justicia el derecho apunta hacia la reparación y no hacia la venganza. Ante la evidencia de que la pena privativa de la libertad, como única respuesta al delito, ha fracasado en muchas ocasiones en su cometido de lograr la resocialización de los delincuentes, el 
derecho penal contemporáneo ha avanzado en el tema de las sanciones alternativas (Uprimmy, 2005; pág. 212).

La justicia transicional hace referencia a un asunto muy antiguo, en cuanto, a determinar qué debe hacer una sociedad frente al legado de graves atentados contra la dignidad humana, cuando se ha llegado al cese de una guerra civil, o un régimen tiránico, se debe castigar a los responsables, o se deben olvidar los excesos para favorecer la reconciliación.

Es así, como la justicia transicional emerge como una opción de transición de la guerra a la paz o de las dictaduras a las democracias, "que justifica ampliamente la creación de la categoría de Justicia Transicional, lo novedoso de ésta justicia es que consiste en la introducción del sustantivo justicia, apareciendo como una exigencia que cualifica de manera importante los procesos transicionales, pero a la vez se ve profundamente determinada por tales procesos" (Uprimmy, 2005; pág. 213).

Por ende, el concepto de justicia adquiere un significado y unas implicaciones particulares que implican las exigencias de justicia en contextos de normalidad. "La Justicia Transicional hace referencia a aquello procesos transicionales mediante los cuales se llevan a cabo transformaciones radicales de un orden social y político determinado, que enfrentan la necesidad de equilibrar las exigencias contrapuestas de paz y justicia" (Uprimmy, 2005; pág. 213).

Perdón, reparación y transición, son los complementos de la justicia transicional que evidencian serios límites para servir de paradigma en un proceso de justicia transicional cualquiera, cuyo proceso restaurador resulta verdaderamente inconveniente para afrontar la transición en caso de que prosperaran las negociaciones de paz con los grupos paramilitares y/o eventualmente, con otros grupos alzados en armas, debido a la falta de garantías que aún existen en el apartado normativo diseñado para este fin.

Dentro de esta línea, se da origen a la Ley 975 de 2005 creando el marco jurídico para facilitar la desmovilización de grupos ilegales en acuerdos con el gobierno. Incluye marginalmente algunas disposiciones 
para las víctimas en materia de verdad y reparación, en consonancia con la justicia transicional.

La concreción de la Ley 975 estuvo antecedida de una multitud de proyectos de Ley que oscilaron entre articulados que respondían, unos a la protección de la garantía de justicia y, otros, a la maximización de la impunidad por un, pretendido, principio de paz. Como resultado, la Ley aprobada inicialmente perfiló la judicialización de los GAOML en función de los intereses de desarticulación de estructuras armadas irregulares y con ello la facilitación del proceso de paz y reincorporación a la vida civil de combatientes.

La "Ley 975 configuró un procedimiento especial estructurado en dos etapas: una administrativa y otra judicial. Los propósitos insertos en el proceso especial de la Ley 975 establecen un particular derrotero de límites, determinando los alcances del cuerpo normativo de justicia y paz. Así” (Ambos, 2009; pág. 8), establece competencias específicas entorno a los hechos punibles que se deben judicializar, la forma de realización y el régimen de pena a imponer; como también, se vincula la vigencia de la Ley de Justicia y Paz -LJP - y los dominios de su implementación a un ámbito especial de aplicación personal y temporal.

El inicio del procedimiento de la Ley 975 se sustenta en el cese de hostilidades. "Para ello la LJP contempla una fase administrativa, en la cual se pretende quebrar la vinculación armada de los integrantes de GAOML. De este modo, en dicho momento se confecciona la desmovilización y dejación de armas, ya sea de manera colectiva o individual" (Ambos, 2009; pág. 9). El inicio judicial del proceso está determinado por la postulación, que se realiza con el arribo de la lista de postulados a la Fiscalía General de la Nación - FGN -.

"Con ello se activa una serie de competencias para el inicio de la investigación tendientes a establecer los presupuestos que sustentarán la formulación de cargos. Las actividades relativas al esclarecimiento de la verdad material, la determinación de autores y partícipes y la identificación de bienes destinados fundamentalmente a la reparación, son de competencia de la FGN, quien actúa a través de un fiscal delegado" (Ambos, 2009; pág. 11).

En el marco procesal de la LJP, la participación de las víctimas tiene un rol determinante. Como derecho, su participación ya ha sido 
reconocida en la normatividad interna. "Fundamentalmente a manera reglamentaria de la Ley 975, los derechos y la participación de las víctimas se han puntualizado principalmente sobre la acreditación de su calidad. La Ley 975 no extingue completamente el castigo, sino solo otorga una considerable reducción de la pena" (Ambos, 2009; pág. 12).

Así, "el colapso de justicia y paz y de cualquier otra norma similar futura, resultó inevitable ante la perspectiva de judicializar 340.000 hechos delictivos derivados sólo de lo conocido en justicia y paz. El actual enfoque investigativo de la justicia penal ordinaria y de la Ley de Justicia y Paz, no le permitió a la Fiscalía General de la Nación concentrar sus esfuerzos y recursos en los casos de los “más responsables” (Observatorio legislativo, 2011; pág. 2), ni dar claridad a los patrones y contextos regionales de la operación de los distintos actores del conflicto. Por el contrario, el modelo de investigación caso por caso fomenta el conocimiento de hechos individuales y aislados.

En suma, en los procesos de justicia transicional, una excesiva concentración en la justicia penal también deja de lado el reconocimiento de las causas por las cuales surgieron los perpetradores, pues estos no son producto de una experiencia individual, sino también colectiva. "Los perpetradores son el reflejo de los errores que se encuentran en la estructura y tejido social de nuestro país. Por medio de una comisión de la verdad, se puede obtener una visión holística del cómo y el porqué del conflicto" (Observatorio legislativo, 2011; pág. 4).

En los procesos de justicia transicional la constancia y persistencia de las víctimas ha sido esencial para obtener los logros y avances indicados. En particular, el papel de las víctimas ha sido relevante en varios aspectos: "en mantener vigente en la agenda pública la necesidad de hacer justicia respecto de los hechos del pasado; en impulsar las investigaciones y procesos al rendir sus testimonios en sede judicial, o mediante el aporte de pruebas o la solicitud de practicar diligencias probatorias (Fundación para el debido proceso legal, 2010; pág. 18); en elaborar argumentos de hecho y de derecho rigurosos y convincentes de manera que los operadores judiciales los puedan acoger y aplicar para resolver los casos.

Después la Ley 1151 de 2007 se presenta con el plan de desarrollo económico y social, incluye capítulo sobre atención a población 
desplazada. Posteriormente la Ley 1152 de 2007 declarada inexequible por la Corte Constitucional, mediante sentencia C-175. (2009), Magistrado Ponente Dr. Luis Ernesto Vargas Silva, el estatuto rural prevé la entrega de tierras de extinción al Fondo de Reparación de Víctimas de la ley 975, programas de permutas, subsidios, retorno y reubicación" (Los complejos debates de la Ley de Víctimas, 2013).

Ahora bien, dentro de las estrategias para buscar reparar las víctimas del conflicto armado interno, surge el proyecto de ley de víctimas y restitución de tierras, iniciativa que tuvo varios tropiezos, haciendo que durará más su proceso para convertirse en ley: Todo comienza, con el documento del proyecto ley de víctimas que se discutió en el Congreso, se dice que era uno de los más largos en páginas y en historia. En total "son 38 páginas, sin contar la exposición de motivos" de igual manera, extenso o no se debió leer y leer para poder ser debatido (Los complejos debates de la Ley de Víctimas, 2011).

Así, la Ley de Víctimas y restitución de Tierras, en general se define como "una iniciativa que establece medidas judiciales, administrativas, sociales y económicas, individuales y colectivas, en beneficio de las víctimas del conflicto interno, en un marco de justicia transicional, buscando que tengan acceso al goce efectivo de sus derechos a la reparación con garantía de no repetición.

Pero, también deja la abierta la incertidumbre normativa frente a lo tratado en los Acuerdos de Paz, al pretender con éste, una rendición de cuentas, frente a un proceso que lleva un trámite judicial y administrativo y que requiere una nueva categorización de víctimas, formando con ello un paralelo entre lo que se ha logrado y lo que se propone en el Acuerdo de Paz.

Es de aclarar que en el actual proceso de paz la situación de las víctimas continúa siendo el interrogante más grande que existe; toda vez, que la negociación continua en un periodo de incertidumbre que no permite tener una claridad sobre lo que va a suceder con las mismas, lo cierto es que se debe continuar en el ascenso de cumplir con los tratados ofrecidos a éstas personas independientemente del proceso de paz.

A hoy tenemos entonces que varios han sido los intentos no solo legislativos sino también económicos y judiciales para la materialización 
o concretización de los derechos de las víctimas del conflicto armado, que han arrojado resultados buenos, parciales o malos, a la luz del lector, pero que si reflejan compromisos serios en la búsqueda de la reivindicación de las mismas, innegable resulta desconocer que después del plebiscito de 2 de octubre de 2016 la sociedad colombiana se dividió en torno a los que apoyan el proceso que se adelantó y en los que no lo apoyan, pero que eso no implique que el común denominador deba ser desatendido siendo este la paz, como valor como principio y como opción de vida.

\section{Conclusiones}

Queda demostrado que para la construcción de procesos de paz en cualquier parte del mundo y por las razones que sean, transición de dictadura a democracia, superación de conflicto armado de naturaleza interna, entre otras, dicha construcción no se podrá hacer sin la participación de las víctimas como pilar fundamental de esos procesos.

Colombia ha acudido a ello y ha hecho su mejor esfuerzo para incluirlas en los acuerdos que hoy están vigentes y que constituyen el pilar fundamental de la denominada construcción de una paz estable y duradera.

La lectura de los resultados del plebiscito del 2 de octubre de 2016 mostro una Colombia dividida en torno a lo aprobado en el primer texto es decir el confeccionado y publicado el 24 de agosto de 2016 que por mandato del pueblo y de la Corte Constitucional tuvo que ser rediseñado dando lugar al definitivo de fecha 24 de noviembre de 2016 el cual no se sometió a aprobación o ante el constituyente primario sino con base en el principio estatal que indica que el presidente como Jefe de Estado puede emitir todas las decisiones que considere pertinentes para mantener el orden nacional.

Las lecturas comportamentales de los anhelos de la sociedad nacional confluyen en que la paz es una necesidad y las discusiones se centran exclusivamente en la forma de conseguirla que de por sí deberá entenderse como una no violenta, pues como lo sufrió Colombia por más de cuatro décadas no feneció sino por el contrario se acrecentó 
dejando más víctimas y dolientes que a la fecha no encuentran satisfechos sus derechos a la verdad, justicia reparación y no repetición.

De cara a esas necesidades se ha efectuado un tratamiento legislativo que ha estado orientado a la satisfacción de los derechos de las víctimas y a dejar de lado el proceso de insensibilización al cual tradicionalmente han estado sometidas, un claro ejemplo de estos es la sucesión de leyes desde Ley 418 de 1997, prorrogada y modificada por las leyes 548 de 1999 y la 782 de 2002 y la 1106 de 2006, su rol fue facilitar acuerdos con grupos armados, aprueba medidas de asistencia humanitaria a víctimas. Así mismo Ley 387 de 1997 que regula acción del Estado para la prevención del desplazamiento forzado y para la atención humanitaria de emergencia y apoyo a la consolidación socioeconómica, al ley 975 de 2005 en lo referente a las víctimas del conflicto armado interno y la mítica e insigne ley 1448 de 2011 Por la cual se dictan medidas de atención, asistencia y reparación integral a las víctimas del conflicto armado interno y se dictan otras disposiciones, reglamentada por el Decreto Nacional 4800 de 2011 y el Decreto Nacional 3011 de 2013, entre otras las cuales se han convertido en bastiones en pro de los objetivos pretendidos en la justicia transicional de cara a las víctimas del conflicto armado; sin embargo como todo proceso de reconciliación de nacional no es ajeno que el nuestro tenga que volverse selectivo, emblemático y colectivo, lo que a la vista de las mismas puede resultar contraproducente al desconocer la verdad individual de lo sucedido.

Los ojos del planeta se centran en el proceso de paz que adelantó y adelanta nuestro país pues suscribir un acuerdo es tan solo el primer paso para la realización de la paz por lo anterior las dicotomías jurídicas que al hoy existen deben superarse; las víctimas deben salir de ese estado de incertidumbre que las ha agobiado desde hace más de cuatro décadas y solo así entenderemos que los procesos de paz además de ser de naturaleza jurídica tienen un alto contenido político, el cual no puede permear el imperio de la ley ni la seguridad jurídica de las instituciones.

Sin embargo, a partir de este análisis se logra establecer que medir a hoy el resultado de lo compendiado en el marco de la reparación de las victimas dentro del acuerdo de paz de la habana y su incidencia en 
la construcción de una paz estable y duradera es precario pues solo estos objetivos se construyen al mediano y largo plazo con algo más que los deseos, sino también los recursos económicos, la legislación y la obligación de las víctimas a olvidar como la obligación de los victimarios a recordar.

\section{Referencias bibliográficas}

Ácero, H. (14 de enero de 2014). Violencia, seguridad y reinserción. El tiempo, pág. 8.

Alto Comisionado para la paz (2017). Acuerdo Final para la Terminación del Conflicto y la Terminación de una paz estable y duradera. http://www. altocomisionadoparalapaz.gov.co/procesos-y-conversaciones/Documentos\%20compartidos/24-11-2016NuevoAcuerdoFinal.pdf

Alto Comisionado para la paz. (2016). El Acuerdo final de paz. Obtenido de http://www.altocomisionadoparalapaz.gov.co/herramientas/Documents/ Nuevo_enterese_version_6_Sep_final_web.pdf

Ambos, Kai, (2009). Procedimiento de la ley de justicia y paz (ley 975 de 2005) y Derecho penal internacional. Ministerio de Relaciones Exteriores (Auswartiges Amt)/Embajada de Alemania en Colombia/ Deutsche Gesellschaft für Technische Zusammenarbeit (GTZ) GmbH Proyecto ProFis.

Congreso de la República de Colombia. (10 de junio de 2011). Ley 1448 de 2011. Por la cual se dictan medidas de atención, asistencia y reparación integral a las víctimas del conflicto armado interno y se dictan otras disposiciones. Diario Oficial 48096 del 10 de junio de 2011. Recuperado de goo.gl/3VhOdT.

Congreso de la República de Colombia. (22 de diciembre de 2006). Ley 1106 de 2006. Por medio de la cual se prorroga la vigencia de la Ley 418 de 1997 prorrogada y modificada por las Leyes 548de 1999 y 782 de 2002 y se modifican algunas de sus disposiciones. Diario Oficial 46490 del 21 de diciembre de 2006. Recuperado de goo.g1/13VhOdT.

Congreso de la República de Colombia. (23 de diciembre de 1999). Ley 548 de 1999. Por medio de la cual se prorroga la vigencia de la Ley 418 del 26 de diciembre de 1997 y se dictan otras disposiciones.. Diario Oficial 43827 del 22 de diciembre de 1999. Recuperado de goo.gl/0VhOdT. 
Congreso de la República de Colombia. (23 de diciembre de 2002). Ley 782 de 2002. Por medio de la cual se prorroga la vigencia de la Ley 418 de 1997, prorrogada y modificada por la Ley 548 de 1999 y se modifican algunas de sus disposiciones. Diario Oficial 45043 del 22 de diciembre de 2002. Recuperado de goo.gl/3VhOdT.

Congreso de la República de Colombia. (24 de julio de 1997). Ley 387 de 1997. Por la cual se adoptan medidas para la prevención del desplazamiento forzado; la atención, protección, consolidación y estabilización socioeconómica de los desplazados internos por la violencia en la República de Colombia. Diario Oficial 43091 del 23 de julio de 1997. Recuperado de goo.gl/45VhOdT.

Congreso de la República de Colombia. (25 de julio de 2005). Ley 975 de 2005. Por la cual se dictan disposiciones para la reincorporación de miembros de grupos armados organizados al margen de la ley, que contribuyan de manera efectiva a la consecución de la paz nacional y se dictan otras disposiciones para acuerdos humanitarios. Diario Oficial 45980 del 25 de julio de 2005. Recuperado de goo.gl/5VhOcT.

Congreso de la República de Colombia. (25 de julio de 2007). Ley 1151 de 2007. Por la cual se expide el Plan Nacional de Desarrollo 20062010. Diario Oficial 46700 del 25 de julio de 2007. Recuperado de goo. gl/45VhOdT.

Congreso de la República de Colombia. (25 de julio de 2007). Ley 1152 de 2007. Por la cual se dicta el Estatuto de Desarrollo Rural, se reforma el Instituto Colombiano de Desarrollo Rural, Incoder, y se dictan otras disposiciones. Diario Oficial 46700 del 25 de julio de 2007. Recuperado de goo.gl/7845VhOdT.

Congreso de la República de Colombia. (26 de diciembre de 1997). Ley 418 de 1997. Por la cual se consagran unos instrumentos para la búsqueda de la convivencia, la eficacia de la justicia y se dictan otras disposiciones. Diario Oficial 43201 del 26 de diciembre de 1997. Recuperado de goo.gl/1VhOdT.

Corte Constitucional, sentencia de constitucionalidad C-175. (2009), Magistrado Ponente Dr. Luis Ernesto Vargas Silva. Colombia.

Corte Constitucional, sentencia de revisión C- 209. (2003). Magistrado ponente: Manuel José Cepeda Espinoza. Colombia.

Corte Constitucional, Sentencia T - 429. (2003). Magistrado ponente: Eduardo Montealegre Lynett. Colombia. 
Ferrajoli, L. (2013). Principia iuris. Teoría del derecho y de la democracia. Teoría del derecho y de la democracia. Madrid: Trotta.

García, M. (septiembre de 2007). Las antinomías en el derecho, el por qué de su origen y el cómo de sus posibles soluciones. Letras jurídicas (5), 1 - 12.

Gómez. (18 de noviembre de 2012). La participación popular, uno de los temas más espinosos. El Tiempo, pág. 8.

Martínez, G. (2012). Derecho e incertidumbre. Dialnet, XXVIII, 97 - 118.

Meltzer, J. (s.f.). Conflicto armado: consideraciones para una posible Cooperación canadiense. Obtenido de http://www.cnrr.org.co/interior_otros/pdf

Rettberg, A. (2012). Construcción de paz en Colombia. Colombia: Uniandes.

Semana. (13 al 20 de abril de 2014). Las heridas invisibles de la guerra. Informe especial(1667), 35-42.

Semana. (8 al 15 de junio de 2014). La habana: la hora de las víctimas. Proceso de paz(1675), 28 -48 .

Uprimny R, Sánchez L y Sánchez N. (Diciembre de 2013). Justicia transicional y proceso de paz en Colombia. Aportes DPL(18), 26 - 27. 


\title{
Reflexiones sobre la naturaleza jurídica del Acuerdo Final ${ }^{41}$
}

\author{
Alejandro Ramelli Arteaga ${ }^{42}$
}

\section{Introducción}

U

no de los aspectos que más controversia suscitó entre los negociadores del Gobierno Nacional y las FARC fue el referente al llamado “blindaje” del Acuerdo Final (en adelante, el Acuerdo o el Acuerdo de Paz). ¿Cómo garantizar que los compromisos acordados en materia de reforma agraria integral, participación en política, garantías de seguridad para los desmovilizados y justicia transicional fueran efectivamente cumplidos? El Acuerdo de Paz ¿Vincula al Estado colombiano en su

41 Articulo resultado producto de investigación del proyecto denominado "Procesos de exigibilidad y justiciabilidad de los Derechos Humanos y el Derecho Internacional Humanitario, en el contexto nacional e internacional.” Adscrito al grupo de investigación Sociohumanistico Categoría A en Colciencias de la Facultad de Derecho de la Universidad Santo Tomás Bogotá

42 Abogado de la Universidad Externado de Colombia, doctor en Derecho por la Universidad de Salamanca, magíster en Derechos Humanos de la Universidad de París X, Nanterre. En la U.de Salamanca también realizó los cursos "Jean Monnet" en Derecho Comunitario Europeo y Derecho Económico Europeo. Desde el 2002 es Magistrado Auxiliar de la Corte Constitucional. Ha sido Secretario en la Corte Constitucional y Fiscal Especializado (Fiscalía General de la Nación). Docente U. Santo Tomás de Aquino Email: aramelli@yahoo.com 
integridad, o únicamente al Presidente de la República? En un futuro, ¿El Congreso de la República puede modificar libremente la legislación que hasta el momento ha sido expedida por la vía del Procedimiento Legislativo Especial para la Paz?

La respuesta a las anteriores preguntas pasa por establecer la naturaleza jurídica del Acuerdo: ¿Se trata exclusivamente de un documento político, o por contrario, en todo o en parte puede ser considerado un texto jurídico?, y en caso afirmativo, ¿Qué implicaciones tiene aquello en términos del ejercicio del control de constitucionalidad en Colombia?

$\mathrm{Al}$ respecto, es preciso tener en cuenta que la implementación del Acuerdo comporta importantes consecuencias en el ámbito institucional, en la medida en que prevé la conformación de diversas instancias relacionadas, entre otros, con los siguientes temas:

- La vigilancia de las elecciones (Tribunal Nacional de Garantías Electorales);

- Actualización del registro de tierras (Sistema de Actualización Catastral);

- Búsqueda de personas desaparecidas (Unidad para la Búsqueda de Personas dadas por Desaparecidas en el Contexto y en Razón del Conflicto Armado);

- Desmantelamiento de las organizaciones criminales (Unidad Especial de Investigación para Desmantelar las Organizaciones Criminales);

- Sustitución de cultivos ilícitos (Agencia de Renovación del Territorio); y

- Justicia (Tribunal para la Paz).

Al mismo tiempo, la implementación del Acuerdo conlleva importantes efectos en el sistema de fuentes del derecho colombiano. De allí que se planteen discusiones en diversos planos relacionales: 
- Acuerdo/Constitución;

- Acuerdo/Orden jurídico internacional;

- Acuerdo/Normas de desarrollo adoptadas por la vía del Procedimiento Legislativo Especial para la Paz (fast track); y

- Acuerdo/Normas relacionadas con temas del Acuerdo expedidas una vez vencido el término del Procedimiento Legislativo Especial para la Paz.

La hipótesis que pretendo demostrar es la siguiente: El Acuerdo Final presenta una naturaleza jurídica mixta, en el sentido de ser, al mismo tiempo, un importante documento político y un texto parcialmente jurídico, lo cual no significa que se trate de una norma de aplicación directa. Tampoco que en su integridad haga parte del bloque de constitucionalidad.

Con miras a demostrar la validez de la referida hipótesis de trabajo, el texto se organiza en dos grandes bloques. En el primero, explico la tesis que hasta el momento ha sostenido la Corte Constitucional, en el sentido de afirmar que el Acuerdo Final es exclusivamente un documento político; en el segundo, pretendo explicar por qué razón aquél también es un texto de carácter jurídico y las implicaciones que ello comporta.

\section{El Acuerdo Final entendido como un documento exclusivamente político}

\section{Efectos de considerar un acuerdo de paz como un texto exclusivamente político}

La Corte Constitucional (Sentencia C-379 de 2016) con ocasión de la revisión automática e integral del Proyecto de Ley Estatutaria No. 94/15 Senado - 156/15 Cámara "por la cual se regula el plebiscito para la refrendación del acuerdo final para la terminación del conflicto y la construcción de una paz estable y duradera” calificó el texto 
del Acuerdo en términos de "política pública", y por ende, carente de fuerza normativa.

En tal sentido, el juez constitucional insistió en que el efecto de la votación del plebiscito no era la inclusión automática de una norma constitucional o legal en el ordenamiento jurídico colombiano, por cuanto "lo que se somete a consideración del Pueblo no es una norma sino una decisión politica del Presidente de la República”.

Precisó además la Corte que el resultado de la votación del plebiscito sólo vinculaba al Presidente de la República, y no a las demás ramas del poder público. De allí que cuando la implementación de la decisión política requiriera del concurso de otras autoridades públicas, sería necesario acudir a los mecanismos de implementación correspondientes, previstos en la Constitución.

En pocas palabras, para la Corte el texto del Acuerdo Final carece por completo de valor jurídico. Se trata simplemente de un documento de carácter político, y por ende, su eficacia dependerá de que el futuro se adopten las correspondientes reformas constitucionales y legales que permitan convertir lo acordado en verdaderas normas jurídicas.

Importa señalar que si el Tribunal Constitucional hubiera concluido que el Acuerdo ofrecía, total o parcialmente, un carácter normativo, y no exclusivamente político, hubiera tenido que declarar inexequible la convocatoria al plebiscito por la paz, como quiera que se habría estado en presencia de un referendo.

La tesis del carácter exclusivamente político del Acuerdo fue recientemente reiterada por la Corte Constitucional (Sentencia C-332 de 2017), al momento de resolver una demanda de inconstitucionalidad formulada contra el Acto Legislativo núm. 01 de 2016, "Por medio del cual se establecen instrumentos jurídicos para facilitar y asegurar la implementación y el desarrollo normativo del Acuerdo Final para la Terminación del Conflicto y la Construcción de una Paz Estable y Duradera”. Como se recordará, se trataba de examinar, entre otros asuntos, si la necesidad de contar con un aval para introducir modificaciones a los proyectos de ley tramitados por la vía del Procedimiento Legislativo Especial para la Paz (fast track), amén del requisito de realizar votaciones en bloque, sustituía elementos definitorios o esenciales de la Constitución de 1991, en especial, el principio de separación de poderes. 
En dicha oportunidad, la Corte reiteró que la vinculatoriedad del Acuerdo Final, en la instancia previa a su implementación, radica exclusivamente en el Presidente de la República, quien suscribió tal documento en ejercicio de su competencia exclusiva para mantener el orden público. Por lo tanto, "si se pretende extender los efectos de lo acordado a los demás poderes públicos y a la sociedad en su conjunto, el vehículo para ello es la implementación normativa sometida a las reglas constitucionales".

Calificar el Acuerdo en términos exclusivos de documento político comporta las siguientes consecuencias:

El texto del Acuerdo carece de fuerza vinculante con lo cual, en estricto sentido: (i) no debería ser empleado a efectos de establecer la existencia de un vínculo entre las normas de desarrollo y aquél (juicio de conexidad); (ii) en caso de lagunas o vacíos que aquejen a las disposiciones de implementación, el operador judicial no podría acudir al mismo como un criterio de interpretación válido (efecto interpretativo); y (iii) el juez constitucional no podría tomar en cuenta los contenidos del Acuerdo a efectos de determinar la validez de sus normas de ejecución (control material).

Si el Acuerdo es sólo un documento político, resulta innecesaria la discusión acerca de su jerarquía en el sistema de fuentes colombiano, es decir, debatir acerca de si se ubica por encima de la Constitución, hace parte del bloque de constitucionalidad en sentido amplio o estricto, o por el contrario, se localiza al mismo nivel que las leyes. Carecería asimismo de sentido confrontar el texto del Acuerdo de Paz con los tratados internacionales vigentes, o incluso, tratar de calificarlo en términos de fuente del derecho internacional público.

Al mismo tiempo, la ejecución de lo pactado, así como su estabilidad, dependerá de la voluntad política de las Partes. Por parte del grupo armado ilegal, mediante la realización de determinados actos de cumplimiento (vgr. desmovilización, reincorporación, entrega de menores y bienes, etcétera); y del Gobierno Nacional, por medio de la tramitación de reformas constitucionales y legales.

La tesis del documento exclusivamente político, en mi concepto, puede llegar a ser válida si un determinado acuerdo de paz no logra superar aquello que la doctrina especializada califica como "el test de juridicidad". 


\section{El test de juridicidad de los acuerdos de paz}

El derecho comparado muestra la inexistencia de un único modelo de comprensión sobre la naturaleza de los Acuerdos de Paz. De allí la preocupación de la academia por crear una metodología científica encaminada a verificar, en cada caso concreto, si se está ante un documento exclusivamente político o, por el contrario, si es un texto mixto (jurídico-político)

Los expertos Abbot, keohane, Moravcsik, Slaughter \& Snidal (2000) propusieron la realización de un "test de juridicidad", destinado a establecer si un determinado acuerdo de paz era sólo un documento politico o si, por el contario, presentaba algunos aspectos jurídicos (texto mixto). Poco después, el test de juridicidad fue retomado y ampliado por Bell, C. (2006). En líneas generales, el test está conformado por los siguientes pasos: (i) La naturaleza de las obligaciones asumidas por las Partes; (ii) El grado de precisión de los compromisos; y (iii) La delegación a un tercero para interpretar o asegurar el cumplimiento del Acuerdo de Paz.

En cuanto a la naturaleza de las obligaciones asumidas por las Partes, los citados autores traen a colación los siguientes indicadores:

- Determinar si cada una de las obligaciones del Acuerdo de paz está redactada como una regla vinculante o un principio ambiguo;

- Verificar si el Acuerdo prevé referencias al derecho internacional como base de sus compromisos;

- Analizar la intención de asegurar el cumplimiento de ambas Partes; y

- Examinar si las autoridades judiciales internas lo han empleado al momento de resolver casos concretos.

Respecto al grado de precisión de los compromisos asumidos por las Partes, los tratadistas invitan a verificar los siguientes aspectos: 
- Determinar si las Partes asumieron compromisos precisos y coherentes;

- Examinar la facilidad para determinar un incumplimiento;

- El establecimiento de objetivos a corto plazo (vgr. cese al fuego, desmovilización, etc); y

- La especificación de los medios de cumplimiento de la obligación.

Por último, en lo atinente a la delegación a un tercero para interpretar o asegurar el cumplimiento del Acuerdo de Paz, los autores proponen examinar:

- La existencia de Estados garantes o acompañantes;

- La creación de nuevos mecanismos o instituciones de verificación; y

- La delegación de la verificación de lo acordado en instancias internacionales

Abbot et al. (2000, p. 20) diseñaron el siguiente cuadro que muestras los extremos entre los cuales se mueven las tres (3) variables. Dada su importancia y claridad, nos permitimos transcribirlo:

Obligación Expresamente no

es una norma jurídica

Precisión Vaguedad

Principio

Delegación Diplomacia
Regla vinculante

(vgr. ius cogens)

Precisa, regla muy elaborada

Cortes u organismos internacionales Aplicación por Jueces internos 
En conclusión: un acuerdo de paz será considerado exclusivamente un documento político si no logra superar el test de juridicidad.

\section{La naturaleza jurídica híbrida del Acuerdo Final}

\section{Efectos de considerar un acuerdo de paz en términos de texto jurídico}

La doctrina especializada coincide en afirmar que los acuerdos de paz son textos híbridos, los cuales asumen, al mismo tiempo, componentes políticos con otros de carácter jurídico. De tal suerte que, en la práctica, tales acuerdos pueden asumir diversas formas, no siendo fácil encuadrarlos en los sistemas de fuentes del derecho internacional e interno.

En el derecho comparado, la discusión sobre la naturaleza jurídica de los Acuerdos de Paz está lejos de encontrarse zanjada. En una tesis doctoral Manzan, I.E. (2016, p. 234) afirma:

"El acuerdo político conserva un carácter atípico plural. A veces aparece como un acto privado, emanado entre particulares; en otras, como un convenio estatal, concluido entre un Gobierno $\mathrm{y}$ un movimiento insurrecto, $\mathrm{o}$ incluso como un verdadero tratado internacional. El análisis comparativo llevado a cabo entre el acuerdo político y otras normas jurídicas, evidencia su carácter versátil. Aparece claramente como una verdadera norma sui generis fluctuante".

De forma análoga, Bell (2006, p. 376) sostiene:

"Los acuerdos de paz suelen tener una naturaleza jurídica mixta, por cuanto pueden ser, al mismo tiempo: (i) un acuerdo humanitario; (ii) un documento político; (iii) un instrumento internacional regulado por el artículo $3^{\circ}$ de la Convención de Viena sobre el 
Derecho de los Tratados, (iv) un acto jurídico unilateral internacional de un Estado; y (v) en algunos casos (vgr. Timor Oriental), un acuerdo vinculante al encontrarse incluido en una Resolución del Consejo de Seguridad de la ONU"

Siguiendo con el contexto africano, Mambo (2012, p. 921), explica:

"Los actores políticos africanos recurren frecuentemente a documentos políticos para solucionar crisis surgidas de desacuerdos. Estos acuerdos políticos a menudo conllevan contenidos jurídicos, destinados a paliar las insuficiencias y lagunas de sus constituciones."

Pensar los acuerdos en paz en términos de textos mixtos conduce a reflexionar sobre los siguientes aspectos:

- En lo atinente a su incorporación al derecho interno, el debate girará entre: (i) estimar que contiene disposiciones de aplicación directa, creando de esta manera derechos y obligaciones incluso para los ciudadanos (vgr. en asuntos penales), o (ii) considerar que precisan de la adopción de normas de derecho interno, sean de rango constitucional, legal o reglamentario;

- Respecto a su jerarquía en el sistema de fuentes la controversia se planteará entre: (i) considerar que, por seguridad jurídica, lo acordado ni siquiera puede ser modificado por una reforma constitucional posterior (supraconstitucionalidad); o si (ii) lo pactado entre las partes tiene rango constitucional. En este último escenario, la discusión se planteará entre: (i) si el clausulado del Acuerdo de Paz servirá como parámetro de constitucional "para todos los efectos”, lo cual incluiría cualquier desarrollo legislativo posterior, o si, por el contrario, lo será sólo en relación con las normas de ejecución propiamente del Acuerdo de Paz; (ii) si el Acuerdo de Paz puede derogar alguna cláusula constitucional; y (iii) si el juez constitucional debe 
confrontar las normas de ejecución del Acuerdo únicamente con este último, o frente a toda la Constitución.

- Así las cosas, al ser el Acuerdo de Paz, en todo o en parte, un texto normativo, será necesario examinar los siguientes posibles escenarios de confrontación: (i) su conformidad con el orden jurídico internacional; (ii) su armonización con la Constitución vigente; y (iii) su vinculatoriedad frente a dos clases de cuerpos normativos: a) las futuras normas de ejecución del Acuerdo; y b) la legislación vigente.

- En cuanto a la estabilidad de lo acordado el debate será entre: (i) erigir en cláusulas pétreas parte o todo el Acuerdo de Paz; o (ii) permitir, con el tiempo, la introducción de ciertos cambios o modificaciones, tomando en consideración que el grupo armado ilegal ingresará a hacer parte de los escenarios de discusión política. En últimas, se trata de buscar un equilibrio entre dos grandes principios: (i) el imperativo de la seguridad jurídica y la estabilidad de lo acordado; y (ii) el principio democrático.

Considerar que, en todo o en parte, un acuerdo de paz tiene carácter jurídico no significa que tenga eficacia directa, es decir, que sea aplicado sin requerir de normas de implementación, bien sea actos legislativos, leyes o decretos.

Siendo ello así, la naturaleza jurídica del Acuerdo se revela en los siguientes escenarios:

- Efecto interpretativo: Los operadores jurídicos, en casos de lagunas o vacíos, pueden acudir al texto del Acuerdo con el fin de acordarle una comprensión mucho más integral a las normas de desarrollo;

- Juicio de conexidad: El juez constitucional debe establecer la existencia de un vínculo material entre el tema regulado en la norma de desarrollo (Acto Legislativo, Ley o decreto con fuerza de ley) y el Acuerdo Final; y 
- Juicio material: La Corte Constitucional debe examinar si las disposiciones mediante las cuales se ejecuta el Acuerdo se ajustan al mismo.

En conclusión: que un acuerdo de paz presente algunos contenidos jurídicos, no significa que tenga eficacia directa, es decir, que no requiera de la expedición de normas de desarrollo. Por el contrario, comporta erigirlo en parámetro para ejercer el control de constitucionalidad sobre las disposiciones normativas que lo desarrollen.

\section{El Acuerdo Final es un documento mixto}

En virtud del artículo $4^{\circ}$ del Acto Legislativo 01 de 2016, derogado por el Acto Legislativo 02 de 2017, es posible afirmar que el Acuerdo Final, suscrito el pasado 24 de noviembre de 2016 entre el Gobierno Nacional y la guerrilla de las FARC-EP es un documento mixto, por cuanto es, al mismo tiempo:

- Un documento político de carácter histórico;

- Parcialmente, un Acuerdo Especial, regulado por el artículo $3^{\circ}$ Común a los Cuatro Convenios de Ginebra de 1949; y

- Un texto normativo que integra el bloque de constitucionalidad en sentido amplio, pero: (i) Únicamente en relación con las normas de derecho internacional humanitario y derecho internacional de los derechos humanos; (ii) Sólo en relación con las normas de desarrollo del Acuerdo Final, sean éstas adoptadas por la vía ordinaria o mediante el Procedimiento Legislativo Especial para la Paz; y (iii) De forma temporal.

En tal sentido, la expedición del Acto Legislativo 02 de 2017 evidencia la existencia de un profundo viraje en la estrategia jurídica diseñada para brindarle seguridad y estabilidad jurídica al nuevo Acuerdo Final.

El Acuerdo de Paz inicial fue acompañado por la expedición del Acto Legislativo 01 de 2016 el cual dispuso la adopción del Procedimiento 
Legislativo Especial para la Paz o “frast track” (arts. 1-3), así como las siguientes medidas (art. 4):

- La calificación del Acuerdo de Paz, en su integridad, en términos de Acuerdo Especial (art. 3 Común a los Cuatro Convenios de Ginebra de 1949);

- Su inclusión en el bloque de constitucionalidad, en sentido estricto, "para ser tenido en cuenta durante el periodo de implementación del mismo como parámetro de interpretación y referente de desarrollo y validez de las Normas y las Leyes de Implementación y Desarrollo del Acuerdo Final";

- La creación, por vía del procedimiento legislativo especial, de un procedimiento de ley aprobatoria del Acuerdo Especial; y

- El establecimiento de un control constitucional relacionado con la aprobación de la ley aprobatoria del Acuerdo Especial, de carácter único y automático.

- Al mismo tiempo, en el Acuerdo inicial de La Habana preveía:

- La calificación del Acuerdo de Paz en términos de "Acuerdo Especial" o acuerdo humanitario;

- El depósito del texto del Acuerdo de Paz ante el Consejo Federal suizo;

- La realización, por parte del Presidente de la República, de una declaración unilateral del Estado ante las Naciones Unidas comunicando el Acuerdo Final y solicitando la incorporación del mismo a un documento del Consejo de Seguridad de las Naciones Unidas en los términos establecidos en el Acuerdo de fecha 11 de mayo de 2016;

- La fijación de una agenda legislativa prioritaria, conformada por: (i) Ley de amnistía; (ii) Acto legislativo de incorporación de la Jurisdicción Especial para la Paz; (iii) Ley de aprobación del Acuerdo Final, según acuerdo de 11 de mayo de 2016; y 
(iv) Acto legislativo de incorporación del Acuerdo Final a la Constitución Política, según acuerdo de 11 de mayo de 2016.

El Acto Legislativo 02 de 2017 deroga el artículo $4^{\circ}$ del Acto Legislativo 01 de 2016, reemplazándolo por unos instrumentos de seguridad jurídica y estabilidad de lo acordado, en los siguientes términos:

El primero artículo contiene una disposición transitoria en virtud de la cual los contenidos del Acuerdo de Paz "que correspondan a normas de derecho internacional humanitario o derechos fundamentales definidos en la Constitución Política, y aquellos conexos con los anteriores", serán obligatoriamente parámetros "de interpretación y referente de desarrollo y validez de las normas y las leyes de implementación y desarrollo del Acuerdo Final".

A renglón seguido, se dispone que las instituciones y autoridades estatales tienen la obligación de cumplir de buena fe lo acordado y que, en consecuencia, los desarrollos normativos del Acuerdo Final y su interpretación deberán "guardar coherencia e integralidad con lo acordado, preservando los contenidos, los compromisos, el espíritu y los principios del Acuerdo Final".

El segundo artículo prevé que la reforma constitucional deroga el artículo $4^{\circ}$ del Acto Legislativo 01 de 2016 “ $y$ rige a partir de su promulgación hasta la finalización de los tres periodos presidenciales completos posteriores a la firma del Acuerdo Final".

En el texto de la exposición de motivos se afirma que el proyecto de Acto Legislativo es conforme con lo previsto en el nuevo Acuerdo de Paz, suscrito el 24 de noviembre de 2016 en Bogotá. En tal sentido, se explica que la fórmula inicial para brindarle seguridad jurídica consistía en calificar el Acuerdo de La Habana en términos de Acuerdo Especial, de conformidad con el artículo 3 Común a los Cuatro Convenios de Ginebra de 1949. De igual manera, se incluía el Acuerdo Final, en su integridad, al bloque de constitucionalidad.

El nuevo Acuerdo de Paz modificó la fórmula para brindarle estabilidad jurídica a lo pactado: si bien se preserva su calificación en términos de Acuerdo Especial, ya no se incorpora al bloque de constitucionalidad, en tanto se acordó derogar expresamente el artículo $4^{\circ}$ del Acto Legislativo 01 de 2016. Al mismo tiempo, se dispone 
que únicamente las normas de Derecho Internacional Humanitario y Derechos Fundamentales definidos en la Constitución y sus conexos, "serán parámetros de interpretación y referente de desarrollo y validez de las normas y leyes de implementación y desarrollo de Acuerdo Final, unicamente por tres periodos presidenciales posteriores".

Los efectos jurídicos de la derogatoria del artículo $4^{\circ}$ del Acto Legislativo 01 de 2016, son enlistados en la "Exposición de motivos":

- El Acuerdo Final, en su calidad de Acuerdo Especial, ya no se incorpora como ley de la República;

- El Acuerdo Especial ya no ingresa a la Constitución;

- No se "incorpora el Acuerdo Final al ordenamiento jurídico colombiano"; y

- Se garantizan unas condiciones de estabilidad jurídica a lo acordado.

Al mismo tiempo, el Acuerdo de Paz, fruto de la renegociación entre el Gobierno Nacional y las FARC, prevé lo siguiente en materia de naturaleza jurídica e implementación del Acuerdo:

- El Acuerdo Final es un Acuerdo Especial. Tras su firma será depositado ante el Consejo Federal suizo y el Presidente de la República efectuará una declaración unilateral del Estado ante las Naciones Unidas, solicitando la incorporación del mismo en un documento del Consejo de Seguridad;

- Se prevé que el acuerdo se incorporará "conforme a las normas constitucionales";

- En cuanto a las prioridades legislativas se prevén, entre otros, los siguientes temas: (i) Ley de Amnistía; (ii) Acto legislativo de incorporación de la Jurisdicción Especial para la Paz, a la Constitución Política, según acuerdo del 7 de noviembre de 2016; y (iii) Acto legislativo para la incorporación de un 
artículo transitorio a la Constitución Política, según acuerdo de 9 de noviembre de 2016;

- Se suprime la referencia al "bloque de constitucionalidad en sentido estricto" y se trae a colación al Comentario número 850 del Comité Internacional de la Cruz Roja (2016), según el cual un acuerdo de paz sí puede ser considerado un "Acuerdo Especial", pero únicamente en los temas humanitarios.

Confrontando el modelo inicial de incorporación y estabilidad jurídica del Acuerdo de La Habana con el segundo, encuentro las siguientes semejanzas y diferencias:

- En ambos modelos, el Acuerdo Final es calificado en términos de "Acuerdo Especial", lo que significa que no se trata de un simple documento político sino de una fuente del derecho, precisando que, en ningún caso estamos ante un tratado internacional, sino ante lo que el artículo 3 de la Convención de Viena sobre el Derecho de los Tratados califica en términos de "Acuerdos internacionales no comprendidos en el ámbito de la presente Convención";

- A pesar de que el acuerdo de paz renegociado califica este texto en términos de "Acuerdo Especial", el Acto Legislativo 02 de 2017 omite cualquier referencia al tema, el cual sólo figura en la "Exposición de motivos".

- La principal diferencia entre ambos modelos es la jerarquía del Acuerdo Final en el sistema de fuentes: mientras que el Acto Legislativo 01 de 2016 lo incorpora directamente a la Constitución (bloque de constitucionalidad) en el proyecto de reforma constitucional es calificado en términos de "parámetro de interpretación y referente de desarrollo y validez de las normas y las leyes de implementación y desarrollo del Acuerdo Final". Lo anterior dentro de un límite material, consistente en limitarlo a los temas de derecho internacional humanitario, 
derechos fundamentales y "aquellos conexos con los anteriores”, pero acompañándolo con un instrumento de seguridad jurídica: "tres períodos presidenciales posteriores a la firma del Acuerdo Final";

- A pesar de las diferencias semánticas, en la práctica, no parecen ser muy diferentes los efectos jurídicos de calificar un determinado texto normativo en términos de "bloque de constitucionalidad", a afirmar que se erige en parámetro de interpretación y validez de otras normas jurídicas. Me atrevería a pensar que se trata, en términos coloquiales, "del mismo perro con distinto lazo".

- Por último, sin lugar a dudas, el segundo modelo es más sencillo y comprensible que el primero. El artículo $4^{\circ}$ del Acto Legislativo, en un afán por lograr seguridad jurídica y seriedad de lo acordado, resultaba ser repetitivo, farragoso y en gran medida confuso: un mismo texto -el Acuerdo Final- era calificado en términos de "Acuerdo Especial", y esa medida, se incorporaba al derecho interno a semejanza de un tratado internacional (ley aprobatoria); al mismo tiempo, se preveía que hacia parte del bloque de constitucionalidad en sentido estricto, lo cual llevaría a pensar que se trataría de una modificación automática y profunda al actual clausulado de la Constitución de 1991, pero, simultáneamente, se debía tramitar un Acto Legislativo para su incorporación a la Carta Política. La pluralidad y dispariedad de vías de incorporación del Acuerdo Final al ordenamiento jurídico colombiano podían llevar a contradicciones e interpretaciones dispares insalvables.

\section{Anotaciones adicionales sobre el Acto Legislativo 02 de 2017}

Un examen atento del texto del Proyecto de Acto Legislativo, y su correspondiente "Exposición de motivos", me suscitan las siguientes observaciones personales: 
- El texto del Acuerdo Final sigue siendo considerado un texto jurídico y no exclusivamente político. Lo anterior por cuanto: (i) se trata de un "Acuerdo Especial”, es decir, un instrumento de derecho internacional público, en cierta forma similar a un tratado internacional; y (ii) el Acuerdo es parámetro de validez e interpretación de sus normas de ejecución.

- Sostener la naturaleza jurídica del Acuerdo Final no significa que el mismo tenga aplicación directa, es decir, que no requiera normas de trasposición o incorporación al derecho interno. En otras palabras: el Acuerdo de La Habana es norma jurídica, no porque sea un texto de aplicación directa, sino por erigirse en parámetro de validez e interpretación de sus normas de ejecución. No se puede confundir la incorporación con la jerarquía de un texto normativo.

- Al mismo tiempo, el Acuerdo Final es un insumo para la elaboración y ejecución de determinadas políticas públicas, del orden nacional y territorial.

A mi juicio, el Acto Legislativo 02 de 2017 presenta, al menos, cuatro ambigüedades:

La primera ambigüedad tiene lugar cuando se afirma que el Acuerdo Final es parámetro obligatorio de "interpretación y referente de desarrollo y validez de las normas y las leyes de implementación y desarrollo del Acuerdo Final". La pregunta es: ¿a que "normas" se está haciendo alusión?; ¿se tratará de normas constitucionales? En caso afirmativo, el texto del Acuerdo Final se ubicaría por encima de las reformas constitucionales de desarrollo del mismo, lo cual, en buen romance, se denomina supraconstitucionalidad. Tal interpretación es conforme con el literal a) del artículo $1^{\circ}$ del Acto Legislativo 01 de 20016, a cuyo tenor:

“a) Los proyectos de ley y de acto legislativo tramitados mediante el Procedimiento Legislativo Especial para la Paz serán de iniciativa exclusiva del Gobierno nacional, y su contenido tendrá por 
objeto facilitar y asegurar la implementación y desarrollo normativo del Acuerdo Final para la terminación del Conflicto y la Construcción de una Paz Estable y duradera.”

La segunda ambigüedad consiste en determinar si la totalidad del Acuerdo de Paz goza de la estabilidad de los tres períodos presidenciales y si es parámetro de validez e interpretación de las normas de ejecución. A primera vista, la respuesta es negativa, por cuanto se precisa que sólo lo será en relación con los contenidos del derecho internacional humanitario "o los derechos fundamentales definidos en la Constitución Política y aquellos conexos con los anteriores”. La pregunta entonces es ¿cuáles son esos contenidos? Podría pensarse que se trata de los temas de justicia transicional, por cuanto guardan una relación directa con el conflicto armado y su terminación. Sin embargo, en gracia de discusión, el tema de la participación en política y el estatuto de la oposición, se relacionan con el ejercicio de derechos fundamentales (derechos políticos); a su vez, ciertos contenidos del tema agrario, se vinculan con el derecho fundamental al retorno, en los términos de la jurisprudencia constitucional. De tal suerte que, quizá, el tema de los cultivos ilícitos sería el único excluido con total certeza.

La tercera ambigüedad consiste en determinar la jerarquía y la estabilidad jurídica que tendrían los contenidos excluidos del artículo transitorio del texto del Proyecto de Acto Legislativo. Al no ser parámetros de la validez e interpretación de sus respectivas normas de ejecución, surgen dudas acerca de su garantía de estabilidad y cumplimiento.

La cuarta ambigüedad, pero no menos importante, consiste en sostener, como se hace en la "Exposición de motivos" que el Acuerdo Final "no se incorporará al ordenamiento jurídico interno, sino que se garantizarán unas precisas condiciones de estabilidad y seguridad jurídica”. Imagino que tales afirmaciones se soportan sobre la supresión del trámite que debía surtir la ley aprobatoria del Acuerdo Final, previsto en el artículo $4^{\circ}$ del Acto Legislativo 01 de 2016. Sin embargo, lo cierto es que mediante el artículo constitucional transitorio también se está incorporando el texto del Acuerdo Final al sistema de fuentes colombiano, aunque de forma directa. Lo anterior, por cuanto, como se explicó, se le erige en parámetro de validez e 
interpretación de las normas de ejecución, al menos en tema de DIH y derechos fundamentales, con un término de permanencia de tres períodos presidenciales.

\section{El Acuerdo Final supera el test de juridicidad}

Más allá de las consideraciones sobre el Acto Legislativo 02 de 2017, considero que el Acto Legislativo 02 de 2017 logra superar el llamado "test de juridicidad". Veamos:

En cuanto a la naturaleza de las obligaciones asumidas por las Partes, advierto que si bien muchos compromisos son programáticos y ambiguos (vgr. garantizar el acceso y la calidad de la educación rural, (punto 1.3.2.2)), también lo es que existen acuerdos asumidos en términos de deberes jurídicos.

\section{“3.4.5 Integración del Cuerpo Élite.}

Como garantía de una acción inmediata del Estado contra las organizaciones y conductas objeto de este acuerdo y su desmantelamiento, se integrará un Cuerpo Élite en la Policía Nacional con enfoque multidimensional. Las y los integrantes que conformen el Cuerpo Élite, serán seleccionados bajo un modelo especial que certifique altos estándares de idoneidad, transparencia y efectividad.” (p.86)

De igual manera, a lo largo del Acuerdo son recurrentes las alusiones al derecho internacional:

“Teniendo presente que el nuevo Acuerdo Final recoge todos y cada uno de los acuerdos alcanzados en desarrollo de la agenda del Acuerdo General suscrita en La Habana en agosto de 2012; y que para lograrlo, las partes, siempre y en cada momento, se han ceñido al espíritu y alcances de las normas de la Constitución Nacional, de los principios del Derecho Internacional, del Derecho Internacional de los Derechos Humanos, del Derecho Internacional Humanitario (Convenios y Protocolos), de lo mandado por el 
Estatuto de Roma (Derecho Internacional Penal), de los fallos proferidos por la Corte Interamericana de Derechos Humanos relativos a los conflictos y su terminación, y demás sentencias de competencias reconocidas universalmente y pronunciamientos de autoridad relativos a los temas suscritos”(p. 2)

\begin{abstract}
Algunas autoridades judiciales colombianas vienen asimismo recurriendo al texto del Acuerdo Final, con el propósito de fijar el alcance de las normas de desarrollo del mismo. Así por ejemplo, la Corte Suprema de Justicia, Sala de Casación Penal (Auto del 28 de junio de 2017) operó la siguiente remisión al texto del Acuerdo Final, en materia de agentes del Estado:

“1. Los agentes del Estado El Acuerdo Final para la Terminación del Conflicto, incluye como destinatarios del componente de justicia a los agentes del Estado que hubieren cometido delitos relacionados con éste y con ocasión del mismo, precisando que se les aplicará un tratamiento diferenciado, pero de forma equitativa, simultánea y simétrica."
\end{abstract}

De igual manera, el Acuerdo Final contiene compromisos con el elevado grado de precisión:

"La recolección y almacenamiento en contenedores del armamento individual que permanece en poder de los (as) integrantes de las FARC-EP dentro de los campamentos en las Zonas se hace de manera secuencial y en tres fases así: 1 Fase: D+90, el 30\%; 2 Fase: D+120, el 30\%; y 3 Fase: D+150, 40\% restante, según la hoja de ruta (cronograma de eventos) acordada por el Gobierno Nacional y las FARC-EP que guía el proceso del Fin del Conflicto luego de la firma del Acuerdo Final.” (p. 67)

En lo que atañe a la delegación a un tercero para interpretar o asegurar el cumplimiento del Acuerdo de Paz, el Acuerdo Final cumple asimismo con este criterio: 
"El mecanismo internacional que apoye al Tribunal para la Paz en las tareas de verificación del cumplimiento de las sanciones previsto en el numeral $53 \mathrm{~d}$ ), será un componente específico de la Misión Política de verificación de las Naciones Unidas que entrará en funcionamiento una vez concluidas las funciones de la Misión de Naciones Unidas encargada de verificar el cese al fuego bilateral y definitivo, en coordinación con la Oficina del Alto Comisionado de Naciones Unidas para los Derechos Humanos en Colombia.” (p. 166)

En conclusión: el Acuerdo Final logra superar los tres (3) pasos que integran el test de juridicidad de un acuerdo paz, a efectos de poder calificarlo como un documento mixto (jurídico-polìtico).

\section{A modo de conclusión}

Los Acuerdos de Paz suelen ser percibidos como una suerte de "cuerpo extraño" en los sistemas de fuentes del derecho. Por decirlo en términos elementales: al interior de la famosa pirámide kelseniana, no parece quedar clara la ubicación de los mismos. ¿Se trata acaso de una suerte de "Constitución paralela transitoria” ?; ¿Cómo armonizar los contenidos del Acuerdo de Paz con la Constitución vigente?; e incluso, ¿Qué tratamiento debe dársele a la teoría de los vicios de sustitución en un contexto de justicia transicional?

Cuando los acuerdos de paz, como sucede en el presente caso, no se limitan a regular la desmovilización de un grupo armado ilegal y su conversión en partido político, sino que prevén la creación de numerosas instancias de decisión política y judicial, es previsible el surgimiento de adicionales problemas de articulación entre las institucionalidades vigente y nueva.

En líneas generales, las discusiones sobre la naturaleza jurídica de los textos contentivos de lo acordado entre las partes han girado entre dos extremos: (i) considerarlos simples documentos políticos; o (ii) acordarles, total o parcialmente, un carácter de norma jurídica.

Autores como Mambo (2012) muestran que, en diversos países africanos, en los cuales se han alcanzado acuerdos de paz, las relaciones 
entre éstos y las constituciones vigentes se han movido en una doble lógica: (i) Una relación conflictiva, caracterizada por la presencia de conflictos al interior de la pirámide normativa que conduce, a su vez, a un fenómeno de desestabilización del orden constitucional; y (ii) Una cohabitación pacífica entre las disposiciones constitucionales preexistentes y los compromisos asumidos por las Partes.

En el caso colombiano, entender el Acuerdo Final como un texto mixto, y no únicamente político, contribuye enormemente a darle seguridad jurídica a lo acordado. En tal sentido, la misión del juez constitucional consistirá en alcanzar interpretaciones armónicas y coherentes entre la Carta Política y el acuerdo de paz.

\section{Referencias bibliográficas}

\section{Libros}

Bernal, Parra, Sierra, Ramelli, Caldas, Andrade \& Zambrano (2016) Reflexiones jurídicas sobre el proceso de paz, Bogotá: Universidad Externado de Colombia.

ICRC (2016) Commentary of Article 3: Conflicts without an international character. Ginebra: ICRC.

Manzan, I.E. (2016), Les accords politiques dans la résolution des conflits armés internes en Afrique, La Rochele: Université de La Rochelle.

Ramelli, A. (2004). Derecho internacional humanitario y estado de beligerancia, Bogotá: Universidad Externado de Colombia.

\section{Artículos de Revistas Especializadas}

Abbot, keohane, Moravcsik, Slaughter \& Snidal (2000). The concept of legalization, IO Foundation and the Massachusetts Institute of Technology, 54 (3).

Aïvo (2015). Le rôle des Accords Spéciaux dans la rationalisations des conflits armés non internationaux, Societé Québecoise de Droit International, 27 (1).

Bell, C. (2006). Peace agreements: their nature and legal status, American Journal of International Law, 100 (2). 
Comité International (1936) Guerre civile en Espagne, Révue internationale de la Croix-Rouge, 67 (409)

Heffes E. \& Kotlik M (2014) Special agreements as a means of enhancing compliance with IHL in non-international armed conflicts: An inquiry into the governing legal regime, International Review of the Red Cross, 2014, 96, (895)

Mambo, P. (2012). Les rapports entre la Constitution et les Accords Politiques dans les États africains: Réflexion sur la légalité constitutionnelle en période de crise. McGill Law Journal, 57 (4).

Mónaco, R (1949) Les Conventios entre belligérants”, Recueil des Cours de l'Academie de Droit International.

Rondeau, S. (2011) Participation of armed groups in the development of the law applicable to armed conflicts. International Review of the Red Cross, 93 (883).

Sassòli, M. (2010). Taking Armed Groups Seriously: Ways to Improve their Compliance with International Humanitarian Law, Journal of International Humanitarian Legal Studies, 1.

\section{Sentencias}

Corte Constitucional (18 de julio de 2016), Sentencia C-379 de 2016 [MP Vargas Silva]

Corte Constitucional (17 de mayo de 2017), Sentencia C-332 de 2017 [MP Lizarazo Ocampo]

Corte Suprema de Justicia, Sala de Casación Penal (28 de junio de 2017), Auto AP4175-2017 [MP. Salazar Cuellar] 



\section{Preguntas y respuestas sobre el derecho a la verdad y la futura Comisión que sobre el particular habrá en Colombia ${ }^{43}$}

Alejandro Valencia Villa ${ }^{44}$

\section{Introducción}

propósito de la inminente puesta en funcionamiento de la Comisión
para el esclarecimiento de la verdad, la convivencia y la no repetición contemplada en el Acuerdo de paz suscrito entre el gobierno colombiano y las Fuerzas Armadas Revolucionarias de Colombia Ejército del Pueblo (FARC - EP), resulta relevante plantear algunas inquietudes sobre lo que significa el derecho a la verdad y los propósitos de una comisión de verdad. Un mayor entendimiento puede abonar para determinar los alcances y expectativas de este mecanismo.

El presente artículo con un sentido pedagógico formula algunas preguntas al respecto e intenta dar elementos sobre dichos interrogantes.

43 Articulo resultado producto de investigación del proyecto denominado "Procesos de exigibilidad y justiciabilidad de los Derechos Humanos y el Derecho Internacional Humanitario, en el contexto nacional e internacional.” Adscrito al grupo de investigación Sociohumanistico Categoría A en Colciencias de la Facultad de Derecho de la Universidad Santo Tomás Bogotá.

44 Abogado colombiano, consultor de derechos humanos, derecho humanitario y justicia transicional. Profesor Maestría de Derechos Humanos y Derecho Internacional Humanitario de la Universidad Santo Tomás Email: valvilla@ hotmail.com 
Más que respuestas se quieren ofrecer aspectos que denotan los alcances y desafíos que implica el derecho a la verdad y cómo se puede realizar este derecho a través de una comisión de verdad.

\section{¿De qué tipo de verdad se está hablando en materia de violaciones de derechos humanos?}

En primer lugar, se trata de la verdad frente a los hechos. Es decir, saber qué pasó, contra quienes, cuándo, dónde, por quiénes, cómo fue, por qué. Determinar el tipo de violación o violaciones ocurridas, quienes fueron las víctimas; las circunstancias de modo, tiempo y lugar de esos hechos; quiénes fueron los perpetradores y cuáles fueron las razones que motivaron los hechos, son las respuestas básicas que se deben esclarecer ante una violación de derechos humanos. La inquietud básica de una víctima o de su familiar tiende a satisfacer estas incógnitas iniciales.

Las respuestas a estos interrogantes generan otras preguntas vinculadas también con los hechos. Veamos algunos ejemplos. Ante una desaparición forzada, los familiares siempre quieren saber el destino de la persona desaparecida, si está viva o muerta, y en tal caso determinar el lugar de su privación de la libertad o dónde se encuentra su cuerpo o sus restos óseos. Si los hechos ocurrieron durante un lapso de tiempo que no fue instantáneo, también se desea conocer el mayor número de detalles relacionados con el suceso. Las características de los perpetradores, su número, su fisonomía, su modo de actuar son también aspectos relevantes que se quieren conocer.

La verdad de los hechos no solo puede tener una utilidad legal sino que satisface de manera primaria el derecho a saber lo ocurrido para cualquier víctima o su familiar. Puede que la verdad de los hechos contribuya en la investigación penal del caso sobre todo para que se identifiquen a los perpetradores, se los capture y juzgue conforme a derecho y se dicte una sentencia que establezca una verdad judicial, es decir, una verdad que por su cobijo legal le otorgue un carácter de veracidad y de realidad a los sucesos de manera irrefutable. Pero además 
de esa verdad judicial, una víctima o su familiar, necesitan saber el mayor número de elementos de lo que pasó para tener una historia que les permita explicar de manera creíble lo ocurrido. La única manera de empezar a reparar lo irreparable es obtener el mayor número de respuestas y ojala no dejar interrogantes o dudas sobre lo sucedido. Acabar con las incertidumbres de los hechos es el inicio de cualquier reparación con una víctima o su familiar.

\section{¿A quién se le debe la verdad?}

La verdad se le debe a las víctimas directas o a sus familiares y a la sociedad. Esta doble dimensión del derecho a la verdad siempre debe satisfacerse.

La dimensión individual pretende que la víctima o su familiar conozcan en detalle lo que les pasó y la dimensión colectiva pretende que la sociedad, los demás, sepan que esa situación ocurrió. No solo la víctima o sus seres cercanos son los destinatarios del derecho a saber, sino que lo debe conocer la comunidad, el país y hasta la comunidad internacional. La verdad no se puede agotar en la víctima directa y/o sus allegados sino también en la sociedad. La única manera de consolidar las garantías de no repetición es que la verdad trascienda lo colectivo para construir una memoria más inclusiva que tenga en cuenta en su conjunto las violaciones de derechos humanos perpetradas.

\section{¿Quién debe decir la verdad?}

Inicialmente la verdad la deben decir los responsables de los hechos. Los perpetradores al ser los autores de los hechos cuentan con todos los elementos para dar respuestas a las inquietudes de lo ocurrido. Ellos son los únicos que pueden dar una explicación correcta de los sucesos. Tanto los autores intelectuales como materiales, como los autores individuales y colectivos, según cada caso, tienen responsabilidades frente a los hechos.

Sin embargo, las experiencias comparadas demuestran que son muy pobres las contribuciones de los responsables a la verdad. La sanción penal no es un aliciente para que ellos satisfagan el derecho a la verdad. 
Por esta razón, la justicia transicional puede dosificar las penas siempre cuando exista una alta contribución de los perpetradores en los derechos a la verdad y a la reparación. Lo que se busca es que los responsables den respuestas. Como decía Primo Levi: "la justicia no tiene que ver con el castigo al culpable (como quiere el derecho) sino con la respuesta a la injusticia y ésta se mantendrá mientras no haya respuestas”.

También las víctimas o sus familiares pueden contribuir a la verdad. Las víctimas al ser las receptoras de las violaciones pueden dar fe de manera muy precisa de qué fue lo que les ocurrió, cuándo y dónde. Tal vez no cuenten con los elementos para responder de manera fidedigna al porqué o por quiénes pero de todos modos su dicho puede ayudar a esclarecer lo sucedido. O son los familiares de las víctimas quienes por su interés legítimo en saber lo que ocurrió con su ser querido, sean los que tengan más información sobre lo sucedido.

Un aspecto adicional a la verdad expresada por los familiares es que puede tener un efecto reparador. Compartir lo vivido, así se trate de hechos graves y dolorosos, puede contribuir a asumir el trauma y los efectos de la violencia con otro significado. El ser escuchado por otros puede transformar la experiencia traumática en una forma más positiva de afrontamiento.

\section{¿Es la verdad un derecho o un deber?}

La verdad aunque en una dimensión filosófica genere preguntas hasta incertidumbres conceptuales, desde el punto de vista legal, su sentido es más preciso. La verdad es un derecho, y es un derecho humano fundamental que tiene una doble dimensión individual y colectiva. Es un derecho individual que asiste tanto a las víctimas como a sus familiares, y también tiene una dimensión colectiva, ya que la sociedad tiene derecho a conocer la verdad sobre los acontecimientos del pasado que se refieren a la perpetración de crímenes aberrantes, así como sobre las circunstancias y los motivos por los que se realizaron, a fin de evitar que se repitan en el futuro.

El derecho a la verdad es un derecho autónomo e inalienable que ha sido reconocido por el derecho internacional en los últimos años. En el sistema universal auspiciado por la Organización de Naciones Unidas 
(ONU) goza de respaldo en diversos instrumentos internacionales y en la doctrina de organismos especializados ${ }^{45}$ y en el sistema interamericano auspiciado por la Organización de Estados Americanos (OEA) ha sido desarrollado por la jurisprudencia de la Corte Interamericana y la doctrina de la Comisión Interamericana de Derechos Humanos. ${ }^{46}$

El Conjunto de principios para la protección y la promoción de los derechos humanos mediante la lucha contra la impunidad ${ }^{47}$, consagra entre otros, como principios el derecho inalienable a la verdad y el derecho de las víctimas a saber. La Convención internacional para la protección de todas las personas contra las desapariciones forzadas, señala en su artículo 24.2 que "toda víctima tiene el derecho de conocer la verdad sobre las circunstancias de la desaparición forzada, la evolución y resultados de la investigación y la suerte de la persona desaparecida". En un estudio sobre el derecho a la verdad realizado por el Alto Comisionado de las Naciones Unidas para los Derechos Humanos se dice:

El derecho a la verdad está estrechamente vinculado a otros derechos, como el derecho a un recurso efectivo, el derecho a la protección jurídica y judicial, el derecho a la vida familiar, el derecho a una investigación eficaz, el derecho a ser oído por un tribunal competente, independiente e imparcial, el derecho a obtener reparación, el derecho a no sufrir torturas ni malos tratos y el derecho a solicitar y a difundir información. ${ }^{48}$

45 Una sistematización de la doctrina del sistema de Naciones Unidas hasta el 2012 puede verse en (Andreu, 2012)

46 Una sistematización de la doctrina del sistema interamericano hasta el 2104 puede verse en Comisión Interamericana de Derechos Humanos, Derecho a la verdad en América, Washington, 2014.

47 Anexo al Informe de Diane Orentlicher, experta independiente encargada de actualizar el conjunto de principios para la lucha contra la impunidad, presentados a la Comisión de Derechos Humanos de las Naciones Unidas en el 2005, E/CN.4/2005/102/Add.1 del 8 de febrero de 2005.

48 Estudio sobre el derecho a la verdad, Informe de la Oficina del Alto Comisionado de las Naciones Unidas para los Derechos Humanos, E/CN.4/2006/91, 9-01 
Además, como consecuencia de lo dicho, la verdad es también un deber, y un deber en doble vía. Por una parte, los victimarios y responsables de los hechos tienen el deber de decir la verdad, de manera completa y veraz, deber que tienen con las víctimas, con las comunidades afectadas y con la sociedad en general. Por otra parte, también existe un deber de recordar, que le compete a las víctimas y/o sus familiares tanto sobre su ser querido afectado como en relación con los hechos y los demás aspectos vinculados con esta experiencia como son los impactos y las formas de resistencia. Pero ese deber de recordar, trasciende al individuo afectado y también le compete a la sociedad. Un país que ha sufrido graves violaciones de derechos humanos si busca construir una ética de convivencia, tiene el deber de recordar esos episodios, por dolorosos que sean. El deber de recordar permite llamar a las cosas como son y ese reconocimiento es un primer paso para que una sociedad asuma su pasado y escriba su historia.

Esa doble faceta de derecho y deber, hacen de la verdad un concepto complejo que refleja una condición ética imprescindible para la humanidad. Los derechos y los deberes son las dos caras de la misma moneda, el anverso y el reverso de nuestra conciencia moral. Decía Albert Camus: "si la preocupación por el deber disminuye es porque cada vez se tienen menos derechos. Sólo tiene fuerza de cumplir con su deber quien es intransigente en cuanto a sus derechos" (Valencia, 2003, pp. 106 y 107).

\section{¿Cuáles son las relaciones del derecho a la verdad con la justicia y la reparación?}

El derecho a la verdad junto con el deber de recordar y el derecho de las víctimas a saber, pretende esclarecer graves violaciones de derechos

de 2006, párrs. 57, 58 y 59. Véase también el derecho a la verdad, Informe de la Oficina del Alto Comisionado de las Naciones Unidas para los Derechos Humanos, A/HRC/5/7, 7 de junio de 2007, párrs. 81 a 86, así como el Informe del Relator Especial sobre la independencia de los magistrados y abogados, E/CN.4/2006/52, 23 de enero de 2006, párr. 60. 
humanos. Por este propósito tiene relaciones muy estrechas con la justicia y la reparación, hasta el punto que pueden considerarse como interdependientes e indivisibles.

Si no hay verdad no se da la justicia y cuando falta la justicia, la verdad se niega fácilmente. El escritor Yosef Yerushalmi decía que es posible que el antónimo del olvido no sea la memoria sino la justicia. Y justo ahora que se está implementando el proceso de paz entre el gobierno colombiano y las FARC - EP, es muy esclarecedora la afirmación de Norberto Bobbio que la mejor alternativa frente a la guerra no es la paz sino la justicia pues según ésta la victoria es de quien tiene la razón, mientras que según aquella la razón es de quien tiene la victoria. (Bobbio, 1992, p. 102).

La mejor reparación para una víctima y para la sociedad es la verdad. La reconstrucción individual o colectiva pasa por conocer el pasado así traiga historias tristes y dolorosas. El saber y el recordar son elementos que buscan satisfacer daños ocasionados que buscan reparar acontecimientos irreparables.

La no repetición de hechos de violencia se empieza a garantizar con el derecho a la verdad. El Nunca más empieza por saber la verdad. Para determinar que políticas públicas o reformas legales deben implementarse como garantías de no repetición es fundamental que estas partan de un conocimiento a fondo de lo ocurrido, puesto que tales garantías deben apuntar a transformar realidades que permitieron o impulsaron las violaciones de derechos humanos.

\section{¿Qué es una Comisión de verdad?}

Las comisiones de verdad son uno de los mecanismos restaurativos con que cuenta la justicia transicional para abordar los crímenes del pasado. En los países que tras un pasado de violencia transitan hacia la paz y/o la democracia, se impone esclarecer lo ocurrido, satisfaciendo de manera particular los derechos de las víctimas a la verdad, a la justicia y a la reparación.

Las comisiones de verdad permiten abordar el derecho a la verdad, el deber de recordar y el derecho de las víctimas a saber. Según Priscilla Heyner, las comisiones de verdad pueden contribuir a alcanzar 
algunos de estos objetivos: "descubrir, clarificar y reconocer formalmente abusos del pasado; responder a necesidades concretas de las víctimas; contribuir la justicia y al rendimiento de cuentas; hacer un esbozo de la responsabilidad institucional y recomendar reformas, y alentar la reconciliación y reducir los conflictos en torno al pasado" (Hayner, 2008, p. 54).

En su discurso de aceptación del premio Nobel, Aleksandr Solzhenitsin abordó las interrelaciones de violencia y mentiras:

La violencia no existe y no puede existir por si sola: está invariablemente entrelazada con la mentira. Están vinculadas del modo más íntimo, orgánico y profundo: la violencia no puede ocultarse detrás de nada excepto las mentiras, y las mentiras no tienen nada que las sostenga salvo la violencia. Cualquiera que haya proclamado alguna vez la violencia como método debe elegir inexorablemente la mentira como su principio. En sus comienzos la violencia actúa abiertamente e incluso se enorgullece de sí misma. Pero tan pronto como cobra fuerza y se instaura firmemente... ya no puede existir sin ocultarse en una neblina de mentiras (Citado por J,M, Coetzee, 2007, p. 165).

Una comisión de verdad sólo puede aspirar a reducir el número de mentiras que circulan sin que nadie las desmienta, a cambiar el marco público del discurso y la memoria, pero nadie las puede acusar de fracaso porque no hayan cambiado las conductas y las instituciones. No era su función. El pasado es siempre una discusión y la función de estas comisiones, consiste en purificarla para disminuir el porcentaje de mentiras permisibles (Ignatieff, 1999, p. 165).

Si como Hannah Arendt dijo, el primer acto del totalitarismo es matar el impulso legal de los ciudadanos, parte de la función que tienen instituciones de las transiciones como las comisiones de la verdad es revivir ese impulso. Un importante impedimento para la resurrección de ese impulso legal ha sido la histórica incapacidad del sistema judicial para encausar a los responsables de las violaciones de derechos humanos (Barahona y otros, 2002, p. 447). 


\section{¿Las comisiones de verdad reemplazan la justicia?}

Las comisiones de verdad no sustituyen a la justicia. El deber de garantía en materia de justicia siempre está en cabeza del Estado y no puede ser delegado o transferido a ningún otro ente. Las comisiones de verdad se convierten en un uno de los mejores aliados de la justicia, ya que contribuyen a esclarecer muchos hechos donde la justicia no ha llegado y de esa manera la complementan. El Conjunto de Principios para la protección y la promoción de los derechos humanos mediante la lucha contra la impunidad de las Naciones Unidas, ${ }^{49}$ señala en su principio $8^{\circ}$ sobre la delimitación del mandato de una comisión de verdad que:

[p]ara evitar los conflictos de competencia se debe definir claramente el mandato de la comisión, que debe estar de acuerdo con el principio de que la finalidad de las comisiones no consistirá en reemplazar a la justicia, tanto civil o administrativa como penal. En particular, únicamente los tribunales penales tienen competencia para determinar la responsabilidad penal individual a fin de pronunciarse, llegado el caso, sobre la culpabilidad y seguidamente sobre la pena.

Por su parte, los Principios de Chicago sobre Justicia Transicional establecen lo siguiente sobre las comisiones de verdad y los posibles vínculos con una acción judicial:

[1] as comisiones de la verdad no son tribunales judiciales, pero pueden apoyarse en el ejercicio de acciones legales, ya sea civiles o penales. Sin embargo, los vínculos con los procesos judiciales

49 Anexo al Informe de Diane Orentlicher, experta independiente encargada de actualizar el conjunto de principios para la lucha contra la impunidad, presentados a la Comisión de Derechos Humanos en el 2005, E/CN.4/2005/102/ Add. 1 del 8 de febrero de 2005. 
deben estar cuidadosamente diseñados para mantener las protecciones fundamentales del debido proceso y no deben comprometer la imparcialidad, la independencia o la competencia de la comisión de la verdad.

Nada impide que estas comisiones puedan recabar pruebas y preservarlas, como lo indica el mismo Principio $8^{\circ}$ de Naciones Unidas ya mencionado, incluso nada obsta para el informe final de una comisión de verdad o sus investigaciones sean valoradas en procesos judiciales, como de hecho ha ocurrido. Sobre el particular ha dicho la Corte Interamericana de Derechos Humanos:

Las verdades históricas que a través de ese mecanismo se logren, no deben ser entendidas como un sustituto del deber del Estado de asegurar la determinación judicial de responsabilidades individuales o estatales por los medios jurisdiccionales correspondientes, ni con la determinación de responsabilidad internacional que corresponda a este Tribunal. Se trata de determinaciones de la verdad que son complementarias entre sí, pues tienen un sentido y alcance propios, así como potencialidades y límites particulares, que dependen del contexto en el que surgen y de los casos y circunstancias concretas que analicen. En efecto, la Corte ha otorgado especial valor a los informes de Comisiones de la Verdad o de Esclarecimiento Histórico como pruebas relevantes en la determinación de los hechos y de la responsabilidad internacional de los Estados en diversos casos que han sido sometidos a su jurisdicción (CIDH, 2003, párrs 131 y 134) $)^{50}$

Conforme a los estándares internacionales ya citados, una comisión de verdad no puede sustituir la justicia, por tal razón, la justicia nacional, mixta o internacional, independiente del mandato aprobado para una

50 También en: Corte Interamericana de Derechos Humanos, Caso Zambrano Vélez y otros, supra nota 17, párr. 128, y Caso La Cantuta, supra nota 16, párr. 224. 
eventual comisión de verdad, debe continuar con su deber de investigar, juzgar y sancionar a los responsables de los crímenes.

Por esta razón, una comisión de verdad tampoco afecta la eventual competencia de la Corte Penal Internacional (CPI) y por el contrario complementa su trabajo. Por un lado, en relación con hechos anteriores al $1^{\circ}$ de noviembre de 2002, fecha de entrada en vigor del Estatuto de la CPI en Colombia, una comisión de verdad puede contribuir como un mecanismo de justicia transicional a esclarecer crímenes que no caben dentro de su competencia. Por el otro, en relación con hechos posteriores al $1^{\circ}$ de noviembre de 2002 que pueden ser de competencia de la CPI y que sean conocidos e investigados por una comisión de verdad, dichas investigaciones pueden ser aprovechas y valoradas por la CPI. Nada le impide a la CPI para que de acuerdo a sus criterios evalúe tanto el Informe Final de una comisión de verdad como las fuentes que tuvo a su disposición para llegar a sus conclusiones.

\section{¿La verdad que busca una comisión se agota en los hechos?}

No. Además de los hechos, hay otros aspectos centrales que deben ser abordados. No solo los hechos en sí son importantes sino los contextos en que ocurrieron. Las dinámicas locales, regionales y nacionales ayudan a entender lo sucedido. Develar las estructuras legales o ilegales que cometieron dichas conductas, así como el modus operandi de las mismas, también hace parte de dicho esclarecimiento.

Los impactos y las formas de resistencia también hacen parte de la verdad. La violencia tiene efectos graves sobre las personas y las comunidades. Dichas consecuencias deben esclarecerse en sus diferencias facetas, no solo en lo que respecta a los daños físicos y materiales sino en lo psicosocial. Un enfoque psicosocial sobre dichos impactos en lo individual, familiar y comunitario es imprescindible para dar una mirada más completa de la verdad.

Qué hicieron o no hicieron las víctimas ante esos hechos también hace parte de esa búsqueda de la verdad. Las respuestas, los 
afrontamientos, las acciones pero también las inercias son un componente que debe ser documentado. Esas respuestas están muy vinculadas con la justicia, la reparación y las garantías de no repetición pero también con formas organizativas o con resistencias colectivas o con mecanismos personales de defensa. Una verdad más integral debe responder también a estos interrogantes.

\section{¿Cuál debe ser la centralidad del trabajo de una comisión de verdad?}

La centralidad de las víctimas es fundamento prioritario para el trabajo de una comisión de verdad. Ellas deben ser las protagonistas. A ellas sobre todo es a quienes se las debe escuchar porque quien cuenta es quien acaba haciendo historia y por eso son las víctimas quienes la deben contar. La toma de testimonios, individuales y colectivos, y las audiencias públicas, son herramientas metodológicas capitales para este proceso. Nadie puede hablar en nombre de la víctima y nadie le puede robar su palabra.

La búsqueda de la verdad debe estar orientada hacia ellas. La verdad tiene sentido es en función de las víctimas. La gran deuda de la verdad es con ellas. Una justicia transicional desde abajo debe rescatar la voz de los humillados y ofendidos, la memoria de los débiles, de los vencidos. Se debe recordar no solo para que la historia no se repita sino sobre todo para hacer justicia a las víctimas. Tomar en serio la figura de la víctima es aceptar que lo que ocurrió forma parte de la realidad. Las víctimas no están de paso, no son pasado, sino que se quedan y transforman la realidad. No se puede hablar de verdad al margen de ellas ya que ellas develan la parte silenciada de la realidad, pero que forma parte de la verdad (Reyes, 2003, p. 138).

Hablar en nombre de otro es robarle su voz, su palabra y su silencio. Nadie puede hablar en lugar de la víctima. Nadie le puede usurpar su palabra. El modo ético de acercarse a la víctima no es tomar la palabra en nombre de la víctima, sino escucharla. El testimonio de las víctimas es la fuente principal de la verdad. 
Dice Emmanuel Lévinas que el testimonio consiste en la asunción de mi responsabilidad ante el otro, de ahí que las comisiones de verdad se construyan a partir de testimonios. Escribía Primo Levi: "Nosotros los que damos nuestro testimonio, los que escribimos, no somos los verdaderos testigos, los verdaderos testigos están muertos. Los verdaderos testigos son aquellos que llegaron hasta el final del enfrentamiento con la Gorgona. Nosotros no somos sino testigos parciales, que sobrevivimos por casualidad, por lo que sólo podemos contar una parte de la experiencia" (Primo, 1989, p. 47).

Las comisiones de verdad construyen la verdad con tres tipos de testigos que son a su vez son víctimas: víctimas con experiencias directas de violación; víctimas con experiencias observacionales, que fueron testigos de la violación; víctimas con aprendizajes de situaciones traumáticas experimentadas por otras personas.

\section{¿Cómo se logra la participación de las víctimas?}

La participación y el empoderamiento de las víctimas en un proceso de verdad es un aspecto bien relevante, sobre todo porque la verdad se construye primordialmente con ellas. La verdad no se agota con un testimonio ni con un informe. De ahí que la pregunta por el cómo resulta capital, máxime cuando lo que se busca es brindar un acompañamiento a las víctimas. Con ellas se debe construir una metodología participativa para el proceso de búsqueda de la verdad resulte reparador en sí. En la medida que una comisión de verdad logre incorporar desde el principio y en todas sus etapas dicha participación se puede consolidar una verdad más inclusiva.

Un enfoque diferencial se impone para buscar una satisfacción integral del derecho a la verdad. Es relevante diseñar mecanismos adecuados y distintos que permitan que víctimas de muy diversa condición den su verdad: niñ@s, adultos mayores, mujeres, sectores LGTBI, indígenas, afrodescendientes, raizales, palenqueros, pueblos rom, personas con discapacidad, entre otros. No es lo mismo la toma de testimonios o la participación de un adolescente a una mujer indígena. 


\section{¿Las comisiones de la verdad deben establecer las responsabilidades de quienes cometieron violaciones de derechos humanos?}

Establecer las responsabilidades en las violaciones de derechos humanos y derecho internacional humanitario ha sido parte del sentido y también de la controversia de distintas comisiones de la verdad. De forma explícita algunas comisiones de la verdad, como la de Chile o Guatemala, no señalaron responsabilidades individuales, tal y como está recogido en los acuerdos o decreto de creación. La comisión de verdad de El Salvador o la Comisión Nacional sobre Desaparición de Personas de (CONADEP) en Argentina podían nombrar responsables, e incluyeron en sus informes algunos listados de perpetradores o personas que consideraban responsables en determinados casos. Otras Comisiones más recientes, como las de Paraguay o Ecuador, incluyeron en su mandato la posibilidad de determinar responsabilidades individuales, con independencia de las cuestiones judiciales. La comisión de verdad y reconciliación de Perú tenía entre su mandato el de "identificar, en la medida de lo posible, las presuntas responsabilidades” en los casos analizados. La comisión de verdad y reconciliación de Sudáfrica, que es la única que tenía un mandato cuasijudicial, identificó a los perpetradores de las violaciones cometidas, y en su caso el comité de amnistía examinó sus casos y determinó si era aplicable un indulto individual.

La cuestión de la responsabilidad ha sido tema de debate jurídico en diferentes comisiones de verdad. El derecho al debido proceso en el ámbito judicial ha sido señalado por quienes se oponen a esta determinación de responsabilidad, dado que la comisión de verdad no es un órgano jurisdiccional. La no determinación de responsabilidades individuales se ha señalado también como una medida que podría facilitar la colaboración de ciertos perpetradores o sectores con información sobre los hechos.

Pero, por otra parte, el derecho a la verdad no puede verse limitado por el miedo a señalar responsables o la coacción de los mismos 
sobre el trabajo de una comisión de verdad o las víctimas. Y además el conocimiento de las responsabilidades es un mecanismo básico de la lucha contra la impunidad y forma parte del sentido de la investigación y del reconocimiento de la verdad.

También las comisiones de verdad han señalado las responsabilidades políticas, más allá de las de carácter directo en la ejecución de las violaciones de derechos humanos. Estas responsabilidades históricas o políticas han tocado a líderes o partidos políticos, sectores empresariales o expresidentes o incluso fuerzas o gobiernos extranjeros en el marco de la guerra fría en otros casos, como en las Comisiones de Guatemala, Perú, Paraguay o El Salvador.

Las comisiones de verdad tienen que velar por esos principios básicos: uno, el nivel de convicción y/o prueba con el que determinar la responsabilidad, y dos, las garantías de escuchar a los nombrados como responsables y mantener garantías legales (no judiciales). El Conjunto de principios para la protección y la promoción de los derechos humanos mediante la lucha contra la impunidad, señala en el Principio 8 que la comisión no sustituye a la justicia, civil administrativa o penal, y por lo tanto son los tribunales los que pueden determinar la culpabilidad penal y la pena en su caso.

Según el principio $8^{\circ}$., además de las directrices establecidas en los principios 12 y 13, el mandato de una comisión de investigación ha de incorporar o reflejar las siguientes estipulaciones: “... c) Sus investigaciones se referirán a todas las personas acusadas de presuntas violaciones de los derechos humanos y/o del derecho internacional humanitario, tanto si las ordenaron como si las cometieron, si fueron autores o cómplices, y tanto si se trata de agentes del Estado o de grupos armados paraestatales o privados relacionados de algún modo con el Estado, como de movimientos armados no estatales. Sus investigaciones podrán abordar asimismo la función de otros protagonistas para facilitar las violaciones de los derechos humanos y del derecho internacional humanitario".

Mientras el Principio 9, relativo a las garantías relativas a las personas acusadas señala algunas directrices a tener en cuenta para que la comisión identifique a los autores en su informe, entre ellas el contraste de la información con diferentes fuentes que la comisión considera 
consistentes, y la escucha a las personas nombradas como responsables. Señala entonces que: “a) La comisión deberá tratar de corroborar la información que implique a esas personas antes de dar a conocer su nombre públicamente; b) Las personas implicadas deberán haber sido escuchadas o, al menos, convocadas con tal fin, y tener la posibilidad de exponer su versión de los hechos en una audiencia convocada por la comisión mientras realiza su investigación, o de incorporar al expediente un documento equivalente a un derecho de réplica".

Después de su trabajo, la comisión de verdad debería poder con una valoración de “sí o no" para la mención en el Informe Final de un presunto responsable, aunque estos puedan tener matices (por ejemplo respecto al tipo de responsabilidad o la contundencia de las pruebas). Pero las categorías que tienden a hacer una escala del sí, intermedio y no, tienden a que lo intermedio sea muy ambiguo. Se trata es de valorar si con los medios de convicción existentes se puede decir sí o no, y si hay un mini debido proceso debería ser suficiente, sobre todo señalando que la mención no tiene efectos legales ni penales, sino para establecer responsabilidades éticas y políticas.

La comisión podría tratar de establecer criterios sobre: responsabilidades intelectuales y materiales; responsabilidades por acción y por omisión; responsabilidad del superior y responsabilidades de mandos medios y bajos; responsabilidades personales e institucionales (aquí no solo estados, sino grupos armados no estatales, transnacionales, empresas, etc); responsabilidades nacionales e internacionales (gobiernos extranjeros).

\section{¿Debe existir un tratamiento simétrico o diferenciado en la adjudicación de responsabilidades entre los agentes del Estado y los miembros de los grupos armados no estatales?}

No es políticamente conveniente ni jurídicamente correcto dar un tratamiento simétrico tanto a los miembros de los grupos al margen 
de la ley con los agentes del Estado, cuando desde un punto legal no es posible equiparar la responsabilidad de un agente del Estado con la de un miembro de un grupo armado al margen de la ley, el primero representa la legalidad y el segundo precisamente es un ilegal. El deber de respeto y garantía de los derechos humanos está en cabeza del Estado según el derecho internacional de los derechos humanos (art. 1.1 de la Convención Americana sobre Derechos Humanos y artículo 2 del Pacto Internacional de Derechos Civiles y Políticos) y por lo tanto se exige una mayor exigencia de respeto por parte de los funcionarios públicos y por ende un mayor reproche a sus conductas violatorias.

Además, en el derecho penal, la teoría del Disvalor de Autor formulada por Gunter Stratenwerth, señala que cuando se comete un injusto, es decir, una acción antijurídica que es culposa o dolosa, al autor se le exige actuar conforme a derecho. Por esta razón, conforme al disvalor de autor, a los miembros de la fuerza pública se les exige un comportamiento ceñido al derecho más exigente que al de un particular, en razón del papel que cumplen como agentes del Estado, guardianes del orden público y garantes de la Constitución (Stratenwerth, 2006). ${ }^{51}$

La experiencia latinoamericana demuestra que medidas transicionales que beneficiaron a agentes del Estado comprometidos en violaciones de derechos humanos bajo la modalidad de amnistías generales e incondicionales o auto amnistías patrocinaron la impunidad. ${ }^{52}$

51 Véase también Fernando Velásquez, Manual de Derecho Penal, Parte General, Cuarta edición, Ediciones Jurídicas Andrés Morales, Bogotá, 2010.

52 La jurisprudencia de la Corte Interamericana de Derechos Humanos en casos de Chile (caso Almonacid Arellano y otros vs. Chile, sentencia de 26 de septiembre de 2006) y Perú (caso Barrios Altos vs Perú, sentencia del 14 de marzo de 2001) ha considerado inadmisibles las auto amnistías y ha rechazado en casos de Brasil (Caso Gomes Lund y otros ("guerrilha do araguaia”) vs. Brasil, sentencia de 24 de noviembre de 2010) y Uruguay (caso Gelman vs Uruguay, sentencia del 24 de febrero de 2011) las amnistías generales y sin condiciones. La sentencia de Corte Constitucional de Colombia C-579/13 hace un recuento bien pormenorizado de las amnistías en el contexto latinoamericano (punto 6.2.4) y colombiano (punto 6.3). 
Aunque algunos sostengan que las responsabilidades entre agentes del Estado y miembros de grupos armados no estatales tiendan a ser más simétricas en un conflicto armado, puesto que la relación es más horizontal, contraria a la relación vertical propia de una dictadura militar (Orozco, 2009, p. 77), la responsabilidad del Estado no se puede minimizar y mucho menos igualarse a la de un particular (Universidad Nacional, 1996). La responsabilidad del Estado frente a todas las personas sujetas a su jurisdicción, ya sean legales o ilegales, es asimétrica, es decir, es mayor la responsabilidad del Estado con las personas que la responsabilidad de éstas con aquél. No se puede generalizar sin límites el concepto de derechos humanos para aplicarlo indistintamente a acciones del Estado o de los particulares (Universidad Nacional, 199, p. 29).

Los ciudadanos delinquen mientras que las autoridades públicas son responsables de asegurar la vigencia de los derechos fundamentales. Esta distinción no es puramente formal, y tiene sentido pues es la que permite dar rigor al análisis de la responsabilidad jurídica y política de un Estado en materia de derechos humanos. Si se elimina tal distinción, entonces termina siendo lo mismo que sea el poder público quien asesine a que sean los particulares quienes lo hagan: en Estados Unidos o en Alemania no se respetaría el derecho a la vida (pues hay asesinatos) de la misma forma en que no se respeta en Colombia (Gallón, 1991, p. 41).

En el Informe Final de la Comisión de Verdad de Sudáfrica, se dice: “... debe decirse que quienes poseen el mayor poder de abusar deben cargar con la mayor responsabilidad. El hecho de que el Estado, que posee el monopolio de la fuerza pública y tiene a su cargo proteger los derechos de los ciudadanos, utilice esa fuerza para violar dichos derechos constituye un asunto de mayor gravedad" (Hilb, 2014, p. 71). Parafraseando a Dostoyevsky, incluyéndole una necesaria perspectiva de género: "El Estado es responsable de todo y de todos las mujeres y los hombres sobre todo y más que todas las mujeres y los hombres" 


\section{¿Se deben promover los reconocimientos de responsabilidades como parte de la satisfacción del derecho a la verdad?}

Además de establecer quiénes son los responsables, el promover el reconocimiento de responsabilidades, está vinculado de manera estrecha con el derecho de la verdad y el derecho de la reparación, puesto que de alguna forma satisface las necesidades de las víctimas. Aunque dicho reconocimiento se puede dar fuera o dentro de una comisión de verdad, este escenario ofrece un espacio ideal para su realización.

Un punto de discusión es si los grupos armados no estatales tienen la obligación de reconocer responsabilidades. Si, en la medida que pueden cometer abusos similares a los Estados. Hay dos ejemplos internacionales poco mencionados sobre prácticas de reparaciones simbólicas de los grupos armados no estatales. El CNA (Consejo Nacional Africano) a comienzos de la década de 1990 implementó interrogatorios públicos para examinar acusaciones de abusos contra presuntos informantes en sus filas. Se realizaron audiencias públicas donde se recogieron pruebas y Nelson Mandela aceptó la responsabilidad colectiva en nombre de los dirigentes del grupo e hizo un pedido de disculpas. El IRA (El Ejército Republicano Irlandés) desde finales del siglo pasado proporcionó datos de la ubicación de los cuerpos de supuestos informantes que fueron desaparecidos, reconoció los hechos, se disculpó por el sufrimiento que causó a las familias por no haber dado esa información y exoneró a los individuos a los que antes había catalogado como informantes. Y también en otra ocasión, el 16 de julio de 2002, se disculpó en términos generales por "todos los no combatientes muertos y heridos”, por causa de la organización (Ron, 2011).

En Colombia, en algunos hechos, los grupos guerrilleros han reconocido responsabilidades. Las FARC-EP en el caso de la masacre de Bojayá (Chocó) del 2 de mayo de 2002, en el que murieron 119 personas y resultaron heridas cerca de 98 más por el lanzamiento de un cilindro bomba, y el Ejército de Liberación Nacional (ELN) en el caso de Machuca, ocurrido en el municipio de Segovia (Antioquia) el 18 de octubre de 1998, en el que murieron 84 personas quemadas tras 
dinamitar un oleoducto. También se han presentado reconocimientos de responsabilidades de otros actores en el marco de procesos judiciales, como es caso de líderes paramilitares a propósito de las sentencias dictadas dentro de la Ley de justicia y de agentes del Estado en sentencias proferidas por el Consejo de Estado o por la Corte Interamericana de Derechos Humanos.

Sin embargo, el reconocimiento de la responsabilidad, ya sea de actores no estatales o estales, debe ir más allá de una simples disculpas o de un pedido de perdón sino que se debe tratar de una declaración formal, pública y concreta que no niegue los hechos en cuestión, que por el contrario los reconozca de manera expresa, que rechace cualquier tipo de violación de derechos humanos e infracciones al derecho internacional humanitario, declaración que debe ir dirigida tanto a las víctimas directas y/o sus familiares como a la sociedad.

Debe haber arrepentimiento y remordimiento en el reconocimiento de responsabilidad (Hilb, 2014). La reivindicación del perdón como virtud política es un asunto harto polémico. Solicitar el perdón de la víctima puede liberar de la culpa al victimario. Como decía Paul Ricouer "El perdón es una forma de curación de la memoria, la terminación de su duelo; liberado el peso de la deuda, la memoria es liberada para los grandes proyectos. El perdón da un futuro a la memoria”.

\section{¿Cómo regula el Acuerdo de paz del gobierno colombiano con las FARC - EP la comisión de la verdad?}

La comisión para el esclarecimiento de la verdad, la convivencia y la no repetición (punto 5.1.1) tendrá una duración de 3 años y contará con una fase preliminar de 6 meses para preparar todo lo necesario para su funcionamiento. No se señala un período exacto de investigación y sería la propia comisión quien lo establezca, pudiendo fijar un período contextual más amplio y uno de esclarecimiento más corto. Como objetivos centrales, deberá contribuir al esclarecimiento de lo ocurrido, promover y contribuir al reconocimiento de las víctimas y promover la convivencia en los territorios. Tendrá 11 comisionados, 
de los cuales no podrán ser más de 3 extranjeros. Los esfuerzos de la comisión estarán centrados en garantizar la participación de las víctimas y podrá celebrar audiencias públicas. Esclarecerá las prácticas y hechos que constituyen graves violaciones de derechos humanos y graves infracciones al derecho internacional humanitario. Contará con enfoques territorial, diferencial (menciona los pueblos indígenas) y de género, así como de los impactos de las violaciones. Establecerá reconocimientos voluntarios de responsabilidades individuales y colectivas. Será un mecanismo extrajudicial pero asegurará a quienes participen debidas garantías y un trato no discriminatorio. Deberá implementar una estrategia de difusión, pedagogía y relaciones con los medios de comunicación. Elaborará un informe final y tomará medidas para preservar los archivos una vez finalizado su trabajo. Se creará un comité de seguimiento y monitoreo a la implementación de las recomendaciones.

El 4 de abril de 2017 mediante decreto presidencial se pone en marcha la comisión, decreto que transcribe los objetivos, los criterios orientadores, el mandato y las funciones señaladas en el Acuerdo de paz. Lo más novedoso del decreto es lo relativo al acceso a la información, en particular de cómo será el acceso a la información reservada y a las funciones que deben cumplir el presidente, el secretario general y el pleno de los comisionados.

\section{¿Cuáles son algunos desafíos de la futura comisión de verdad de Colombia?}

Varios retos y desafíos se ciernen en el corto plazo para la conformación, estructuración y funcionamiento a cabalidad de esta Comisión de Verdad. Lo primero pasa por la designación de los 11 comisionadas y comisionadas que no solo garanticen su independencia, autonomía e imparcialidad sino que tengan la suficiente sensibilidad para priorizar las demandas de las víctimas y que demuestren un compromiso por el respeto y garantía de los derechos humanos. Así mismo, que el personal que laborará en dicha comisión tenga esos mismos perfiles. Se espera que el proceso de postulaciones, selección y designación 
de las comisionadas y comisionados se realice durante agosto y octubre de 2017, con el propósito que la comisión empiece sus labores lo antes posible. Ojala hacia principios del año 2018 la Comisión abra sus puertas, lo que implicaría que previamente haya agotado su etapa preliminar en la que tendrá que definir su metodología, el despliegue territorial en las diversas regiones del país e iniciar una amplia campaña pedagógica para convocar a las víctimas del conflicto armado colombiano para que se acerquen a rendir sus testimonios.

El período de los años objeto de investigación debe ser lo suficientemente amplio para que esté acorde con la gravedad de la violencia política. Aunque el período que enmarque las violaciones de derechos humanos e infracciones al derecho internacional humanitario para la toma de testimonios pueda ser menor que el de un contexto más general, dicho período debe ser lo suficientemente extenso para abarcar el mayor número posible de víctimas. No se compadece con el pasado de violencia un lapso de tiempo que no cumpla con las expectativas de esclarecer el mayor número posible de hechos. Aunado a lo anterior se deben investigar las violaciones más graves ocurridas durante el conflicto armado que vulneraron los derechos a la vida, a la integridad personal y sexual, a la dignidad personal y a la libertad personal, así como analizar los casos más paradigmáticos que por su masividad e impactos hacen parte de la historia reciente de Colombia.

Garantizar los diversos enfoques que debe tener la comisión no es tarea fácil en un país que durante varias décadas ha tenido miles de víctimas a lo largo y ancho del país, en donde no se ha respetado el género, la edad, la raza, las etnias, las opiniones políticas, entre otras. No solo esos enfoques deben estar circunscritos a los hechos sino también a los impactos y a las diversas formas de afrontamiento, así como a la inclusión de una metodología diferencial.

Aunque la comisión sea un mecanismo extrajudicial ese no es un obstáculo para que pueda establecer responsabilidades de quienes perpetraron las violaciones. Ojala la comisión puede avanzar más que otras comisiones oficiales que ha tenido América Latina en desentrañar la verdad de los victimarios. Responsabilidades institucionales, individuales, colectivas, nacionales e internacionales hacen parte de esa función de esclarecimiento. Es de esperar que quienes 
cometieron los hechos de violencia, si piensan ser favorecidos con las medidas de justicia que trae el acuerdo de paz, contribuyan de manera efectiva contando la verdad, asumiendo su responsabilidad y pidiendo perdón.

El Informe Final debe ser lo suficientemente comprensivo para que pueda ofrecer una verdad oficial de lo sucedido en Colombia durante el conflicto armado. Su contenido no puede reducirse simplemente a la confrontación armada entre el gobierno nacional y las FARC - EP, sino que debe incluir el esclarecimiento de hechos perpetrados por otros actores como es el caso de los grupos paramilitares y otras organizaciones guerrilleras. Además, la comisión no se agota con el Informe Final sino que debe ofrecer un proceso de acompañamiento a las víctimas que pueda promover la convivencia en los territorios, justo el tercer objetivo señalado en el acuerdo. El seguimiento de sus recomendaciones será capital para contribuir a reconstruir el tejido social de las comunidades afectadas. Por lo demás, los diferentes componentes del sistema integral de verdad, justicia, reparación y no repetición deben estar lo suficientemente equilibrados y coordinados, implementados de manera coherente para que todos cumplan con sus propósitos y no generen desbalances en cada uno de sus componentes.

Es de esperar que con este mecanismo contribuya de manera significativa a construir un marco público de un discurso de memoria que establezca un nuevo paradigma oficial de verdad, ya que los actuales estándares de la justicia transicional señalan que es uno de los mecanismos que de forma más satisfacen el derecho a la verdad. Si la justicia será modulada con un sistema de penas donde no serán tan cruciales las penas privativas de la libertad, se requiere que existan altas dosis de verdad para que la justicia transicional esté más acorde con los estándares internacionales. Como ha escrito Michael Ignatieff, una comisión de verdad por lo menos disminuye un número relevante de mentiras que existen en contextos en los cuales han ocurrido graves violaciones de derechos humanos o infracciones graves al derecho internacional humanitario. Es de esperar que la que muy próximamente empiece a funcionar a Colombia, acabe con algunas de esas mentiras y funde una verdad que contribuya de manera más decida a la paz entre los colombianos y colombianas. 


\section{Referencias bibliográficas}

Alexandra Barahona de Brito, Paloma Aguilar Hernández y Carmen González Enríquez (editores), Las políticas hacia el pasado, Istmo, Madrid, 2002, p. 447.

Comisión Interamericana de Derechos Humanos, Derecho a la verdad en América, Washington, 2014.

Corte Interamericana de Derechos Humanos, Caso Myrna Mack Chang Vs. Guatemala. Fondo, Reparaciones y Costas. Sentencia de 25 de noviembre de 2003. Serie C No. 101

Federico Andreu, El derecho a la verdad y derecho internacional, Comisión Colombiana de Juristas, Bogotá, 2012.

Fernando Velásquez, Manual de Derecho Penal, Parte General, Cuarta edición, Ediciones Jurídicas Andrés Morales, Bogotá, 2010.

Gunter Stratenwerth, Disvalor de acción y disvalor de resultado, Segunda edición, Hammurabi. Argentina, 2006.

Gustavo Gallón Giraldo (editor), Derechos humanos y conflicto armado en Colombia, Comisión Colombiana de Juristas Seccional Colombiana, Bogotá, 1991.

Iván Orozco Abad, Justicia Transicional en tiempos de deber de memoria, Editorial Temis, Universidad de los Andes, Bogotá, 2009.

Citado por J.M. Coetzee, “Censura y polémica: Solzhenitsin”, en J.M. Coetzee, Contra la censura, ensayos sobre la pasión por silenciar, Editorial Debate, Barcelona, 2007.

Michael Ignatieff, El Honor del guerrero, Taurus, Barcelona, 1999.

Norberto Bobbio, El problema de la guerra y las vías de la paz, Editorial Gedisa, Barcelona, 1992

Oficina del Alto Comisionado de las Naciones Unidas para los Derechos Humanos, E/CN.4/2006/91, 9 de enero de 2006.

Oficina del Alto Comisionado de las Naciones Unidas para los Derechos Humanos, A/HRC/5/7, 7 de junio de 2007.

Primo Levi, Los hundidos y los salvados, Muchnik Edtores S.A., Barcelona, 1989.

Priscilla Hayner, Verdades innombrables, el reto de las comisiones de verdad, Fondo de Cultura Económica, México, 2008. 
Relator Especial sobre la independencia de los magistrados y abogados, E/ CN.4/2006/52, 23 de enero de 2006.

Reyes Mate, Memoria de Auschwitz, actualidad moral y política, Editorial Trotta, Madrid, 2003.

Ron Dudai, "Salvar la brecha: reparaciones simbólicas y grupos armados", en Revista Internacional de la Cruz Roja, diciembre de 2011, No. 883.

TRC, report, volumen I, cap 4, párr. 80, citado por Claudia Hilb “Justicia, reconciliación, perdón ¿Cómo fundar una comunidad después del crimen?" en Claudia Hilb, Philppe - Joseph Salazar y Lucas G. Martin (editores), Lesa humanidad, Argentina y Sudáfrica: reflexiones después del mal, Katz Editores, Buenos Aires, 2014.

Universidad Nacional de Colombia, Facultad de Derecho, Ciencias Políticas y Sociales, Asociación Nacional de Especialistas en Derechos Humanos, La responsabilidad en derechos humanos, Bogotá, 1996.

Valencia Villa, Diccionario Espasa Derechos Humanos, Espasa, Madrid 2003, pp. 106 y 107. 

SEGUNDA PARTE

GÉNERO Y DERECHOS HUMANOS 



\title{
El principio de igualdad y no discriminación y los enfoques diferenciales como herramienta ${ }^{53}$
}

\author{
Liliana Rocío Chaparro Moreno ${ }^{54}$
}

\section{Introducción}

$\mathrm{D}$ esde hace un poco más de una década en Colombia es frecuente el uso de la categoría 'enfoques diferenciales' tanto en políticas públicas como en el trabajo diario de organizaciones sociales e instituciones estatales, sin que su contenido, alcance y forma de materialización sea clara y uniforme, lo cual más que contribuir al avance en la protección de derechos de grupos históricamente discriminados, en ocasiones lleva a un uso meramente retórico que no aporta al objetivo para el cual fueron creados.

53 Articulo resultado producto de investigación del proyecto denominado "Procesos de exigibilidad y justiciabilidad de los Derechos Humanos y el Derecho Internacional Humanitario, en el contexto nacional e internacional.” Adscrito al grupo de investigación Sociohumanistico Categoría A en Colciencias de la Facultad de Derecho de la Universidad Santo Tomás Bogotá.

54 Abogada de la Universidad Nacional de Colombia y docente de la Maestría de defensa de los derechos humanos y el derecho internacional humanitario ante organismos, tribunales y cortes internacionales de la Universidad Santo Tomás, sede Bogotá. Documento elaborado en septiembre de 2017. Email lilianachaparro@usantotomas.edu.co 
Este documento pretende ofrecer unos mínimos conceptuales que permitan iniciar un diálogo abierto sobre lo que son y no son los enfoques diferenciales, sus posibilidades y sus limitaciones, en consonancia con los avances del principio de igualdad y no discriminación en el marco del Derecho Internacional de los Derechos Humanos.

Para ello, el texto se divide en tres partes: 1 . El sustento del principio de igualdad y no discriminación; 2. El concepto de enfoques diferenciales y; 3. Elementos de aproximación a una herramienta.

\section{Principio de igualdad y no discriminación}

Todos los tratados internacionales de protección de derechos humanos incorporan una cláusula que incluye la igualdad y no discriminación no solo como un derecho autónomo, sino como un principio, es decir, como un elemento orientador de la protección de todos los derechos (Shelton, 2008).

En el caso de la Convención Americana sobre Derechos Humanos (CADH), el artículo 1 señala el compromiso que adquieren los Estados de "respetar los derechos y libertades reconocidos en ella y [de] garantizar su libre y pleno ejercicio a toda persona que esté sujeta a su jurisdicción, sin discriminación alguna por motivos de raza, color, sexo, idioma, religión, opiniones políticas o de cualquier otra índole, origen nacional o social, posición económica, nacimiento o cualquier otra condición social" (subrayado propio).

Según la interpretación reiterada de la Corte Interamericana de Derechos Humanos (Corte IDH), esto significa que los Estados no solo deben proteger de manera autónoma el derecho a la igualdad de las personas, sino que todos los derechos humanos deben garantizarse sin ningún tipo de discriminación (OC-18/03, Caso Veliz Franco, p. 204; Caso Duque, p. 93; Caso Flor Freire, p. 111; Caso I.V., p. 239). De allí que erradicar cualquier forma de discriminación no solo contribuye a garantizar la igualdad sino a restablecer las condiciones para que todos los derechos humanos sean satisfechos (Comité de Derechos Humanos, 1989. parágrafo 1). 
El alcance de este principio es de tal magnitud que ha sido declarado como parte del ius cogens, es decir, no puede ser desconocido bajo ninguna circunstancia, ni siquiera en estados de excepción, por ser inherente a la naturaleza y dignidad humana: "Sobre él descansa el andamiaje jurídico del orden público nacional e internacional y permean todo el ordenamiento jurídico" (Corte IDH, Caso Duque, p. 91; Caso Flor Freire, p. 109; Caso IV, p. 238). Además, su dimensión es tal que no solo ilumina toda la actuación estatal sino que genera efectos inclusive con respecto a particulares (Corte IDH, OC-18/03).

Para el caso del Sistema Interamericano, existe adicionalmente la Convención Interamericana contra toda forma de discriminación e intolerancia, que establece la siguiente definición de discriminación, la cual ha sido desarrollada de forma similar por la Corte IDH (Caso Atala, p. 81; Caso Duque, p. 90):

Discriminación es cualquier distinción, exclusión, restricción o preferencia, en cualquier ámbito público o privado, que tenga el objetivo o el efecto de anular o limitar el reconocimiento, goce o ejercicio, en condiciones de igualdad, de uno o más derechos humanos o libertades fundamentales consagrados en los instrumentos internacionales aplicables a los Estados Partes.

La discriminación puede estar basada en motivos de nacionalidad, edad, sexo, orientación sexual, identidad y expresión de género, idioma, religión, identidad cultural, opiniones políticas o de cualquier otra naturaleza, origen social, posición socioeconómica, nivel de educación, condición migratoria, de refugiado, repatriado, apátrida o desplazado interno, discapacidad, característica genética, condición de salud mental o física, incluyendo infectocontagiosa, psíquica incapacitante o cualquier otra.

Este concepto de discriminación incorpora tres elementos, todos los cuales deben coexistir para que se configure la afectación al principio, puesto que no todo acto de distinción es arbitrario, con lo cual no toda distinción es discriminatoria (Corte IDH, OC-4/84, parágrafo 56; Comité DESC, 2009, parágrafo 13). Los elementos son: 1. Cualquier distinción, exclusión, restricción o preferencia; 2. Basada en algún motivo prohibido; 3. Cuyo objetivo (intencionalidad) o efecto (resultado), sea el de anular o limitar el reconocimiento, goce o ejercicio de algún derecho. 
En este sentido, el principio de igualdad y no discriminación comporta dos dimensiones: la formal (respecto de leyes que no discriminen y procuren cerrar las brechas de la desigualdad) y la material (referida al respeto, protección y garantía efectiva de todos los derechos sin ningún tipo de discriminación de facto). A su vez, implica por lo menos tres deberes: el de abstención de realizar acciones que creen de jure o de facto situaciones de discriminación; el de adoptar medidas positivas para revertir o cambiar situaciones discriminatorias y; el de protección frente a actos y prácticas de terceros que mantengan las situaciones discriminatorias ‘bajo su tolerancia o aquiescencia' (Corte IDH, Caso Duque, p. 92; Caso Flor Freire, p. 110; Caso IV., p. 238. Caso Karen Atala, p. 80. Caso Jessica Lenahan, p. 109).

Esta definición es amplia y recoge la discriminación no solo intencionada (la que tiene por objeto discriminar), sino la denominada discriminación indirecta (cuyo resultado es anular o menoscabar derechos aún cuando no haya la voluntad o consciencia de hacerlo), de tal forma que normas o actuaciones que parecen neutras pueden violar este principio por las repercusiones negativas y los impactos desproporcionados que provocan en ciertas poblaciones (Corte IDH, Caso Fecundación in vitro, p. 286, 287; Comité DESC, 2009, parágrafo 10.b).

El Derecho Internacional de los Derechos Humanos ha avanzado en la identificación de los 'motivos prohibidos', siendo la Convención Interamericana contra toda forma de discriminación e intolerancia la que establece de forma detallada un número importante de motivos, sin que sea una lista cerrada. Sobre este punto, es importante resaltar que la argumentación de discriminación por alguno de esos motivos tiene un carácter contextual y relacional, es decir, el que una persona sea discriminada por un motivo de los enunciados dependerá del contexto en el que se desarrolle el acto (puesto que no en todos los contextos tiene relevancia el motivo) y su observancia se verá en relación con el grupo que no es discriminado (puesto que para comprender la arbitrariedad de la decisión o trato deberá compararse qué habría pasado si la persona no estuviera inmersa en el motivo alegado, es decir, si no fuera parte del grupo poblacional discriminado). 
Para efectos de este documento es de especial importancia tener en cuenta que el requisito de los motivos es amplio y puede contemplar situaciones y personas que contextualmente sean discriminadas inclusive perteneciendo a grupos privilegiados, como podría ocurrir con un extranjero europeo discriminado en Colombia en ciertos contextos, basándose en el motivo de su nacionalidad, idioma y origen social, o un hombre discriminado por su sexo, sin embargo, ello no significa que ambos no se encuentren en una condición de privilegio por estos motivos en relación con el contexto sociocultural colombiano o en relación con las mujeres. Más allá de estas situaciones que serían probablemente puntuales, el espíritu de la citada Convención y del principio de igualdad y no discriminación apunta a reconocer que hay ciertos grupos poblacionales que por su sola pertenencia a los mismos pueden ser objeto de discriminación y, de hecho, son desproporcionadamente afectados por actos de discriminación por encontrarse en un contexto sociocultural que, basándose en estereotipos, prejuicios y estigmas, los considera inferiores. De allí que la Corte IDH haya señalado que es incompatible con la noción de igualdad 'toda situación que, por considerar superior a un determinado grupo, conduzca a tratarlo con privilegio; o que, a la inversa, por considerarlo inferior, lo trate con hostilidad o de cualquier forma lo discrimine del goce de derechos que sí se reconocen a quienes no se consideran incursos en tal situación de inferioridad' (Corte IDH, OC-4/84, parágrafo 55).

Recientemente, en el caso IV contra Bolivia, la Corte Interamericana interpretó que la protección del artículo 1.1 de la $\mathrm{CADH}$ establece unos criterios diferenciadores (o motivos prohibidos), que 'aluden a: i) rasgos permanentes de las personas de los cuales éstas no pueden prescindir sin perder su identidad; ii) grupos tradicionalmente marginados, excluidos o subordinados, y iii) criterios irrelevantes para una distribución equitativa de bienes, derechos o cargas sociales' (Corte IDH, Caso IV, p. 240). En el mismo sentido ya se había pronunciado la Corte Constitucional colombiana al agrupar en estas mismas categorías los criterios diferenciadores (C371/2000; C-481 de 1998). 
La hipótesis que quiero sostener en este documento, es que los enfoques diferenciales hacen alusión al primero de estos criterios, es decir, a la protección particular de aquellas personas que pertenecen a grupos poblacionales identificados por rasgos de los cuales no pueden prescindir so pena de perder su identidad y que, al identificarse como tales, se encuentran en una situación de subordinación en el marco de relaciones sociales que los consideran inferiores. Si bien es cierto cualquier persona puede ser víctima de discriminación, existe una mayor probabilidad de ser discriminada si la persona hace parte de uno de estos grupos sociales considerados inferiores - justamente por la existencia de esta jerarquía social - y, por esta razón, el tipo de actuación que se demanda del Estado es distinta y tiene un carácter reforzado al estar ligada a contextos de histórica discriminación.

\section{Concepto de 'enfoques diferenciales'}

La protección internacional del principio de igualdad y no discriminación tiene su correlato en el artículo 13 de la Constitución Nacional, el cual exige tanto de manera formal como material la protección del derecho a la igualdad. Dicho esto, no solo es legítimo sino una obligación derivada de las normas nacionales e internacionales la adopción de mecanismos que garanticen que tanto de jure como de facto todas las personas sean protegidas a fin de evitar cualquier acto que resulte discriminatorio.

En este contexto, el uso de la noción de enfoques diferenciales ha sido específicamente desarrollado en Colombia en el marco de la defensa y protección de los derechos de la población víctima del conflicto armado y, con el tiempo, se ha extendido a la mayoría de políticas públicas.

Su génesis se encuentra en dos principales fuentes: de un lado la jurisprudencia de la Corte Constitucional en la sentencia T-025 de 2004, que si bien no usa exactamente esta expresión, sí reconoce que ciertas poblaciones requieren de 'ayuda' y 'atención diferencial', lo cual dio lugar a diversos autos de seguimiento que se concentraron en el reconocimiento de las diferencias que debían obtener una respuesta 
distinta por parte del Estado. De otro lado, el ACNUR en sus informes impulsó el uso de esta categoría, entendiéndola de la siguiente manera:

\begin{abstract}
“Según Donny Meertens, el enfoque diferencial es "un método de análisis que toma en cuenta las diversidades e inequidades en nuestra realidad con el propósito de brindar una adecuada atención y protección de los derechos (...) Parte de los principios básicos del libre ejercicio de los derechos, de la equidad y del reconocimiento de las diferencias entre los grupos poblacionales. Emplea un análisis de la realidad que pretende (en particular) hacer visibles las diferentes formas de discriminación contra aquellas poblaciones consideradas diferentes" (ACNUR, 2007, p. 243, 244).
\end{abstract}

El uso de esta expresión fue ampliándose a la sociedad civil organizada y a las políticas públicas, generando una variedad de conceptualizaciones. A manera de ejemplo, la Ley 1448 de 2011 lo define así: "El principio de enfoque diferencial reconoce que hay poblaciones con características particulares en razón de su edad, género, orientación sexual y situación de discapacidad. Por tal razón, las medidas de ayuda humanitaria, atención, asistencia y reparación integral que se establecen en la presente ley, contarán con dicho enfoque (...)" (art. 13). El Subcomité Técnico de Enfoque Diferencial del Sistema Nacional de Atención y Reparación Integral a las Víctimas (SNARIV) lo define como "un principio rector de la política pública para la prevención, atención, asistencia y reparación integral a las víctimas desde su dimensión individual y colectiva, que permite focalizar nuestra mirada y reconocer que hay poblaciones con características particulares en razón de su edad, género, orientación sexual y discapacidad; (...) y en razón de su pertenencia étnica (...)" (2014). El Departamento para la Prosperidad Social (DPS) lo entiende como "el instrumento jurídico idóneo para revertir o evitar los procesos y actos que generan las condiciones actuales o históricas de discriminación e impiden el goce efectivo de derechos" (2015).

Estos ejemplos de definición, si bien pueden ser parecidos, acentúan algunos aspectos (como las 'características particulares' o 'las 
condiciones actuales o históricas de discriminación’) y eliminan otros (como el método de análisis), por lo cual resulta útil proponer elementos que sean coincidentes y tiendan a materializar el principio de la igualdad.

Este documento propone que se entienda que los enfoques diferenciales son un método o herramienta de análisis que permite observar las diferencias y los modos en los que se han constituido condiciones de discriminación histórica en contra de determinados grupos basándose en sus rasgos de carácter inmutable, los cuales causan violaciones particulares a sus derechos - ya sea directamente o por sus impactos -, y limitan la posibilidad de un desarrollo pleno de sus derechos humanos basado en el respeto al principio de igualdad y no discriminación ${ }^{55}$.

De allí que no toda diferencia entre grupos sociales pueda asociarse a los enfoques diferenciales. Tal y como ha venido evolucionando el uso del concepto, podemos afirmar que esta expresión se limita a aquellas diferencias que son inherentes a las personas e inmutables, siendo esto último "una característica difícil de controlar de la cual una persona no puede separarse a riesgo de sacrificar su identidad" (CIDH, 2010, p. 94).

Básicamente esos rasgos inmutables pueden asociarse a las siguientes categorías: 1. La identidad de género, orientación sexual y diversidad corporal; 2. La raza y la etnia; 3 . La edad y; 4. La discapacidad. Este listado no es exhaustivo y no niega el deber de los Estados de tener en consideración las situaciones de especial vulnerabilidad en que se encuentran ciertas personas. Así, otras variables que podrían generar exclusión o subordinación como la pobreza, la victimización, la religión, la afiliación política, el liderazgo, entre

55 En un sentido similar, la Oficina del Alto Comisionado de las Naciones Unidas para los Derechos Humanos entiende los enfoques diferenciales como "un método de análisis y una guía para la acción. En el primer caso, emplea una lectura de la realidad que pretende hacer visibles las formas de discriminación contra aquellos grupos o pobladores considerados diferentes por una mayoría o por un grupo hegemónico. En el segundo caso, toma en cuenta dicho análisis para brindar adecuada atención y protección de los derechos de la población" (OACNUDH, s.f.). 
otras, no se encuentran incluidas dentro de las categorías de enfoques diferenciales, básicamente porque no son rasgos inherentes a las personas, no son inmutables y no hacen presumir la discriminación, aún cuando pueden jugar un rol determinante en la violación de derechos. Por ello es preciso alertar sobre la importancia de hacer dialogar los enfoques diferenciales con estas otras condiciones que necesariamente afectan la vivencia de las personas y pueden aumentar los efectos de la discriminación.

Un ejemplo puede resultar de utilidad: tal como lo ha mencionado la Corte Constitucional colombiana, toda la población desplazada forzadamente se encuentra en una situación de debilidad manifiesta, no obstante, "en algunos casos se conjugan en las víctimas de desplazamiento condiciones adicionales -relativas a la salud, el sexo, la edad, la raza, etc.- que maximizan su estado de debilidad manifiesta, aún frente a otros desplazados. Esta población demanda un esfuerzo superior del aparato estatal encauzado a atender con un enfoque diferencial su urgente necesidad de vivienda" (Corte Constitucional, sentencia T-661/2016. Subrayado propio).

Como puede verse, es posible y necesario distinguir entre dos categorías: personas en situación de debilidad manifiesta y personas inscritas a grupos protegidos a través de los enfoques diferenciales (que pueden estar también en situación de debilidad manifiesta). En el primer caso se trata de personas o grupos que requieren de una especial atención del Estado porque sus derechos se encuentran en riesgo, sin que esa vulneración se asocie necesariamente a una histórica discriminación o a la consideración social de su inferioridad y sin que su pertenencia al grupo obedezca a un rasgo inherente e inmutable. Tal es el caso de sindicalistas, personas que profesan una religión, o afiliación política, personas en pobreza, etc. En el segundo caso, por el contrario, debe presumirse la discriminación por el motivo de pertenecer a ese grupo, dado que esa condición es inherente a la persona e inmutable y hay una situación de histórica discriminación y consideración de inferioridad que exige del Estado no solo proteger los derechos para evitar que sean vulnerados, sino crear condiciones que tiendan a eliminar las causas estructurales que hacen que ese grupo haya sido históricamente discriminado. 
En el primer grupo, el de identidad de género, orientación sexual y diversidad corporal, asociado a los rasgos de sexo y género, encontramos como históricamente discriminadas a las mujeres, personas con orientaciones sexuales e identidades de género no hegemónicas y personas intersex. Los hombres cisgénero y heterosexuales son quienes se encuentran en el lugar de privilegio por estos rasgos y la discriminación se asocia al machismo y la homofobia, en el marco del sistema patriarcal.

En el segundo grupo, el de raza y etnia, encontramos que en Colombia han sido históricamente discriminados personas y colectivos afros, indígenas, palenqueros, rom y raizales. Escapan de la discriminación las personas mestizas para el contexto colombiano ${ }^{56}$ y la discriminación se asocia al racismo.

En el tercer grupo referido a la edad, resultan como históricamente discriminados los niños, niñas, adolescentes y personas adultas mayores. Están en posición de privilegio las personas adultas y la discriminación se asocia al adultocentrismo.

En el cuarto grupo sobre la discapacidad, resultan históricamente discriminadas aquellas personas que tienen diversidades mentales, intelectuales, físicas y sensoriales. La posición de privilegio la ostentan quienes no poseen esas diversidades y la discriminación se asocia al capacitismo.

Todos estos grupos han sido beneficiarios de tratados y/o declaraciones internacionales de Derechos Humanos específicos, de los cuales los más relevantes se presentan en la siguiente tabla ${ }^{57}$ :

56 Esto es por supuesto objeto de amplios debates académicos y sociales que aunque no se desconocen no anulan la afirmación de la posición de discriminación.

57 Aunque claramente los tratados y las declaraciones tienen una naturaleza jurídica distinta, incluyo las declaraciones como manifestación de un sector importante de la comunidad jurídica internacional que apunta hacia la protección de ciertos grupos poblacionales. 
TABLA NO. 1

Grupos han sido beneficiarios de tratados y/o declaraciones internacionales de Derechos Humanos

\begin{tabular}{|c|c|c|c|c|}
\hline Enfoque & $\begin{array}{l}\text { Grupo } \\
\text { protegido }\end{array}$ & $\begin{array}{l}\text { Sistema } \\
\text { Universal }\end{array}$ & $\begin{array}{l}\text { Sistema } \\
\text { Interamericano }\end{array}$ & \begin{tabular}{|l} 
Otros \\
instrumentos \\
de \\
importancia $^{1}$
\end{tabular} \\
\hline \multirow{2}{*}{$\begin{array}{l}\text { Identidad } \\
\text { de género, } \\
\text { orientación } \\
\text { sexual y } \\
\text { diversidad } \\
\text { corporal }\end{array}$} & Mujeres & $\begin{array}{l}\text { Convención } \\
\text { sobre la } \\
\text { Eliminación } \\
\text { de Todas las } \\
\text { Formas de } \\
\text { Discriminación } \\
\text { contra } \\
\text { la Mujer } \\
\text { (CEDAW), } \\
\text { 1979. }\end{array}$ & $\begin{array}{l}\text { Convención } \\
\text { Interamericana } \\
\text { para Prevenir, } \\
\text { Sancionar } \\
\text { y Erradicar } \\
\text { la violencia } \\
\text { contra la mujer } \\
\text { (Convención de } \\
\text { Belem do Pará), } \\
1994 .\end{array}$ & |--- \\
\hline & $\begin{array}{l}\text { Personas con } \\
\text { orientaciones } \\
\text { sexuales e } \\
\text { identidades } \\
\text { de género no } \\
\text { hegemónicas } \\
\text { y personas } \\
\text { intersex }\end{array}$ & $\begin{array}{l}\text { Declaración } \\
\text { sobre } \\
\text { Identidad } \\
\text { Sexual y } \\
\text { Orientación } \\
\text { de Género } \\
\text { presentada a } \\
\text { la Asamblea } \\
\text { General de la } \\
\text { ONU el } 18 \text { de } \\
\text { diciembre de } \\
2008 .\end{array}$ & $\begin{array}{l}\text { Resoluciones } \\
\text { de la Asamblea } \\
\text { General de } \\
\text { la OEA ( } 8 \\
\text { resoluciones } \\
\text { entre } 2008 \\
\text { y } 2016, \\
\text { disponibles en } \\
\text { http://www.oas. } \\
\text { org/es/cidh/lgtbi/ } \\
\text { enlaces/ }\end{array}$ & $\begin{array}{l}\text { Principios de } \\
\text { Yogyakarta. } \\
\text { Principios } \\
\text { sobre la } \\
\text { aplicación de } \\
\text { la legislación } \\
\text { internacional } \\
\text { de derechos } \\
\text { humanos en } \\
\text { relación con } \\
\text { la orientación } \\
\text { sexual y la } \\
\text { identidad de } \\
\text { género, } 2006 .\end{array}$ \\
\hline $\begin{array}{l}\text { Raza y } \\
\text { etnia }\end{array}$ & $\begin{array}{l}\text { Personas y } \\
\text { colectivos } \\
\text { afros, } \\
\text { indígenas, } \\
\text { palenqueros, } \\
\text { rom y raizales }\end{array}$ & $\begin{array}{l}\text { Convención } \\
\text { Internacional } \\
\text { sobre la } \\
\text { Eliminación } \\
\text { de todas las } \\
\text { Formas de } \\
\text { Discriminación } \\
\text { Racial, } 1965 .\end{array}$ & $\begin{array}{l}\text { Convención } \\
\text { Interamericana } \\
\text { contra el Racismo, } \\
\text { la Discriminación } \\
\text { Racial y Formas } \\
\text { Conexas de } \\
\text { Intolerancia, } 2013 \\
\text { Declaración } \\
\text { Americana sobre } \\
\text { los derechos de los } \\
\text { pueblos indígenas, } \\
2016 .\end{array}$ & $\begin{array}{l}\text { Convenio } \\
169 \text { de la } \\
\text { Organización } \\
\text { Internacional } \\
\text { del Trabajo } \\
\text { sobre pueblos } \\
\text { indígenas y } \\
\text { tribales, } 1989 .\end{array}$ \\
\hline
\end{tabular}




\begin{tabular}{|c|c|c|c|c|}
\hline Enfoque & $\begin{array}{l}\text { Grupo } \\
\text { protegido }\end{array}$ & $\begin{array}{l}\text { Sistema } \\
\text { Universal }\end{array}$ & $\begin{array}{l}\text { Sistema } \\
\text { Interamericano }\end{array}$ & $\begin{array}{l}\text { Otros } \\
\text { instrumentos } \\
\text { de } \\
\text { importancia }{ }^{1}\end{array}$ \\
\hline \multirow[b]{2}{*}{ Edad } & $\begin{array}{l}\text { Niños, niñas } \\
\text { y adolescentes }\end{array}$ & $\begin{array}{l}\text { Convención } \\
\text { sobre los } \\
\text { Derechos del } \\
\text { Niño, } 1989 .\end{array}$ & --- & --- \\
\hline & $\begin{array}{l}\text { Personas } \\
\text { adultas } \\
\text { mayores }\end{array}$ & --- & $\begin{array}{l}\text { Convención } \\
\text { Interamericana } \\
\text { sobre la } \\
\text { Protección de } \\
\text { los Derechos } \\
\text { Humanos de } \\
\text { las Personas } \\
\text { Mayores, } 2015 . \\
\end{array}$ & --- \\
\hline Discapacidad & $\begin{array}{l}\text { Personas con } \\
\text { diversidades } \\
\text { mentales, } \\
\text { intelectuales, } \\
\text { físicas y } \\
\text { sensoriales }\end{array}$ & $\begin{array}{l}\text { Convención } \\
\text { sobre los } \\
\text { derechos de las } \\
\text { personas con } \\
\text { discapacidad, } \\
2006 .\end{array}$ & $\begin{array}{l}\text { Convención } \\
\text { Interamericana } \\
\text { para la } \\
\text { Eliminación } \\
\text { de todas las } \\
\text { Formas de } \\
\text { Discriminación } \\
\text { contra las } \\
\text { Personas con } \\
\text { Discapacidad, } \\
\text { 1999. }\end{array}$ & --- \\
\hline
\end{tabular}

Fuente: Elaboración propia

Como puede verse, estos cuatro grandes bloques de población han sido objeto de mecanismos internacionales de protección que, aunque en su mayoría no establecen derechos específicos, sí buscan la toma de medidas puntuales y transversales para lograr equilibrar condiciones de poder desiguales que merman su capacidad de ejercer plenamente la totalidad de sus derechos humanos. Aparte de estos grupos poblacionales, en el caso del Sistema Interamericano no existen otros tratados que protejan a grupos en específico y en el caso del Sistema Universal solo se cuenta en adición con la Convención internacional sobre la protección de los derechos de todos los trabajadores migratorios y de sus familiares de 1990. Esto da cuenta de la relevancia que el Derecho Internacional de los Derechos Humanos ha dado a estas poblaciones y su interés particular por protegerlas de la discriminación. 
Visto desde otro ángulo, solo se encuentran al margen de estos cuatro bloques de poblaciones protegidas los hombres cisgénero heterosexuales, mestizos, adultos y sin discapacidades, es decir, la minoría de la población. Sobre todas las demás personas recae una presunción de discriminación y deben activarse mecanismos de análisis de sus realidades a fin de identificar si esos rasgos inmutables tienen un rol en la eventual violación de sus derechos o sus impactos y, en todo caso, a fin de prevenir que sus derechos se vean amenazados como producto de dichos rasgos.

De allí que resulte absolutamente necesario que los enfoques diferenciales no se circunscriban a la experticia de ciertas personas conocedoras del tema, sino que se transversalicen para alcanzar la mayor cantidad de población posible. Por ello, apuntar hacia una herramienta de análisis puede resultar fructífero a fin de materializar el principio de igualdad y no discriminación, para lo cual a continuación se presentan algunos elementos.

\section{Elementos de aproximación a una herramienta}

Teniendo claro que los enfoques diferenciales constituyen una herramienta, este apartado pretende aportar algunos elementos básicos para el análisis tanto de situaciones abstractas para la formulación de políticas públicas, como de situaciones concretas para dar respuesta a violaciones a los derechos humanos de personas o grupos en específico.

Debe aclararse que los enfoques diferenciales, como método para garantizar el principio de igualdad y no discriminación, deben activarse de dos maneras: 1 . A través de políticas y programas específicos que sirvan como medidas afirmativas para cerrar las brechas de desigualdad entre los grupos históricamente discriminados y, 2. De manera transversal a todas las políticas públicas, a fin de que tengan en cuenta las particularidades de cada sector y eviten una neutralidad que podría constituir discriminación indirecta.

Para cualquiera de estas formas de aplicación, al igual que para el análisis de situaciones concretas, deben tenerse en consideración como 
mínimo tres escenarios: i. el contextual, ii. el de las violaciones a los derechos y iii. el de los impactos. Cada uno de ellos debe a su vez ser estudiado atendiendo a análisis diferentes y teniendo en cuenta que son situados espacio-temporalmente y relacionales, tal como se detalla a continuación:

FIGURA NO. 1

Escenarios a tener en cuenta
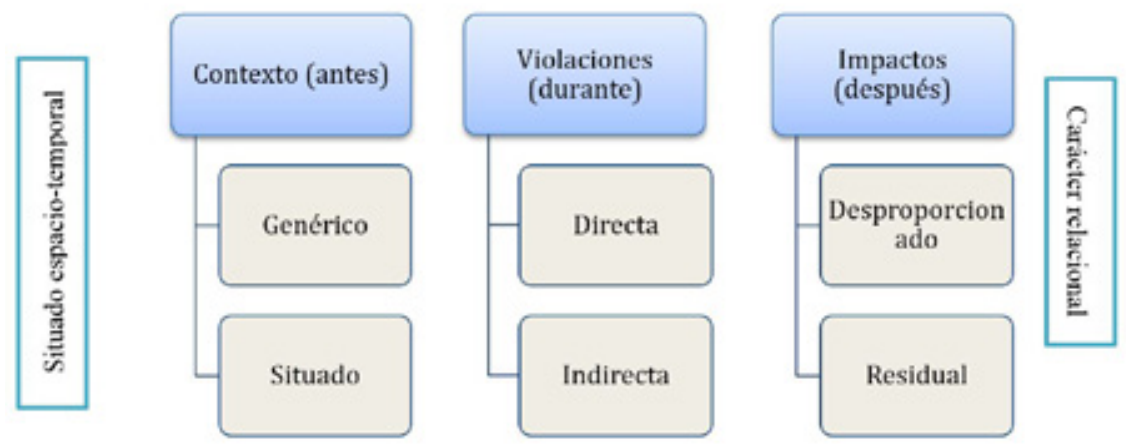

Fuente: Elaboración propia.

El carácter situado de los enfoques diferenciales hace referencia a su carácter histórico, contingente y cambiante, que si bien comparte elementos comunes en distintas sociedades (dada su particular construcción como sistema de dominación según sea el grupo de que se trate), se materializa de forma distinta en cada sociedad. Esto hace que el análisis deba ser situado tanto en términos espaciales como temporales, con lo cual no solo se requiere un conocimiento de la construcción sociocultural de las relaciones de poder entre el grupo privilegiado y el subordinado, sino de estas construcciones en el momento y lugar específico que se analice.

Por otro lado, el análisis de los enfoques diferenciales implica reconocer su carácter relacional. Dado que hablamos de relaciones de poder asimétricas, esta herramienta analítica exige que el estudio no solo se enfoque en la parte subordinada de la relación, sino en la 
relación misma, es decir, en comprender cómo se ha construido tanto el privilegio como la ausencia de este (en el marco de esa relación, puesto que puede darse ese privilegio en otras esferas). Esto significa que, por ejemplo, el enfoque de género esté incompleto si sólo se analiza la situación de las mujeres y se ignora la de los hombres, no solo porque obviar la otra parte conlleva a ignorar la relación de poder y subordinación, sino porque sólo puede entenderse hasta qué punto un asunto o situación está ligado al género si se compara lo que le ocurre a una mujer frente a lo que le ocurre a un hombre; o a un niño frente al adulto, etc.

Teniendo como telón de fondo estos dos elementos transversales, a continuación formulo una propuesta de herramienta que permita acercarse en una escala temporal al análisis de los enfoques diferenciales, tomando como base una mirada contextual (antes), de las violaciones (durante) y de los impactos (después).

\section{Análisis contextual}

El análisis contextual apunta a evaluar de manera general y concreta, en función del enfoque que pretenda evaluarse, cuáles son los roles, estereotipos y expectativas sociales en relación con el grupo poblacional del que se trate, en el que se desarrolló la situación. Puede ser genérico, en el sentido del contexto en el que se desarrolla la situación que busca intervenirse, o situado respecto de una persona concreta, a fin de evaluar su sincronía o no con el contexto general.

A manera de ejemplo, si la intención es analizar desde los enfoques diferenciales un hecho de amenaza contra una mujer afrocolombiana líder de población desplazada, lo primero que debe hacerse es identificar cuáles son los estereotipos de género y raciales en el contexto en el que se desarrolla la amenaza. Esto significa que debe establecerse en el municipio o región en el que la víctima efectuaba el liderazgo cómo son vistas las mujeres, qué se espera de ellas, qué tipo de actitudes y comportamientos se supone que debe realizar. Lo mismo debe hacerse en relación con el factor racial (si es que se determina que es relevante para el caso). Además, deben contemplarse otras posibles variables como la edad, la orientación sexual y la 
condición de discapacidad, en caso de existir. Una vez establecido el contexto genérico, procede el análisis en el contexto situado, es decir, si la persona cuyo caso estoy analizando responde o se ajusta a esos roles y comportamientos esperados, en relación con cada una de las variables. Esto permitirá definir quién era esa persona en su contexto particular. En el caso concreto de la mujer afrocolombiana podré contrastar si cumplía con sus roles de cuidado frente al hogar en función de la expectativa social; si por el hecho de ser afro no se esperaba que cumpliera roles de liderazgo en la organización, por ejemplo; si además era una persona joven, entonces podría estar contraviniendo los mandatos de disponibilidad sexual, etc.

Para poder hacer este ejercicio tanto genérico como situado, es necesario que quien realiza el análisis tenga conocimientos sobre estereotipos de los grupos poblacionales protegidos, entendiendo por estereotipos:

\begin{abstract}
"la visión o preconcepción generalizada de los atributos o características que los miembros de un grupo particular poseen, o de los roles que juegan o deben jugar... [Un] estereotipo presume que todos los miembros de un cierto grupo social poseen atributos o características particulares... [En consecuencia] se considera que una persona, simplemente por su pertenencia a dicho grupo, se ajusta a la visión generalizada o la preconcepción".
\end{abstract}

Esta comprensión sobre los estereotipos es de tal punto relevante que la Corte IDH lo ha utilizado como eje fundamental para determinar la existencia de la violencia de género (Corte IDH, Caso Campo Algodonero, p. 401; Velásquez Paiz, p. 180-183; Caso I.V., p. 187).

\title{
Análisis sobre las violaciones
}

Tratándose de violaciones a los derechos humanos podemos afirmar que el paso anterior, el del contexto, sirve como telón de fondo para analizar el 'antes' de la violación. Este punto, a diferencia de ese, examina el 'durante', es decir, la forma como las violaciones a los derechos 
humanos se establecieron y de qué manera la pertenencia a ese grupo poblacional afectó o incidió en su ejecución.

Para ello se pueden distinguir por lo menos dos posibilidades: i. cuando la violación es directamente motivada por la discriminación en contra del grupo estudiado y ii. cuando aunque su motivo no es esa condición de pertenencia, el hecho sí se aprovecha de la misma. Por supuesto siempre puede existir la posibilidad de que la pertenencia al grupo poblacional no tenga ninguna incidencia en el hecho.

Volviendo al ejemplo de la mujer afro lideresa, tendría que estudiarse si la forma como se ejecutó el acto tuvo relación con su condición de género o racial, entre otras. Es posible que la amenaza se dé en términos desobligantes por su condición racial, señalando que su lugar es, por ejemplo, ejerciendo labores de servicio. O por su condición de género, tildándola de mala madre por salir al escenario público. En estos casos hablamos de una violencia directa. Igual ocurriría si, por ejemplo, la amenaza es de cometer actos de violación, o de atacar a sus hijas e hijos, puesto que el objeto del ataque es su sexualidad o sus personas a cargo, elementos típicamente relacionados con lo femenino.

De otro lado, es posible que no encontremos elementos de violencia directa motivados por su condición de género o racial, pero sí que estos elementos faciliten la comisión del hecho, es decir, que el agresor cometa violencia oportunista. Tres ejemplos pueden servir para la comprensión: el despojo es mucho más fácil de cometer en contra de las mujeres por su relación históricamente precaria con la tierra (debido a la escasa titularidad de bienes a su nombre). En este caso si bien el objetivo no es atacar a las mujeres por su condición de tales, sí hay un aprovechamiento de su condición que facilita la ejecución del hecho. En otro ejemplo podemos encontrar ejecuciones extrajudiciales en la modalidad de 'falsos positivos' en contra de personas con discapacidad mental o intelectual. El hecho no se comete por ser discapacitados, pero sí pueden ser seleccionados como población objetivo por ser mucho más sencillo de cometer el ataque. Un tercer ejemplo lo plantea la Corte Constitucional (sentencia C-438/2013): 
El sólo reconocimiento del enfoque diferencial, es decir, de la existencia de grupos particulares en un mayor grado de vulnerabilidad, implica afirmar que no todas las necesidades de las víctimas guardan una relación directa con el hecho victimizante, pues muchas de éstas son previas al mismo y no fueron generadas por el hecho violento. Por el contrario, como lo establece la misma ley, en muchos casos estas necesidades "previas e indirectas" (como una discapacidad o la minoría de edad) facilitaron el ambiente propicio para que se configuraran los hechos que originaron la victimización. Así por ejemplo, la situación de indefensión en la que se encuentra una mujer con discapacidad en una zona geográfica en conflicto, agrava su riesgo de ser víctima de violencia sexual por parte de grupos armados.

En este ejemplo que plantea la Corte podemos observar un hecho de violencia sexual que presenta una doble connotación: probablemente oportunista frente a la discapacidad (puesto que 'facilita' la comisión del hecho) y directa frente al hecho de ser mujer (si entendemos la violación como un tipo de violencia paradigmática de género, tal y como la ha entendido la Corte IDH, caso Rosendo Cantú, p. 109).

Tanto en la violencia directa como en la oportunista encontramos elementos que se asocian al concepto de discriminación y, por tanto, los enfoques diferenciales deberían permitir desentrañar aspectos de verdad y justicia.

Para que ello sea posible, quien analice los hechos debe plantearse preguntas sobre el por qué, cómo, para qué y establecer indicios de discriminación. Estos, a su vez, están estrechamente ligados con los estereotipos y roles esperados que se señalaron en el momento contextual.

La principal dificultad radica en la prueba, puesto que difícilmente se encontrarán hechos en los que sea evidente la motivación o el aprovechamiento de la condición. Por ello los indicios y el conocimiento profundo de estereotipos resulta fundamental. En este sentido se ha pronunciado la Corte Constitucional colombiana al analizar el tipo penal del feminicidio: 
"la intención de dar muerte por motivos de género, al descubrir patrones de desigualdad intrincados en la sociedad y tener el potencial de tomar tantas formas resulta extremadamente difícil de probar bajo esquemas tradicionales que replican las desigualdades de poder. Por lo tanto, la garantía del acceso a la justicia para las mujeres supone un cambio estructural del derecho penal que integre una perspectiva de género tanto en los tipos penales que lo componen como en su investigación y sanción. Lo anterior, se concreta, entre otros, en una flexibilización del acercamiento a la prueba en el feminicidio que permita que el contexto conduzca a evidenciar el móvil. Esto no implica que la valoración del hecho punible como tal abandone los presupuestos del derecho penal, el debido proceso o el principio de legalidad, pero sí que su apreciación tenga la posibilidad de reconocer las diferencias de poder que generan una discriminación sistemática para las mujeres que desencadena una violencia exacerbada y cobra sus vidas en la impunidad. Lo contrario supondría que el feminicidio constituya un tipo penal simbólico desprovisto de eficacia, lo cual convertiría los bienes jurídicos que tutela en una protección de papel" (Corte Constitucional, sentencia C-297/16).

\section{Análisis sobre los impactos}

El tercer momento se refiere a los impactos, es decir, a los efectos de los hechos de violencia o de los contextos que se pretenden intervenir: al 'después'.

Tratándose de la elaboración de políticas públicas, un análisis de impactos desde enfoques diferenciales debería permitir establecer si leyes en apariencia neutras pueden afectar de manera particular a un grupo por su condición. Esta afectación puede ser directa o indirecta; la intencionalidad carece de importancia. Un ejemplo puede ilustrar: la elaboración de políticas sobre movilidad que no incorpora el componente de discapacidad puede resultar discriminatoria por no contener aspectos como rampas, lenguaje para personas ciegas, etc. (Comité sobre los Derechos de las Personas con Discapacidad, 2014). 
En el análisis de situaciones concretas encontramos casos en los cuales los impactos pueden verse potenciados por su pertenencia a un determinado grupo (impacto desproporcionado). Este análisis es distinto al realizado en el momento de la violación, porque aunque un hecho no haya estado motivado por la pertenencia al sector, sí puede afectar de manera distinta. Los ejemplos abundan en la jurisprudencia de la Corte Constitucional sobre los impactos del desplazamiento forzado.

Además del impacto desproporcionado, tenemos otro tipo de impacto que es indirecto, residual, en el que quien vive el efecto no es quien vive la violación pero aún así su pertenencia a un grupo poblacional genera un efecto mayor. Un ejemplo lo encontramos cuando una persona se ve afectada por una mina antipersona; si ese hecho redunda en una discapacidad, es posible presumir que quien cuidará de ella sea una mujer en ejercicio de su rol de cuidadora. Ella ha tenido un impacto residual por encontrarse en el radio de acción de la víctima (y puede ser también objeto de discriminación 'por motivo de' dicha condición, aunque no la viva directamente).

$\mathrm{Al}$ igual que en los momentos anteriores, para poder hacer este análisis de impactos es necesario tener conocimientos sobre estereotipos y roles esperados de los grupos poblacionales objeto de protección, lo cual puede hacer presumir efectos particulares.

Como puede observarse, los enfoques diferenciales son un método porque implica un análisis de realidades asociadas a la discriminación histórica materializada en distintos momentos, todos ellos ligados a estereotipos. De allí que sea absolutamente necesario conocer de estereotipos para comprender las distintas formas en que se presenta la discriminación y poder superarla.

Es imperativo reivindicar el carácter de método de los enfoques diferenciales, a fin de revertir la tendencia a utilizar de manera retórica esta herramienta y hacer de ella un mecanismo que posibilite transformar la discriminación y no reforzarla aún más con argumentos basados en estereotipos.

Finalmente, para que esta herramienta no tienda a sectorizar el análisis es necesario incorporar una mirada interseccional que permita comprender la variedad de elementos identitarios que pueden 
incidir en la discriminación y que no se reduce a la mera suma de los mismos. Tal como lo señala la Corte IDH, en ciertos casos múltiples factores pueden derivar "en una forma específica de discriminación que resultó de la intersección de dichos factores, es decir, si alguno de dichos factores no hubiese existido, la discriminación habría tenido una naturaleza diferente" (Corte IDH, Caso González Lluy, p. 290; Caso I.V., p. 318, 321). Identificar la naturaleza particular y situada de la discriminación y de sus efectos es un propósito del uso de los enfoques diferenciales.

\section{Conclusiones}

La elaboración teórica de los enfoques diferenciales constituye una oportunidad para revertir las causas y los efectos de la histórica discriminación que recae en contra de ciertos grupos debido a los rasgos inherentes e inmutables que los determinan. En este sentido, delinear los límites de los enfoques diferenciales y potenciar su carácter de herramienta puede servir de canal para materializar el principio de igualdad y no discriminación, de tal forma que constituya una guía programática para las políticas públicas y un mecanismo en el análisis de situaciones concretas que facilite el respeto y protección de los derechos de aquellas personas y grupos que han sido históricamente discriminados y socialmente subordinados.

La herramienta propuesta apunta a utilizar como telón de fondo los estereotipos construidos en torno a estos grupos poblacionales, de tal forma que permitan develar situaciones - reales o presuntas - en las que las características que los definen puedan conllevar a situaciones de discriminación y violencia, con lo cual se requiere un análisis contextual, de las violaciones y de sus impactos. Esto permitirá construir políticas públicas basadas en la idea de la prevención de la discriminación y estudiar situaciones concretas de violaciones a los derechos humanos que acerquen la verdad y la justicia a las específicas condiciones de las víctimas. 


\section{Referencias}

Agencia de la ONU para los Refugiados (ACNUR). (2007). Balance de la política pública para la atención integral al desplazamiento forzado en Colombia. Enero 2004 - Abril 2007.

Cook, R. J., \& Cusack, S. (2010). Gender Stereotyping: Transnational Legal Perspectives. University of Pennsylvania Press. Recuperado a partir de http://www.jstor.org/stable/j.ctt3fhmhd

Departamento para la Prosperidad Social, Grupo de Enfoque Diferencial. (2015). Descripción Enfoque Diferencial. Recuperado a partir de http:// www.prosperidadsocial.gov.co/ent/gen/prg/Documents/Descripción \%20 Enfoque\%20Diferencial.pdf.

Oficina del Alto Comisionado de las Naciones Unidas para los Derechos Humanos (OACNUDH). (s.f.). ¿Qué es el enfoque diferencial? Recuperado a partir de http://www.hchr.org.co/migracion/index.php/76-boletin/ recursos/2470-ique-es-el-enfoque-diferencial

Shelton, D. (2008). Prohibición de Discriminación en el Derecho Internacional de los Derechos Humanos. Anuario de Derechos Humanos, 0(4). https://doi.org/10.5354/0718-2279.2008.13488

Subcomité Técnico de Enfoque Diferencial. (2014). Presentación. Recuperado a partir de https://rni.unidadvictimas.gov.co/sites/default/files/Documentos/PRESENTACION.PDF

\section{Convenciones y tratados internacionales}

Organización de las Naciones Unidas. Convención Internacional sobre la Eliminación de todas las Formas de Discriminación Racial (1965).

Organización de las Naciones Unidas. Convención sobre Eliminación de todas las Formas de Discriminación contra la Mujer (CEDAW) (1979).

Organización de las Naciones Unidas. Convención sobre los Derechos del Niño (1989).

Organización de las Naciones Unidas. Convención internacional sobre la protección de los derechos de todos los trabajadores migratorios y de sus familiares (1990).

Organización de las Naciones Unidas. Convención sobre los Derechos de las Personas con Discapacidad (2006). 
Organización de las Naciones Unidas. Declaración sobre Identidad Sexual y Orientación de Género presentada a la Asamblea General de la ONU (2008).

Organización de los Estados Americanos. Convención Americana sobre Derechos Humanos (1969).

Organización de los Estados Americanos. Convención Interamericana para Prevenir, Sancionar y Erradicar la Violencia contra la Mujer (Convención de Belém do Pará) (1994).

Organización de los Estados Americanos. Convención Interamericana para la Eliminación de todas las Formas de Discriminación contra las Personas con Discapacidad (1999).

Organización de los Estados Americanos. Convención Interamericana contra el Racismo, la Discriminación Racial y Formas Conexas de Intolerancia (2013).

Organización de los Estados Americanos. Convención Interamericana contra toda forma de discriminación e intolerancia (2013).

Organización de los Estados Americanos. Convención Interamericana sobre la Protección de los Derechos Humanos de las Personas Mayores (2015).

Organización de los Estados Americanos. Declaración Americana sobre los derechos de los pueblos indígenas (2016).

Organización Internacional del Trabajo. Convenio 169 sobre pueblos indígenas y tribales (1989).

Principios de Yogyakarta. Principios sobre la aplicación de la legislación internacional de derechos humanos en relación con la orientación sexual y la identidad de género. (2006).

\section{Observaciones, recomendaciones e informes temáticos}

Comisión Interamericana de Derechos Humanos. (2015). Violencia contra personas LGBTI.

Corte Interamericana de Derechos Humanos. (1984). Opinión Consultiva OC-4/84. Propuesta de Modificación a la Constitución Política de Costa Rica Relacionada con la Naturalización. 
Corte Interamericana de Derechos Humanos. (2013). Opinión Consultiva 18/03. Condición jurídica y derechos de los migrantes indocumentados.

Comité de Derechos Humanos. Organización de las Naciones Unidas. (1989). Observación General No 18. No discriminación.

Comité de Derechos Económicos, Sociales y Culturales. Organización de las Naciones Unidas. (2009). Observación General No 20. La no discriminación y los derechos económicos, sociales y culturales.

Comité sobre los Derechos de las Personas con Discapacidad. Organización de las Naciones Unidas. (2014). Observación General No. 2 sobre el artículo 9: accesibilidad.

\section{Sentencias e informes de casos internacionales}

Comisión Interamericana de Derechos Humanos. Caso 12.504 de Karen Atala contra el Estado de Chile (el 17 de septiembre de 2010).

Comisión Interamericana de Derechos Humanos. Caso 12.626 Caso Jessica Lenahan (Gonzales) y Otros vs. Estados unidos. Informe de Fondo No. 80/11 (el 21 de julio de 2011).

Corte Interamericana de Derechos Humanos. Caso González y otras ("Campo Algodonero") vs. México (el 16 de noviembre de 2009).

Corte Interamericana de Derechos Humanos. Caso Rosendo Cantú y otra vs. México (de agosto de 2010).

Corte Interamericana de Derechos Humanos. Caso Artavia Murillo y Otros ("Fecundación In Vitro") vs. Costa Rica (el 28 de noviembre de 2012).

Corte Interamericana de Derechos Humanos. Caso Atala Riffo y Niñas vs. Chile (el 24 de febrero de 2012).

Corte Interamericana de Derechos Humanos. Caso Veliz Franco y Otros vs. Guatemala (el 19 de mayo de 2014).

Corte Interamericana de Derechos Humanos. Caso Gonzales Lluy y Otros vs. Ecuador (el 1 de septiembre de 2015).

Corte Interamericana de Derechos Humanos. Caso Velásquez Paiz y Otros vs. Guatemala (el 19 de noviembre de 2015).

Corte Interamericana de Derechos Humanos. Caso Duque vs. Colombia (el 26 de febrero de 2016). 
Corte Interamericana de Derechos Humanos. Caso Flor Freire vs. Ecuador (de agosto de 2016).

Corte Interamericana de Derechos Humanos. Caso IV vs. Bolivia (el 30 de noviembre de 2016).

\section{Sentencias nacionales}

Corte Constitucional. Sentencia C-481, M.P. Alejandro Martínez Caballero (1998).

Corte Constitucional. Sentencia C-371, M.P. Carlos Gaviria Díaz (2000).

Corte Constitucional. Sentencia T-025, M.P. Manuel José Cepeda Espinosa (2004).

Corte Constitucional. Sentencia C-438, M.P. Alberto Rojas Ríos (2013).

Corte Constitucional. Sentencia C-297, M.P. Gloria Stella Ortiz Delgado (2016).

Corte Constitucional. Sentencia T-661, M.P. Alberto Rojas Ríos (2016). 



\title{
Violencia de género institucional $^{58}$
}

\author{
María Constanza Ballesteros Moreno ${ }^{59}$ \\ Álvaro Moreno Duran ${ }^{60}$
}

\section{Introducción}

Ta violencia ejercida sobre las mujeres por el sólo hecho de serlo, _ castigadas y controladas, es uno de los efectos más feroces del patriarcado, como producto de las relaciones injustas de poder entre hombres y mujeres, fruto de la desigualdad y la discriminación persistentes.

En todos los países se presentan manifestaciones de discriminación en razón al género, la tolerancia social en torno a dicha discriminación

58 Este capítulo es el resultado de investigación del proyecto La violencia de género Institucional, estudio de casos. Feminicidios en ciudad Juárez, esterilizaciones forzadas en Perú, la madres de los "falsos positivos" Colombia. del Grupo de Investigación Estudios en Derecho Privado, de la Facultad de Derecho de la Universidad Santo Tomás. El mencionado proyecto de investigación es financiado por la Universidad Santo Tomás.

59 Abogada Universidad Santo Tomás, Especialista en Derecho Público Universidad Externado de Colombia, Magíster en Derechos Fundamentales Universidad Carlos III de Madrid, Doctora en Derechos Humanos Universidad Carlos III de Madrid. Docente de la Universidad Santo Tomás y de la Universidad Pedagógica y Tecnológica de Colombia, seccional Chiquinquirá. Correo electrónico: mariaballesteros@usantotomas.edu.co

60 Doctor en Sociología Jurídica. Docente e Investigador de la Universidad Santo Tomas. Correo electrónico: alvaromoreno@usantotomas.edu.co 
sigue vigente, la división sexual del trabajo y de las responsabilidades familiares, las mujeres que mueren a manos de sus parejas o exparejas, o que sufren a diario violencia física, psicológica, económica, sexual, etc, y que no se atreven a denunciar por temor, por la relación de dependencia afectiva, económica y emocional que existe entre víctima y agresor, por presión social y/o familiar o por la desconfianza en una Institucionalidad que minimiza la versión de la víctima o que de entrada la culpa por "provocar" la situación, por exagerar, etc, constituyen hechos normalizados por un sistema social que asigna unos comportamientos propios de las mujeres y que originan y justifican las desigualdades.

Las situaciones de violencia sobre las mujeres bajo la perspectiva de discriminación por razón de género, de alguna manera vienen siendo objeto de atención por parte de los Estados, bajo el entendido que las normas de derecho público Internacional, los Tratados Internacionales sobre derechos Humanos condenan este tipo de conductas e ingresan a nuestro ordenamiento jurídico por vía del bloque de constitucionalidad. Así las cosas, por ejemplo en Colombia han sido expedidas normas como la ley 1257 de 2008 "por la cual se dictan normas de sensibilización, prevención y sanción de formas de violencia y discriminación contra las mujeres, se reforman los Códigos Penal, de Procedimiento Penal, la Ley 294 de 1996 y se dictan otras disposiciones" y la ley denominada Rosa Elvira Cely 1761 del 6 de julio de 2015, “por la cual se crea el tipo penal de feminicidio como delito autónomo y se dictan otras disposiciones".

Pese a los esfuerzos mencionados, según datos de medicina legal, las cifras de mujeres agredidas y asesinadas por sus parejas siguen siendo alarmantes, en lo que tiene que ver con violencia de pareja con lesiones no fatales, de enero a septiembre de 2017 se presentaron 5.187 casos dónde la víctima era varón, frente a 31.971 dónde la víctima era mujer ${ }^{61}$. Ahora bien, si bien es cierto es necesario erradicar la carga cultural de desigualdad de género existente en todos los aspectos de la vida de las mujeres, de modo tal que como sociedad alcancemos la igualdad real

61 Boletín estadístico mensual, septiembre de 2017, Instituto de medicina legal, disponible en http://www.medicinalegal.gov.co/documents/2828356/5757566/ septiembre-2017+\%282\%29.pdf/ffe0b596-4e85-46a1-a875-a72de1cdf49e (consultada el 8 noviembre de 2017) 
en todos los ámbitos de la vida personal, familiar, y laboral, es también necesario que la desigualdad desaparezca a partir del Estado mismo, que en realidad el Estado sea garante de los derechos de los seres humanos independientemente de su género, atendiendo a los postulados del concepto y el fundamento de los Derechos Humanos, que radica en la Dignidad Humana.

Es preciso establecer que el respeto, la garantía y la protección de los Derechos Humanos es una obligación del Estado, es el Estado el primer actor llamado a respetar, garantizar, promover, y cumplir los Derechos Humanos. Infortunadamente, en relación con los Derechos Humanos de las mujeres, esto aún es algo incompleto, es por ello que surge la inquietud de determinar si es posible afirmar que el Estado puede ejercer violencia de género. Dentro de este contexto, nuestra pregunta de investigación consiste en determinar si ¿̇es posible afirmar que existe la violencia de género institucional?.

Como respuesta provisional a la pregunta formulada, es preciso indicar que en efecto, el Estado trata de manera desigual y desfavorable a las mujeres en razón a la pertenencia al género femenino y por lo tanto las discrimina, en esta medida, dichas discriminaciones pueden ser constitutivas de violencia de género.

Para llevar a cabo nuestra investigación, se han seleccionado tres experiencias emblemáticas, los casos de feminicidios en ciudad Juárez, México, las esterilizaciones forzadas en el Perú y las Madres de los "falsos positivos” de Soacha, Colombia. Por tanto, como objetivo general, nos proponemos encontrar factores comunes de discriminación en los tres casos objeto de estudio, por lo que el reto consiste en analizar el papel del Estado en cada uno de los casos mencionados para identificar si existe un elemento común de violencia de género institucional.

El enfoque de la investigación es de carácter jurídico, en razón a que el objeto de la misma es el conocimiento de las normas jurídicas nacionales e internacionales. El tipo de investigación es de carácter descriptivo, exploratorio y crítico en razón a que su objetivo es examinar un problema de investigación poco conocido y estudiado.

Para resolver el problema formulado, se plantean tres objetivos específicos. En primer término es necesario estudiar y analizar a fondo cada uno de los casos escogidos: Feminicidios en ciudad Juárez, 
esterilizaciones forzadas en Perú, la madres de los "falsos positivos" de Soacha, Colombia. Establecer los hechos y las consecuencias de cada uno. Posteriormente, como segundo objetivo específico, es pertinente analizar la respuesta del Estado frente a cada una de las experiencias y determinar posibles responsabilidades, y finalmente, el tercer objetivo es analizar el concepto de violencia institucional con el fin de determinar si en los casos estudiados se puede afirmar la presencia de este tipo de violencia.

\section{El término violencia de género}

De manera inicial es necesario hacer claridad en cuanto a determinar a qué hacemos referencia cuando hablamos de violencia de género. Para el efecto es necesario tener en cuenta el contenido de la Convención Interamericana para prevenir, sancionar y erradicar la violencia contra la mujer "Convención de Belem do Para”, en su artículo 1:

Para los efectos de esta Convención debe entenderse por violencia contra la mujer cualquier acción o conducta, basada en su género, que cause muerte, daño o sufrimiento físico, sexual o psicológico a la mujer, tanto en el ámbito público como en el privado.

Por su parte, la ley 1257 de 2008 "por la cual se dictan normas de sensibilización, prevención y sanción de formas de violencia y discriminación contra las mujeres, se reforman los Códigos Penal, de Procedimiento Penal, la Ley 294 de 1996 y se dictan otras disposiciones”, en su artículo 2, dispone:

Por violencia contra la mujer se entiende cualquier acción u omisión, que le cause muerte, daño o sufrimiento físico, sexual, psicológico, económico o patrimonial por su condición de mujer, así como las amenazas de tales actos, la coacción o la privación arbitraria de la libertad, bien sea que se presente en el ámbito público o en el privado. 
Conforme lo descrito, la violencia de género hace referencia a cualquier daño físico, psicológico, sexual, económico que se cause a una mujer, por el hecho de su pertenencia al género femenino, es decir por el sólo hecho de ser mujer.

Así las cosas, es preciso indicar que el término género responde a una construcción social y cultural que se determina a partir de las diferencias biológicas entre los sexos femenino y masculino. En esta medida la diferencia sexual responde a características biológicas, en tanto las diferencias basadas en el género responden a construcciones sociales, culturales, estereotipos y roles de lo que se espera debe corresponder con el hecho de ser "hombre" y ser "mujer" o mejor al contenido de lo masculino y lo femenino.

Como lo señala Nuria Varela, la violencia de género responde a la discriminación histórica y negación de derechos que han sufrido y sufren aún hoy en día, las mujeres en todo el mundo, situación que está basada en una construcción cultural, por lo que afirma, "ser mujer es factor de riesgo" (Varela, 2008, p. 257).

La violencia de género es uno de los más graves problemas a los que se enfrentan las actuales sociedades, pues a pesar de promover la igualdad entre los seres humanos, hombres y mujeres, infortunadamente las diferencias culturales y estereotipos basados en el género persisten y se siguen transmitiendo generacionalmente. Es por ello que la ONU, como parte de la estrategia de la lucha contra este tipo de violencia, declaró el 25 de noviembre como día internacional para la eliminación de la violencia contra las mujeres ${ }^{62}$.

Las desigualdades persistentes entre hombres y mujeres obedecen a motivos culturales, religiosos, de roles y de estereotipos como

62 Las hermanas Mirabal, Patria, Minerva, y María Teresa, conocidas como "las mariposas", opositoras del régimen del dictador Trujillo en República Dominicana, fueron asesinadas el día 25 de noviembre de 1960 por parte de la policía secreta del dictador. La asamblea general de Naciones Unidas, instituyó desde 1999, el día 25 de noviembre como día de la eliminación de la violencia de género en conmemoración del triple asesinato (A/RES/54/134 7 de febrero de 2000). 
consecuencia del sistema patriarcal ${ }^{63}$, generando así relaciones injustas de poder, de dominación y explotación, una de las consecuencias más nocivas de este sistema es precisamente la violencia de género. Por tanto, tal vez la estrategia más eficaz para luchar contra esta clase de violencia, consista en eliminar las desigualdades a través de la coeducación eliminando la socialización de niños y niñas basada en roles y estereotipos basados en la pertenencia a uno u otro sexo.

\section{Hechos}

Una vez hay claridad en relación con el concepto de violencia de género, consideramos pertinente conocer los hechos de cada uno de los tres casos escogidos para esta investigación, veamos:

\section{Feminicidios en Ciudad Júarez, México}

Ciudad Juárez se encuentra en el Estado de Chihuahua, México, es una ciudad industrial fronteriza donde las maquilas constituyen el motor económico de la ciudad, por lo que se presenta un importante tránsito de migrantes extranjeros y mexicanos, además la mano de obra femenina es un factor característico. En Juárez, por su situación geográfica, convergen diversos factores de delincuencia como el narcotráfico, la trata de personas, el lavado de dinero, el tráfico de armas, etc (Sentencia Caso González y Otras (campo algodonero) vs México, 2009). Es precisamente allí donde a partir del año 1993 se vienen presentado casos de desapariciones y asesinatos de mujeres jóvenes, cuyos cuerpos aparecen mutilados, y con señales de violencia sexual. Hasta la fecha han sido desaparecidas y/o asesinadas al menos mil ochocientas mujeres.

Precisamente en relación con la situación de las mujeres en ciudad Juárez existe un importante pronunciamiento por parte de la justicia interamericana. En efecto, la Corte Interamericana de Derechos Humanos, mediante sentencia de fecha 16 de noviembre de 2009, caso

63 El término patriarcado hace referencia a un sistema social, a una situación persistente de explotación y dominación de los hombres sobre las mujeres. 
González y otras (“campo algodonero”) vs México, declaró la responsabilidad internacional del Estado Mexicano por la violación de los Derechos Humanos en relación con tres mujeres víctimas de desaparición y posterior asesinato. La Corte Interamericana identifica la deficiente respuesta del Estado en este caso y la existencia de un patrón de discriminación contra las mujeres en Juárez.

Ahora bien, dentro del asunto que nos compete, en este punto es pertinente destacar la utilización del término feminicidio, el cual hace referencia al asesinato de mujeres por hombres, por el sólo hecho de serlo o por no serlo de manera adecuada (Fuentes, 2004).

El término feminicidio tiene su origen en el femicidio, utilizado por Diana Rusell por primera vez para referir a los asesinatos de mujeres en razón a la pertenencia al género femenino (Russell, 1982). Posteriormente, se acuña el término feminicidio, por parte de la antropóloga mexicana Marcela Lagarde, para describir el sistemático asesinato de niñas y mujeres (Snaidas, 2009). Para Lagarde el feminicidio es un crimen de Estado, ya que éste favorece la impunidad (Lagarde, 2005).

De acuerdo con lo dicho, no cualquier asesinato de una mujer o una niña representa un feminicidio, ni un femicidio. En efecto, cuando referimos el término femicidio debemos entender que la conducta obedece a razones de discriminación por razón de género, por el hecho de ser mujeres. Cuando referimos el término feminicidio, se hace dentro del contexto de vincular la responsabilidad del Estado por negligencia, pasividad, discriminación, etc.

Por tanto, al utilizar la expresión feminicidios en ciudad Juaréz, necesariamente vinculamos la existencia de la responsabilidad del Estado mexicano, de acuerdo con la sentencia "Campo algodonero" de Corte Interamericana de Derechos Humanos.

\section{Esterilizaciones forzadas en Perú}

Entre la década de 1990 a 2000 en Perú, se llevó a cabo una de las prácticas más vergonzosas llevadas a cabo en contra de la Dignidad Humana de las mujeres, como política de Estado, y con el fin de reducir las altas tasas de natalidad en los sectores más pobres del Perú, se 
realizó la esterilización ${ }^{64}$ forzada a 314.605 mujeres en el marco del Programa Nacional de Planificación Familiar del gobierno de Alberto Fujimori. El problema radicó en que las mujeres a quienes se les aplicó el procedimiento, fueron engañadas, coaccionadas, obligadas a tal práctica; por lo que se determina que el consentimiento no fue "genuino" ni libre,. Adicionalmente, muchas de estas mujeres sufrieron daños en su salud y muchas murieron como consecuencia de las malas prácticas e irregularidades en el procedimiento quirúrgico. En efecto, las mujeres habían sido presionadas para aceptar la operación, o no habían recibido una correcta atención post-quirúrgica con algunas complicaciones conducentes a la muerte, o habían sido operadas durante la práctica de una cesárea sin haber sido consultadas previamente. Cladem y Amnistía Internacional denuncian que los métodos utilizados fueron la amenaza, el hostigamiento y el chantaje, agravado por el hecho de que eran mujeres de escasos recursos económicos, en su mayoría indígenas.

La esterilización forzada constituye una violación a los Derechos Humanos de las mujeres a la salud, a la integridad corporal, a la familia, su libertad sexual y a sus derechos sexuales y reproductivos, consagrados en diversos instrumentos internacionales adicionalmente la esterilización forzada está consagrada como un delito de lesa humanidad en el Estatuto de Roma (art. 7). Como factor añadido es preciso señalar que la mayoría de las mujeres que sufrieron este tipo de procedimientos eran indígenas pertenecientes a la etnia Quechua, por lo que se denuncia la existencia de un genocidio expectante, pues la finalidad era acabar con un determinado grupo poblacional (Puertas, 2002).

La Comisión Interamericana de Derechos Humanos tuvo conocimiento del caso específico de la esterilización forzada de la señora María Mamérita Mestanza Chávez, quién luego del procedimiento

64 La esterilización femenina se conoce como una forma de anticoncepción permanente para las mujeres en donde se bloquean las trompas de Falopio para que el óvulo no llegue al útero. La esterilización tiene una efectividad del 100\% para prevenir el embarazo ya que se hace por medio de un método quirúrgico en el que se atan y luego se cortan o sellan las trompas de Falopio, por lo que es permanente. 
quirúrgico de la esterilización, debido a la mala práctica de la misma, lamentablemente murió. Los familiares de la víctima y el Estado peruano llegaron a un acuerdo amistoso dentro del Sistema Interamericano de Derechos Humanos ${ }^{65}$, no obstante la ComisiónIDH determinó que las víctimas de estos hechos tienen derecho a una indemnización, a la rehabilitación, y a la garantía de no repetición.

Está ampliamente documentado el carácter sistemático de la esterilización forzada como método de control de natalidad en Perú, el cual fue aplicado por operadores de salud, a partir de una decisión política del Estado. La implementación de la política estuvo condicionada al cumplimiento de metas, y estos operadores para cumplirlas, realizaron acciones dirigidas exclusivamente a la captación de usuarias de métodos definitivos de control de la natalidad, utilizando como mecanismos de presión la amenaza, la coacción, el trato humillante, etc. Todo esto, valiéndose del poder que ejercían sobre la población como agentes de salud. (Corimaita, 2010)

La prioridad dada por el gobierno a la ligadura de trompas, mediada por objetivos focalizados e incentivos para el personal médico para cumplir con estos objetivos, crearon un clima que era contrario a la libre toma de decisión de las mujeres. Estos objetivos fueron perseguidos notablemente a través de la celebración de "festivales de la ligadura de trompas y vasectomía”, organizados por el personal del MINSA en varias regiones pobres del país. (Rousseau, 2007).

El Estado Peruano ha pedido disculpas públicas por estos hechos, y las víctimas se han organizado con el fin de obtener reparación y justicia.

\section{Madres de Falsos positivos, Soacha, Colombia.}

El término de “falso positivo" responde al concepto acuñado, hacia mediados del 2006, en Colombia para hacer referencia al asesinato o ejecución extrajudicial de ciudadanos inocentes, muchos de ellos menores de edad, que fueron reclutados y engañados para luego presentarlos como guerrilleros muertos en combate, para lo cual eran despojados

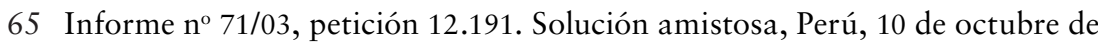
2003 Comisión Interamericana de Derechos Humanos. 
de sus ropas, vestidos con uniformes camuflados y dotados de armas de fuego, todo con el fin de mostrar "resultados" por parte de la fuerza pública ${ }^{66}$. De acuerdo con Cruz Rodríguez, la política de la seguridad democrática del gobierno del Presidente Uribe fue exitosa en cuanto debilitó de manera importante a la guerrilla, esta "subordinó lo político a lo militar, privilegió la seguridad nacional en desmedro de la ciudadanía y generó incentivos perversos, como las recompensas y la evaluación de resultados en términos de bajas que produjeron problemas como los falsos positivos" (Cruz Rodríguez, 2015, p. 14).

En abril de este año fueron condenados por los delitos de concierto para delinquir, desaparición forzada y homicidio agravado 21 miembros de las fuerzas militares, los hechos que originaron dicha condena ocurrieron en el año 2008, cuando 19 jóvenes habitantes de Soacha, Cundinamarca (Colombia) fueron reportados como desaparecidos por parte de sus familiares y pocos días después sus cuerpos fueron encontrados en Ocaña, Norte de Santander. Habían sido registrados por el ejército como guerrilleros abatidos en combate, a cambio de beneficios y recompensas. Hoy se sabe que los jóvenes fueron engañados mediante falsas ofertas de trabajo y fueron "vendidos" al ejército para mostrar resultados.

En efecto, cuando las madres y demás familiares de estos jóvenes acuden ante las autoridades para presentar las denuncias en relación con la desaparición de sus hijos, no fueron tenidas en cuenta, recibían respuestas de parte de los funcionarios como que ellas no tenían razones para dar por desaparecidos a sus hijos, que sus hijos andaban de fiesta, con sus novias, etc, lo que llevó a las familias a pasar por la dolorosa situación de tener que ir ellas mismas a buscar a sus desaparecidos en lugares como hospitales, medicina legal, etc.

Las madres de los falsos positivos de Soacha fueron repetidamente desatendidas, humilladas e ignoradas por la burocracia y deficiencia del sistema judicial colombiano, y burladas por parte de la defensa militar utilizando estrategias para dilatar los procesos. De

66 El Ministerio de Defensa expidió la Directiva 029 de 2005, que fijaba los criterios para el pago de recompensas, otorgando una cantidad de dinero por cada guerrillero o paramilitar abatido. 
manera posterior al conocimiento de los hechos, el descomunal daño sufrido por los familiares fue incrementado por la falta de acompañamiento en procesos en los cuales debió haberse hecho manifiesta la presencia del Estado, como lo son el proceso de duelo y esclarecimiento de la verdad. Dicho abandono tuvo como consecuencia que los derechos de las víctimas fueran especialmente vulnerados e incluso concluyó con la aparición de nuevas modalidades de violencia en contra de los familiares.

En relación con las investigaciones del caso, es evidente que la respuesta del Estado frente a las ejecuciones extrajudiciales de los jóvenes de Soacha ha sido negligente ocasionando la revictimización de los familiares, en particular de las madres, quienes han tenido que luchar para que las conductas en relación con el asesinato de sus hijos, no quede en la impunidad. Es así como las "madres de Soacha”, se organizaron y fundaron un movimiento con el propósito de obtener la verdad, la justicia y la reparación por los hechos ocurridos. Sólo la decisión de no permitir la impunidad permitió que estás madres consiguieran una respuesta del Estado, que llegó 9 años después de ocurridos los hechos.

Ahora bien, en este caso el reproche es mayor, en la medida en que la fuerza pública es la encargada de proteger a los ciudadanos, es así como en los hechos descritos, no sólo no se cumplió ese deber de protección, sino que además la fuerza pública fue quien ejecutó a los civiles.

\section{Interseccionalidad}

La doctrina especializada ha evidenciado casos específicos donde confluyen diversos tipos de discriminación, es decir donde en cabeza de un mismo individuo es posible identificar varias causas de tratamiento diferenciado desfavorable. A esta circunstancia se denominó inicialmente doble discriminación, o múltiple discriminación de acuerdo al número de factores que estuvieran presentes. De tal manera que no es lo mismo ser mujer blanca a ser mujer negra, en quien confluyen dos factores de discriminación: género y racial; o además contar con otros factores, una niña, negra, en condición de pobreza, estaríamos 
ante una discriminación múltiple frente a factores de edad, raciales, económicos y de género.

Así las cosas, ante una situación de discriminación múltiple la situación para quien la sufre es más compleja y la respuesta y protección del Estado debe ser mayor. En esta medida, decíamos, la doctrina propone el concepto de interseccionalidad para determinar que en el caso de confluir varias discriminaciones, éstas interseccionan de forma diferente cada situación personal o grupal, por lo que a efectos de políticas antidiscriminatorias, éstas intersecciones deben ser analizadas de manera específica y proponer respuestas específicas e integrales que respondan a todos los factores. (Molina, 2012).

La interseccionalidad hace referencia pues, al cruce de diversos factores de discriminación, que convergen y afectan a los seres humanos de manera diferente, por tanto la respuesta institucional ante diversas manifestaciones de discriminación agravadas, debe ser reforzada (Barrére Unzueta, 2011).

\section{Concepto de violencia institucional}

En lo que tiene que ver con el concepto de violencia institucional, necesariamente ésta vincula al Estado y a sus autoridades en la medida en que representan la institucionalidad, en cuanto están llamados a promover y proteger los derechos consagrados Constitucionalmente y sancionar su vulneración. Así las cosas la doctrina ha vinculado la responsabilidad del Estado en los casos de violencia de género, en la medida en que le corresponde a éste proteger a las mujeres y brindarles una vida libre de violencias, en condiciones de igualdad, pero infortunadamente en muchos casos el Estado no sólo no protege sino que además mediante acciones u omisiones, ocasiona directamente el perjuicio sobre los derechos de las mujeres víctimas.

De acuerdo con lo expuesto, el concepto de violencia institucional hace referencia a las acciones u omisiones del Estado en relación con la protección, promoción de los derechos protegidos por el ordenamiento jurídico. En relación con el tema que nos interesa, la violencia institucional vincula la escasa o nula respuesta que brinda el Estado 
en relación con las situaciones de discriminación en razón de género, o muchas veces, porque es el Estado quien directamente discrimina.

De esta manera la violencia institucional no sólo incluye aquellas manifestaciones de violencia contra las mujeres en las que el Estado es directamente responsable por su acción u omisión, sino también aquellos actos que muestran una pauta de discriminación o de obstáculo en el ejercicio y goce de los derechos. (Bodelón, 2014, p. 133)

Desde este punto de vista, y siguiendo a Encarna Bodelón, es imposible abordar la violencia de género sin tener en cuenta tres factores fundamentales y determinantes:

Primera, entender que la violencia es una manifestación de una discriminación social, de una estructura social desigual y opresiva contra las mujeres; segunda, el concepto tiene que permitir explicar que la violencia contra las mujeres tiene varias manifestaciones, aunque se trata de un fenómeno único; Tercero, que las intervenciones jurídicas, especialmente las que provienen del ámbito penal, puede incluir prácticas de violencia institucional hacia las víctimas, es decir, que la intervención jurídica debe realizarse partiendo de la consideración de que el Estado mismo es una agente que puede producir y reproducir violencia hacia las mujeres. (Bodelón, 2014, pp. 137, 138).

\section{Resultados}

Conforme lo dicho y teniendo en cuenta el contenido del literal C. del artículo 2 de la Convención Interamericana para prevenir, sancionar y erradicar la violencia contra la mujer "Convención Belem do Pará", es posible hablar de Violencia de género institucional cuando los actos de violencia de género con perpetradas o toleradas por el Estado:

\section{Artículo 2}

Se entenderá que violencia contra la mujer incluye la violencia física, sexual y psicológica:

a. que tenga lugar dentro de la familia o unidad doméstica o en cualquier otra relación interpersonal, ya sea que el agresor 
comparta o haya compartido el mismo domicilio que la mujer, y que comprende, entre otros, violación, maltrato y abuso sexual; b. que tenga lugar en la comunidad y sea perpetrada por cualquier persona y que comprende, entre otros, violación, abuso sexual, tortura, trata de personas, prostitución forzada, secuestro y acoso sexual en el lugar de trabajo, así como en instituciones educativas, establecimientos de salud o cualquier otro lugar, y

c. que sea perpetrada o tolerada por el Estado o sus agentes, donde quiera que ocurra.

Adicionalmente, los Estados tienen el deber de adoptar políticas públicas con el fin de luchar contra la violencia de género, así lo consagra la Convención Belen do Pará:

\section{Artículo 7}

Los Estados Partes condenan todas las formas de violencia contra la mujer y convienen en adoptar, por todos los medios apropiados y sin dilaciones, políticas orientadas a prevenir, sancionar y erradicar dicha violencia y en llevar a cabo lo siguiente:

a. abstenerse de cualquier acción o práctica de violencia contra la mujer y velar por que las autoridades, sus funcionarios, personal y agentes e instituciones se comporten de conformidad con esta obligación;

b. actuar con la debida diligencia para prevenir, investigar y sancionar la violencia contra la mujer;

c. incluir en su legislación interna normas penales, civiles y administrativas, así como las de otra naturaleza que sean necesarias para prevenir, sancionar y erradicar la violencia contra la mujer y adoptar las medidas administrativas apropiadas que sean del caso; d. adoptar medidas jurídicas para conminar al agresor a abstenerse de hostigar, intimidar, amenazar, dañar o poner en peligro la vida de la mujer de cualquier forma que atente contra su integridad o perjudique su propiedad; 
e. tomar todas las medidas apropiadas, incluyendo medidas de tipo legislativo, para modificar o abolir leyes y reglamentos vigentes, o para modificar prácticas jurídicas o consuetudinarias que respalden la persistencia o la tolerancia de la violencia contra la mujer;

f. establecer procedimientos legales justos y eficaces para la mujer que haya sido sometida a violencia, que incluyan, entre otros, medidas de protección, un juicio oportuno y el acceso efectivo a tales procedimientos;

g. establecer los mecanismos judiciales y administrativos necesarios para asegurar que la mujer objeto de violencia tenga acceso efectivo a resarcimiento, reparación del daño u otros medios de compensación justos y eficaces, y

h. adoptar las disposiciones legislativas o de otra índole que sean necesarias para hacer efectiva esta Convención.

Desafortunadamente, dentro de las tres experiencias estudiadas es evidente que el Estado no cumplió diligentemente con su deber de protección y por el contrario discriminó a las mujeres en razón a su condición de mujeres. Es así como podemos afirmar que hubo discriminación institucional por razón de género y violencia de género institucional en los tres casos, por omisión y negligencia en el caso de México y Colombia y por acción en el caso de Perú.

\section{Conclusiones}

En primer término es preciso señalar, que en efecto, es posible afirmar que existe la violencia de género institucional, en la medida en que el Estado puede ejercer actos discriminatorios y constitutivos de violencia sobre las mujeres, ya sea por acción o por omisión.

En los tres casos analizados se evidencia como factor común de discriminación el hecho de ser mujer y en esta medida se determina que el Estado no dispuso los mecanismos necesarios para luchar contra dicha discriminación y no actúo con la diligencia debida para prevenir, sancionar y erradicar la violencia contra las mujer. 
De acuerdo con lo anterior, se evidencia que en relación con los feminicidios de Juárez, México y las madres de Soacha en Colombia, cada Estado, respectivamente, discriminó a las víctimas y a sus familiares por motivos de la falta de atención, negligencia y revictimización de la que fueron objeto. Por su parte, el Estado Peruano discriminó a sus mujeres al someterlas a la esterilización forzada, es decir no sólo no las protegió, sino que además llevó a cabo acciones propias de violencia de género.

Adicionalmente, se puede afirmar que en los tres casos analizados: el Estado Peruano, Mexicano y Colombiano encontramos como factor común de discriminación la pertenencia al género femenino, es decir, las mujeres reciben un tratamiento diferente y desfavorable, en razón a que son mujeres. Es así como se evidencia que los Estados ejercieron violencia de género en contra de las mujeres en cada uno de los casos descritos, de conformidad con el literal c) del artículo 2 de la Convención Interamericana para Prevenir, Sancionar y Erradicar la violencia contra la mujer "Convención Belem do Para”.

Por otra parte, en casos analizados, concurren diversos factores de discriminación, lo que la doctrina ha denominado discriminación interseccional, debido a que no sólo se trata de un tratamiento diferente y desfavorable basado en razón a la pertenencia al género femenino, sino que además son mujeres de escasos recursos, de bajo nivel cultural, en algunos casos analfabetas, mujeres cabeza de hogar, mujeres menores de edad y en el caso específico del Perú, mujeres indígenas, aumentando su nivel de vulnerabilidad.

Cuando se habla de violencia de género siempre se hace relación a la necesidad de transformar, educar y sensibilizar en relación con la igualdad entre los hombres y las mujeres, sin embargo a través de este estudio, se ha podido verificar que además es necesario una reestructuración del Estado para que precisamente la protección de uno de los colectivos históricamente más vulnerados, sea realidad.

\section{Referencias bibliográficas}

Varela, N. (2008). Feminismo para principiantes. Barcelona : Ediciones B. 
Sentencia Caso González y Otras (campo algodonero) vs México (Corte Interamericana de Derechos Humanos 16 de noviembre de 2009).

Fuentes, J. M. (2004). "Feminicidio y marginalildad urbana en Ciudad Juárez en la década de los noventa", en Violencia contra las mujeres en contextos urbanos y rurales. México: El Colegio de México.

Russell, D. E. (1982). Crimes against Women: The Proceedings of the International. San Francisco, California: Frog in the Wel.

Snaidas, J. (2009). El feminicidio en América Latina. Historia y perspectivas. Buenos Aires.

Lagarde, M. (2005). "El feminicidio, delito contra la humanidad". México: Comisión Especial para Conocer y Dar Seguimiento a las Investigaciones Relacionadas con los Feminicidios en la República Mexicana y a la Procuración de Justicia Vinculada.

Puertas, L. (25 de Julio de 2002). Fujimori ordenó la esterilización forzosa de 200.000 mujeres indígenas en el Perú. El País .

Corimaita, K. C. (2010). Huellas psicológicas de la esterilización forzada. Revista Ideele, 06.

Rousseau, S. (2007). Las políticas de salud reproductiva en el Perú: reformas sociales y derechos ciudadanos. Revista Estudos Feministas , 10.

Cruz Rodríguez, E. (2015). Relaciones cívico-militares, negociaciones de paz y postconflicto en Colombia. Criterio jurídico garantista , 12-41.

Molina, C. E. (2012). ¿Qué es eso de la interseccionalidad? . investigaciones feministas , 203-222.

Barrére Unzueta, M. Á. (2011). SUBORDISCRIMINACIÓN Y DISCRIMINACIÓN INTERSECCIONAL, Elementos para una teoría del Derecho antidiscriminatorio. Anales de la Cátedra Francisco Suarez, 45, 15-42.

Bodelón, E. (2014). Violencia Institucional y violencia de género. Anales de la cátedra Francisco Suárez 48 , 131-155.

Corte interamericana de derechos humanos. (7 al 22 de Noviembre de 1969). Organizacion de los estados americanos. Obtenido de https://www.oas. org/dil/esp/tratados_b-32_convencion_americana_sobre_derechos_humanos.htm

FERTILAB. (16 de Marzo de 2017). FERTILAB. Obtenido de Que es la esterilizacion quirurgica femenina: http://www.fertilab.net/ginecopedia/anticoncepcion/esterilizacion_femenina/ que_es_la_esterilizacion_quirurgica_femenina_1 
Vida Humana Internacional. (08 de Abril de 2011). Vida bumana Internacional. Obtenido de http://www.vidahumana.org/esterilizacion/ item/91-la-esterilizaci\%C3\%B3n-forzosa-o-coactiva-en-el-mundo-actual

Nürnberger Menschenrechtszentrum . (17 de Julio de 1999). Nürnberger Menschenrechtszentrum . Obtenido de http://www.menschenrechte.org/ lang/es/regionen/la-dictadura

Naciones Unidas. (10 de Diciembre de 1948). Naciones Unidas. Obtenido de La Declaración Universal de Derechos Humanos: http://www.un.org/es/ universal-declaration-human-rights/

Comision interamericana de derechos humanos. (2003). INFORME $N^{\circ} 71 / 03$ SOLUCION AMISTOSA. Perú: Organizacion de los estados americanos .

Centro por la Justicia y el Derecho Internacional. (2010). CIDH condena impunidad por esterilizaciones forzadas en Perú. Washignto, D.C.: Centro por la Justicia y el Derecho Internacional.

Revista IIDH. (Vol. 43). La ejecución extrajudicial o el homicidio en las legislaciones de América Latina. Revista IIDH , 284-285.

Semana. (12 de Julio de 1982). ¿La noche quedó atrás? Obtenido de http:// www.semana.com/nacion/articulo/la-noche-quedo-atras/367-3

Colectivo de abogados José Alvear Restrepo. (14 de Marzo de 2006). Consolidación paramilitar e impunidad en Colombia.

Redacción El Tiempo. (2010). Turbay dicta polémico Estatuto de seguridad (1978 - 1982). El Tiempo .

Jiménez, C. (2008). La doctrina de seguridad nacional en Colombia: efectos en materia de Derechos Humanos. Universidad Sergio Arboleda .

Rugeles, G. (2013). Las convivir que se volvieron organizaciones paramilitares. Las Dos Orillas .

Redacción Judicial. (2008). Del Estatuto de Seguridad a la Seguridad Democrática. El Espectador .

Castañeda, G. G. (2004). Violencia Sexista. México: UNAM.

Medina Rosas, A. (2011). Campo algodonero definiciones y retos ante el feminicidio en México. dfensa , 6-7.

Salvador Bernabéu, A. (2015). El feminicidio de Ciudad Juarez. Repercusiones legales y culturales. Sevilla: Universidad Internacional de Andalucía.

Puleo, A. (1998). Patriarcado. En C. Amorós, 10 palabras claves sobre mujer (págs. 21-54). Navarra: Verbo Divino. 
JONAS, H. (1995). El principio de responsabilidad. Ensayo de una ética para la civilización tecnológicaa. Barcelona, Cataluña, España: Herder.

AQUINO, T. d. (1989). Suma Teológica. Madrid, España: Biblioteca de Autores Cristianos.

Carr, N. (2010). Superficiales.¿Qué está haciendo Internet con nuestras mentes? Bogotá: Distribuidora y Editora Aguilar, Altea, Taurus, Alfaguara S.A.

Foucault, M. (2005). Historia de la Sexualidad. Vol 1 La voluntad de saber. México: Siglo XXI Editores de c.v.

Han, B. -C. (2014). Psicopolítica. Neoliberalismo y nuevas téenicas de poder. Barcelona: Herder.

Mateos, A. S. (2017). Nomofobia, el motivo psicológico por el que no eres capaz de dejar de mirar el móvil. Obtenido de La Vanguardia. Sección: Psicología: http://www.lavanguardia.com/vivo/psicologia/20170331/42857887210/ nomofobia-adiccion-movil.html

SecurEnvoy. (2012). 66\% of the population suffer from Nomophobia the fear of being without their phone. Obtenido de https://www.securenvoy.com/ blog/2012/02/16/66-of-the-population-suffer-from-nomophobia-the-fearof-being-without-their-phone/

Verónica García, A. F. (2014). Nomofolia vs. Nomofobia, irrrupción del teléfono móvil en las dimensiones de vida de los jóvenes, un tema pendiente para los estudios en comunicación. Monterrey, México: Sistema de Información Científica Red de Revistas Científicas de América Latina y el Caribe, España y Portugal.REVISTA RAZÓN Y PALABRA vol. 18, núm. 86.

Lyon, Z. B. (2013). Vigilancia Líquida. Barcelona: Espasa Libros S.L.U.

Fayos, A. (2015). Los derechos a al intimidad y a la privacidad en el siglo XXI. Madrid: Dykinson.

Orwell, G. (1949). 1984. Editorial Destino. 



\title{
El Género: una herramienta a favor de los derechos humanos de las mujeres y de las minorías con género no hegemónico ${ }^{67}$
}

\author{
Cecilia Barraza Morelle ${ }^{68}$
}

\section{Introducción}

$\mathrm{D}$ urante el año pasado en Colombia en el marco del debate político que generó el Acuerdo de Paz entre el gobierno nacional y las FARC -EP, uno de los temas en los que se concentró la controversia alrededor de los contenidos de dicho documento fue el de la incorporación y uso de la categoría de análisis de género. Tratándose de un acuerdo de paz podría pensarse que la temática de género no era un tema relevante ni mucho menos decisivo en la votación de un plebiscito a favor o en contra de dicho Acuerdo. Sin embargo, para sorpresa de muchos no solo estuvo en el centro de la discusión sino que se convirtió en uno de los temas que más se abordó mediáticamente. Las

67 Articulo resultado producto de investigación del proyecto denominado "Procesos de exigibilidad y justiciabilidad de los Derechos Humanos y el Derecho Internacional Humanitario, en el contexto nacional e internacional.” Adscrito al grupo de investigación Sociohumanistico Categoría A en Colciencias de la Facultad de Derecho de la Universidad Santo Tomás Bogotá.

68 Magister en Ciencias Políticas, Licenciad en Historia y geografía. Profesora de la maestría en Defensa de los Derechos Humanos y el Derecho internacional Humanitario Facultad de Derecho de la Universidad Santo Tomás Bogotá. Email: cbarraza@humanas.org.co 
discusiones y opiniones fueron diversas y abordaron temas como qué es género, a qué población se le aplica la categoría, frente a qué hechos, cuánto género tiene el Acuerdo, incluso se realizaron conteos para señalar cuántas veces y con qué sentido se usaba el término.

Adicionalmente un grupo importante de quienes se oponían a la ratificación del Acuerdo, plantearon que a través de la llamada "ideología de género" que contenía el documento, se buscaba modificar la Constitución Política en lo que respecta a la definición de familia. Recientemente, en otros Estados de la región en diferentes debates públicos a favor de los derechos de las mujeres se ha criticado el uso de la categoría género en las políticas públicas etiquetándola también bajo el nombre de "ideología de género" con una clara connotación negativa ${ }^{69}$.

Este debate no es nuevo en el panorama mundial, por ejemplo, durante la década del noventa del siglo pasado, en el marco de las discusiones que se dieron para la aprobación del Estatuto de Roma, uno de los temas álgidos estuvo vinculado justamente a la definición de género que debía incorporarse en dicho tratado. Por lo demás, primer instrumento internacional que incluyo incluyó esta categoría ${ }^{70}$.

Considerando los debates que el concepto género ocasiona en la opinión pública, es evidente que pese a que el termino término se encuentra acuñado desde hace medio siglo en las ciencias sociales aún no es aprehendido por el conjunto de la sociedad generando polémicas que dejan ver que los contenidos de la noción cuestionan el status quo y su potencial transformador de las realidades sociales. Incluso más allá de su uso como categoría de análisis social muestra que puede ser usado como un factor polarizador de importantes decisiones políticas a nivel nacional e internacional.

Sin embargo, pese a los cuestionamientos que el concepto y su uso han generado en la opinión pública no es menos cierto que en los

69 Un ejemplo reciente es el dado en Chile a raíz de los debates alrededor del Proyecto de ley de despenalización parcial del aborto.

70 En el numeral 3 del artículo 7 del Estatuto de Roma se señala "3. A los efectos del presente Estatuto se entenderá que el término "género" se refiere a los dos sexos, masculino y femenino, en el contexto de la sociedad. El término "género" no tendrá más acepción que la que antecede." 
últimos 30 años el concepto ha sido incorporado en las políticas públicas, especialmente en las dirigidas a la igualdad para las mujeres y en estos últimos años en las políticas de reconocimiento de la diversidad de género. También, paulatinamente comienza a ser usado en las sentencias de tribunales nacionales e internacionales y se reconoce su aporte para propender por la vigencia de los derechos humanos particularmente de las mujeres.

Considerando la vigencia del concepto género, en el presente artículo, se busca revisar y analizar los contenidos de dicha categoría y como cómo esta se constituye en una herramienta potente, aunque no única, a favor de los derechos humanos de las mujeres y de las minorías que adquieren un género no hegemónico al mandato social imperante y para contribuir a transformar realidades. Se revisa también, el vínculo del género con el enfoque diferencial de derechos y los presupuestos que este enfoque debiera considerar para ser una herramienta eficaz para un desarrollo basado en la superación de las discriminaciones y garantía de igualdad sustantiva para el conjunto de la sociedad.

\section{El género como categoría de análisis}

Desde su aparición a finales de la primera mitad del siglo XX hasta la fecha, el concepto de género como toda categoría de análisis social ha sido construido y deconstruido, de hecho, existen diferentes aproximaciones e interpretaciones del concepto según las vertientes teóricas y epistemológicas que lo analizan. Incluso las evoluciones del concepto o alguno de los elementos que lo constituyen e interpretan han generado debates con respecto a su aceptación e incorporación como herramienta de análisis para la definición e implementación de normas y políticas públicas que contienen dicha categoría a favor de grupos discriminados. Al mismo tiempo, se ha vuelto un lugar común en el marco de las agendas públicas de los Estados contemporáneos señalar que la intervención social debe realizarse con enfoque o perspectiva de género, situación muchas veces declarativa puesto que a la hora de ejecutar la intervención no se concreta dicho enfoque o perspectiva en ninguna de las etapas del ciclo de la planeación. 
Dado que el propósito de esta reflexión se centra en el género como dispositivo a favor de los derechos de las mujeres y de las minorías que adquieren un género no hegemónico al mandato social imperante se revisará la noción de género sin el interés de profundizar en las diferentes vertientes teóricas sino haciendo énfasis en los elementos constituyentes de la categoría y en la evolución de estos para poder enfatizar en su vínculo con los derechos humanos.

En la definición más amplia, el género es un concepto que busca, a partir de la diferencia sexual explicar las relaciones construidas entre hombres y mujeres -lo masculino y lo femenino- que se dan en un determinado momento histórico y que contribuyen a determinar parámetros socio culturales de comportamiento. En el origen del concepto género se encuentra la pregunta sobre si hay algo distinto al sexo biológico que explica el comportamiento social y la construcción de la identidad de los sujetos sexuados, frente a lo cual el género responde que es a través del proceso de socialización y asignaciones culturales que recibe el sujeto sexuado que se construye lo femenino y lo masculino. Se genera así la diferencia entre sexo y género, sexo aquellos elementos biológicos que determinan el ser hombre o mujer, y el género aquellos elementos socioculturales que definen la feminidad y la masculinidad.

Si bien el concepto ha sido desarrollado en las diferentes ramas del conocimiento, el género como categoría analítica a partir de la década de los setenta del siglo XX, se convirtió en una herramienta no sólo teórica para entender la realidad sino sobre todo política. Esto porque permitió en parte -porque existen otros factores que se revisarán más adelante- explicar que la realidad que viven las mujeres y los hombres en sus relaciones públicas y privadas no están determinadas por su naturaleza -sexo- sino que pueden transformarse dado que es una construcción sociocultural -género-. Ese reconocimiento generó un cambio político a favor de la igualdad de derechos de las mujeres con respecto a los hombres que ha sido usada a nivel global por el feminismo de diferentes vertientes. Por tanto, el género como categoría social de análisis es una herramienta para las ciencias humanas y sociales, pero sobretodo es un dispositivo político para la igualdad, cuestionador del status quo de cualquier sistema social. Esto porque la discriminación que afecta a las mujeres o a lo considerado socialmente 
femenino, al no fundamentarse en un determinismo biológico, es un acto de poder expresado en dominación, subordinación y opresión producido por un sistema socialmente jerarquizado que opera en un momento histórico determinado.

Joan Scott conceptualizó que el género "es un elemento constitutivo de las relaciones sociales basadas en las diferencias percibidas entre los sexos y es una forma primaria de relaciones significantes de poder" (Scott, 1990, p 56). Para la autora, el género se funda en cuatro áreas: representaciones simbólicas; conceptos normativos; construcción a través del parentesco, economía y organización política, y la construcción de la identidad subjetiva. Como lo señala Tarrés “uno de los logros en esta construcción fue situar la categoría de género en el nivel simbólico-cultural y definirla desde ahí a partir de relaciones de poder cuyo cambio o reproducción está sujeto a factores vinculados con la historicidad de las instituciones y la organización social de los espacios donde se desarrolla la experiencia de los individuos". (Tarrés, 2013, p 180)

Varios elementos requieren considerarse a la hora de aplicar el género, la primera es que existe una relación entre sexo y género que construye lo que se ha llamado el sistema sexo/género que puede definirse como el conjunto de las normas y valores implícitos y explícitos, las prácticas reales y simbólicas y sus representaciones, y los imaginarios sociales que las sociedades construyen, interpretan y reinterpretan para el relacionamiento entre personas a partir de la diferencia biológica y cultural que se asigna al comportamiento sexuado de las personas.

Un segundo elemento tiene que ver con la distribución del poder en las relaciones sociales dado que el sistema sexo/género ha producido una sociedad altamente jerarquizada caracterizada por relaciones de poder desiguales entre hombres y mujeres o entre lo considerado el deber ser de lo femenino o masculino. Para algunos autores este tipo de jerarquización social ha sido llamada patriarcado, para otros androcentrismo. Independientemente del nombre y de las teorizaciones alcanzadas, da cuenta de la asimetría en la distribución del poder real y simbólico, poder que ha recaído históricamente en los hombres que responden al modelo masculino socialmente normativo.

En consecuencia, un tercer elemento es el hecho que el género es histórico y por ello para su análisis es necesario tomar en cuenta el 
contexto espacio temporal en que se dan las relaciones sociales. Así, el análisis de género tendrá elementos constituyentes diferentes para cada momento histórico y para el tipo de sociedad que se analice. No se pueden yuxtaponer los elementos entre una cultura y otra al realizar el análisis de género. No obstante, es una constante histórica que en el análisis de género realizado a las sociedades actuales de oriente y occidente se ha evidenciado una asimetría en la distribución del poder que favorece a los hombres y a lo masculino dominante.

Un cuarto elemento es el carácter relacional del género, esto implica que la lectura que se realice debe ser relacional entre lo masculino y lo femenino. Así cuando se está aplicando la categoría de análisis género no se está analizando a las mujeres -lo femenino- por una parte ni a los hombres -lo masculino- por otra, sino la forma en que interactúan relacionalmente en la sociedad y las causas y consecuencias que tiene esa interacción para el conjunto de la sociedad, aunque esté afectando deliberadamente a un solo sujeto social o un solo sujeto social sea la causa de análisis.

Un quinto elemento hace referencia a la idea explícita en muchos de los estudios de género de que el sexo es un determinante biológico (natural) mientras que el género es cambiante en la medida que al ser cultural puede ser transformado. Situación que estableció la relación sexo/género como una dicotomía. No obstante, en los noventa los estudios de Judith Butler fueron críticos frente a este elemento. Al respecto, Tarres señala que Butler, “propone una deconstrucción de la dicotomía sexo/género y muestra cómo el sexo está tan culturalmente construido como el género, de modo que la contraposición sexo/ género y naturaleza/cultura pierden su razón de ser" (Tarrés, 2013, p 186). Así el sistema sexo/género dejaría de ser una dicotomía y pasaría a ser un continuo, ambos formados culturalmente ${ }^{71}$. Tarrés analiza que Butler, cuestiona el sistema binario dado que parte del reconocimiento que el acceso a la realidad es mediado por la cultura y el lenguaje, por tal razón los cuerpos están construidos culturalmente como

71 Esta definición ha sido retomada por la CIDH en su informe del 2015 sobre población LGBT. 
femeninos y masculinos. Por ello, para Butler no sería posible precisar sexo y género, y se debe utilizar sexo o género o sexo/género como un continuo. Los estudios de Butler han sido de gran importancia para cuestionar la idea tradicional de que los géneros son solo dos, puesto que su teoría del continuo plantea que no hay razón para suponer que a un sexo le corresponde solo un género y que incluso aunque el sexo fuera invariable no necesariamente los géneros seguirán siendo dos. (Tarrés, 2013, p 187).

Más allá de estas diferencias en las aproximaciones teóricas conceptuales, la categoría género ha hecho posible leer en diferentes constructos sociales las desigualdades y el ejercicio del poder en las relaciones entre hombres y mujeres generando profundas transformaciones al cuestionar el orden establecido. Incluso incorporando el análisis de Butler sobre el continuo, si el sexo y el género son culturales todo es posible de transformar y por tanto la realidad de los discriminados es posible superarla.

Por los elementos señalados, el género no ha estado ausente en las estrategias de desarrollo, durante la década de los 80 se incorporó esta categoría como parte de las políticas de desarrollo promovidas por las agencias partes del sistema de Naciones Unidas, especialmente como consecuencia del impulso que generaron las Conferencias de la Mujer promovidas por Comisión de la Condición Jurídica y Social de la Mujer.

En un primer momento, el género en el desarrollo se asoció a la búsqueda de estrategias para empoderar a las mujeres y alcanzar la equidad entre los sexos, se partía del reconocimiento que las relaciones entre hombres y mujeres eran desiguales y que era necesario nivelar el terreno de juego para garantizar oportunidades a las mujeres en el acceso a los recursos, autonomía y toma de decisiones. Durante esta primera etapa se hizo énfasis en el reconocimiento del triple rol que ejercían las mujeres al considerar sus aportes en el mundo de lo productivo, reproductivo y comunitario. Con este enfoque se dejaban de lado las políticas de desarrollo que se habían enfocado en considerar a las mujeres como el centro del problema y para resolverlo bastaba con incorporarlas a procesos productivos, y generar programas de carácter asistencial preferentemente dirigidos al binomio madre / 
hijo. En esta lógica las mujeres son funcionales para el desarrollo. (De la Cruz, 1999, p 56)

Actualmente, el género en el desarrollo ha tenido una variación producto del acercamiento que se ha venido construyendo a partir de los noventa entre el desarrollo y los derechos humanos. De esta forma el desarrollo hoy en día incorpora a la igualdad entre los géneros como una condición para alcanzar el desarrollo sostenible y por tanto las políticas públicas deben tomar en cuenta entre sus acciones aquellas dirigidas a garantizar a las mujeres acceso, control y poder sobre los recursos y sus relaciones como una condición para la igualdad y para el desarrollo.

La incorporación del género al desarrollo ha sido una herramienta útil para analizar y comprender los cambios que experimentan las sociedades y ha brindado explicaciones a problemas sociales de diverso orden relacionados con el uso y control de los recursos, los roles de género y las políticas de redistribución, las posibilidades de regular el espacio doméstico, y la comprensión de las dinámicas de los espacios privados como áreas de disputa de poder y de desigualdad, entre otras. Para ello, se ha promovido como principal herramienta la transversalización de género o mainstreaming ${ }^{72}$.

La transversalización de género es una estrategia para alcanzar la igualdad entre los géneros, y desde este abordaje la igualdad es comprendida como las garantías que se generan para que los sujetos sociales accedan a la redistribución y el reconocimiento. Los aspectos relacionados con lo distributivo se refieren a las estructuras específicas

72 El Consejo Económico y Social de las Naciones Unidas define mainstreming como: "transversalizar la perspectiva de género es el proceso de valorar las implicaciones que tiene para los hombres y para las mujeres cualquier acción que se planifique, ya se trate de legislación, políticas o programas, en todas las áreas y en todos los niveles. Es una estrategia para conseguir que las preocupaciones y experiencias de las mujeres, al igual que las de los hombres, sean parte integrante en la elaboración, puesta en marcha, control y evaluación de las políticas y de los programas en todas las esferas políticas, económicas y sociales, de manera que las mujeres y los hombres puedan beneficiarse de ellos igualmente y no se perpetúe la desigualdad. El objetivo final de la integración es conseguir la igualdad de los géneros.” (ECOSOC, 1997) 
de género que generan formas de injusticia en el acceso y uso de los recursos y servicios, incluyendo la explotación basada en género y la marginación. Por su parte, el reconocimiento busca modificar los patrones culturales institucionalizados que no permiten que los miembros de una sociedad accedan a participar plenamente en la interacción social gozando de los beneficios que esta proporciona. La ausencia de reconocimiento genera discriminación, exclusión o marginación y por tanto negación o falta de garantía de derechos (Fraser, 1997). Es la interdependencia entre redistribución y reconocimiento y su equilibrio, lo que hace posible la igualdad entre los géneros, y para lograrlo hay que partir del reconocimiento de las diferencias que existen entre los sujetos sociales, puesto que la intervención social deberá generar medidas temporales para alcanzar esa igualdad.

Incorporar el análisis de género en las políticas públicas - entendidas estas, como los planes y programas de carácter gubernamental y como las normas y leyes que regulan un Estado,- es ante todo una decisión política de evidenciar que las diferencias entre los géneros han ocasionado desigualdades en el ejercicio de los derechos y es una apuesta por modificar las estructuras de poder vigentes ya que al redistribuir y reconocer se modifican las relaciones de poder cuyo último resultado es la igualdad. Por ello, no es extraño, aunque sí peyorativo, que un sector que se opone a la incorporación del género como categoría de análisis en las políticas públicas se refiera a esto como "ideología de género" puesto que efectivamente es una apuesta política transformadora. El uso de la expresión "ideología de género” fue inicialmente de la Iglesia Católica y más tarde retomada por otras iglesias cristianas, su principal objeción es justamente al aspecto transformador que aporta el análisis de género ya que se cuestiona que este se base en el hecho que el sistema sexo/género sea socialmente construido y no se reconozca como una creación divina y por tanto inmodificable (Lemaitre, 2016, p1).

El género es una herramienta clave para realizar análisis social que al aplicarla permite dar una explicación de porqué ocurre determinada situación social, pero el género no es el sujeto de la discriminación. El sujeto de la discriminación es la persona individual o el sujeto colectivo que al no recibir igualdad en el trato por su condición/situación de 
género no accede a la distribución y uso de los recursos y no goza del reconocimiento social suficiente para acceder de lleno a los beneficios de la interacción social o dicho en otras palabras se le vulneran sus derechos humanos por razones de género. Comúnmente, la desigualdad entre los géneros se ha aplicado a las relaciones entre hombres y mujeres. No obstante, la aplicación del análisis de género, también permite analizar la desigualdad que afecta a aquellas personas que adquieren un género no hegemónico al mandato social imperante. Por tal razón, se ha aplicado el análisis de género a las discriminaciones que afectan a sujetos individuales y colectivos homosexuales, bisexuales, transgéneros, intergéneros u otra categoría que implique alguna forma de desigualdad de género.

El análisis de género permite leer la realidad social, pero en parte, ya que no es unívoco, puesto que el sujeto individual y colectivo no es definido y construido sólo por su género. En las sociedades se han producido y reproducido otras formas de jerarquización social que generan discriminación y vulneración de derechos y que son necesarias de considerar. El valioso aporte del género es que explica un tipo de relacionamiento social, el dado por el sistema sexo - género que a pesar de su carácter histórico, no había sido considerado como un factor de desigualdad y discriminación y por ende de vulneración de derechos, afectando a más de la mitad de la población.

Así el género como categoría de análisis ha evolucionado y adquirido en estos años nuevos constructos que permiten considerarlo como un dispositivo para la igualdad política y social y que en un análisis multifactorial con otros elementos como el étnico, la clase o la raza tiene un potencial transformador de las desigualdades y la discriminación aportando a la garantía de derechos y a la igualdad sustantiva.

\section{Los derechos de las mujeres y el género}

Solo en 1993, durante la Conferencia Mundial de las Naciones Unidas en Viena se reconoció que los derechos de las mujeres son parte inalienable, integrante e indivisible de los derechos humanos universales, reconocimiento bastante tardío para el avance que en ese momento ya había alcanzado el derecho internacional de los derechos humanos en 
materia de garantía y protección de los derechos de las mujeres. Por ejemplo, la Convención sobre la Eliminación de Todas las Formas de Discriminación contra la Mujer, en adelante CEDAW, había sido firmado por los Estados partes de Naciones Unidas en 1979. Por tanto, más allá del reconocimiento formal de los derechos de las mujeres como parte del corpus de los derechos universales, ya se contaba con el principal instrumento universal a favor de la igualdad de las mujeres.

La Convención de la CEDAW se fundamenta en el principio de no discriminación que implica terminar con cualquier barrera que anule o menoscabe la igualdad para las mujeres. La CEDAW define en su artículo 1 discriminación contra la mujer como aquella que:

\begin{abstract}
...denotará toda distinción, exclusión a restricción basada en el sexo que tenga por objeto o por resultado menoscabar o anular el reconocimiento, goce o ejercicio por la mujer, independientemente de su estado civil, sobre la base de la igualdad del hombre y la mujer, de los derechos humanos y las libertades fundamentales en las esferas política, económica, social, cultural y civil o en cualquier otra esfera. (Cedaw 1979, p 2).
\end{abstract}

En estricta correlación con el artículo 1, la CEDAW en su artículo 2 se refiere a la igualdad, al señalar que los Estados Partes, no solo condenarán la discriminación sino que generarán políticas para garantizar la igualdad formal y de factor ${ }^{73}$. Incluso más allá, en su artículo 4

73 En el artículo 2 señala las siguientes medidas: a) Consagrar, si aún no lo han hecho, en sus constituciones nacionales y en cualquier otra legislación apropiada el principio de la igualdad del hombre y de la mujer y asegurar por ley u otros medios apropiados la realización práctica de ese principio; b) Adoptar medidas adecuadas, legislativas y de otro carácter, con las sanciones correspondientes, que prohíban toda discriminación contra la mujer; c) Establecer la protección jurídica de los derechos de la mujer sobre una base de igualdad con los del hombre y garantizar, por conducto de los tribunales nacionales o competentes y de otras instituciones públicas, la protección efectiva de la mujer contra todo acto de discriminación; d) Abstenerse de incurrir en todo acto a práctica de discriminación contra la mujer y velar porque las autoridades e instituciones públicas actúen de conformidad con esta obligación; e) Tomar 
estipula que no puede considerarse discriminación a aquellas medidas de carácter temporal que los Estados partes implementen para acelerar la igualdad de facto entre el hombre y la mujer. Estas medidas temporales y sus respectivas políticas han sido interpretadas como el mainstreaming o enfoque de género en las políticas.

Dado el contexto histórico al momento de elaboración de la CEDAW, el texto de la Convención no hace referencia explícita al concepto de género. No obstante, señala en su artículo 5 que los Estados Partes deberán tomar medidas para "Modificar los patrones socioculturales de conducta de hombres y mujeres, con miras a alcanzar la eliminación de los prejuicios y las prácticas consuetudinarias y de cualquier otra indole que estén basados en la idea de la inferioridad o superioridad de cualquiera de los sexos o en funciones estereotipadas de hombres y mujeres". (CEDAW, 1979, p 4). Como se verá más adelante, los elementos mencionados en este artículo de la Convención constituyen categorías básicas del análisis de género.

En estos últimos 40 años el reconocimiento de los derechos humanos de las mujeres ha tenido un desarrollo progresivo tanto al interior del sistema de Naciones Unidas como el sistema interamericano. Estos instrumentos normativos como la jurisprudencia proferida coinciden en referirse a la discriminación que afecta a las mujeres como una discriminación histórica, idéntico concepto usado en otros instrumentos internacionales que refieren a la discriminación histórica, que por ejemplo, afecta a la población indígena u originaria y a la población afro descendiente y otras diferentes formas de racismo, dado que la discriminación hacia las mujeres y el racismo han estado presentes a través de la historia en todas las formas de organización socio política y económica sin que se haya logrado superarla del todo (Garay: 2008, p 271).

\section{El Comité de la CEDAW y el género}

todas las medidas apropiadas para eliminar la discriminación contra la mujer practicada por cualesquiera personas, organizaciones o empresas; f) Adaptar todos las medidas adecuadas, incluso de carácter legislativo, para modificar o derogar leyes, reglamentos, usos y prácticas que constituyan discriminación contra la mujer; g) Derogar todas las disposiciones penales nacionales que constituyan discriminación contra la mujer. 
Para la Convención y para las interpretaciones del Comité de la CEDAW, es claro que el sujeto de la discriminación es la mujer(es) en la cual las características atribuibles a su sexo y a su género son las que generan la discriminación. El Comité de la CEDAW ha profundizado en la temática de género particularmente en la Recomendación General 28 y en la reciente Recomendación General 35 permitiendo una interpretación progresiva que ha fortalecido los estándares de derechos humanos.

En particular, la Recomendación General 28 aclara el alcance y el significado del artículo 2 de la Convención de la CEDAW. En su parágrafo 5 señala:

\begin{abstract}
El término "sexo" se refiere aqui a las diferencias biológicas entre el hombre y la mujer. El término "género" se refiere a las identidades, las funciones y los atributos construidos socialmente de la mujer y el hombre y al significado social y cultural que la sociedad atribuye a esas diferencias biológicas, lo que da lugar a relaciones jerárquicas entre hombres y mujeres y a la distribución de facultades y derechos en favor del hombre y en detrimento de la mujer. El lugar que la mujer y el hombre ocupan en la sociedad depende de factores políticos, económicos, culturales, sociales, religiosos, ideológicos y ambientales que la cultura, la sociedad y la comunidad pueden cambiar”. (Comité CEDAW, 2010, p 2)
\end{abstract}

Este punto entonces permite afirmar que la discriminación por motivos de género está contenida en el artículo 1 de la Convención, lo que supone que los Estados partes tienen la obligación de no discriminar por razones de género a las mujeres ya sea por acción u omisión y deben tomar las medidas para prevenirlas ya sean cometidas por el Estado o por particulares. Incluso, el Comité señala que la intervención que puede realizar el Estado partiendo del supuesto de que las políticas son neutras puede ser considerado discriminación por omisión, si priva a las mujeres de sus derechos o no toma en cuenta las desventajas por motivos de género (Comité CEDAW, 2010, 2).

La Recomendación General 28, también avanza en desarrollar el concepto de discriminación directa e indirecta al señalar que la 
discriminación directa contra las mujeres "es la que supone un trato diferente fundado explícitamente en las diferencias de sexo y género. La discriminación indirecta contra la mujer tiene lugar cuando una ley, una política, un programa o una práctica parece ser neutra por cuanto se refiere tanto a los hombres como a las mujeres, pero en la práctica tiene un efecto discriminatorio contra la mujer porque las desigualdades preexistentes no se han tenido en cuenta en la medida aparentemente neutra" (Comité CEDAW, 2010, p 4). Así mismo, el Comité vuelve a señalar como ya lo había hecho en la Recomendación General 19, que la violencia contra las mujeres por motivos de género $^{74}$ es una forma de discriminación y que puede constituir una violación a la Convención, aunque la CEDAW no mencione expresamente el concepto de violencia.

Es interesante para los propósitos de este artículo mencionar que esta Recomendación iguala los términos principio de igualdad entre el hombre y el de la mujer con el de igualdad entre los géneros. Además, introduce el concepto de interseccionalidad, al señalar "que la discriminación de la mujer por motivos de sexo y género está unida de manera indivisible a otros factores que afectan a la mujer, como la raza, el origen étnico, la religión o las creencias, la salud, el estatus, la edad, la clase, la casta, la orientación sexual y la identidad de género. La discriminación por motivos de sexo o género puede afectar a las mujeres de algunos grupos en diferente medida o forma que a los hombres" (Comité CEDAW, 2010, p 5).

Por su parte, la Recomendación General 35 emitida este año, proporciona a los Estados orientaciones complementarias a la Recomendación General 19 para avanzar en la eliminación de la violencia de género contra las mujeres. Complementa la aplicación del concepto de interseccionalidad al incorporar tácitamente variables como:

...etnia / raza, situación indígena o minoritaria, color, condición socioeconómica y lo casta, idioma, religión o creencias, opiniones

74 La Recomendación General 19 define la violencia basada en el género, como aquella dirigida contra una mujer porque es hecho de ser una mujer o que la afecta desproporcionadamente. 
politicas, origen nacional, estado civil y / o maternidad, edad, situación de salud, discapacidad, propiedad, ser lesbiana, bisexual, transgénero o intersexual, analfabetismo, trata de mujeres, conflicto armado, buscar asilo, ser refugiado, desplazamiento interno, apátrida, migración, jefas de hogares, viudez, vivir con VIH, las mujeres que luchan por sus derechos, incluidos los defensores de los derechos humanos ${ }^{75}$ (Comité CEDAW, 2017, p 4).

El Comité reconoce que la violencia de género - expresión de discriminación- afecta a las mujeres en diferentes grados y con un efecto agravante, también señala que la discriminación está presente en todos sus ciclos de vida, por tanto incluye a las niñas como víctimas de violencia de género.

En el parágrafo 19 de la Recomendación 35, se expresa que la violencia de género contra las mujeres se encuentra enraizada en " $\mathrm{fac}$ tores relacionados con el género, como la ideología del derecho y el privilegio de los hombres sobre las mujeres, las normas sociales relativas a la masculinidad, la necesidad de asegurar el control o el poder masculino, prevenir, desalentar o castigar lo que se considera un comportamiento femenino inaceptable"76 (Comité CEDAW, 2017, p 6). Situaciones que permiten la aceptación social y por ende la impunidad frente a estos casos.

También es de destacar que esta Recomendación General, enfatiza en la necesidad de garantizar una reparación efectiva a las víctimas de violencias de género. Dicha reparación implica compensación económica y acceso a servicios de salud y legales, así como recuperación de la víctima, satisfacción y garantías de no repetición, en concordancia con otras recomendaciones del mismo Comité. Para el caso colombiano en este contexto es interesante recalcar que el Comité señala que los Estados deben establecer fondos de reparación específicos o incluir asignaciones para la violencia de género contra la mujer dentro de los

75 Traducción al español propia, no oficial.

76 Traducción al español propia, no oficial. 
fondos existentes, incluso en el marco de los mecanismos de justicia de transición. (Comité CEDAW, 2017, p 7).

Como se ha podido observar, el Comité de la CEDAW, a través de sus recomendaciones generales, ha fortalecido el corpus original permitiendo una interpretación progresiva que ha fortalecido los estándares de derechos humanos y su relación directa con el uso del concepto de género.

\section{El Sistema Interamericano y el género}

El Sistema Interamericano de Derechos Humanos tampoco se ha quedado atrás en incorporar el concepto de género, particularmente en el tratamiento de las violencias contra las mujeres. Se destaca el caso "Raquel Martín de Mejía vs. Perú” en el cual la Comisión Interamericana de Derechos Humanos, en 1996, calificó la violación sexual como tortura. Más tarde, en el 2001, con el caso "María Da Penha Maia Fernándes vs. Brasil”, la Comisión fortaleció sus argumentos, particularmente sobre la debida diligencia (Fernández, 2017, p 5).

La Corte Interamericana por su parte en el 2006 con el caso "Penal Miguel Castro-Castro vs. Perú" inició su intervención en las temáticas de género. Sin embargo su hito más relevante lo constituye la sentencia "González y otras vs. México", caso más conocido bajo el nombre de Campo Algodonero, esta sentencia avanzó en lo que respecta a la debida diligencia de los Estados y en la sanción y medidas de reparación. Señaló explícitamente que las investigaciones debían tener perspectiva de género y contar con personal calificado en la materia. Uno de los avances más relevante de caso Campo Algodonero se relaciona con la definición que proporciona la Corte con respecto a los estereotipos de género, al definirla como una preconcepción de atributos o características propias que son o se espera que sean realizadas por hombres y mujeres y que en ellas se encuentra la causa y consecuencia de la violencia contra las mujeres. Con posterioridad, en otras sentencias la Corte ha seguido usando el concepto de estereotipos de género incluidos los relacionados con orientación sexual, señalando que 
estos estereotipos pueden afectar tanto al hombre como a la mujer de manera desproporcionada (Fernández, 2017, p 8).

\section{La normativa colombiana y el género}

Si bien la Constitución Política de Colombia en su texto original no utiliza el concepto género este si ha sido incorporado con la modificación del artículo 107, mediante acto legislativo dado en el 2009, referente a los partidos y movimientos políticos, en el cual se señala que uno de sus principios rectores para su organización será la equidad de género. También algunas leyes tales como: Ley 248 de 1995, Ley 823 de 2003, Ley 984 de 2005 y la Ley 1098 de 2006, entre otras utilizan la expresión género o perspectivas de género (Campillo-Vélez: 2013).

En Colombia existe un acumulado importante, particularmente de las Altas Cortes con respecto a garantías de igualdad para las mujeres en desarrollo del artículo 13 y 43 de la Constitución Política de 1991. La Corte Constitucional se ha pronunciado sobre el tema en diversas sentencias vinculadas con derechos de familia, educación, igualdad, intimidad y dignidad, participación, salud, desarrollo de la libre personalidad, derecho a una vida libre de violencia, trabajo y derechos laborales, conflicto armado, desplazamiento, mujeres privadas de la libertad, derechos sexuales y reproductivos de las mujeres, mujeres indígenas desde una perspectiva de género entre otras ${ }^{77}$.

En particular, la Corte Constitucional relaciona las discriminaciones en el ejercicio de los derechos de las mujeres como materias de género al perpetuar estereotipos culturales. La Corte también ha asumido las diferencias entre sexo y género, asignándole a la primera un componente biológico y a la segunda un componente social impuesto a través de roles. En muchos casos utiliza los conceptos sexo y género como sinónimos aunque aclara que cuando lo hace es porque comprenden la dimensión biológica y social de manera integrada. También, esta Corte se ha pronunciado sobre las múltiples discriminaciones

77 Para mayor información se puede consultar la página web:

http://www.corteconstitucional.gov.co/inicio/equidaddegenero.php 
señalando que la discriminación que afecta a las mujeres basadas en género se expresa junto con otras discriminaciones como la étnica y la etaria (Campillo-Vélez: 2013).

\section{La discriminación múltiple}

Como ya se planteó, tanto el sistema universal a través del Comité de la CEDAW, como las instancias del sistema interamericano y la Corte Constitucional colombiana, han reconocido que la discriminación puede llegar a ser múltiple. En efecto, la identidad del sujeto individual o colectivo es múltiple, ya que se construye a partir de un conjunto de rasgos, atributos y características que lo diferencian de otros. El género $^{78}$ es un factor de discriminación para el ejercicio de los derechos, pero no es el único factor a considerar puesto que en la construcción e identidad del sujeto entran a jugar otros factores que son determinantes para generar o no discriminación como la clase, posición educativa, ubicación urbano/rural, pertenencia étnica, etaria, entre otros. Dichos factores pueden ser condicionantes o situacionales, en ambos casos es necesario un abordaje desde las multiplicidades de la discriminación para poder brindar una atención integral del sujeto social que apunte a garantizar la igualdad.

La discriminación múltiple hace referencia aquella que es producida por diversas causas o motivos -factores- de discriminación que actúan de manera conjunta y simultánea. Por tal razón, si se analiza la discriminación tomando en cuenta solo uno o solo una parte de los motivos de discriminación se corre el riesgo de realizar un análisis parcializado de la realidad. La discriminación múltiple se puede clasificar en dos tipos: la acumulativa y la interseccional. En los casos en que la discriminación se debe a la existencia, al mismo tiempo, de varios motivos o causas, en la cual un motivo se agrega a otro, se clasifica como discriminación múltiple acumulativa. Por su parte, la discriminación múltiple interseccional, hace referencia a los casos en los cuales diversos

78 Es necesario tener presente que la orientación sexual tampoco es un asunto solo determinado por el género. 
motivos o causas de discriminación al actuar de manera conjunta y simultánea producen una nueva forma de discriminación. La discriminación múltiple acumulativa puede ejemplificarse, en el caso de una mujer en situación de desplazamiento que busca trabajo, en el primer lugar que la entrevistan es rechazada porque se presume que no cuenta con las condiciones físicas para desempeñar el cargo y en el segundo lugar, es rechazada aduciendo problemas de seguridad por encontrase en situación de desplazamiento, hay dos motivos de discriminación que se añaden, el primero por ser mujer y el segundo por su situación de desplazamiento. Mientras que la discriminación múltiple interseccional se podría ejemplificar en la discriminación que sufre una mujer indígena, en tanto la discriminación que la afecta es consecuencia de la interacción de ser mujer e indígena, en la cual las vivencias de mujer e indígena coactúan, no de manera sumatoria sino reproductiva generando una nueva forma de discriminación (De Lama, 2013, 274-275).

Estos factores -causas y motivos- que generan discriminación y desigualdad se fundamentan en las diferentes formas de jerarquización social que se construyen y que responden a un momento histórico determinado. Las formas de jerarquización social actúan según tan cerca o tan lejos se esté del paradigma sociocultural de los sujetos predominantes o dominantes en una sociedad. Es decir, entre más semejanzas con los sujetos sociales predominantes o dominantes más garantías de igualdad, puesto que se hace parte de los "iguales" y viceversa, a menor semejanzas mayor desigualdad pues se constituye la otredad y es justamente la construida a partir de las diferencias entre hombres y mujeres una de las otredades más evidentes en las sociedades.

La asimetría en las relaciones de poder que genera la jerarquización social y que se expresa en la desigualdad entre los sujetos sociales es multifactorial y varía según el contexto, por ejemplo, las mujeres han sido históricamente discriminadas por razones de género pero las formas de discriminación de género no son necesariamente las mismas en el siglo XIX que en el XXI, en la cultura islámica, en la cultura judeocristiana o en las culturas indígenas. Tampoco puede equipararse la discriminación de género que afecta a las mujeres colombianas en la segunda década del siglo XXI con las mismas desigualdades como si fueran un todo y único conjunto social, ya que la discriminación de 
género estará mediada por otras formas de discriminación que afectarán a las mujeres (y a lo considerado femenino) y que interactuarán como un dispositivo acumulador de la discriminación o como dispositivo de otras nuevas discriminaciones.

\section{El enfoque diferencial de derechos}

Actualmente es recurrente en el campo de las ciencias sociales utilizar el término enfoque diferencial como herramienta para abordar los problemas sociales y las estrategias para afrontarlos, se utiliza para estudios cuantitativos como cualitativos, permite realizar análisis desagregados para dar cuenta de la diversidad que compone la realidad social, particularmente incluyen variables de análisis como sexo, género, etnia, edad, urbano/rural, entre otros.

En materia de enfoque diferencial se han registrado importantes avances en desagregación de información cuantitativa. También, se registran avances en análisis cualitativos, en el caso concreto de los estudios de género, se ha avanzado en áreas diversas, tanto de la vida pública como privada, destacan los estudios sobre trabajo, mercado laboral, informalidad, economía del cuidado, participación social y política, educación, salud, violencia, entre otros. Incluso en algunos casos se ha avanzado en estudios que incorporan otros motivos de discriminación que han permitido no solo caracterizar las diferencia entre hombres y mujeres generadoras de discriminación sino también las diferencias entre las mujeres incorporando variables como la etnia, la edad o el nivel educativo, entre otras.

Si bien las desigualdades existentes en la sociedad generadoras de discriminación han sido abordadas por las políticas públicas desde diferentes perspectivas con el propósito de alcanzar el desarrollo, en estos últimos años se ha posicionado como una alternativa la del enfoque diferencial de derechos. Particularmente en América Latina, se ha recurrido a la aplicación del enfoque diferencial de derechos, como mecanismo para la superación de las múltiples discriminaciones que afectan a los sujetos sociales. No sobra señalar, que tanto en la incorporación del género en particular como del enfoque diferencial de derechos en general en las políticas públicas, han jugado un papel 
fundamental los movimientos sociales y de derechos humanos en especial el de mujeres y feministas.

El enfoque diferencial de derechos busca considerar a los sujetos desde la diversidad y diferencias que los constituyen, es decir desde el reconocimiento de las identidades múltiples y las diversas formas de discriminación que pueden generar basándose en la obligación del Estado de proteger los derechos fundamentales aplicándolo al conjunto de la intervención social - análisis, actuación y evaluación- que se realiza desde el Estado a través de políticas públicas. Básicamente se busca que el sujeto social de la intervención pública sea considerado un sujeto con derechos y con capacidad de exigibilidad en el cual el Estado tiene la obligación y responsabilidad de actuar. Sin duda, este enfoque es una clara evidencia del vínculo entre derechos humanos y desarrollo, en el cual la guía del desarrollo se sustenta en el marco conceptual del derecho internacional de los derechos humanos (Abramovich, 2004, p 7).

Discursivamente en las políticas públicas que se diseñan e implementan en Colombia ${ }^{79}$ suele separarse el enfoque diferencial del enfoque de género, probablemente con la intención política de enfatizar específicamente en el enfoque de género como condición sine qua non de la intervención pública que se realice, aunque no se puede desconocer que el uso del género como categoría de análisis es un herramienta del enfoque diferencial puesto que el reconocimiento de los derechos de las mujeres y de las minorías con género no dominante se hace efectivo a través del análisis de género en todo el ciclo de la planeación ${ }^{80}$. El género es un componente del enfoque diferencial de derechos.

79 Un claro ejemplo se encuentra en los LINEAMIENTOS DE LA POLÍTICA PÚBLICA NACIONAL DE EQUIDAD DE GÉNERO PARA LAS MUJERES y en el CONPES 161 que contiene la política pública para las mujeres del gobierno nacional para el período 2013 - 2016. También, el ACUERDO FINAL PARA LA TERMINACIÓN DEL CONFLICTO Y LA CONSTRUCCIÓN DE UNA PAZ ESTABLE Y DURADERA firmado por el gobierno de Colombia y la FARC - EP, diferencia para garantizar derechos tres enfoques: de género, territorial y diferencial.

80 Dado que reconoce la existencia de una desigualdad de género entre hombres y mujeres y las minorías que adquieren un género no hegemónico al mandato 
Teóricamente, el enfoque diferencial de derechos permite implementar acciones afirmativas que contribuirían a garantizar la igualdad sustantiva y finalmente a transformar los imaginarios sociales y culturales que están en la base de las diversas formas de discriminación. No obstante, llevar el enfoque a la implementación de la intervención social no es tarea fácil. Es posible plantear que a la hora de avanzar en la intervención social, el enfoque diferencial de derechos -incluido el de género- comienza a perder la riqueza del reconocimiento de las identidades múltiples que interactúan socialmente y por ende de las discriminaciones múltiples que lo afectan generando una intervención que fragmenta o compartimenta al sujeto social y que genera una sectorialización de la intervención que muchas veces profundiza la discriminación, dado que no logra atender las múltiples discriminaciones de manera articulada y/o enfrenta o polariza a los grupos sociales por el acceso a los recursos que proporciona la intervención. Esto no significa que se quiera afirmar que el enfoque diferencial de derechos no se constituya en una vía efectiva para garantizar que las políticas públicas contribuyan a superar las desigualdades, solo que en la práctica presenta tensiones que requieren ser atendidas.

El enfoque diferencial de derechos - incluido el de género- en las políticas públicas tiene un gran potencial puesto que parte de reconocer que los grupos discriminados y por tanto excluidos de los beneficios del desarrollo tienen derechos, es otorgarles de entrada un poder para la exigibilidad. Además este enfoque asume como punto de partida que los derechos son interdependientes, situación que implica que el abordaje de las políticas debe ser multisectorial. Y si bien como lo plantea Abramovich, "los derechos no nos dicen mucho acerca del contenido de las políticas, pero si pueden decirnos algunas cosas sobre su orientación general y nos brindan un marco de conceptos que debe guiar su formulación y su implementación” (Abramovich, 2004, p 8).

social imperante, pero también reconoce a las mujeres - y a las minorías con género no hegemónico como un conjunto heterogéneo los cuales no son posibles de generalizar, puesto que la vivencia del género está determinada por la interacción de otras diferencias y diversidad sociocultural que pueden generar o no generar discriminaciones múltiples. 
En otras palabras el enfoque diferencial de derechos no señala las acciones que debe emprenderse sino las orientaciones que deben seguirse en las políticas públicas. Orientaciones que pueden resumirse en las obligaciones de los Estados de respetar, proteger, garantizar y promover el derecho o los derechos que están siendo abordados a partir de los estándares del derecho internacional de los derechos humanos. Como lo señala Abramovich, citando a Van Hoof y a Asbjorn Eide: "Las obligaciones de respetar se definen por el deber del Estado de no injerir, obstaculizar o impedir el acceso el goce de los bienes que constituyen el objeto del derecho. Las obligaciones de proteger consisten en impedir que terceros injieran, obstaculicen o impidan el acceso a esos bienes. Las obligaciones de garantizar suponen asegurar que el titular del derecho acceda al bien cuando no puede hacerlo por si mismo. Las obligaciones de promover se caracterizan por el deber de desarrollar condiciones para que los titulares del derecho accedan al bien" (Abramovich, 2004, p 16).

En particular, para la concreción del principio de igualdad y no discriminación, el enfoque diferencial de derechos permite avanzar hacia la igualdad sustantiva (igualdad material) puesto que exige al Estado la protección especial de los grupos afectados por condiciones/situaciones de discriminación histórica que deben concretarse en medidas efectivas e inmediatas que transformen esa desigualdad basándose en los desarrollos del derecho internacional de los derechos humanos. Concurrente con esto, supone desarrollar también los mecanismos para la participación tomando en cuenta las particularidades de los grupos excluidos y las medidas especiales para garantizar la participación, así como el acceso a la información pública y a los procesos de rendición de cuentas (Abramovich, 2004, p 32).

El enfoque de derechos es un deber ser, un paradigma de desarrollo que busca alcanzar el desarrollo a través de la garantía de los derechos humanos, orienta el camino que las políticas públicas deben seguir, responde al para qué alcanzar el desarrollo y al por qué. Para que el sujeto social ejerza sus derechos como garantía para la superación de la desigualdad y esto porque las personas son sujetos de derechos exigibles al Estado y este tiene la obligación de garantizárselos. No obstante, no define el cómo hacerlo, aunque dice qué aspectos deben 
considerarse para garantizar que lo que se realice cuente con participación, información pública y rendición de cuentas. El Estado es el que define -con la participación de los sujetos sociales- qué acciones en concreto se implementarán y cuales no se implementarán para garantizar los derechos.

Teóricamente durante el proceso de diseño de una política puede aplicarse un test de estándares de derechos humanos y determinar, el cumplimiento o no de esos estándares. Sin embargo, a la hora de implementar la política no es tan fácil señalar qué acciones se van a priorizar -con la participación de los involucrados- para garantizar que los estándares de derechos humanos se alcancen. Situación que se complejiza aún más por los recursos limitados, incluyendo tiempo y debilidades en la inversión económica que se realiza.

Tampoco será fácil realizar la evaluación de la política, puesto que lo que se requiere medir no es solo lo que tangiblemente se realizó sino aquello que transformó al sujeto social de la política como garante del derecho. Es decir, la ejecución fue capaz de permitir la superación de la vulneración y los sujetos sociales superaron su situación/condición de discriminación.

Por ello, sin duda los mayores desafíos del enfoque se encuentran en la definición de las acciones concretas que se deberán aplicar para garantizar derechos, puesto que entran a jugar en las decisiones aspectos como recursos, actores involucrados, prioridades institucionales, entre otras. Pero tal vez la mayor complejidad está dada por el vínculo entre reconocimiento de las múltiples discriminaciones que afectan al sujeto social, la interdependencia de los derechos y el fin último de garantizar la superación de la discriminación.

Por ejemplo, en una política para la igualdad de derechos entre hombres y mujeres en Colombia, no solo deberán considerarse las diferencias entre mujeres y hombres en el acceso y uso de los recursos y el reconocimiento que gozan en la sociedad, sino que será necesario considerar las diferencias que existen entre las mujeres que componen la población colombiana. El objeto de la política son las mujeres colombianas en su totalidad, incluso es posible que en general la exigibilidad de derechos sea la misma, derechos a una vida libre de violencia, derecho a la salud, a la participación, etcétera. Es decir, se está 
reconociendo la diversidad del sujeto y la interdependencia de derechos, pero la acción dirigida a una niña urbana en edad escolar para garantizarle sus derechos será muy distinta a la de una mujer indígena desplazada. A ambas habrá que garantizarles sus derechos a la igualdad como mujeres -parte de un colectivo históricamente discriminado-, pero en una deberá considerarse la variable etaria y en la otra se considerarán su origen étnico y su situación de desplazamiento de manera interdependientes reconociendo la discriminación múltiple, y aunque se consideren las diferencias a la hora de aplicar la intervención no hay garantía de transformación de la realidad.

En los casos que se busque garantizar más de un derecho o en los cuales los sujetos a los que se le dirige la política son diversos y con interseccionalidad de discriminaciones la definición es aún más compleja puesto que la intervención deberá ser múltiple aún más si se busca la superación de una discriminación histórica. A esto hay que agregarle, el hecho que en general en América Latina las políticas públicas no han tenido vocación de derecho sino un fuerte componente asistencial u objetivando al sujeto, siendo la persona un objeto al servicio del desarrollo y no el centro de este.

Por tanto, no es solo necesario aplicar a las políticas públicas unos test para verificar si cumplen o no con los estándares internacionales de derechos ni puede reducirse a que los tribunales nacionales e internacionales se pronuncien si los Estados están o no cumpliendo o que los sujetos realicen exigibilidad de derechos a través de los tribunales. Por tal razón, para que las acciones concretas que se realicen garanticen los derechos del sujeto social focalizado y generen la superación de la igualdad identificada, sería necesario contemplar, los siguientes supuestos:

a. La sociedad en su conjunto ha realizado un pacto social para superar las desigualdades como apuesta de desarrollo, es decir, existe un compromiso social con la igualdad: Para ello, es necesario un diálogo social de carácter integral promovido por el Estado con la participación de los diversos grupos sociales, que permita apuestas globales de desarrollo y no fraccione o compartimente a los sujetos. Es decir, que el diálogo social genere un poder que sume positivo, en el cual las políticas que 
se implementen se reviertan en una ganancia exponencial para todos los sujetos discriminados y no solo para aquellos que reciben el beneficio directo, así se reducen las competencias entre desiguales por escasos recursos y el temor de los que ya han alcanzado los beneficios del desarrollo de perder sus derechos.

b. Aplicación de test de estándares en derechos humanos: Las políticas deben garantizar los estándares mínimos de derechos humanos y no puede justificarse una política que por considerar la diversidad cultural no respete dichos mínimos.

c. Se ha difundido al conjunto de la sociedad la información sobre la intervención incluido objetivos, presupuesto y prioridades y se realizan procesos de rendición de cuentas periódicos y participativos.

d. La política pública responde a un criterio de universalidad pero focalizado: es decir están dirigidas a un grupo o colectivo al cual se le ha vulnerado un derecho o más de uno y se encuentra en situación de vulnerabilidad o discriminación. Los objetivos a lograr y los resultados son de carácter universal pero la definición de acciones es focalizada, y para realizar dicha focalización es necesario tomar en cuenta los otros factores de discriminación que intervienen.

e. La política define con precisión qué derechos debe garantizar para superar la discriminación que busca atender, pero la intervención en su conjunto debe tomar en cuenta otras formas de discriminación que afectan al sujeto y debe ser complementaria con otras intervenciones.

f. Responden a realidades territoriales: Las acciones que implementen las políticas se deben definir en el territorio físico o simbólico. Esto significa que siendo el mismo objetivo la acción depende de las múltiples discriminaciones que interfieren en el sujeto y que se viven en un territorio. El territorio cumple un papel fundamental como espacio para la definición del que se hará en la intervención. En esta lógica las unidades 
administrativas requieren ser descentralizadas o con poder para la toma de decisiones, incluida la inversión, para estar a cargo de la intervención social.

Las condiciones necesarias para la aplicación del enfoque diferencial de derechos hacen pensar que se requiere de una reingeniería social e institucional que haga posible el piso adecuado para implementarlo, pues si no, se corre el riesgo de acciones aisladas con inversiones poco proporcionadas a las realidades que se quieren modificar, con fuerte desgaste para los sujetos sociales involucrados y con competencia entre grupos discriminados para hacer exigibles sus derechos. Así mismo, se corre el riesgo de generar un sobre uso de los sistemas de justicia para la exigibilidad de derechos, cuyos pronunciamientos pasan a ser declarativos por la incapacidad del Estado de dar respuestas oportunas y pertinentes (Abramovich, 2004, p 35).

\section{Conclusiones}

El escenario del post conflicto colombiano es un momento propicio para reconocer las diversas formas de discriminación que han afectado en el marco del conflicto y fuera de él a los sujetos sociales, entre ellos a las mujeres y a las minorías de género no hegemónico. Esto porque la finalización del conflicto armado a través de la firma del Acuerdo de Paz, se constituye en un nuevo pacto social, en el cual se reconoce, entre otros, que el conflicto reprodujo diversas formas de discriminación social, la afectación en las víctimas y el efecto que tuvo en ellas, según sus particularidades, así como el compromiso estatal para la implementación del Acuerdo a través de planes y políticas con la participación del conjunto de la sociedad colombiana.

El Acuerdo Final incluye alrededor de 120 medidas que reconocen el impacto diferencial que el conflicto tuvo en las mujeres y la población LGBTI (Plataforma Cinco Claves, 2017). Estas medidas, en conjunto con otras de reconocimiento a las diversidades y de poblaciones afectadaspor diversas formas de discriminación, serán implementadas a través de leyes y políticas públicas a nivel nacional y territorial. En otras palabras, es un escenario para hacer posible, el 
enfoque diferencial de derechos en las políticas públicas del postconflicto colombiano. El texto del Acuerdo señala ${ }^{81}$ :

El Acuerdo está compuesto de una serie de acuerdos, que sin embargo constituyen un todo indisoluble, porque están permeados por un mismo enfoque de derechos, para que las medidas aquí acordadas contribuyan a la materialización de los derechos constitucionales de los colombianos y colombianas. El Acuerdo Final reconoce, sin discriminación alguna, la primacía de los derechos inalienables de la persona como fundamento para la convivencia en el ámbito público y privado, y a la familia como núcleo fundamental de la sociedad y los derechos de sus integrantes. La implementación del Acuerdo deberá regirse por el reconocimiento de la igualdad y protección del pluralismo de la sociedad colombiana, sin ninguna discriminación. En la implementación se garantizarán las condiciones para que la igualdad sea real y efectiva y se adoptarán medidas afirmativas en favor de grupos discriminados o marginados, teniendo en cuenta el enfoque territorial, diferencial y de género (Gobierno de Colombia Y FARC - EP: 2016, p 6).

Así numerosos desafíos se vislumbran para garantizar el éxito del proceso, y en particular en materia de garantía de derechos y superación de las múltiples discriminaciones. Estos desafíos podrán ser superados en la medida en que el Estado colombiano genere un diálogo social

81 El nuevo Acuerdo Final para la Paz, señala en su página 3: Subrayando que el nuevo Acuerdo Final presta especial atención a los derechos fundamentales de las mujeres, de los grupos sociales vulnerables como son los pueblos indígenas, las niñas, niños y adolescentes, las comunidades afrodescendientes y otros grupos étnicamente diferenciados; de los derechos fundamentales de los campesinos y campesinas y de los derechos esenciales de las personas en condición de discapacidad y de los desplazados por razones del conflicto; de los derechos fundamentales de las personas adultas mayores y de la población LGBTI. GOBIERNO DE COLOMBIA Y FARC - EP. Acuerdo Final para la Terminación del Conflicto y la Construcción de una Paz Estable y Duradera. 24.11.2016. Disponible en: http:// www.altocomisionadoparalapaz.gov.co/procesos-y-conversaciones/Documentos $\% 20$ compartidos/24-11-2016NuevoAcuerdoFinal.pdf 
con participación y representación de los diversos grupos sociales, generando alianzas que superen la fragmentación y polarización política que existe actualmente. Se requiere a su vez un ejercicio permanente de la sociedad civil y de la justicia colombiana, para garantizar que en la implementación de las políticas públicas del post conflicto se apliquen los estándares del derecho internacional de los derechos humanos. También, es necesario no solo garantizar la difusión del proceso sino fomentar la participación ciudadana y realizar acciones de control y rendición de cuentas en el marco de los principios de transparencia y anticorrupción.

Las acciones que se adelanten deberán en la práctica articular de manera integral los enfoques de género, territorial y diferencial, garantizando el criterio de universalidad y focalización de las políticas públicas, brindando una atención integral que permita la superación de las múltiples discriminaciones que atraviesan a los sujetos sociales.

El Acuerdo de Paz contempla la creación de un nuevo aparato institucional como soporte para las medidas que busca implementar, no obstante, es necesario garantizar un diálogo fluido con las instancias estatales preexistentes al Acuerdo de Paz, para evitar por un lado, choques institucionales, y por otro, para que la inversión social que adelante el conjunto del Estado colombiano se revierta no solo en la superación del impacto del conflicto sino en el desarrollo del país, expresado en un Estado que garantiza la igualdad sustantiva al conjunto de su diversa y plural sociedad.

De no superarse estos desafíos no solo los procesos de exigibilidad de derechos aumentarán en número en el sistema de justicia sino muy probablemente el Acuerdo de Paz será uno más de los intentos de construcción inacabados en su propósito de garantizar el enfoque diferencial de derechos, particularmente para las mujeres y las minorías con género no hegemónico.

\section{Referencias bibliográficas}

Abramovich, Víctor. (2004)“Una Aproximación al Enfoque de Derechos en las Estrategias y Políticas de Desarrollo de América Latina”. Documento preparado para "Derechos y Desarrollo en América Latina: Una Reunión 
de Trabajo" Santiago, Chile Diciembre 9 y 10 del 2004. Disponible en: http://www.dhl.hegoa.ehu.es/ficheros/0000/0057/enfoque_de_dchos_en_ estrategias_y_politicas_desarrollo_Am_Lat.pdf

Abramovich, Víctor. "De las violaciones masivas a los patrones estructurales: nuevos enfoques y clásicas tensiones en el Sistema Interamericano de Derechos Humanos". V. 6 No. 11, Revista SUR Revista Internacional de Derechos Humanos, 2009. Disponible en: http://www.corteidh. or.cr/tablas/r24902.pdf

Campillo-Vélez, Beatriz Eugenia, (2013) "La ideología de género en el derecho colombiano", en Díkaion 22-1. pp. 13-54. Universidad de La Sabana. Disponible en: http://dikaion.unisabana.edu.co/index.php/dikaion/ article/view/2784/3259

Naciones Unidas. (1979). Convención sobre la eliminación de todas las formas de discriminación contra la mujer - CEDAW. Disponible en: www. un.org/womenwatch/daw/cedaw/text/sconvention.htm

Comité De La Cedaw. Recomendación General 28 relativa al artículo 2 de la Convención sobre la eliminación de todas las formas de discriminación contra la mujer. Disponible en: http://www.right-to-education.org/sites/right-to-education.org/files/resourceattachments/ CEDAW_Recomendaci\%C3\%B3n_General_28_ES.pdf

Comité De La Cedaw. (2017) General recommendation No. 35 on gender-based violence against women, updating general recommendation No. 19. Disponible en: http://tbinternet.ohchr.org/Treaties/CEDAW/Shared\%20Documents/1_Global/CEDAW_C_GC_35_8267_E.pdf

Cruz Jaimes, (2007) Guadalupe. Igualdad: valemos lo mismo, pero somos diferentes. CIMAC I México DF.- 08/05/2007. Disponible en: http://www. cimacnoticias.com.mx/node/51210

De La Cruz, Carmen. (1999) Guía metodológica para integrar la perspectiva de género en proyectos y programas de desarrollo, Emakunde-Instituto Vasco de la Mujer, Vitoria-Gasteiz Disponible en: http://www.inmujeres. gub.uy/innovaportal/file/18616/1/12de_la_cruz_carmen._med_a_ged.pdf

De Lama, Aymá Alejandra. (2013) Discriminación múltiple. ADC, tomo LXVI, 2013, fasc. I. Disponible en: https:/www.boe.es/publicaciones/.../abrir pdf.php?...Discriminación_múltiple

Fernández Valle, Mariano. (Marzo de 2017). Aproximación a las temáticas de género en la jurisprudencia interamericana. Universidad Torcuato Di Tella. Facultad de Derecho. Revista Argentina de Teoría Jurídica (Volumen 17). Disponible en: http://www.utdt.edu/ver_contenido.php?id_contenido=12835\&id_item_menu=5858 
Fraser, Nancy. (997) Justicia Interrupta. Universidad de los Andes. Siglo del Hombre Editores.

Fries, Lorena y Lacrampette, Nicole, (2013) "Feminismos, género y derecho", en Lacrampette, Nicole (Ed.), Derechos Humanos y Mujeres: Teoría y Práctica, Centro de Derechos Humanos, Facultad de Derecho, Universidad de Chile. Disponible en: http://www.cdh.uchile.cl/media/publicaciones/pdf/101.pdf

Garay Montañez, Nilda. (2008) Alcances sobre la discriminación racial o étnica y su vinculación histórica con la discriminación por sexo. Mujeres en Democracia: Perspectivas jurídico-políticas de la Igualdad / coord. Por María Nieves Montesinos Sánchez, María del Mar Esquembre Cerdá), págs. 271-298. 2008. Disponible en: https://dialnet.unirioja.es/servlet/ articulo? codigo $=3002234$

Gobierno De Colombia Y Farc - Ep. (2016) Acuerdo Final para la Terminación del Conflicto y la Construcción de una Paz Estable y Duradera. 24.11.2016. Disponible en: http://www.altocomisionadoparalapaz.gov.co/ procesos-y-conversaciones/Documentos\%20compartidos/24-11-2016NuevoAcuerdoFinal.pdf

Lemaitre, Julieta.(2016) ¿Qué es una ideología de género? La silla vacía. Disponible en: http://lasillavacia.com/blogs/que-es-una-ideologia-de-genero-57494

Tarrés, María Luisa. A (2013) propósito de la categoría género: leer a Joan Scott. Estudios Sociológicos, vol. XXXI, núm. 91, enero-abril, 2013, pp. 380 -390. Colegio de México. Disponible en: https://www.revistas.ufg. br/fchf/article/viewFile/22406/13417

Osborne, Raquel y Molina Petit, Cristina. (2008) La evolución del concepto de género. Empiria: Revista de metodología de ciencias sociales, ISSN 1 139-5737, No 15, 2008, págs. 147-182 Disponible en: https://dialnet. unirioja.es/servlet/articulo?codigo $=2686277$

Plataforma Cinco Claves Para Un Tratamiento Diferencial De La Violencia Sexual En Los Acuerdos Sobre La Justicia Transicional En El Proceso De Paz. (2017)Equidad de género y derechos de las mujeres en el Acuerdo Final de Paz. Bogotá. Disponible en: http://humanas.org.co/alfa/dat_particular/ar/ar_7354_q_Equidad-Genero-Mujeres-Acuerdo-final-1-1.pdf

Scott W Joan. (1990)El género: una categoría útil para el análisis histórico. En Nash y Amelang (editores). Historia y género: Las mujeres en la Europa moderna y contemporánea. Disponible en http://www.herramienta.com.ar/cuerpos-y-sexualidades/ el-genero-una-categoria-util-para-el-analisis-historico 

TERCERA PARTE

LAS REDES SOCIALES Y DERECHOS DE LIBERTAD, EDUCACIÓN EN DERECHOS HUMANOS Y DEFENSA DEL ESTADO 



\title{
"Choose life": privacidad, redes sociales y big data ${ }^{82}$
}

\author{
LuCía Gómez CASTRO ${ }^{83}$ \\ JUAN ANDRÉS AMADOR ${ }^{84}$ \\ DaVID VALencia ${ }^{85}$
}

Rite the things which thou hast seen, And the things which are, and the things which shall be hereafter

Rev. $1,19^{86}$

82 Artículo resultado de investigación proyecto "Memoria Del Estado-Desastre: Trauma Y Capitalismo De Shock En Colombia”, adscrito al Centro de Investigaciones de la Facultad de Derecho de la Universidad Santo Tomás (USTA). La expresión "Choose life", tomada de las películas Trainspotting (1996) y T2 Trainspotting (2017) de Danny Boyle, funciona como marcador meta-irónico del estado de cosas en esta tecnosfera destotalizada actual. Vale decir, si la traducción es "escoge vivir" o "escoge la vida", ésta se refiere a la falsa (?) libertad en el mundo digital contemporáneo. Se intenta una parodia, una mueca invertida, un sarcasmo especialmente dirigido a la forma como las redes sociales y los mass media configuran y determinan el alcance de la libertad; desplegando un verdadero formateo de las emociones y las identidades sociales.

83 Estudiante de Derecho de la Universidad Santo Tomas (Sede Bogotá)

84 Abogado de la Universidad Santo Tomas (Sede Bogotá). Correo Electrónico: juanamador1991@gmail.com

85 Abogado, Magister y Doctor en Historia. Profesor e Investigador de la Universidad Santo Tomas (Sede Bogota), miembro del grupo de Investigación Socio-humanística del Derecho. Correo Electrónico: davidvalencia@usantotomas.edu.co

86 "Escribe pues, lo que has visto: lo que ya es y lo que va a suceder más tarde" Apocalipsis 1,19. Biblia de Jerusalén. 
"Choose live-blogging, from your first wank 'til your last breath;

human interaction reduced to nothing more than data." 87

Trainspotting 2

C ste articulo platea una reflexión crítica sobre el concepto de libertad
en el mundo de las redes sociales, tomando como enfoque el derecho a la privacidad en la era digital y el uso del Big Data. Comienza evidenciando cómo el uso masivo de la tecnología ha transformado las formas en que las personas interactúan con su entorno, seguido por varios interludios que plantean las opciones posibles que ofrecidas por el sistema. Finalmente concluye a través de un estudio de caso que plantea una relación entre sus resultados y la serie británica de televisión Black Mirror.

Parece que en este punto de la historia escoger acceder o no a la tecnología es algo que se sale del ámbito de la voluntad, la sociedad ha

87 Este epígrafe, expresado por Marc Renton (interpretado por Ewan McGregor en la película Trainspotting de 2017) se incluye no solo por su irónico acercamiento hacia una esfera social importante de la vida humana en el entorno digital, sino también por abarcar un contexto temporal clave en la cronología de este mismo entorno digital. Trainspotting (1996) aparece como una adaptación al cine hecha por Danny Boyle de la novela homónima de Irvine Welsh (1993). "Choose life" es el monologo con el que inicia la película, este no es solamente el slogan de una campaña antidrogas de los 80’s en UK, comprende además un discurso acerca de cómo viven sus personajes en un periodo histórico (entre 1996 y 2017), siendo este una fuerte crítica a la posibilidad de "escoger" que brinda el capitalismo, dice este monólogo: "Choose life. Choose a job. Choose a career. Choose a family, Choose a fucking big television, Choose washing machines, cars, compact disc players, and electrical tin openers”. Elecciones previamente dispuestas por un sistema económico que seduce para el consumo masivo, que convierte al ciudadano en consumidor. Es por ello que para renovarlo o "actualizarlo" se tocó una parte importante de nuestra sociedad digital, lo cual se materializa en el discurso de la siguiente manera: "Choose Facebook, Twitter, Snapchat, Instagram and a thousand others ways to spew your bile across people you've never met. Choose updating your profile, tell the world what you had for breakfast and hope that someone, somewhere cares", una libertad de compartir que en realidad no lo es. Definitivamente, un tono a la vez reaccionario y revolucionario frente al impacto que tienen los rituales virtuales diarios, especialmente las redes sociales en las cuales se expone la vida entera por diversión. 
hecho tránsito a la vida digital, es inevitable y no hay vuelta atrás. De allí la necesidad de escribir al respecto, tal vez como un único aliento capaz de transmitir ante tanta novedad un punto de vista crítico y lento ${ }^{88}$ sobre esta fascinación que tenemos al respecto y que sin duda está trayendo efectos secundarios propios de una adicción, una verdadera locura virtual (Virtual insanity) ${ }^{89}$.

Hoy la ansiedad es un estado de ánimo que invade este mundo acelerado y conectado, esa sensación que provoca el "visto", el mensaje por Whatsapp del jefe en horas no laborales (si estas aún existen y si alguien aún las quiere), una publicación sin "like”, el desahogo al puntuar con cero estrellas al conductor de Uber que hizo algo mal o simplemente no fue amable, todos son algunos de los síntomas de la inmersión digital posible gracias a los dispositivos personales que fascinan y a la vez atrapan (literalmente). Este atrapamiento se evidencia en el llamado "sunken place" [lugar hundido o lugar del hundimiento] del film GET OUT (2017) en el que simplemente se hace parte como espectador, mesmerizado, idiotizado e (in)conscientemente esclavizado

88 Lento en el sentido opuesto a la inmediatez que exige la tecnología, ya que el acto de escribir y de leer exige al contrario de una publicación de Facebook que se olvida al instante, una reflexión acerca de lo que se quiere expresar o abstraer del texto, Haruki Murakami lo expresa de esta manera respecto de la escritura: "para explicarlo mejor, y sirviéndome de un ejemplo concreto, diría que la velocidad es un poco superior a la de caminar e inferior a la de ir en bicicleta".

89 “virtual insanity" o "locura virtual " una canción del artista Jamiroquai lanzada en el año 1997, quien además de romper las reglas en la realización del video clip deja una interesante reflexión en un época en que se comenzaba a dilucidar la adicción a la tecnología, siempre comandado por nuestro amor ciego a la misma. "Oh yeah, what we're living in (let me tell ya)/ It's a wonder man can eat at all /When things are big that should be small/Who can tell what magic spells we'll be doing for us/And I'm giving all my love to this world/ Only to be told/ I can't see/ I can't breathe/ No more will we be/ And nothing's going to change the way we live/ 'Cause we can always take but never give/ And now that things are changing for the worse,/ See, its a crazy world we're living in/ And I just can't see that half of us immersed in sin/ Is all we have to give these/ Future made up virtual insanity now/ always seem to, be governed by this love we have / for useless twisting/ our new technology/ oh now there is no sound for we all live underground". 
esperando cada lanzamiento o más bien cada actualización de esos gadgets digitales. Estos que se han convertido en el caballo de Troya de la privacidad, la trampa a la democracia, toda una traición ante la confianza.

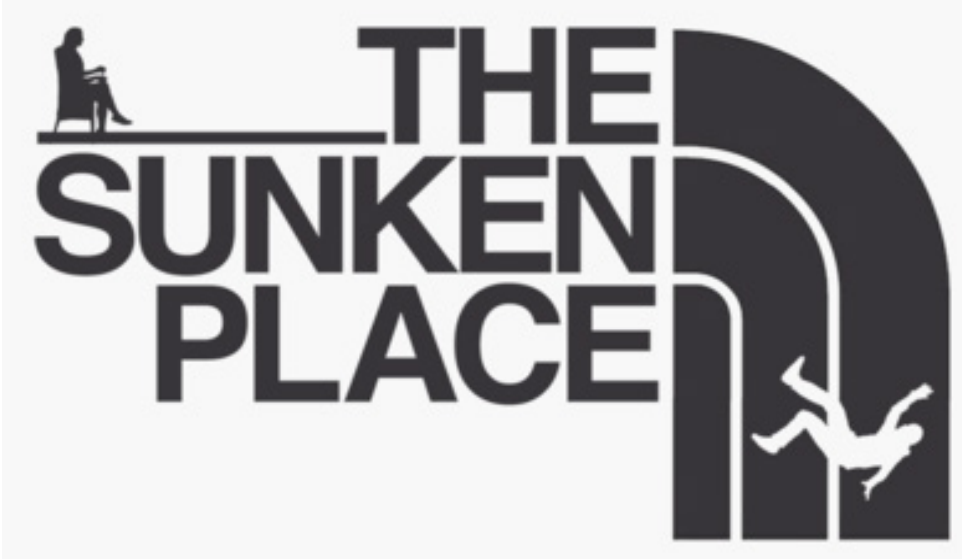

Estilización de la escena del film GET OUT conocida como "Sunken Place"

Algunos pensarán, ¿por qué sentirnos traicionados por nuestro nuevo Smartphone? ¿Por Google, Facebook, Twitter, Intagram? ¿Por qué dejar de publicar lo que comemos, lo que hacemos, con quien nos vemos, a dónde vamos?, ¿Por qué! si este es el estado actual de las cosas?

La tecnología es neutral, "decidimos" qué hacer con ella ${ }^{90}$ (Carr, 2010), ¿es así? En definitiva una cuestión que hay que pensar y muy bien, ya que debido a la complejidad de los sistemas es difícil de

90 Niocolas Carr, escribe citando a Mcluhan lo cobarde de la decisión de tomar un punto de vista neutral hacia la tecnología, la creencia de que nosotros tenemos el control y decidimos que hacer con ella. En primer lugar existe con un motivo, ser el dispositivo más personal y así cambiando nuestra percepción del mundo. "nuestra respuesta convencional a todos los medios, en especial de que la idea que cuenta es cómo se lo usa, es la postura adormecida del idiota tecnológico". 
observar el poco control que tenemos sobre ellos, aun así. ¿No se debería sospechar de un dispositivo que está casi pegado al cuerpo?, desde que nos levantamos hasta que nos acostamos el Smartphone es el objeto predilecto de deseo, más de un millón de veces tocado al año ${ }^{91}$, en el sueño y en la vigilia, pero no solamente deberíamos preocuparnos por este, también por nuestras computadoras, autos, neveras, casas, Drones ${ }^{92}$, los cuales próximamente estarán conectados a la gran fuente, internet ${ }^{93}$. Tim Berners Lee su creador (quien a propósito no patento su invento a pesar de las ganancias que pudo haber tenido con ello) vio en este un lugar (o no- lugar) un espacio libre, descentralizado y sin gobierno en el cual las personas pudieran compartir, crear e innovar a cada paso. Ahora, 25 años después de ello es consiente que no funcionó del todo así "I believe that the future of the web is under threat from some governments that may abuse their powers, some businesses that may try to undermine the open market... But mass surveillance, and particularly the reported attempts by intelligence agencies in the US and UK to break commercial encryption systems to make it easier to spy on people, is the

91 https://blog.dscout.com/mobile-touches

92 Durante el desarrollo de este escrito se hace indispensable incorporar piezas musicales que desarrollen las relación de las mismas con la tecnología, es por esto que se encuentra ambientado con canciones que tienen un propósito especial, no solamente porque son posibles gracias a la misma, sino también porque tienen un tono reflexivo respecto del su uso, DRONES es el Último disco de la banda británica MUSE lanzado el 8 de junio de 2015 y el cual que nace como una fuerte crítica a la forma en que la tecnología digital transforma las relaciones humanas, centrándose especialmente en las practicas armamentistas por el uso de Drones, el texto se desarrolla a través de una metáfora que comprende sus 12 sencillos en los cuales su personaje principal sufre una asombrosa transformación, Mattew Bellamy el cantante de la banda lo explica en una entrevista " The whole thing will seem like an interesting topic and a rule again as real sign of our times that we live in and how far technology has come and how far it's kind of, and how much is créate distance, $i$ think you know betwen people essentialy a think that's kind of i guess the theme of the álbum and the drones have seen that route sort of methaphore to use..." (https://www.youtube.com/watch?v=-8JJDt1X7-c)

93 Gracias al internet de las cosas. 
most worrying of all, because it could engender a loss of trust and lead to Balkanisation of the web. " ${ }^{94}$ (Subrayado fuera de texto).

\section{¿Dime qué escojo? (primer interludio)}

Escoge ser un investigador sénior según Colciencias. Escoge endeudarte. Escoge pagarle a la Dian todo lo que te pida. Escoge embriagarte con águila cero. Escoge siempre zapatos de marca. Escoge una deliciosa e higiénica Big-Mac. Escoge no mirar el celular por más de una hora. Escoge tener el miedo terrorista que te inducen los medios. Escoge la guerra y la paz de acuerdo a intereses que nadie comprende. Escoge el café sin azúcar. Escoge que RCN y Caracol decida qué es estar informado. Escoge ignorar la obsolescencia programada. Escoge no contestar el cel. Escoge el último i-phone. Escoge siempre el último i-phone. Escoge que nadie te pida que escojas. Escoge el nibilismo. Escoge que te fastidia escoger. Escoge sólo dos gripas al año. Escoge que da igual lo que escojas. Escoge ser ecológico como estrategia de mercado. Escoge el lado coca-cola de la vida. Escoge creer que escoges.

\section{$¿$ Es el internet un lugar libre?}

¿Somos libres al estar en ella tras interfaces como las redes sociales, smartphones, computadoras, tabletas, smartewatches etc? ${ }^{95}$. El proble-

94 http://www.wired.co.uk/article/tim-berners-lee

95 El filósofo Byung Chul Han, habla de la libertad en el comienzo de su obra Psicopolitica (Han, 2014) (un concepto que surge gracias al manejo masivo de datos en la web) sugiriendo que la libertad en nuestro siglo solamente es un "entreacto", es decir que la libertad que sentimos es solamente un episodio intermedio hasta establecerse en definitiva como coacción "vivimos en una fase histórica en que la libertad del poder hacer genera más coacciones que el disciplinario deber. El deber tiene un límite es por ello que la coacción del poder hacer es ilimitada. Nos encontramos por tanto en una situación paradójica. La libertad es la contrafigura de la coacción. La libertad, que ha de ser el contrario de la coacción, genera coacciones" (Han, 2014, 
ma explícito desde el epígrafe "Human interaction reduced to nothing more tan data”. Pero, ¿a qué se refiere esto?

Todo lo que hago es captado, la música que escucho en YouTube mientras escribo este texto, las páginas que he visitado a través de Google para sustentarlo, la distancia que recorro a mi trabajo, lo que compro con mi tarjeta de crédito, a quien llamo, la duración de las llamadas, donde vivo, a quien le escribo, los contenidos de mis correos, a quien van dirigidos, toda mi información personal, privada, intima que me define, toda ella reducida a trozos de información, a datos emanados del caballo de Troya en mi bolsillo, el cual creó una sombra, pero no de cualquier clase, no necesita luz, es digital y me acompaña a todas partes, lamentablemente no es solo a mí, es a todos, la interacción humana ha sido reducida a nada más que datos los cuales son analizados por algoritmos capaces de predecir mis comportamientos a futuro. ¿Ciencia ficción? No. Definitivamente algo de lo cual usted señor lector debería preocuparse.

La sombra digital se convierte en una representación de lo que somos, una cantidad de datos almacenados que permiten conocer de primera mano nuestros hábitos, preferencias religiosas, sexuales, políticas, artísticas, futbolísticas, en fin, todos los ámbitos que nos atraen, los cuales viéndolos en conjunto pueden establecer una aproximación en ocasiones muy acertada de lo que realmente somos. Esto ha permitido que las publicidad personalizada envuelva a las personas en un círculo en el cual solo ven lo que quieren ver, o más bien lo que su sombra digital dice que son sus preferencias, que la información que les llegue sea parcializada a su gusto, manipulada con el objetivo de obtener un provecho sobre la persona. El hombre reducido a sus datos pasó a ser objeto de escrutinio y manipulación por

12) en este entendido se explota esa libertad de "poder hacer" esa libertad de "poder postear, poder consumir, poder compartir, poder hiper- comunicarnos" (acciones que generan ganancias exorbitantes aun siendo gratuitas) las cuales se terminan convirtiendo en coacción, ya que una vez inmersos allí, la voluntad necesaria para poder salir, se convierte en un reto. 
parte de gobiernos ${ }^{96}$ y grandes empresas que buscan captar al bueno, aquel que ha escogido la vida y se comporta como debe, consumiendo y posteando todo lo que le rodea, para así ofrecerle más y más de ello, convirtiéndolo en usuario Premium o ciudadano ejemplar y mientras esto sucede también se transforma en una herramienta de exclusión, convirtiendo en sospechoso a aquel que no escoge la tecnología, o que la escoge y la utiliza con otros fines.

Ahora bien, la exclusión sufrida por Renton (Ewan Mcgregor) en la primera película de Trainspotting en el momento en que escogió no escoger la vida "i chose not to choose life: I chose something else. And the reasons? There are no reasons. Who needs reasons when you've got heroin?”, decisión producto de su desprecio por lo que la vida le ofrecía: trabajo, hijos, seguridad social, hipotecas, impuestos, fiestas, televisión, comida chatarra, etc. Acciones previamente establecidas por el modo de vivir occidental y de las cuales este personaje no quería participar. Ahora en el discurso actualizado se evidencia lo que debemos escoger en nuestra era, o más bien las posibilidades que tenemos de escoger amigos, postear en Facebook desde el primer aliento hasta la muerte, publicar fotos de lo que comemos, de dónde vamos, escoger el filtro para las fotos o la forma en que las modificamos, estar más delgado, con la piel más joven, escoger un IPhone hecho en china por una mujer que saltó por una ventana en vez de un Samsung hecho en circunstancias similares etc.

96 Edward Joseph Snowden es un consultor tecnológico estadounidense asilado en Rusia por filtrar documentos clasificados como alto secreto sobre la forma en que la NSA (Agencia De Seguridad Nacional por sus siglas en inglés) realizaba proyectos de vigilancia masiva nivel mundial a través de medios electrónicos, las revelaciones se publicaron en periódicos tales como "The guardian" y "The Washington Post". Una aproximación a su vida y la importancia de sus revelaciones se encuentra en el largometraje "SNOWDEN" dirigido por Oliver Stone y protagonizada por Joseph Gordon Levi en 2016, así como el documental "Citizen Four" dirigido por Laura Poitras, ganador del premio de la Academia a mejor documental largo (Academy Award for Best Documentary Feature). 
Renton por el contrario se pregunta (mientras cae al suelo exhalando su última bocanada de humo ${ }^{97}$ ) "But why do i want to do a thing like that?" 98 Escogiendo a la heroína como salida (como resistencia y evidente desinterés a la sociedad y sus promesas), ya que bajo sus efectos no existían el tiempo y las preocupaciones de su sociedad, situación que le trajo exclusión social y casi la cárcel (como instrumento de corrección a su conducta desviada).

En nuestro contexto, el no escoger la vida podría asimilarse a no escoger la tecnología, las redes sociales y demás, circunstancias que además del síndrome de abstinencia traería también exclusión social, dicha sanción es de tal entidad que puede sacar del contexto de una vida "normal" a aquel que decida no escoger, siendo sospechoso en los aeropuertos y embajadas, sospechoso para el empleador que cada día usa más las redes sociales como criterio de selección (además de las pruebas ilegales como el polígrafo), la imposibilidad de comunicarse con sus semejantes a la distancia, de buscar mapas de la ubicación de lugares, de compartirlos, de evitar trancones, de estar disponible todo el día, de chismosear la vida de los otros ${ }^{99}$, en sí misma una decisión que generaría una total exclusión, cayendo en lo que Zygmunt Bauman denominó un Banóptico ${ }^{100}$.

Estas situaciones son difíciles de observar, suceden en la web, ese lugar en el que estamos conectados todo el día todos los días, aumentando la información que reposa de nosotros en los grandes servidores

97 Trainspotting 01: 32

98 ¿Por qué querría yo hacer algo como eso?

99 Película esencial para entender el contexto de la vigilancia.

100 Palabra que proviene de (ban: exlusion) y óptico de (ver), acuñada como una alusión al Panóptico, un modelo de prisión cuya estructura arquitectónica en forma de anillo permitía a un solo vigilante hacerse cargo de los reclusos, verlos a todos a la vez, instalarse en sus mentes y crearles la sensación de ser observados todo el tiempo haciéndolos cambiar su conducta a través de la vigilancia permanente. Esta institución nació en 1789 fruto de las ideas del pensador Utilitarista Jeremy Bentham. Un estudio profundo sobre los fundamentos evolución se realiza en la tesis de grado denominada "Panóptico digital" contenida en el libro “Derecho Penal Vigilancia y Control Sial”(Ibañez, 2016) 
ubicados en algún gigantesco centro de datos ${ }^{101}$ en Estados Unidos o Suiza, claro está, fuera de la jurisdicción Colombiana. Datos sobre nosotros y sobre los cuales no tenemos ningún control (siendo esta la "materialización" del derecho a la intimidad en la era digital).

La recolección masiva de dichos datos y su análisis ha permitido que las prácticas de perfilado hayan invadido el campo de la política, convirtiéndose en la herramienta fundamental en la consecución de votantes, haciendo que el concepto de democracia como lo conocemos haya sufrido un cambio que merece un profundo estudio.

Un ejemplo de ello fueron las implicaciones de la empresa "Cambridge Analítica" 102 en las últimas elecciones de los Estados Unidos $^{103}$, ya que esta utilizó los datos personales de los ciudadanos americanos identificando, perfilando y luego enviando propaganda personalizada a los votantes indecisos, acomodando el contenido del mensaje dependiendo del gusto del usuario, qué tipo de persona es o lo que sus datos dicen que es, influenciando con ello la toma de su decisión y por ende ayudando enormemente a la victoria de Donald $\operatorname{Trump}^{104}$ (sin olvidar lo realizado por esta misma empresa en el desarrollo del Brexit). Esto evidencia un modo de proceder del poder, una forma de dominación disfrazada de libertad que direcciona la "posibilidad de escoger" entre los candidatos y propone posiciones que se relacionen con los gustos que el ciudadano comparte en las redes sociales, trayendo como consecuencia una suerte de manipulación invisible del electorado quien no conoce de estas prácticas puestas en marcha sin su consentimiento.

Lo anterior, fue posible gracias a una nueva aplicación de la psicología llamada "Psicometrics", método que se fundamenta en la

101 http://www.datacenterknowledge.com/the-facebook-data-center-faq/

102 https://www.privacyinternational.org/node/1440

103 http://cnnespanol.cnn.com/tag/cambridge-analytica/

104 Un estudio acerca de la importancia de las técnicas de vigilancia y de control desde la sociedad industrial hasta la sociedad digital se encuentra en los textos texto Panóptico Digital y Pornóptico (N)infomanía y emopolítica contenidos en el libro "Derecho Penal, Vigilancia y control social” (Ibañez, 2016). 
información proveniente de los datos de los usuarios en internet, especialmente de los likes de Facebook, los cuales permiten tener una comprensión de la personalidad del individuo más allá de la información que brindan los estudios sobre el género, la nacionalidad o la raza $^{105}$, permitiendo detallar casi taxonómicamente las características psicológicas de las personas acorde con los gustos evidenciados por su perfil, el cual, valga la pena recalcar, se construye a través de lo que compartimos $^{106}$ (aunque lo que no compartimos también cuenta: gelocalización, distancias diarias recorridas, páginas visitadas, las llamadas, el contenido de las mismas, etc. )

Este método de estudio utiliza algoritmos capaces de analizar las grandes cantidades de datos emanados por el usuario (Big Data y Meta) los cuales permiten mediante un cruce y posterior estudio de la información, predecir el comportamiento que tendrá respecto de una situación en particular, clasificándolo dentro de cinco criterios esenciales que evidencian su tipo de personalidad, mostrando la estrategia con la cual se le puede persuadir bien sea el marketing o en el campo de la política, los criterios son : 1) Opennes: how open you are to new experiences? ${ }^{107} 2$ ). Conscientiousness (how much of a perfectionist are you? 3) Extroversion: how sociable are you? 4) Agreeableness (how considerate and cooperative you are?) 5) Neuroticism (are you easily upset?).

Los resultados de dichos análisis permiten conocer con un grado de certeza las preferencias de una persona, estén explicitas o no en el contenido de lo que comparte (religión, sexo, nacionalidad, partido político, sus relaciones sociales, estrato, características de sus compras, de sus viajes y de su familia) lo cual analizado desde la

105 Si desea ser analizado Psicométricamente puede ingresar al siguiente link de la Universidad de Cambridge"

$106500 \mathrm{Mb}$ por día, es el aproximado de información emanada por persona a nivel mundial (daily data output per person globally):

107 Openess ¿Qué tan abierto eres para nuevas experiencias? 2) Conscientiousness ¿Qué tan perfeccionista eres? 3) Extroversion: ¿Qué tan sociable eres? 4) Agreeableness : ¿Qué considerado y cooperativo eres? 5) Neuroticism ¿Te molestas con facilidad? 
minucia hasta lo más grande, posibilitan el pronóstico de un comportamiento posterior.

El Dr. Michal Konsiski psicólogo y científico de datos de la Universidad de Stanford desarrolla esta idea en la entrevista "The end of privacy" 108 tomando como ejemplo el conocimiento que alguien puede adquirir sobre un ser querido, bien sea un amigo o un familiar cercano "si tú conoces a alguien, serás capaz de predecir su comportamiento en el futuro ... tu lees un libro y en este momento dices "mi amigo, ese que es muy organizado y habla de esos temas, podría amar este libro", eso es una predicción, conoces a tu amigo y algunas de sus inclinaciones, permitiéndote extrapolar el conocimiento que tienes de él dentro de otras áreas, tu básicamente ves un nuevo libro, un nuevo juego o una nueva actividad y puedes predecir cuál de ellos le gustaría a tu amigo ". Los algoritmos realizan algo similar a lo propuesto por el Dr. Kosinsky, ya que utilizando la información que disponible de una persona explotan su psique, permitiendo vaticinar qué cosas podría llegar a hacer o a gustarle, direccionándolo gracias a ello hacia la compra de libros, planes vacacionales, candidatos electorales, tipos de mujeres etc. Por ser estos solo algunos de los ejemplos.

Todo aquello que comprenda un gusto o comportamiento, podrá ser medido, analizado y posteriormente utilizado para plantearle sugerencias acorde con sus gustos, encadenándolo a este aparato de producción que sustenta y sostiene la economía de lo digital.

Estas prácticas no solamente permiten establecer patrones de comportamiento personales, sino también ponen de manifiesto formas en que la sociedad interactúa, llegando a conclusiones imposibles sin los datos que los usuarios brindan de manera voluntaria el Dr. Kosinsky continúa. "las personas que leen ese libro o las que visitan este tipo de páginas en internet, o escuchan esta clase de música, también tienden a ser conservadores o a estudiar psicología o trabajar en cuentas, así que ahora podemos hacer esas simples clases de predicciones, digo simples pero a gran escala, volviéndose muy poderosas."

108 https://www.youtube.com/watch?v=X9jVjCVOUIM 
Estas conclusiones, difíciles de observar para los humanos se hacen evidentes gracias a los los algoritmos matemáticos, los cuales analizando ceros y unos (o no necesariamente estos, ya que Watson de IBM ${ }^{109}$ es la primera computadora que comprende el lenguaje humano) permiten establecer conexiones entre comportamientos que a simple vista parecen no tener relación alguna.

Kosinsky concluye que la privacidad en la era digital no existe, ya que considera a este punto de la historia como un estadio post-privacidad, en el entendido beneficios recibimos al entregarla son una característica de nuestro tiempo y por ende no los podemos simplemente dejar a un lado (Facebok, Twitter, Instagram, Snapchat, Google, etc.) "Los cuales hacen nuestras vidas más fáciles, seguras, interesantes, gratificantes y demás”.

Esta posición evidencia el "dataismo digital" el cual cree ciegamente en los beneficios de la acumulación masiva de datos sin cuestionarse acerca de las repercusiones que trae para la sociedad en general, la cual está cediendo su privacidad permitiendo formas sutiles en el ejercicio del poder, el cual se ejerce de manera imperceptible y de allí su gran impacto, haciendo que se ponga en duda el propio concepto de libertad, ya que direccionados a partir de sugerencias, no es posible evidenciar por la persona la coacción existente en estas plataformas que se muestran benéficas.

Sin embargo, existe aún la paradoja acerca de los beneficios obtenidos por nuestros dispositivos y redes sociales, haciendo que valga la pena preguntarse de nuevo ¿Soy libre al publicar todo lo que soy? y si no lo hago ¿Es legal que gobiernos y multinacionales utilicen mi información intima para direccionarme a algo en concreto? ¿Qué tan acertada es mi sombra digital? ¿Por qué Facebook, Twitter, Instragram negocian con nuestros datos y no nos dan nada por ello? ¿Por qué usan "Psicometrics" sin nuestro consentimiento? ¿Por qué se manipula para obtener votos en las elecciones? ¿Tenemos una adicción a lo digital? ¿Es un juego? ¿Una traición a la confianza? Como se dijo, la interacción humana reducida solamente a datos. Una cuestión a dilucidar

109 https://es.wikipedia.org/wiki/Watson_(inteligencia_artificial) 
con seriedad, ya que si queremos un lugar para la privacidad en la era digital, es hora de ponernos a pensar ${ }^{110}$.

Habrá entonces que decidir de qué lado se está, ya que las premisas del Dr. Kosinsky difieren de las nuestras, las cuales no son simples apreciaciones, ya que se apoyan en posturas críticas tanto filosóficas, sociológicas y jurídicas, planteando preguntas clave en esta revolución digital que se desarrolla ante nuestros ojos, la cual según lo evidenciamos, utiliza nuestros datos de formas que si el usuario conociera, ciertamente no aceptaría ¿’o sí?

Es hora entonces de desprenderse de la idea de regulaciones acorde a límites territoriales y jurisdiccionales para pensar como una comunidad global que se encuentra conectada a Google y a las redes sociales, reflexionar seriamente acerca del uso que se le está dando a estas plataformas a través de nuestros dispositivos personales y a la información que emana de ellos, para posteriormente decidir qué hacer para poder tener una sociedad digital verdaderamente libre, fuera de la vigilancia y el control.

\section{¿Dime qué escojo? (segundo interludio)}

Escoge una foto de perfil bien sexy. Escoge ver todas las series de Netflix. Escoge enamorarte de alguna cuchi-barbie o algún cuchi-ken que te mantenga por siempre. Escoge una universidad prestigiosa. Escoge dormir lo necesario para levantarte descansado y seguir la cadena de producción infinita. Escoge revisar el historial de navegación de tu novio. Escoge dejar de tener i-phone y usar una flecha. Escoge sospechar que Google lo sabe todo de ti. Escoge entristecerte de acuerdo a los calendarios afectivos de las empresas. Escoge a Homero Simpson como arquetipo de lo humano. Escoge ir a "vitriniar" al Centro comercial. Escoge no molestarte cuando tú pareja está en línea y no te contesta. Escoge antojarte de todo. Escoge pensar que eres libre en un

110 Slavoj Zizek, No actúes, solo piensa. En Big Think, 2016: Disponible en https://www.youtube.com/watch?v=IgR6uaVqWsQ 
mundo donde todas las decisiones han sido prediseñadas. Escoge la ilusión de que escoges. Escoge no saber las dinámicas trans-nacionales que determinan qué escoges. Escoge desinformarte viendo CNN, RCN y Caracol. Escoge vivir en la burbuja que te fabrican los mass media. Escoge vivir engañado con las "últimas noticias". Escoge cuál de los setecientos canales de TV deseas que obstruya tu verdadera capacidad de ver de otra forma el mundo. Escoge que lo que escoges a nadie le importa.

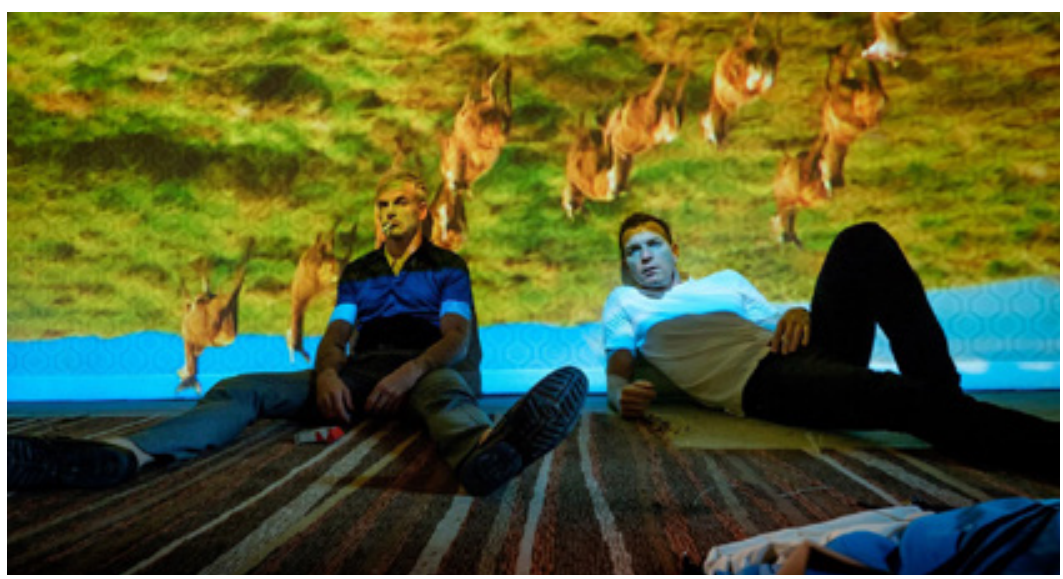

Fotograma de T2 Trainspotting (2017). Tomado de http://www.dazeddigital. com/artsandculture/article/34509/1/trainspotting-t2-danny-boyle-casting-outdemons

\section{¿Qué tan inmersos estamos?}

"Choose Facebook, Twitter, Snapchat, Instagram and a thousand others ways to spew your bile across people you've never met. Choose updating your profile, tell the world what you had for breakfast and hope that someone, somewhere cares"

Se podría decir, que la manera en la que estamos inmersos es: abrumadora. El uso que le damos a las redes sociales es, abrumador. Este calificativo se presenta como el más pertinente en el caso, debido a que es tal la inmersión de la vida de cada individuo que existe en el siglo XXI en las redes sociales, que provoca una especie de "ceguera mental", el ser objeto de tan continuos estallidos de información circulante en el escenario reinante de la intangibilidad. Ceguera, porque 
aunque estamos presentes, aunque somos parte del fenómeno, aunque somos consumidores activos (hiperactivos) del mismo, no vemos (o no queremos ver) los efectos normalmente negativos que colateralmente ocasiona en nuestra calidad de vida.

El concepto de red social en este contexto es de suma relevancia, para lograr entender la dinámica que enmarca la presente discusión. En su acepción más simple, una red social podría entenderse como un conjunto de personas que están interconectadas por vínculos directos e indirectos simultáneamente, en un entorno común para ellos, de modo que coexisten diferentes grados de relacionamiento, con el fin de satisfacer necesidades e intereses comunes. "En ella existen elementos que repercuten sobre aspectos de las relaciones sociales entre los actores de red. Tales son la intensidad de la relación, la posición del actor y la accesibilidad de un actor respecto a los demás”Fuente especificada no válida.. A pesar de que estas características son retomadas de 1989 (ad portas de detonarse la globalización mediante la informática), tales elementos siguen plenamente vigentes; mas lo que sí cambió radicalmente con la llegada de la Internet, fue su contenido.

Una red social en aquel entonces, se definía bajo el entendido de que en un $90 \%$ las relaciones interpersonales por más escasas que fueran, eran personales, presenciales, preminentemente mediadas por el contacto físico. Hoy, habitando el mundo de la "Modernidad Líquida" elocuentemente nominada por Bauman, las relaciones humanas se mueven sobre una dimensión inmaterial, fluida, imperceptible y lo más importante: impersonal; el flujo sensorial que tenía lugar en una conversación personal ya superó el factor presencial, y se trasladó a lo meramente visual, avecinando dos continentes a la distancia de una pantalla. Así, la característica icónica de esta Modernidad Líquida, es la de la relativización del tiempo y espacio, en una carrera por el máximo aprovechamiento del tiempo, y donde la velocidad, en lugar de ser un medio, pasó a convertirse en un fin.

En consecuencia, los límites propios de los elementos de una red social antes mencionados, se expanden conforme las barreras físicas se derrumban, haciendo posible que una relación con otro ubicado a miles de kilómetros, sea mucho más intensa que la relación sostenida con aquel que se encuentra a la distancia de un muro o un par de baldosas. 
Esta intensidad aumenta proporcionalmente a la accesibilidad de un actor respecto a los demás, gracias a la conectividad permanente que proporciona la web 2.0, haciendo del estado: "disponible" una forma de vida, un estado posible en todo momento.

La informática inundó la cotidianidad del ser humano, y subió de categoría al pasar de ser un recurso exclusivo de elite, a ser una herramienta necesaria en distintos órdenes sociales, que en la actualidad se arroga el carácter de indispensable. Bajo este supuesto, las redes sociales dejan de ser lo que conocíamos antes de la década de los 80's y se traslapan al mundo digital, transformando su estructura a la de una interfaz interactiva que posibilita la adecuación de un individuo a cualquier rol social que se le antoje, pues, la esencia de su creación es la de "compartir" los aspectos de su vida que desea sean vistos, en la forma en que desea que sean vistos, presentados bajo el "perfil" de persona que desearía tener en su realidad (real) social.

En un mundo digitalizado entonces, una red social viene a ser un medio masivo de comunicación informático que globaliza la conectividad de sus usuarios, y les permite ocupar un rol social deseado.

Así, el empleo de una red social en la actualidad va desde poder contactarse con seres queridos a largas distancias, hasta ser el medio publicitario predilecto, por las potencias económicas comerciales mundiales. En medio de esos dos extremos, está el que aquí se considera como la piedra angular de su creación: complacer el constante apetito social de ser visto, de recibir atención.

Puede que sus creadores no fueran conscientes de tal intención en el momento incipiente de su invención, pero no hay negocio más rentable, que el de paladear la vanidad, por lo que el afianzamiento de un portal interactivo de exposición social es la menor de las dificultades, cuando el "core" del negocio consiste en mantener convencidos a sus consumidores de que obtienen la aprobación social que ansían.

Y es que ese es el punto neurálgico de la sostenibilidad de negocios en particular como Facebook, Instagram, Snapchat y Twitter (por mencionar los más populares). Lo que consumen los usuarios activos de estos portales eminentemente es: aprobación social o reconocimiento social. Bajo esta premisa, es necesario distinguir entre los diferentes tipos de consumidores de las redes, pues hay quienes explotan a cabalidad 
las posibilidades interactivas que ofrecen tales plataformas de comunicación: chatean, suben fotos, indican su ubicación, comparten páginas videos, variados contenidos, consignan estados, participan en grupos, etc., y todo, de manera continua en la semana o en el día. Hay otros un poco más reservados ${ }^{111}$, cuyo uso de dichas posibilidades es muy esporádico, y está asociado normalmente a algo que causa impacto o se cree meritorio de ser difundido; por otro lado, están aquellos que se declaran apáticos a esas dinámicas, y restringen su uso meramente a lo necesario, bien sea por condiciones de estudio o trabajo, en los que se ha impuesto la red social como medio de información continua. Si se pertenece a la última categoría, no podría hablarse de que aunque sea inconscientemente, el uso de la red social se deba a la búsqueda de aceptación porque claramente el contexto cambia.

En concordancia con lo tratado hasta el momento, es curioso notar que el uso mayoritario de las redes sociales se hace con la convicción, de que ello combate la soledad y el aburrimiento, ya que la disponibilidad y los medios facilitan que otro se ponga en contacto ${ }^{112}$.

"En un mundo donde el tiempo es dinero y en el que estamos presionados para lograr más y más, nuestra vida social se ve afectada y se vuelve más demandante que antes. Luego está la tecnología: simple, esperanzadora, optimista, siempre joven. Nos volvemos adictos al romance virtual disfrazado por la red social qué nos da una plataforma impresionante y nos permite manejar nuestra vida social con más efectividad, pero nuestras fantasías acerca de la substitución comienzan

111 Sobre ésta categoría, cabe agregar que los autores del presente artículo encuadramos dentro de sus características. Específicamente a partir de esta claridad, se pretende ilustrar la sintomatología del uso inadvertido y casi que incontenible del uso de las redes sociales, a través de la experiencia personal de la coautora. De ahí que la narrativa del mismo cobre un sentido introspectivo.

112 En este sentido, en una entrevista realizada en el programa Salvados, dirigido y presentado por el periodista Jordi Évole a Zygmunt Bauman, este afirma que "somos solitarios en contacto permanente" y por ello, "el éxito de Facebook es que está basado en el miedo a estar solo". http://www. lasexta.com/programas/salvados/mejores-momentos/diablo-tiene-forma-telefono-movil-otras-acertadas-reflexiones-filosofo-zygmunt-bauman-salvados_2017022058aac6810cf2d2743e03a129.html 
a pasar factura. Coleccionamos amigos como barajitas sin distinguir cantidad de calidad y convirtiendo el profundo significado de intimidad y amistad en el intercambio de fotos y conversaciones en chat; al hacer esto sacrificamos la conversación por la simple conexión, creando una situación paradójica en la que decimos tener muchos amigos pero en realidad estamos solos.

Mensajes, e-mails, publicaciones, todas estas cosas nos permiten mostrarnos como quisiéramos ser; podemos editar. Y eso significa que podemos borrar. En vez de construir verdaderas amistades, nos obsesiona la promoción personal ilimitada, invertimos horas creando un perfil, buscando el óptimo orden para las palabras de nuestro siguiente mensaje, escogiendo las fotos donde mejor nos vemos, todo, al servicio de una imagen idealizada de lo que somos. Esperamos más de la tecnología y menos de nosotros mismos.

Las redes sociales no sólo cambian lo que hacemos, si no también lo que somos. Y es que en la mayoría de nosotros, la tecnología apela a nuestro punto más vulnerable, y somos vulnerables: estamos solos. Pero tenemos miedo a la intimidad.

La ilusión gratificante de que nunca estaremos solos, está creando una nueva forma de ser, y la mejor manera de describirla es bajo el paradigma de: comparto, luego existo.

Usamos la tecnología para definirnos, compartiendo pensamientos, sentimientos e incluso mientras los vamos teniendo; lo que es más, fingimos experiencias para tener algo que compartir y así sentirnos vivos. Nos convencemos de que estar siempre conectados nos hará sentir menos solos pero corremos un riesgo, pues lo opuesto es verdad, sí no somos capaces de estar solos, entonces lo único que aprenderemos será a ser: Solitarios”. (The Innovation of Lonliness ${ }^{113}$ )

Lo anterior es la razón por la que las multinacionales tengan voraces campañas publicitarias por estas plataformas, pues saben la acogida que tienen entre el público, entre otras cosas porque en el mundo del capitalismo salvaje, la soledad, es el catalizador perfecto para estimular el consumismo desmedido. Ante la ausencia de vínculos verdaderos

113 https://www.youtube.com/watch?v=zgxeZWvMRPQ 
y por tanto de estabilidad emocional, es fácil encontrar un alivio ilusorio en lo material; se pretende llenar el vacío afectivo con lo acumulable de lo que compra el dinero. Cada "like" cada click, deja una huella sobre las preferencias que dejamos ver, y se crea un rastreo interminable de pistas que conducen a volvernos objetivos descubiertos de toda compañía que busca captar clientes. Ciertamente, otra aplicación a parte del arquetipo psico-dependiente antes descrito sobre el uso de las redes sociales.

Ese arquetipo se exacerba toda vez que un individuo logra escapar fácilmente de la incomodidad que le representa estar en un lugar solo, pero rodeado de gente. Tales eventos en los que hay que guardar turno en una sala de espera, haciendo fila, o en un salón de clases sin encontrar conocidos, son los momentos en los que la soledad se refugia en la pantalla del celular, y en las vitrinas virtuales de exhibición social, dándole una "ocupación productiva" a la intranquilidad que le produce su soledad. Lo contradictorio es, que mientras se permanece "conectado" con más personas de manera ficticia, cada vez los individuos son más incapaces de producir vínculos espontáneos con quienes los rodean físicamente. En otras palabras, cada vez somos más ávidos socialmente en la red, pero cada vez más ineptos socialmente en la realidad

Ahora bien, en cuanto al uso de las redes sociales y cuántas veces se accede a ellas con base en la experiencia personal, inicialmente indiqué que pertenezco a la segunda categoría de usuario de las redes sociales. Para ser más específica, siempre me he declarado consciente de los efectos perjudiciales adyacentes que ellas conllevan, mas por fuerza de su evolución y fijación cada día más en las actividades cotidianas, tuve que tomar la decisión de "sumarme a la lista de los adictos”. Siendo coherente con mi lógica, me restrinjo a dar mi aprobación sobre la invasión a mi intimidad sólo en el caso de Facebook, WhatsApp y Messenger (y eso ya es ceder mucho).

Tratándose de Facebok, desde el primer momento en que tuve mi cuenta, la usaba con objetivos meramente sociales y distractores: husmear lo que mostraban los otros sobre sus vidas, pero más que todo, el propósito era "conocer" y estar en contacto con personas que no conocía y/o que no eran tan cercanas. Hoy, 7 años después, lo uso con los mismos fines, pero adicionando la funcionalidad de estar al tanto 
de los deberes académicos que se ventilan por los grupos creados con ese fin; sin embargo, es mucho mayor la frecuencia con la que ingreso a dicho portal, y se ha intensificado el acto indiscriminado, casi que inconsciente (penosamente casi que necesario), de entrar y deslizar el dedo por la pantalla por incontables minutos, para ver variados contenidos que me distraigan de la ocupación o el momento presente.

Resulta a veces ridículo cuántas veces en el día se opta por hacer esta misma operación, aun cuando se ve exactamente lo mismo. Concluyo entonces que este tipo de tecnologías embrutecen al cerebro, y lo engolosinan con el gancho de lo visual. Se crea una latencia inducida a entretenerse fácil y sobre todo: rápido.

Por limitaciones propias, de la mano con convicciones propias, no cuento con un plan de datos que me permita estar "conectada" en todo momento a donde voy. Para poder estarlo, dependo de una red wifi. Y sigue siendo igual de sorprendente cómo tan insignificante aspecto, cambia tan sustancialmente mi diario vivir, respecto de otra persona que sí lo tiene. Del modo en que lo veo, ésta restricción me permite tener momentos "libres" de esa "hiperdisponibilidad"; son momentos en los que obligadamente acepto que ese lado digital de mi vida, se detiene. Porque ese es ahora otro paradigma, una persona corriente habitante del mundo, cuenta con dos vidas: una en el mundo material (real) y otra virtual, en la red. Lo abrumador, como se calificaba al inicio, es que en el presente, ha adquirido tal fuerza esa otra vida virtual, que en la mayoría de las ocasiones subsume a la real. Es decir, que sin notarlo, la vida real debe verse ajustada y desarrollarse en función de la virtual, debido a que precisamente el ritmo de la segunda va a billones de megabites más rápido por segundo que la primera, por lo que no en ir en sincronización con ella, a muchos les significa dejar de vivir un poco de la vida misma. Irónico: dejando de estar presentes en los momentos reales, dejando de vivir la vida que pasa mientras se está en el teléfono, se siente un mayor aprovechamiento del tiempo, que se está viviendo más.

Si no existiese siquiera WhatsApp la lógica de un día normal para cualquier mortal seria mayúsculamente diferente, pues no es lo mismo establecer contacto por otras redes como Messenger o Instagram o cualquier otra, dado que no cuentan con la inmediatez que aquella ofrece. 
Las redes sociales tienen una relación simbiótica con los dispositivos móviles, en especial, los celulares. Sin ellos, la omnipresencia de la conectividad no sería posible en este interregno de la Modernidad Líquida. Con los celulares, cada individuo (que a veces cuenta con más de un dispositivo), se convierte en un "target" de localización, de consumo, y de alienación. El celular ya no es un objeto independiente, por lo menos en mi caso, aun cuando no soy $100 \%$ esclava de la conexión a la red, se convirtió en una extensión más de mi mano, es otra palma, es otro par de ojos anclados a ella. No conozco persona que cuente con un "Smartphone" que al menos en un día no revise más de 10 veces el celular.

Aun con la limitante mencionada, he notado mi dependencia a estar revisando el teléfono y hacerle seguimiento a las dos redes con las que cuento, incluso sin tener ninguna notificación de novedad. Otro punto introspectivo sumamente ridículo. Se hace evidente: padezco de todos los síntomas propios de una adicción psicotrópica, sólo que a ésta le podría llamar una adicción "psico-tecnológica"114. Reitero, y eso que no cuento con un plan de datos.

A más de los que puedo contar, es recurrente escuharles decir: "casi pierdo el celular, mi vida entera está ahí”; "se me acaba el mundo, si boto el celular"; "yo no podría, sabiendo que no tengo datos"; "me desespera, no me llegan los mensajes porque estoy sin datos”. El afán y la Ansiedad: las máximas del mundo posmoderno.

A fuerza de realizar un análisis con datos verificables sobre mi experiencia, tuve conocimiento de una aplicación que cuantifica las veces en las que desbloqueo el celular al día, y decidí descargarla, a sabiendas de que probablemente me sorprenderían los resultados. La app se llama "Cheky", lleva el conteo de las veces en que se desbloquea el

114 Resulta vital mencionar en este punto, el término de Nomofobia, traducción al español de la expresión no-movil-phonephobia, acuñado a partir de distintos estudios realizados (SecurEnvoy, 2012) con el fin de analizar el fenómeno actual de la dependencia al uso del celular a diario (García y Fabila, 2014) el cual, a pesar de no declararse aún como un trastorno de orden psicológico, su manifestación es totalmente equiparable a uno de tal categoría (Mateos, 2017). 
celular al día, y deja el registro de la cantidad acumulada del día anterior; por infortunio, no deja el registro desde el primer día en que se descargó la aplicación para poder establecer una constante, no obstante, me fijé en recordar las cifras para llegar a los siguientes resultados:

- La aplicación la descargué hace una semana, puntualmente, un martes a eso de las 5.30pm, de modo que desde ahí, empezó el conteo. Para las 12am, me registró que había desbloqueado el celular 32 veces. Esto en un margen de 6 hs y media.

- Miércoles y Jueves, tuve un promedio por día de 70 a 100 por todo el día.

- Pero casualmente, el Viernes y el Sábado por ser días usualmente de esparcimiento social, tuve 127 y 110 veces respectivamente.

- El Domingo por el contrario, fue aproximadamente 68.

- Y en lo que va corrido de la semana, he mantenido un promedio siempre superior a 70 hasta 103.

De lo anterior puedo colegir que me tomé muy en serio la frase que con ironía expresaba: "me sumaré a la lista de los adictos”. Y en efecto, la experiencia sería aún más reveladora si la app cuantificara las veces en que se ingresa a una de las redes sociales en el celular.

A partir de esa experiencia, es posible corroborar, que aun manteniendo ciertas reservas respecto del uso de las redes sociales, la sumersión de la vida humana en ellas, es total y de paso, dependiente. Ya que somos seres psico-afectivamente dependientes, plataformas como las de las redes sociales, que alimentan la impresión de ser "socialmente apetecido", se convierten en el medio de cultivo perfecto para desatar variados fenómenos conductuales capaces de reconfigurar el modo y el propósito de establecer una relación “interpersonal”. Es un efecto con tal potencialidad de cambio, que tiene incidencia directa hasta en la economía y las lógicas de mercado.

\section{¿Qué escojo? (tercer interludio)}

Escoge drogarte. Escoge hablar como todo el mundo. Escoge diferenciarte de todos comprando los mismos productos y las mismas marcas que tienen todos. Escoge comprar lo que no necesitas. Escoge comer saludable. Escoge tener un cuerpo escultural. Escoge ser socialmente 
responsable del dinero que ganas. Escoge Linux. Escoge no perderte la avalancha tsunámica de banalidades del mundo del espectáculo. Escoge soñar dentro de los límites y de acuerdo al increíblemente estrecho marco de posibilidades del sistema capitalista. Escoge ser ecológico. Escoge no usar tantas bolsas plásticas. Escoge no saber cuántas especies vegetales se extinguen cada día. Escoge bailar salsa. Escoge la niebla cuando amanece. Escoge sólo leer en pantalla. Escoge el candidato que puntea en las encuestas. Escoge solo el candidato que siempre puntea en las encuestas. Escoge la inanidad de ser popular. Escoge bien tus amigos. Escoge jamás pagar las deudas bancarias. Escoge no leer nunca los "términos y condiciones". Escoge ver cine-arte. Escoge llorar escondido. Escoge Transmilenio. Escoge caminar por recovecos oscuros. Escoge estudiar derecho. Escoge no trasnocharte, o si lo haces que al otro día nadie se dé cuenta. Escoge perder el año. Escoge eliminar las embarazosas fotos de Facebook. Escoge un plan con minutos ilimitados. Escoge que tu vida la consuman pantallas. Escoge atrofiar tu mente con Disney Channel. Escoge oponerte a tus padres. Escoge que al envejecer te verás como Amparo Grisales. Escoge la alegría refrita y prefabricada de los comerciales. Escoge anestesiar tu sentido crítico. Escoge no dar limosna. Escoge la redención santificante del mundo consumista. Escoge no saber los nombres de tus bisabuelos. Escoge estar "siempre en contacto". Escoge ignorar qué es "estar siempre en contacto" y sus implicaciones neuro-afectivas. Escoge no leer nada aburrido. Escoge imaginar que tus hijos serán existosos. Escoge Juan Valdez. Escoge tu rostro sin acné. Escoge nunca ir a una galería de arte. Escoge que nunca te hagan sextorsion. Escoge la falacia de una libertad engañosa. Escoge no sacar el paraguas y preciso mojarte. Escoge una estética cyber-punk. Escoge embriagarte pero no tener guayabo. Escoge una manilla tejida. Escoge ignorar que en el océano hay más plástico que plancton. Escoge una carrera que dé "harta platica”. Escoge una identidad bien vacía. Escoge el equipo de fútbol que alguien escogió para ti. Escoge rezar la novena en diciembre. Escoge perderte en el laberinto que es todo centro comercial. Escoge un restaurante bien fashion. Escoge estudiar en Harvard. Escoge el mapa y no el territorio. Escoge enfermarte justo el día del examen. Escoge no tener hermanos. Escoge el número de tu cédula. 


\section{Escoge Black Mirror ${ }^{115}$}

For as his Emanation divided, his Spectre also divided in terror of that starry wheels and the Specter stood over Los howling in pain: a blackening shadow blackening dark and opaque. William Blake, Jerusalem, p. 6, 1-5.

Las ideas expresadas anteriormente tienen una elocuente representación en una serie británica televisiva de nombre Black Mirror, cuyo argumento gira entorno a la escenificación hiperbolizada de una realidad ficticia donde la tecnología consumió en un 100\% variados aspectos de la cotidianidad de la vida humana, y cada capítulo representa un caso distinto al otro donde sus personajes acaban siendo víctimas de esa nueva lógica social en la que quedan anulados por la misma sociedad.

La serie realiza una verdadera apología al efecto paradójico producido por el poder de la tecnología de facilitar la vida del hombre y en especial, de "ampliar" su círculo social. Uno de los capítulos que es el mejor reflejo de ello, es "Nosedive" 116 (Caída en picada), el cual recrea la vida de una mujer que reúne varias de las características de una chica con potencial para ser socialmente aceptada en el contexto de un típico estilo de vida norteamericano: joven, delgada, atractiva, refinada, una chica de suburbio y económicamente ubicada en un rango medio-alto.

Su mundo es reinado por la calificación numérica dada en estrellas, a través de lo que parece una aplicación del celular, en el que por cada encuentro con otra persona, o por cualquier contenido que suba a la red, recibe desde 1 a 5 estrellas, que sumadas, generan una calificación numérica entre 1 y 5, la cual indica la posición social de cada cual.

Es un capítulo con mucha vigencia en la actualidad, y que ha sido objeto de numerosos análisis, por simbolizar de manera muy acertada

115 Black Mirror. Serie de televisión británica lanzada en 2012, creada por Charlie Brooker y producida por Zeppotron para Endemol.

116 “Nosedive” o "Caída en picada”. Capítulo 1 - Temporada 3 de Black Mirror, dirigido por Joe Wright, lanzado en 2016. 
lo que en un futuro cercano puede llegar a suceder, a causa de la cada vez más profunda sujeción de nuestra vida a la dinámica de las redes sociales.

Para hacer más explícito el sentido del tema en comento, del capítulo pueden extraerse muchas escenas ilustrativas sobre la problemática que expone su trama; algunas se retomarán a lo largo del escrito:

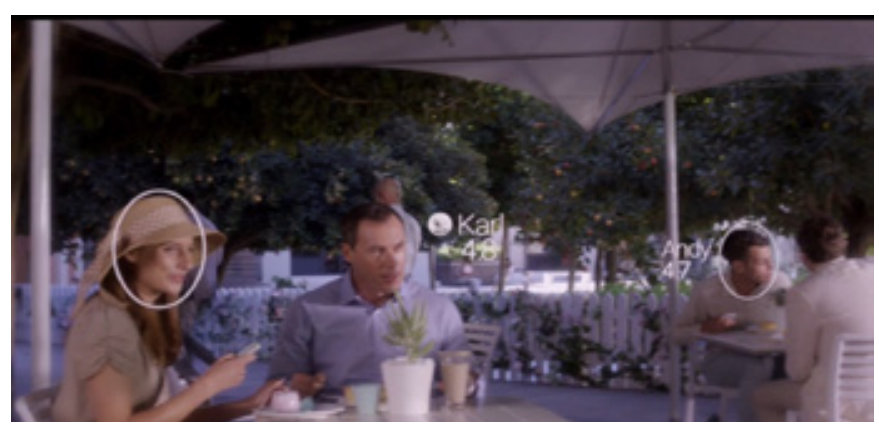

En esta imagen por ejemplo, se muestra cómo un día cualquiera en un café, la protagonista ve a las personas que allí pasan el tiempo, ranqueados numéricamente al posar su mirada sobre ellos, gracias a un lector de reconocimiento facial; los números que aparecen al lado de sus rostros, corresponden a la calificación social lograda por la alta valoración en estrellas dada por los demás.

Uno de los factores críticos que se derivan del análisis de la imagen es, que cada persona está llamada a interactuar con el otro, dependiendo de la información que le brinda el filtro de ranking de posicionamiento y popularidad social integrado en los lentes adheridos a sus ojos. A partir de ello, se dan muchos puntos a tocar: no se establecen relaciones sociales espontáneas, casuales, desinteresadas, sino que condicionadas totalmente a la conveniencia de sus estatus (un aspecto muy parecido al hoy, pero llevado a un extremo muy dable en el futuro); está tan supeditado a dicho ranking el relacionamiento, que el filtro no es una herramienta externa e independiente al individuo, sino que hace parte de él, lo lleva adherido por lentes a sus ojos, uno de los órganos que más información le aporta del entorno; física y mentalmente, su existir se condiciona a la tarifa social del otro. La superficialidad que hoy 
aun es superable, allí se vuelve irrenunciable; este sistema de registro personal, funciona al igual que en el presente, con una autorizada invasión a la privacidad117, ya que el reconocimiento facial integrado a él, al mostrar la calificación en un contexto como ese, da luz sobre mucha de la demás información privada del otro: su clase económica, lugar donde posiblemente vive, las personas y lugares que frecuenta, etc. Porque el ubicarse en un rango superior a 4.0, significa tener alta aprobación social, ser aceptado en varios aspectos que componen la vida de cualquier ser humano.

La aprobación social se convierte en la unidad de cambio por excelencia, significa el grado de poder adquisitivo con el que cuenta un individuo. Ello le permite acceder a ciertos servicios a los que otros no, puede acceder y disfrutar de ciertos espacios que sólo personas de alta categoría visitan. Muy similar al hoy, pero diferenciándose en que hoy es el dinero (un elemento tangible y externo) la unidad de cambio, mientras que allí, se le otorga peligrosamente el mismo poder económico a la aceptación social (una condición propia, inherente del ser humano), y potencia su capacidad de agraviar al otro.

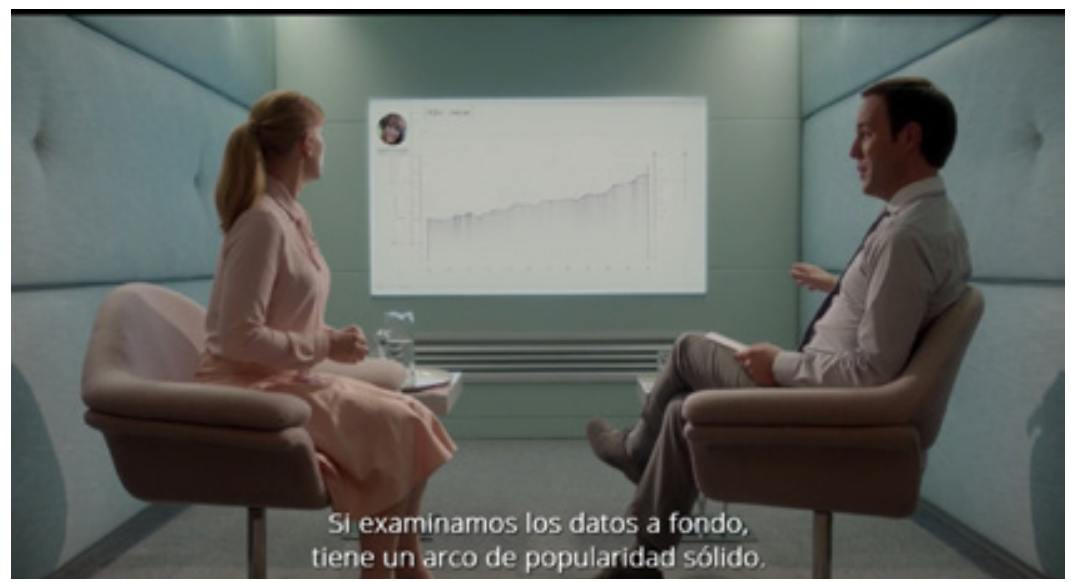

117 La obra coordinada por Antonio Fayos Gardó ofrece una ampliación respecto a la polémica afectación a la privacidad y el ámbito jurídico que lo rodea, desde una perspectiva global. (Fayos, 2015). 
Este paradigma se vislumbra en ésta imagen, en la que la protagonista se encuentra con un analista de reputación social, la empresa de la que él hace parte, se llama "Reputelligent". Una forma de interpretarlo sería, una empresa cuyo "core" es brindar asesoría sobre cómo obtener y mantener una alta reputación social de forma "inteligente". Ella acude a tales dependencias, ya que busca subir su calificación y así poder ser parte de la categoría de "Usuarios Premium", quienes están calificados por encima de 4.5 y pueden comprar ciertos inmuebles sofisticados y lujosos.

Ambos personajes se encuentran sentados en una sala de proyección destinada a evaluar los arcos de popularidad del solicitante (como muestra el diálogo), lo que implica el examen de su círculo social, y sus publicaciones en redes; el sistema de puntuación social es tan o más crucial que el sistema financiero, la figura del analista es totalmente equiparable a la de un asesor de finanzas personales. En ese mundo, es tan trasversal a la vida, llevar un buen récord de puntuación, que existe toda una lógica dirigida a que los individuos proyecten el crecimiento de su reputación. En definitiva, es un capítulo que significa lo que sería la vida, si seguimos fortaleciendo la injerencia de las redes sociales y rindiéndole tributo a la vanidad: todo un encomio a la frivolidad y al empobrecimiento del vínculo con el otro.

Sin embargo esa dinámica social, no sólo fija la directriz en términos materiales (económicos), sino que también funge como mecanismo de control, como un medio punitivo.

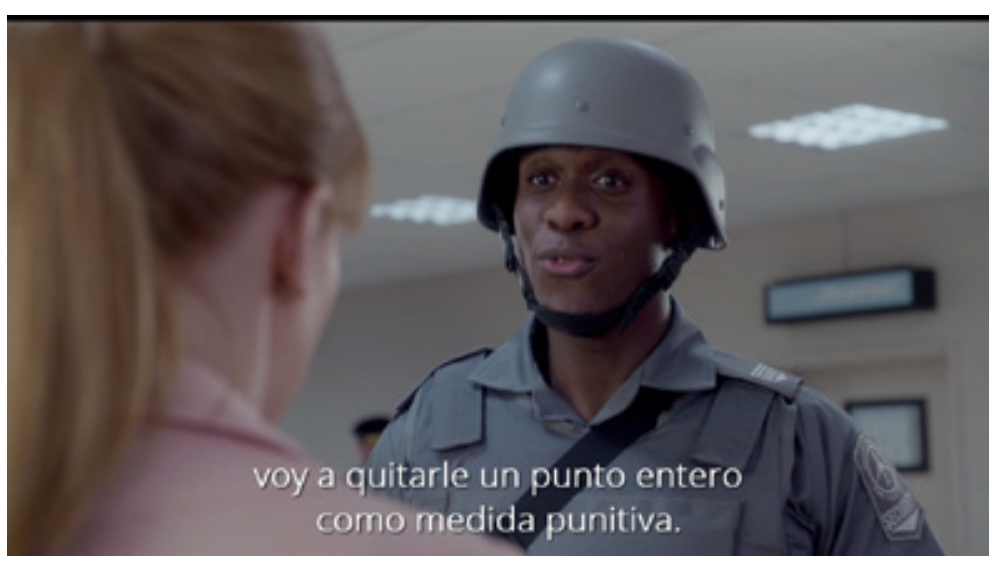


En ésta imagen se ve a un agente de seguridad del aeropuerto en el que a ella le surgen problemas para reprogramar su vuelo, gracias a que de camino al aeropuerto, tuvo pequeños roces con personas que se cruzó en el trayecto, lo cual le causó una progresiva caída en su calificación por cuenta de tales personas y ello le privó de poder acceder a la reprogramación. En medio del desespero, se salió de los límites de cordialidad fingida a la que siempre debía someterse, y tuvo un disgusto con la funcionaria. Ésta llamó a seguridad, y el agente sin darle chance de hablar a la protagonista, procede a quitarle un punto entero de su calificación informándole que adicionalmente, cada calificación negativa que reciba de ahí en adelante, se multiplicará al doble, castigo al que le llama "doble perjuicio", como sanción por su comportamiento. Sólo un punto, representa un perjuicio enorme para cualquier persona, debido a que socialmente la diferencia entre un dígito y otro es muy significativa, pues la traslada a una clase social muy inferior, que la priva del estilo de vida anhelado por todos, y por el que en principio estaba luchando por posicionar. Teniendo en cuenta que dadas las circunstancias, recibir otra calificación negativa es muy posible, duplicar éstas al doble, sin duda le provocó una caída en picada, como bien se titula el capítulo.

Las repercusiones que esa medida tiene, son ciertamente lesivas para un individuo, similar a una sanción económica, medida cautelar, entre otras, en razón a que coarta ciertos derechos subjetivos, con miras a compensar una violación a la ley, y castigar una conducta antijurídica. En el capítulo, moralmente reprochable además.

De forma pertinente un ciudadano ingles del común, por medio de un video en Youtube ${ }^{118}$ comparte un análisis frente a "Nosedive", llamándolo paralelamente: "Antisocial Media", como parte de su reflexión. Trae a colación varios puntos importantes que son coincidentes con el análisis realizado, en tanto menciona que es ésta escena la que quizá lo dice todo sobre éste capítulo, pues evidencia el poder de afectación que tiene el ranking social, al punto de ser una medida que bien podría reemplazar la necesidad de usar el arma portada por el

118 https://www.youtube.com/watch?v=px0oxAPSIdA 
agente, ya que en sí misma resulta más perjudicial para la integralidad de su vida, extraerla de su estatus y condenarla a seguir agravándolo, que realizar una amenaza física directa.

Y es que siempre será más poderoso el efecto pos sanción, que la sanción misma, aun tratándose de nuestra realidad. Porque es después de haber sido encarcelado, y de haber perpetuado en la hoja de vida de un individuo, su pasado judicial, que vive la pena más dura: ser anulado socialmente. Las posibilidades de materializarse una reinserción social, son ficticias, pues nada puede suprimir más las vías de realización personal, que cargar con el estigma de haber sido judicialmente condenado. Siguiendo el video, la reputación social, incluso en nuestro mundo, demarca la accesibilidad que se puede tener para conseguir empleo, muchos trabajos piden acceso a las redes sociales, casi que con el fin policivo de conocer lo que un trabajador hace fuera de su jornada laboral, el ámbito personal aunque pertenece a la esfera de la intimidad, es una zona restringida para los empleadores, aparentemente, porque en caso de que soliciten tal información y no sea dada, da pie para generar sospechas y sembrar desconfianzas que no habrían inicialmente surgido, las cuales se pueden volver motivos que camuflados en otros pretextos, cierren la puerta a ese empleo. Incluso, para no ir muy lejos, ese poder calificativo en el ámbito laboral ya lo vivimos: por ejemplo, para quienes trabajan en Uber o quienes realizan trabajo freelance, son modalidades laborales que dependen por lo menos en más de un $70 \%$ de la calificación dada por el usuario, ya que de no lograr una buena reputación, quedan inhabilitados para seguir trabajando o son descartados por los mismos usuarios.

Por otro lado, otro de los puntos neurálgicos de esta reflexión que se debe tocar, es que en medio del afán por ser visto en la manera en la que nos exponemos ante la sociedad mediante las redes sociales, como ocurre también en el capítulo, de conservar la fachada del modus vivendi deseado, es que se pierde la noción de lo que es realmente vivir. Como bien dice el inglés, siquiera se está viviendo, más bien se reduce a "una mera existencia” que haya su razón de ser en satisfacer a los demás. De ahí que la protagonista no fuese consiente de si en verdad sabía lo que significaba vivir para el status que tanto buscaba, lo que representaba conseguirlo y más difícil aun, conservarlo. Se persigue 
entonces, la idea ilusoria de llegar a una felicidad dibujada por otros, que ni siquiera satisface a cada uno de ellos, se pierde el valor del presente y se pierden en la búsqueda de un futuro perfecto.

Además porque se estima que otro efecto colateral del uso excesivo de tales plataformas, es que recarga el lugar de la temporalidad hoy en día; lo que se publicó, compartió, etc., tiene valor solo por contados instantes, y el afán por ser el centro de atención, se adueña con mayor velocidad de sus consumidores, conforme pasa el tiempo y se diversifican las aplicaciones para hacerlo.

De hecho Fuente especificada no válida. en su obra: Virality, propone la teoría del contagio, en la que, postula en su parte introductoria, cómo la era de las redes es en realidad La Era del Contagio. Una era en la que el vehículo de contagio son las redes, y el "virus" son las emociones tanto positivas como negativas, intencionalmente provocadas y esparcidas por medio de las redes sociales. Se da una virtualización del sentir, que al igual que el neuromarketing, trata de ejercer control social a través de la provocación de ciertas emociones y generar reacciones dependientes.

Esta teoría del contagio según la claridad hecha por el autor, virality no pretende desarrollar una teoría nutrida por analogías conceptuales sobre enfermedad, inmunidad, entre otros, sino que la describe como el ejercicio de fuerzas desplegadas como relaciones entre fuerzas y encuentros que determinarán las características funcionales en el ámbito social. Esto quiere decir, que lo que se da en el plano de lo social es una fluctuación de deseos inconscientes que impulsan el relacionamiento entre los individuos, y que en un contexto donde las redes sociales acaparan la capacidad social de los individuos, se busca lograr el propósito de alimentar esos deseos inconscientes a través de la "transmisión" de afectos, sentimientos y emociones impelidos por lo que él llama "amplificadores culturales" inmersos en mercancías como la cafeína, novelas sentimentales y la pornografía, que pueden remodificar la conducta de formas impredecibles. Un mundo que él describe como inundado de hormonas y bienes de consumo, en donde se hace a las personas tristes o felices, apáticas o empáticas, un espacio que en el que los afectos son transferidos paulatinamente a través de las sugerencias de otros, cada vez más y más, a través de las redes. 
La era del contagio tiene total aplicabilidad en un escenario como el de Nosedive, donde el orden social está determinado por los presupuestos de una "emopolítica" y del ejercicio de un "biopoder (Foucault, 2005)" que juega con esa parte tan vulnerable del hombre: su emocionalidad, su dependencia afectiva, su apetencia por la atención. El biopoder manipula ese lado vivo y casi indomable del ser humano que le hace ser presa de su propio afán por dejar de ser sí mismo y ser lo que los otros esperan de él.

Yendo más lejos, planteamos que es posible hablar -más que de una biopolítica al estilo delineado por Michel Foucault (2008)-, de una monstruosa, abarcadora y cyber-punk DATA-POLÍTICA, donde los algoritmos han reemplazado el ADN mismo de los seres vivos.

De tal suerte que los Numerati (Baker, 2009) acaban por controlar las decisiones geo-políticas más trascendentes ${ }^{119}$.

Sampson (2012) retomando la teoría del sociólogo francés Gabriel Tarde (1843-1904), califica al sujeto social como sonámbulos. Sonámbulos porque interactúan con otros a partir de la hipnosis que recibe de la sociedad, y su inevitable imitación, a fuerza de buscar sentir, que pertenece. Esto es justamente lo que tratamos de caracterizar como DATA-POLÍTICA, un modo de dominación donde son los avatares y sombras digitales (digital shadow) los "agentes", los individuos que no solo manipulan tecnologías "inter-activas", sino, siguiendo intuiciones de Slavoj Zizek (2006) hablamos más bien de "inter-pasividad”.

Extendiendo el marco psico-analítico lacaniano que Zizek utiliza en su ensayo, diríamos que esta extraña y paradójica "inter-pasividad"

119 "Baker interviews people who are studying, developing and implementing the technologies and techniques used to capture and analyze many of our everyday actions as we communicate, travel and make purchases. He explains how the initial goal of this data capture and analysis is typically to identify sets of characteristics, which makes it easier to manage the billions of data points these sets may contain. As these characteristics are grouped, it is hoped that the members of each group can be better understood. This information can then be used, with varying but often increased success, in early incident detection, to predict outcomes, project the effect of stimulus on the groups and, in many cases, to influence group members' behaviour" https://en.wikipedia.org/wiki/The_Numerati. 
da el tono del mundo data-político en que seguimos hundiéndonos. Donde se supera la dupla activo/pasivo (usuario o agente "humano" activo frente a máquina o software pasivo) marcando una doble pasividad sin sujeto activo alguno. Así deambulamos hipnotizados y sonámbulos frente a la pantalla de nuestros gadgets, hiperconsumidos por redes sociales que desplazan la idea de un "agente político" y nos determinan a "escoger" pasivamente la última versión de I-phone, de Whatsapp o de la red social que libremente nos elige.

Del sugerente análisis Sampson/Zizek que hibridamos aquí se desprende cómo hasta la forma de recrear los espacios donde se desarrolla la historia, son monocromáticos y estrictamente sobrios, todo el actuar de los individuos está automatizado en función de operar bajo una cordialidad excesiva, e hipócrita. Sólo son admitidas públicamente las emociones politicamente correctas, y ya no es natural una conversación fluida, sino entorpecida. Los integrantes de ese modelo de sociedad, se vuelven entes, productores de falacias y de contención de rabias, virtualmente aptos, pero socialmente ineptos, sonámbulos porque deambulan persiguiendo una vida irreal, y que a su vez les arrebata el regalo de ciertamente vivir.

"La caída en picada" o "Los medios antisociales" como bien los denomina el inglés, muestran el efecto dominó que sufre un individuo en el que el sistema social se cimenta sobre el "emoconsumo" (Illouz, 2007). No lejos de la realidad está ésta teatralización del caer en la dependencia de la puntuación social; mucho de su lógica, ya opera entre nosotros cada día, y es cada vez más contagioso ser parte de esa dinámica de: "comparto, luego existo", "me siguen, luego importo" 120.

120 "Emotional contagion is the phenomenon of having one person's emotions and related behaviors directly trigger similar emotions and behaviors in other people. One view developed by Elaine Hatfield et al. is that this can be done through automatic mimicry and synchronization of one's expressions, vocalizations, postures and movements with those of another person. When people unconsciously mirror their companions' expressions of emotion, they come to feel reflections of those companions' emotions. Emotions can be shared across individuals in many different ways both implicitly or explicitly. For instance, conscious reasoning, analysis and imagination have all been found to contribute to the phenomenon. Emotional contagion is important to personal relationships 
La paradoja que se reitera con el avance tecnológico, es la de que conforme se sofistican los adelantos en el mismo y se tecnifica la vida cotidiana, se acelera el detrimento de la calidad de vida. Puede que se simplifiquen para el hombre muchas de sus actividades diarias gracias a la tecnología, en el caso de las redes sociales, que le abran puertas a personas lejanas y desconocidas, pero ella también le despoja de lo que lo mantiene mentalmente sano: la estabilidad y solidez de su círculo social, y simultáneamente le va a atrofiando su necesidad de: ser humano. , metahumano (DC Comics expanded universe, dixit) o trasbumano Evans (2015).

La indispensable película The Circle (2017) ambienta este sentido crítico muy en la línea de los tecno-dramas que nos presenta la serie Black Mirror, a medio camino entre la fascinación imbécil y la pesadilla insufrible, inter-pasivos nos arrojamos de cabeza a ese abismo luminoso (The sunken place) de negrura magnífica que es la DATAPOLÍTICA actual.

Operando a escala planetaria esta metamorfosis del aburrido panóptico foucaultiano (perspicazmente diagramatizado en Deleuze, 1988) al seductor pornóptico (Amador, Valencia, 2016), nos afantasmamos en las cuentas de los Numerati en que todos nos hemos convertido como parte de esta sociedad del rendimiento y del "me gusta” (like).

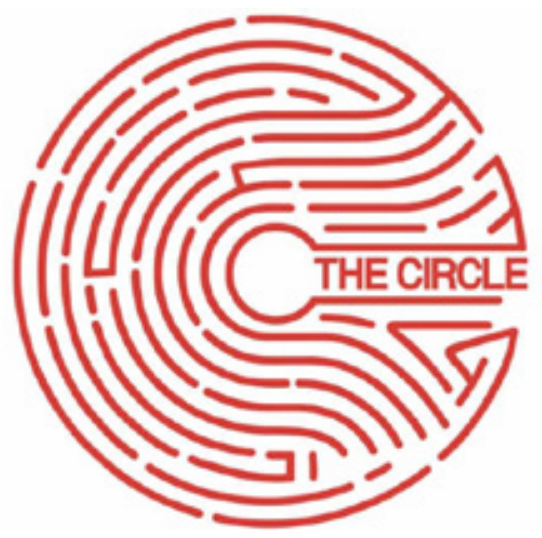

because it fosters emotional synchrony between individuals. A broader definition of the phenomenon was suggested by Schoenewolf: "a process in which a person or group influences the emotions or behavior of another person or group through the conscious or unconscious induction of emotion states and behavioral attitudes". https://en.wikipedia.org/wiki/Emotional_contagion 


\section{¿Dime qué escojo? (a manera de infinitiva c o n c l u s i ó n )}

Escoge ser rebelde de acuerdo al derecho de obligaciones. Escoge que a Julian Assange le apliquen la pena de muerte. Escoge cambiar la localización de las letras en el teclado. Escoge un perfil falso en Facebook. Escoge un signo zodiacal diferente. Escoge excitarte con sexting. Escoge jamás comprar en supermercados. Escoge ropa vintage. Escoge hablar un segundo idioma. Escoge la depresión según te la pintan. Escoge shampoo con acondicionador. Escoge salir de la ciudad los domingos. Escoge cámaras de seguridad en los baños. Escoge la sabia hipocresía de un personaje de telenovela. Escoge bañarte todos los días. Escoge ignorar que el control mental a escala planetaria existe y es perfectamente operativo. Escoge bajarte el sueldo. Escoge que la paz en Colombia dependa solo de acabar la guerrilla. Escoge no creer en fantasmas. Escoge cambiar tus claves con frecuencia. Escoge hacer parte de alguna "tribu urbana". Escoge no querer saber qué es una "tribu urbana”. Escoge que al envejecer te verás como Sean Connery. Escoge ignorar los grupos de Whatsapp que creaste y te aburren infinitamente. Escoge un Rolex. Escoge la amistad diseñada por cerveza Poker. Escoge que comprar carro hoy en día es un exabrupto. Escoge video-juegos de guerra. Escoge nunca aburrirte. Escoge no pagar la declaración de renta. Escoge un esmalte barato. Escoge que nunca visitas al médico. Escoge saber los nominados a los Óscares. Escoge inyectarte heroina o escoge que nunca serás adicto. Escoge dibujar sin colores. Escoge que en las nubes ves dragones. Escoge sólo tres canales de TV. Escoge dormir la siesta. Escoge no sonrojarte. Escoge llegar siempre tarde. Escoge que tus pantalones nunca combinen. Escoge creerte todas las cortinas de humo. Escoge memes chistosos. Escoge una medida diferente al sistema métrico décimal. Escoge ser más bonita que la foto del carnet. Escoge ir a la peluquería temprano. Escoge hacer la lista antes de ir de compras. Escoge que esa lista es interminable. Escoge intereses reducidos. Escoge que nunca se va la luz en tu casa. Escoge recordar bonito a tu ex-novio. Escoge que la señorita Colombia de veras gana Miss Universo. Escoge cerveza al clima. Escoge un perfume exclusivo. 
Escoge que lo que escogiste como exclusivo lo usan muchas personas. Escoge que la puerta de Transmilenio se cierre en tu cara. Escoge romper la necesidad de escoger. Escoge que nunca te pidan limosna. Escoge viajar fuera del país una vez al año. Escoge jamás tener que llamar a la policía. Escoge que te de sueño en el trabajo. Escoge comprar libros que no leerás. Escoge tener un tic bien sensual. Escoge no enamorarte. Escoge esconder tus verdaderas intenciones. Escoge respetar siempre la fila. Escoge un partido político minoritario. Escoge desconocer la versión que no cuenta la "historia oficial" de los hechos. Escoge obligatoriamente el relativismo. Escoge una realidad alternativa en la que Eva no fue creada de una costilla. Escoge que las páginas de este libro no siguen un orden secuencial. Escoge la inutilidad de tomar cualquier decisión. Escoge únicamente escuchar música clásica. Escoge criticar el vegetarianismo por inviable. Escoge que en el mundo no existan maquilas. Escoge que el capitalismo neoliberal no sea el único modelo económico aplicable sobre el planeta. Escoge puntos. Escoge siempre acumular más y más puntos.

\section{Referencias bibliográficas}

Amador, J. y Valencia, D. (2016). Pornóptico (N)infomanía y Emopolitica. En: Derecho Penal. Vigilancia y Control Social. Bogotá: Ibañez/ EdicionesUSTA.

Varela, N. (2008). Feminismo para principiantes. Barcelona : Ediciones B.

Sentencia Caso González y Otras (campo algodonero) vs México (Corte Interamericana de Derechos Humanos 16 de noviembre de 2009).

Fuentes, J. M. (2004). "Feminicidio y marginalildad urbana en Ciudad Juárez en la década de los noventa", en Violencia contra las mujeres en contextos urbanos y rurales. México: El Colegio de México.

Russell, D. E. (1982). Crimes against Women: The Proceedings of the International. San Francisco, California: Frog in the Wel.

Snaidas, J. (2009). El feminicidio en América Latina. Historia y perspectivas. Buenos Aires.

Lagarde, M. (2005). "El feminicidio, delito contra la humanidad". México: Comisión Especial para Conocer y Dar Seguimiento a las Investigaciones 
Relacionadas con los Feminicidios en la República Mexicana y a la Procuración de Justicia Vinculada.

Puertas, L. (25 de Julio de 2002). Fujimori ordenó la esterilización forzosa de 200.000 mujeres indígenas en el Perú. El País .

Corimaita, K. C. (2010). Huellas psicológicas de la esterilización forzada. Revista Ideele, 06.

Rousseau, S. (2007). Las políticas de salud reproductiva en el Perú: reformas sociales y derechos ciudadanos. Revista Estudos Feministas , 10.

Cruz Rodríguez, E. (2015). Relaciones cívico-militares, negociaciones de paz y postconflicto en Colombia. Criterio jurídico garantista , 12-41.

Molina, C. E. (2012). ¿Qué es eso de la interseccionalidad? . investigaciones feministas , 203-222.

Barrére Unzueta, M. Á. (2011). SUBORDISCRIMINACIÓN Y DISCRIMINACIÓN INTERSECCIONAL, Elementos para una teoría del Derecho antidiscriminatorio. Anales de la Cátedra Francisco Suarez, 45 , 15-42.

Bodelón, E. (2014). Violencia Institucional y violencia de género. Anales de la cátedra Francisco Suárez 48 , 131-155.

Corte interamericana de derechos humanos. (7 al 22 de Noviembre de 1969). Organizacion de los estados americanos. From https://www.oas.org/dil/ esp/tratados_b-32_convencion_americana_sobre_derechos_humanos.htm

FERTILAB. (16 de Marzo de 2017). FERTILAB. From Que es la esterilizacion quirurgica femenina: http://www.fertilab.net/ginecopedia/anticoncepcion/ esterilizacion_femenina/que_es_la_esterilizacion_quirurgica_femenina_1

Vida Humana Internacional. (08 de Abril de 2011). Vida humana Internacional. From http://www.vidahumana.org/esterilizacion/ item/91-la-esterilizaci\%C3\%B3n-forzosa-o-coactiva-en-el-mundo-actual

Nürnberger Menschenrechtszentrum . (17 de Julio de 1999). Nürnberger Menschenrechtszentrum . From http://www.menschenrechte.org/lang/ es/regionen/la-dictadura

Naciones Unidas. (10 de Diciembre de 1948). Naciones Unidas. From La Declaración Universal de Derechos Humanos: http://www.un.org/es/ universal-declaration-human-rights/

Comision interamericana de derechos humanos. (2003). INFORME $N^{\circ} 71 / 03$ SOLUCION AMISTOSA. Perú: Organizacion de los estados americanos . 
Centro por la Justicia y el Derecho Internacional. (2010). CIDH condena impunidad por esterilizaciones forzadas en Perú. Washignto, D.C.: Centro por la Justicia y el Derecho Internacional.

Revista IIDH. (Vol. 43). La ejecución extrajudicial o el homicidio en las legislaciones de América Latina. Revista IIDH , 284-285.

Semana. (12 de Julio de 1982). ¿La noche quedó atrás? From http://www.semana.com/nacion/articulo/la-noche-quedo-atras/367-3

Colectivo de abogados José Alvear Restrepo. (14 de Marzo de 2006). Consolidación paramilitar e impunidad en Colombia.

Redacción El Tiempo. (2010). Turbay dicta polémico Estatuto de seguridad (1978 - 1982). El Tiempo .

Jiménez, C. (2008). La doctrina de seguridad nacional en Colombia: efectos en materia de Derechos Humanos. Universidad Sergio Arboleda .

Rugeles, G. (2013). Las convivir que se volvieron organizaciones paramilitares. Las Dos Orillas .

Redacción Judicial. (2008). Del Estatuto de Seguridad a la Seguridad Democrática. El Espectador .

Castañeda, G. G. (2004). Violencia Sexista. México: UNAM.

Medina Rosas, A. (2011). Campo algodonero definiciones y retos ante el feminicidio en México. dfensa , 6-7.

Salvador Bernabéu, A. (2015). El feminicidio de Ciudad Juarez. Repercusiones legales y culturales. Sevilla: Universidad Internacional de Andalucía.

Puleo, A. (1998). Patriarcado. In C. Amorós, 10 palabras claves sobre mujer (pp. 21-54). Navarra: Verbo Divino.

JONAS, H. (1995). El principio de responsabilidad. Ensayo de una ética para la civilización tecnológicaa. Barcelona, Cataluña, España: Herder.

AQUINO, T. d. (1989). Suma Teológica. Madrid, España: Biblioteca de Autores Cristianos.

Carr, N. (2010). Superficiales.¿Qué está haciendo Internet con nuestras mentes? Bogotá: Distribuidora y Editora Aguilar, Altea, Taurus, Alfaguara S.A.

Foucault, M. (2005). Historia de la Sexualidad. Vol 1 La voluntad de saber. México: Siglo XXI Editores de c.v.

Han, B. -C. (2014). Psicopolítica. Neoliberalismo y nuevas técnicas de poder. Barcelona: Herder. 
Mateos, A. S. (2017). Nomofobia, el motivo psicológico por el que no eres capaz de dejar de mirar el móvil. From La Vanguardia. Sección: Psicología: http://www.lavanguardia.com/vivo/psicologia/20170331/42857887210/ nomofobia-adiccion-movil.html

SecurEnvoy. (2012). 66\% of the population suffer from Nomophobia the fear of being without their phone. From https://www.securenvoy.com/ blog/2012/02/16/66-of-the-population-suffer-from-nomophobia-the-fearof-being-without-their-phone/

Verónica García, A. F. (2014). Nomofolia vs. Nomofobia, irrrupción del teléfono móvil en las dimensiones de vida de los jóvenes, un tema pendiente para los estudios en comunicación. Monterrey, México: Sistema de Información Científica Red de Revistas Científicas de América Latina y el Caribe, España y Portugal.REVISTA RAZÓN Y PALABRA vol. 18, núm. 86.

Lyon, Z. B. (2013). Vigilancia Líquida. Barcelona: Espasa Libros S.L.U.

Fayos, A. (2015). Los derechos a al intimidad y a la privacidad en el siglo XXI. Madrid: Dykinson.

Orwell, G. (1949). 1984. Editorial Destino.

Varela, N. (2008). Feminismo para principiantes. Barcelona : Ediciones B.

Sentencia Caso González y Otras (campo algodonero) vs México (Corte Interamericana de Derechos Humanos 16 de noviembre de 2009).

Fuentes, J. M. (2004). "Feminicidio y marginalildad urbana en Ciudad Juárez en la década de los noventa", en Violencia contra las mujeres en contextos urbanos y rurales. México: El Colegio de México.

Russell, D. E. (1982). Crimes against Women: The Proceedings of the International. San Francisco, California: Frog in the Wel.

Snaidas, J. (2009). El feminicidio en América Latina. Historia y perspectivas. Buenos Aires.

Lagarde, M. (2005). "El feminicidio, delito contra la humanidad". México: Comisión Especial para Conocer y Dar Seguimiento a las Investigaciones Relacionadas con los Feminicidios en la República Mexicana y a la Procuración de Justicia Vinculada.

Puertas, L. (25 de Julio de 2002). Fujimori ordenó la esterilización forzosa de 200.000 mujeres indígenas en el Perú. El País .

Corimaita, K. C. (2010). Huellas psicológicas de la esterilización forzada. Revista Ideele, 06. 
Rousseau, S. (2007). Las políticas de salud reproductiva en el Perú: reformas sociales y derechos ciudadanos. Revista Estudos Feministas , 10.

Cruz Rodríguez, E. (2015). Relaciones cívico-militares, negociaciones de paz y postconflicto en Colombia. Criterio jurídico garantista , 12-41.

Molina, C. E. (2012). ¿Qué es eso de la interseccionalidad? . investigaciones feministas , 203-222.

Barrére Unzueta, M. Á. (2011). SUBORDISCRIMINACIÓN Y DISCRIMINACIÓN INTERSECCIONAL, Elementos para una teoría del Derecho antidiscriminatorio. Anales de la Cátedra Francisco Suarez, 45 , 15-42.

Bodelón, E. (2014). Violencia Institucional y violencia de género. Anales de la cátedra Francisco Suárez 48 , 131-155.

Corte interamericana de derechos humanos. (7 al 22 de Noviembre de 1969). Organizacion de los estados americanos. From https://www.oas.org/dil/ esp/tratados_b-32_convencion_americana_sobre_derechos_humanos.htm

FERTILAB. (16 de Marzo de 2017). FERTILAB. From Que es la esterilizacion quirurgica femenina: http://www.fertilab.net/ginecopedia/anticoncepcion/ esterilizacion_femenina/que_es_la_esterilizacion_quirurgica_femenina_1

Vida Humana Internacional. (08 de Abril de 2011). Vida humana Internacional. From http://www.vidahumana.org/esterilizacion/ item/91-la-esterilizaci\%C3\%B3n-forzosa-o-coactiva-en-el-mundo-actual

Nürnberger Menschenrechtszentrum . (17 de Julio de 1999). Nürnberger Menschenrechtszentrum . From http://www.menschenrechte.org/lang/ es/regionen/la-dictadura

Naciones Unidas. (10 de Diciembre de 1948). Naciones Unidas. From La Declaración Universal de Derechos Humanos: http://www.un.org/es/ universal-declaration-human-rights/

Comision interamericana de derechos humanos. (2003). INFORME $N^{\circ} 71 / 03$ SOLUCION AMISTOSA. Perú: Organizacion de los estados americanos .

Centro por la Justicia y el Derecho Internacional. (2010). CIDH condena impunidad por esterilizaciones forzadas en Perú. Washignto, D.C.: Centro por la Justicia y el Derecho Internacional.

Revista IIDH. (Vol. 43). La ejecución extrajudicial o el homicidio en las legislaciones de América Latina. Revista IIDH , 284-285.

Semana. (12 de Julio de 1982). ¿ La noche quedó atrás? From http://www.semana.com/nacion/articulo/la-noche-quedo-atras/367-3 
Colectivo de abogados José Alvear Restrepo. (14 de Marzo de 2006). Consolidación paramilitar e impunidad en Colombia.

Redacción El Tiempo. (2010). Turbay dicta polémico Estatuto de seguridad (1978 - 1982). El Tiempo .

Jiménez, C. (2008). La doctrina de seguridad nacional en Colombia: efectos en materia de Derechos Humanos. Universidad Sergio Arboleda .

Rugeles, G. (2013). Las convivir que se volvieron organizaciones paramilitares. Las Dos Orillas .

Redacción Judicial. (2008). Del Estatuto de Seguridad a la Seguridad Democrática. El Espectador.

Castañeda, G. G. (2004). Violencia Sexista. México: UNAM.

Medina Rosas, A. (2011). Campo algodonero definiciones y retos ante el feminicidio en México. dfensa, 6-7.

Salvador Bernabéu, A. (2015). El feminicidio de Ciudad Juarez. Repercusiones legales y culturales. Sevilla: Universidad Internacional de Andalucía.

Puleo, A. (1998). Patriarcado. In C. Amorós, 10 palabras claves sobre mujer (pp. 21-54). Navarra: Verbo Divino.

JONAS, H. (1995). El principio de responsabilidad. Ensayo de una ética para la civilización tecnológicaa. Barcelona, Cataluña, España: Herder.

AQUINO, T. d. (1989). Suma Teológica. Madrid, España: Biblioteca de Autores Cristianos.

Carr, N. (2010). Superficiales. ¿Qué está haciendo Internet con nuestras mentes? Bogotá: Distribuidora y Editora Aguilar, Altea, Taurus, Alfaguara S.A.

Foucault, M. (2005). Historia de la Sexualidad. Vol 1 La voluntad de saber. México: Siglo XXI Editores de c.v.

Han, B. -C. (2014). Psicopolítica. Neoliberalismo y nuevas técnicas de poder. Barcelona: Herder.

Mateos, A. S. (2017). Nomofobia, el motivo psicológico por el que no eres capaz de dejar de mirar el móvil. From La Vanguardia. Sección: Psicología: http://www.lavanguardia.com/vivo/psicologia/20170331/42857887210/ nomofobia-adiccion-movil.html

SecurEnvoy. (2012). 66\% of the population suffer from Nomophobia the fear of being without their phone. From https://www.securenvoy.com/ blog/2012/02/16/66-of-the-population-suffer-from-nomophobia-the-fearof-being-without-their-phone/ 
Verónica García, A. F. (2014). Nomofolia vs. Nomofobia, irrrupción del teléfono móvil en las dimensiones de vida de los jóvenes, un tema pendiente para los estudios en comunicación. Monterrey, México: Sistema de Información Científica Red de Revistas Científicas de América Latina y el Caribe, España y Portugal.REVISTA RAZÓN Y PALABRA vol. 18, núm. 86.

Lyon, Z. B. (2013). Vigilancia Líquida. Barcelona: Espasa Libros S.L.U.

Fayos, A. (2015). Los derechos a al intimidad y a la privacidad en el siglo XXI. Madrid: Dykinson.

Orwell, G. (1949). 1984. Editorial Destino.

FILMOGRAFÍA \& TV SERIES

BLACK MIRROR (2011-present). Ex. Prod/Creator Charlie Brooker. Zeppotron/ House of Tomorrow. UK.

TRAINSPOTTING (1996). Channel Four Films Dir. Danny Boyle. UK.

T2 TRAINSPOTTING (2017). Dir. Danny Boyle . UK.

GET OUT (2017). Dir. Jordan Peele. Universal Pictures. USA.

THE CIRCLE (2017). Dir. James Ponsoldt. STX Entertainment. USA. 


\title{
Consideraciones sobre la pertinencia de la educación en derechos humanos: Un camino para la consolidación de la paz y la democracia en Colombia ${ }^{121}$
}

\author{
Elsa Bonilla Piratova ${ }^{122}$
}

“... La concepción de que los pueblos pueden autogobernarse en un pie de igualdad política, dueños de todos los recursos e instituciones necesarios para ese fin, seguirá siendo...una pauta imperativa, aunque exigente, en el afán de establecer una sociedad donde las personas convivan en paz, respetando cada una la igualdad intrínseca de las demás y procurando entre todas alcanzar la mejor vida posible" ${ }^{123}$

Robert Dalh

121 Articulo resultado producto de investigación del proyecto denominado "Procesos de exigibilidad y justiciabilidad de los Derechos Humanos y el Derecho Internacional Humanitario, en el contexto nacional e internacional.” Adscrito al grupo de investigación Sociohumanistico Categoría A en Colciencias de la Facultad de Derecho de la Universidad Santo Tomás Bogotá.

122 Bonilla Piratova. Licenciada en Ciencias Sociales, Universidad Pedagógica Nacional. Magister en Historia, Universidad Externado de Colombia. Estudios de especialización en Gestión Pública, Escuela Superior de Administración Pública-Universidad del Tolima. Docente Universitaria. Maestra de Ciencias Sociales, Gimnasio Moderno, Bogotá. Estudiante Doctorado en Educación, Universidad Santo Tomás. elsabonillapi@yahoo.com

123 En Democracia y sus críticos (1989, 428 - 429.) y en Democracia. Guía para ciudadanos Dalh propondrá que la igualdad supondrá que cada personas tiene la capacidad de poseer su idea de bien y concebir a su vez un sentido de 


\section{A manera de introducción}

El presente documento es el resultado de algunas reflexiones derivadas de las actividades de investigación y de Dirección de trabajos de grado con los estudiantes de la Maestría en defensa de los Derechos Humanos y del Derecho Internacional Humanitario ante organismos, tribunales y cortes internacionales, en la línea de investigación: Derechos Humanos, Derecho Internacional Humanitario y Derecho Penal Internacional. El área de trabajo que fundamenta este resultado, se circunscribe a la Educación en Derechos Humanos y Formación ciudadana.

En incontables ocasiones se afirma sobre la importancia del papel de la educación como factor determinante para el avance y el progreso en la construcción de país, ya que posibilita el acceso al conocimiento, convirtiéndose en un dispositivo que fortalece la cultura, el espíritu, los principios axiológicos que caracterizan a los seres humanos. Es a su vez, considerada como una necesidad y como un medio para alcanzar el bienestar social y económico acortando de esta manera, las desigualdades económicas y sociales, propiciando el mejoramiento de las condiciones culturales de los ciudadanos, pero sobre todo coadyuvando a la creación de las relaciones de las sociedades para el avance democrático y el fortalecimiento del Estado de derecho y obviamente impulsa el desarrollo de la ciencia, la tecnología y la innovación.

El propósito de esta contribución es la explicar el papel de la Educación en derechos humanos en la consolidación de la democracia, desentrañando algunas tensiones que se refieren por una parte, a la existencia de un espacio académico/materia/contenido/

justicia, de tal manera que cada uno de los ciudadanos estará en dotado de las condiciones para autogobernarse en el sentido de toma de decisiones colectivas e individuales, de tal suerte que nadie tendrá el derecho de someter a otros a su voluntad y cada ciudadano estará en capacidad de desobedecer a un sistema político que atente con el ordenamiento jurídico que es aceptado y respetado por todos, ni obedecerá a un régimen político que no cuente con el consentimiento de los ciudadanos en condición de igualdad 
relación transversal del currículo que permita comprender la dimensión real en términos de la construcción de la formación de ciudadanos comprometidos y responsables del cumplimiento de los derechos humanos que vaya más allá de dar a conocer o a memorizar la Declaración Universal de Derechos Humanos y por otra, el debate suscitado respecto al papel que la escuela y las organizaciones sociales deben cumplir como instituciones mediadoras que permitan afianzar los principios y valores que le dan sentido a la ciudadanía fortaleciendo los procesos democráticos mediante la educación en derechos humanos.

Consideramos, inicialmente que la formación/ educación en Derechos Humanos es uno de los medios más expeditos para afirmar la dignidad humana, coadyuvar al desarrollo pleno de la personalidad, fortalecer y promocionar el respeto a los demás derechos humanos, promover la participación ciudadana y social y favorecer el respeto de las diferencias entre las personas, pero sobretodo en sociedades como la nuestra, la educación en derechos humanos permitirá a los ciudadanos crear escenarios futuros mediante la construcción de la conciencia histórica que este tipo de ejercicio requiere.

Es pertinente señalar que hasta el momento, la Educación en Derechos Humanos ha sido superficialmente comprendida como ese proceso de aprendizaje que favorece la reproducción de conocimientos y actitudes favorables como la tolerancia, la cooperación y la solidaridad en las lógicas normativas que rigen las acciones particulares y colectivas de los sujetos que participan de esta práctica pedagógica con el propósito de garantizar una convivencia armónica con/entre los demás seres humanos en el marco de una sociedad democrática. Se trata entonces, a grandes rasgos, de la apuesta por formar ciudadanos que puedan comprometerse con los nobles deseos que son en sí mismos los Derechos Humanos, además de propiciar prácticas concretas de organización, administración y gestión democrática entre sujetos que se reconocen como iguales en derechos y en dignidad al punto de crear una forma de ser y vivir que sea consecuente con el deseo de bienestar que tal panorama plantea. 


\section{Una manera de contextualizar la Educación en Derechos Humanos: aspectos generales}

La Educación en Derechos humanos se compone de un conjunto de reflexiones, discursos e ideas que se han venido constituyendo durante el siglo XX a partir del discurso de los DDHH, particularmente lo expuesto en la Declaración de 1948, cuyo fin radica en la pretensión de materializar una cultura de los derechos humanos, esto es, de lograr integrar los DDHH en las prácticas cotidianas, mediante una práctica pedagógica que articule elementos como la transversalidad, los principios democráticas, la subjetividad, entre otros ${ }^{124}$.

En este contexto que pretende establecer una relación sobre la historicidad de la educación en derechos humanos con el fin de comprender sus finalidades y los principios orientadores que entraña. Para tal efecto, es importante detenernos en la Declaración de los Derechos Humanos con el fin de comprender como dicho discurso se fue posicionando en el transcurso del siglo XX, en el marco de acontecimientos que se derivaron de la guerra fría: la guerra de Corea, la guerra de Vietnam, los procesos descolonizadores en África, los procesos dictatoriales en América latina, especialmente en el cono sur.

Ahora bien, luego de la Segunda Guerra Mundial, teniendo como referente inmediato las atrocidades que se habían presentado en términos de degradación de la dignidad humana a inicios del siglo XX en el marco del Holocausto nazi, el mundo se vio abocado a establecer como uno de los temas de agenda los Derechos Humanos, resultando de ello, la Declaración Universal de los Derechos Humanos de 1948 mediante la cual se buscaba que los Estados garantizaran a sus

124 En referencia a lo señalado, el señor Kofi Annan, Secretario General de las Naciones Unidas expresa que: "Sin educación, no podemos ver más allá de nosotros mismos y nuestro estrecho entorno y comprender la realidad de la interdependencia mundial. Sin educación, no podemos comprender cómo las personas de otras razas y religiones comparten nuestros mismos sueños y esperanzas. Sin educación, no podemos reconocer la universalidad de los objetivos y las aspiraciones humanas." 
ciudadanos las condiciones necesarias para el pleno ejercicio de sus libertades, sin ningún tipo de temor a ser perseguidos, torturados, explotados, etc.(ONU, 1948). Sin embargo, durante el siglo XX se presentaron diversos fenómenos sociales, políticos, culturales, tecnológicos, entre otros; el mundo se agrupó en dos bloques, el soviético - comunista y el demócrata capitalista hasta la década del noventa, lo que conllevó a lo que se denominó la Guerra Fría, la que, a su vez, derivó en la consolidación de "guerras calientes" en los países en vías de desarrollo, las violaciones a los derechos humanos y al derecho internacional humanitario se convirtieron en hechos recurrentes que se justificaba a partir de ideologías y proyectos políticos, que condujo a las entidades supranacionales a llevar a cabo acciones y procesos mediante los cuales los gobiernos se sintieran en la obligación de salvaguardar los derechos humanos de sus ciudadanos. Prueba de ello fue la creación por ejemplo para el continente americano, de la Comisión Interamericana de Derechos Humanos en 1959 y, posteriormente, la Corte Interamericana de derechos humanos en 1969. Se consideró, que la educación en derechos humanos no podía percibirse únicamente como un instrumento jurídico, sino que éstos además se sustentaban en la ética y en la dignidad humana, por lo cual se expuso que "la clave para lograr este mundo diferente era lograr un cambio de la mente y de los corazones que diera lugar al nacimiento una nueva conciencia ética, y esto sólo sería posible mediante la educación" (Pérez, 2005, p. 20). Se trataba de comprender la educación en derechos humanos como un ejercicio de paz, la cual para ser materializada debía partir de "un cambio radical en los hábitos de comportamiento" (Pérez, 2005, p. 20), lo cual sólo sería posible mediante la educación, en tanto ésta es "el pilar capaz de garantizar el desarrollo cultural y material de la sociedad y asegurar la gobernabilidad democrática” (p. 20). Así, la EDHH no se puede limitar únicamente como el acceso al conocimiento experto e instrumental, sino, considerada en su dimensión pedagógica como el camino para la formación de ciudadanos éticos que comprendieran y asumieran responsablemente el ejercicio de la democracia.

En términos de Hevia (s.f), se debía establecer la finalidad de los derechos humanos y así mismo a la educación como derecho: 
La finalidad última de los derechos humanos es que todas las personas gocemos plenamente de nuestra libertad, pero la condición para ello es sentirse liberados del temor y la miseria. Para asegurar el goce de la libertad se consensuaron los Derechos Civiles y Políticos. Para asegurar la condición necesaria, que es la igualdad, se proclamaron los Derechos Económicos, Sociales y Culturales, los DESC. Y para asegurar el goce de todos los derechos humanos se estableció el derecho a la educación, epítome de todos los derechos humanos (p. 26)

Por tanto, la educación en derechos humanos se convierte quizás en el camino que puede garantizar el goce de todos los derechos humanos, es el compendio de los mismos. Sin una educación en y para los derechos humanos, ninguna declaración, pacto, tratado o convenio tendrían trascendencia en la vida humana. Por tanto, el pensar la educación como sinopsis de los derechos humanos, conlleva a partir de un concepto de educación que no se limita a la profesionalización ni a la capacitación técnica, sino que

implica desarrollar una educación éticamente pertinente, orientada hacia los valores fundamentales de la tolerancia, la seguridad, la capacidad de tomar decisiones en favor de los demás, el respeto a la diversidad cultural, la educación para la paz, la no violencia y el desarrollo sostenible (Hevia, s.f, p. 31).

En este contexto, vale acotar además que, el criterio para determinar la calidad de la educación no es única y exclusivamente "el acceso a la enseñanza, sino además la obligación de eliminar la discriminación en todos los planos del sistema educativo, establecer unas normas mínimas y mejorar la calidad". (Jaimes, 2016, p. 248)

Así, la educación en y para los derechos humanos busca formar sujetos que cuenten con las competencias para desenvolverse en un régimen democrático, por lo que 
la principal tarea, se supone, consistiría en formar, modelar, prefigurar los futuros ciudadanos que ejercerán sus derechos, entre ellos su derecho al voto, y, sobre todo, formar o moldear las conciencias que incidirán o padecerán el ordenamiento social establecido. En la escuela, estos futuros ciudadanos no solo están en proceso de formación de su personalidad, sino también de sus subjetividades, ideales, principios y valores. Por esta razón, es vital, en las políticas nacionales e internacionales, fijar los esfuerzos, prácticas, técnicas y formas de subjetivación. (Espinel, 2013, p. 110)

Por tanto, la educación en derechos humanos y ciudadanía se concibe como un componente fundamental dentro del proceso formativo integral del sujeto, en la medida en que se aspira a formar sujetos que además de conocer las normas, sea capaz de desarrollar las dimensiones educativas que entrañan su accionar político como ciudadano.

Para Magendzo, (2009) la importancia de la transferencia de poder ciudadano en el marco de la educación en derechos humanos, radica en el hecho de que la marginación no se reduce a la carencia de condiciones materiales, sino que además hay formas culturales y sociales de marginación las cuales pueden superarse mediante el empoderamiento ciudadano. Empoderamiento que debe encarnarse en el ser considerado como un interlocutor válido, como sujeto de derechos con un proyecto de felicidad particular y por tanto debe gozar de las garantías y condiciones suficientes y necesarias para el goce efectivo de sus derechos y la materialización de sus deseos y proyectos.

En este marco, la consolidación de una cultura de los Derechos Humanos se lograría mediante

un sistema de valores, significados, representaciones, imaginarios y prácticas basado en la dignidad humana, que promueven el ejercicio, el respeto, la defensa y la protección de los derechos de la persona y de los colectivos humanos en los marcos público y privado de un Estado (Ministerio de educación Nacional, 2009, p. 75). 
Es importante aquí prestar atención al sentido otorgado a la cultura, comprendida como los diferentes marcos normativos y sistemas de valores que orientan prácticas y las formas de ser, pensar, sentir y actuar, los cuales se adquieren mediante los diferentes procesos de socialización - la familia y la escuela- (Durkheim, 1979).

En este contexto, resulta pertinente recurrir al concepto de hábitus desarrollado por Bourdieu (1989), que se explica como el sistemas de percepción, apropiación y acción de prácticas sociales los cuales son estructurados y a su vez estructurantes del campo social (Cf, Uregui, 2002). En este orden de ideas lo que se pretende en la EDH es la configuración de habitus, de un modo de ser en sociedad, o en otros términos, de una "forma de existencia" que comprenda el respeto a los derechos humanos y oriente su accionar mediante la puesta en práctica de los mismos como un imperativo categórico.

En este sentido, para dicho fin es necesaria la

comprensión de las representaciones sociales que encauzan las acciones de los sujetos en su vida diaria; la resignificación del sentido sobre lo que es deseable en términos sociales; la transformación de las prácticas, hábitos y procedimientos que orientan los acontecimientos; y la revisión de los marcos de referencia desde donde se elabora y significa la experiencia, de forma tal, que el reconocimiento de la dignidad humana, el respeto, la solidaridad, la autonomía y la justicia con equidad, se constituyan efectivamente en referentes comunes y cotidianos para la acción individual y colectiva (Ministerio de Educación Nacional, 2009, pp. 75-76)

En este orden de ideas, la educación en derechos humanos debe emerger como la brújula determinante en la vida cotidiana, reconfigurando a su vez, el funcionamiento de los diferentes grupos sociales y regulando las relaciones entre éstos (Ministerio de Educación Nacional, 2009, p. 66).

Desde una perspectiva social, los referentes comunes en el proceso educativo pueden comprenderse como aquellos elementos que se consideran importantes y por tanto deben ser aprendidos y no enseñados, sobre aquellos principios, valores y competencias que son arbitrariamente definidas y transmitidas en forma de capital cultural. 
Ahora bien, las primeras experiencias de educación en derechos humanos como mecanismo para lograr el goce efectivo de los mismos, se llevaron a cabo por "movimientos sociales o movimientos de educación popular, planteándose como una educación problematizadora y política" (Magendzo y Donoso, 1992, citado en Magendzo y Pavéz, 2015, p. 59). No obstante, en estas iniciativas "Predominaba un discurso racional y fraccionado sobre la $\mathrm{EDH}$, sin que todavía se instalara decididamente la noción de que los derechos humanos debían ser sistémicos, vivenciales, éticos y sostenidos igualmente en un discurso emocional (Magendzo y Pavéz, 2015, p. 68).

En sus inicios, la educación en derechos humanos más que propender por el establecimiento de una cultura de paz, fue una "educación política, ya que buscó formar personas comprometidas con la transformación de la sociedad en una más justa e igualitaria y en la cual los derechos humanos sean parte integral de la cultura ciudadana” (Magendzo y Pavéz, 2015, p. 68).

Estas primeras experiencias de $\mathrm{EDH}$, se ubicaron teóricamente en la visión crítica de Paulo Freire, quien sustentaba su planteamiento en el concepto de concienciación desarrollado por la escuela de Frankfort, mediante el cual se buscaba que los sujetos agenciaran la realidad para transformarla, por lo que más que instruir o formar en derechos humanos, lo que se pretendía era empoderar al sujeto como un agente de cambio.

De otro lado, entre las finalidades de la EDH (Educación en derechos humanos) se destacan a) Fortalecer el respeto de los derechos humanos y las libertades de la dignidad del ser humano; b) Desarrollar plenamente la personalidad humana y el sentido de la dignidad del ser humano; c) Promover la comprensión, la tolerancia, la igualdad entre los sexos y la amistad entre todas las naciones, las poblaciones indígenas y los grupos raciales, nacionales, étnicos, religiosos y lingüísticos; d) Facilitar la participación efectiva de todas las personas en una sociedad libre; e) Intensificar las actividades de las Naciones Unidas en la esfera del mantenimiento de la paz" (Ministerio de Educación Nacional, 2009, p. 65).

En este contexto, la responsabilidad de las instituciones educativas no radica únicamente en el hecho de educar e instruir a los estudiantes 
en áreas específicas de conocimiento, sino, fundamentalmente en lograr establecer un ambiente democrático sustentado en el respeto a la diferencia, la dignidad humana y orientada al pleno desarrollo de la dignidad humana.

De otra parte, la educación en derechos humanos se propone además,

cuestionar críticamente y poner en entredicho las democracias ... [...]... Democracias de élite; democracias construidas con bajos niveles de participación de la sociedad civil, democracias en la que la política está desacreditada y los jóvenes se marginan de ésta; democracias marginadoras y excluyentes; democracias en que crecen las inequidades y las desigualdades...(Magendzo, 2009, p. 8).

\section{Por tanto,}

Desde esta perspectiva uno de los propósitos de la EDH es que "las personas crean en la vida y en que las cosas pueden ser distintas, en su capacidad de organizarse para defender la paz (entendida como justicia social), y en que puedan generar normas que contribuyan a la convivencia y a ejercer el respeto por los derechos humanos como una forma de vida que evalúa ética y críticamente la realidad social” (Ministerio de educación Nacional, 2009, p. 67).

Se trata así, de la construcción de una cultura democrática basada en una ética ciudadana que reconstruya relaciones históricamente deterioradas desde la puesta en marcha de la Educación en Derechos Humanos, ya que a ésta se le considera como la forjadora del camino que lleve al hombre a la plenitud del ejercicio de las libertades desde la aceptación y el reconocimiento de quienes son diferentes, la propagación de la sensibilidad, la autoestima y especialmente la reconciliación. Todo ello claramente se remite al reto que ha de ser asumido en los lugares donde ésta propuesta pedagógica vehiculiza sus propósitos: la escuela, pues es precisamente allí en donde se quiere estructurar los primeros pasos en la conversión de la democracia como una 
práctica cotidiana basada en una concepción humanizadora /humana de la educación, es decir, centrada en la persona y en el respeto hacia su dignidad (Mujica, s.f. p. 5).

\section{Algunos debates sobre el reconocimiento jurídico de la educación en Derechos humanos}

La EDH cuenta con un marco jurídico internacional mediante el cual los Estados orientan sus políticas y planes de educación en y para los derechos humanos, el cual se configuró a partir de tratados, convenciones y pactos de carácter internacional, los cuales si bien no abordan directamente la EDH, sí consideraban a la educación como un elemento central que debía ser tenido en cuenta por los Estados para un óptimo cumplimiento de lo establecido en dichos tratados. Por ello, resulta necesario reconocer las diferentes convenciones, pactos y tratados a partir de los cuales se fue estableciendo un marco normativo para la construcción de lo que sería el Plan Mundial de educación en derechos humanos.

En este orden, en el presente apartado de realiza una mirada histórica a partir de las diferentes convenciones, pactos y tratados en materia de educación en Derechos Humanos, tanto en el ámbito nacional como internacional.

Antes de iniciar el recorrido histórico por la normatividad nacional e internacional relacionada con la $\mathrm{EDH}$, resulta pertinente aclarar que tanto el discurso de los derechos humanos, así como la declaración de los derechos del hombre, surgieron en el marco de una filosofía liberal burguesa, por lo que "la superioridad del concepto de derecho tiene mucho que ver con el individualismo burgués, con la sociedad burguesa que estaba surgiendo en ese momento y que, después de conseguir la hegemonía económica, luchó por conseguir la hegemonía política que se consolido con las revoluciones francesas y americana" (De Sousa, 2014, p . 25). 
Esto conlleva a que tanto el derecho como el campo jurídico se encuentran atravesados por relaciones de fuerza en donde la ideología es elemento vital, por lo que resultaría inoperante y bastante simplista comprender el campo jurídico ${ }^{125}$ como un universo independiente de las dinámicas sociales y de las ideologías que se configuran en determinados momentos históricos (Giménez, 1989, p. 87).

No obstante, las ideologías que configuran el campo jurídico, tal y como lo plantean Giménez (1989) y Bourdieu (2000) se presentan bajo la pretensión de una neutralidad enmarcada en un discurso cientificista con pretensiones de universalidad.

El discurso sobre el derecho se presenta en forma de ideologías teóricas que representan, interpretan o reconstruyen argumentativamente los fenómenos jurídicos en una óptica legitimadora o crítica, aunque frecuentemente con pretensión de neutralidad científica (Giménez, 1989, p. 86).

De otro lado, resulta necesario además mencionar que el derecho en tanto discurso experto es un discurso de poder ${ }^{126}$, esto es, el derecho no solamente se queda en actos de enunciación y difusión, sino que además cuenta con una capacidad performativa, por lo que incide en los modelos de comportamiento produciendo realidades nuevas o modificando las realidades preexistentes Gimpenez, 1989, p. 71). En otros términos, el derecho tiene la potestad de instituir imaginarios y representaciones preexistentes.

125 El campo jurídico desde una perspectiva sociológica pude comprenderse como "un campo cuya lógica específica está doblemente determinada: en primer lugar, por las relaciones de fuerza específicas que le confieren su estructura y que orientan las luchas, o, con mayor precisión los conflictos de competencia que se dan en él; en segundo lugar, por la lógica interna de las acciones jurídicas que limitan en cada momento el espacio de lo posible y con ello el universo de las soluciones propiamente jurídicas” (Bourdieu, 2000, p.150).

126 Podría afirmarse que la capacidad performativa del derecho se debe en gran medida a su elevada racionalización, la cual bajo el marco de un discurso cientificista y tecnocrático ha colonizado lo que autores como Habermas (1987) denomina el mundo de la vida o la también conocida racionalidad sustantiva según Weber. 
En términos de Bourdieu, (2000)

Los actos simbólicos de nominación tienen toda su eficacia de enunciación creadora en la medida y solo en la medida en que proponen principios de visión y de división objetivamente ajustados a las estructuras preexistentes, de las que son el producto; eficacia que al consagrar todo aquello que enuncia, lo lleva a un nivel superior plenamente realizado, el de la institución instituída (p. 199).

Ahora bien, el marco jurídico sobre el que se sustenta la educación en y para los derechos humanos, tiene como punto de partida la Declaración Universal de los Derechos Humanos de 1948, la cual en su preámbulo expone que "la enseñanza y la educación son el medio por el cual debe promoverse, tanto entre los individuos como en las instituciones, el respeto de los derechos y libertades en ella consignados" (ONU, 1948). De igual forma, en el artículo 26 de la declaración se establece que

1.Toda persona tiene derecho a la educación. La educación debe ser gratuita, al menos en lo concerniente a la instrucción elemental y fundamental. La instrucción elemental será obligatoria. La instrucción técnica y profesional habrá de ser generalizada; el acceso a los estudios superiores será igual para todos, en función de los méritos respectivos. 2.La educación tendrá por objeto el pleno desarrollo de la personalidad humana y el fortalecimiento del respeto a los derechos humanos y a las libertades fundamentales; favorecerá la comprensión, la tolerancia y la amistad entre todas las naciones y todos los grupos étnicos o religiosos; y promoverá el desarrollo de las actividades de las Naciones Unidas para el mantenimiento de la paz (ONU, 1948).

El hecho de que la educación sea concebida como un derecho en la declaración de 1948, evidencia que para occidente el tema de la paz y la convivencia armónica pasa por una cuestión cultural más que propiamente técnico - jurídica. Es decir, que por más normas que se establezcan en pro de garantizar la paz y el pleno ejercicio de los derechos humanos, es necesario una formación elemental en 
donde el ser humano interioriza y asume como parte de su forma de vida los Derechos Humanos. Muestra de ello es la alusión que se hace a la educación en los diferentes pactos y tratados internacionales surgidos en la segunda mitad del siglo XX

Uno de estos tratados es la Declaración Americana de los derechos y deberes del hombre de la OEA, la cual, en el artículo XII plantea que "Toda persona tiene derecho a la educación, la que debe estar inspirada en los principios de libertad, moralidad y solidaridad humanas" (OEA, 1948), de igual forma se establece la obligatoriedad de la educación primaria y se afirma que el objetivo de la educación es capacitar al ciudadano para una digna subsistencia (OEA, 1948).

De otra parte, el protocolo de San Salvador de 1988 es el primer instrumento jurídico en América Latina que alude de manera directa a la educación, sus finalidades y su orientación, sin desconocer aspectos como el pluralismo, la justicia y la paz (Ministerio de educación Nacional, 2009 y Salcedo, 2017). Concretamente, en el artículo XIII sobre el derecho a la educación, el documento expone entre otras cosas que

Los Estados partes en el presente Protocolo convienen en que la educación deberá orientarse hacia el pleno desarrollo de la personalidad humana y del sentido de su dignidad y deberá fortalecer el respeto por los derechos humanos, el pluralismo ideológico, las libertades fundamentales, la justicia y la paz. Convienen, asimismo, en que la educación debe capacitar a todas las personas para participar efectivamente en una sociedad democrática y pluralista, lograr una subsistencia digna, favorecer la comprensión, la tolerancia y la amistad entre todas las naciones y todos los grupos raciales, étnicos o religiosos y promover las actividades en favor del mantenimiento de la paz (OEA, 1988).

Asimismo, la convención interamericana contra todas las formas de discriminación racial también hace mención a la educación, en tanto desde allí es posible allanar el camino para eliminar los prejuicios y estigmas a causa de la raza. Por tanto, una de las acciones establecidas en dicha convención es 
c) La sensibilización de la población, a través de campañas de educación encaminadas a eliminar prejuicios, estereotipos y otras actitudes que atentan contra el derecho de las personas a ser iguales, propiciando de esta forma el respeto y la convivencia con las personas con discapacidad (OEA, 1999).

En esta misma línea se encuentra también la convención para la eliminación de todas las formas de discriminación contra las personas con discapacidad que, al igual que la convención para la eliminación del discriminación racial, contempla la educación como un mecanismo para fomentar el respeto hacia las personas en condición de discapacidad, y llama a los Estados a implementar políticas, planes y programas que contribuyan en dicho fin (OEA, 1999).

De otra parte, se encuentra la convención interamericana para prevenir, sancionar y erradicar la violencia contra la mujer, la cual en el artículo 8, literal b, expone como uno de los objetivos el lograr "Modificar los patrones socioculturales de conducta de hombres y mujeres", para lo cual resulta pertinente "el diseño de programas de educación formales y no formales apropiados a todo nivel del proceso educativo". En el documento también se menciona la importancia de educar a los funcionarios, jueces y demás funcionarios del sector público en cuanto a temas de violencia contra la mujer, además de "Fomentar y apoyar programas de educación gubernamentales y del sector privado destinados a concienciar al público sobre los problemas relacionados con la violencia contra la mujer, los recursos legales y la reparación que corresponda" (OEA, 1996).

También se encuentran instrumentos jurídicos que aluden a la protección y garantía de los derechos de las comunidades indígenas y pueblos tribales, tal es el caso del convenio 169 de la OIT en donde se menciona la educación como el mecanismo para garantizar la eliminación de los prejuicios hacia dichas comunidades.

Artículo 31. Deberán adoptarse medidas de carácter educativo en todos los sectores de la comunidad nacional, y especialmente en los que estén en contacto más directo con los pueblos interesados, 
con objeto de eliminar los prejuicios que pudieran tener con respecto a esos pueblos. A tal fin, deberán hacerse esfuerzos por asegurar que los libros de historia y demás material didáctico ofrezcan una descripción equitativa, exacta e instructiva de las sociedades y culturas de los pueblos interesados (Naciones Unidas, 1989).

En lo que respecta a la educación en derechos humanos a las fuerzas armadas, Colombia adoptó en 1960 los cuatro convenios de Ginebra de 1949, los cuales,

en sus artículos 47, 48, 127 y 144, respectivamente, obligan a los estados a incorporar la enseñanza del Derecho Internacional Humanitario (DIH) en los programas de formación militar y de ser posible civil. Este mismo compromiso internacional de los estados fue reiterado en el art. 83 del Protocolo I de 1977 y en el art. 19 del Protocolo II de 1977, adicionales a los cuatro Convenios de Ginebra de 1949 (Ministerio de educación Nacional 2009, p. 22).

En sintonía con los cuatro convenios de Ginebra, la convención contra la Tortura y otros tratos o penas crueles, inhumanos o degradantes, busca que los Estados implementen una educación y una información completas sobre la prohibición de la tortura en la formación profesional del personal encargado de la aplicación de la ley, sea éste civil o militar, del personal médico, de los funcionarios públicos y otras personas que puedan participar en la custodia, el interrogatorio o el tratamiento de cualquier persona sometida a cualquier forma de arresto, detención o prisión (Naciones Unidas, 1984).

Por otra parte, en 1990, en el marco de la Conferencia Mundial de Educación para todos auspiciada por la UNESCO en Jotiem, se señaló como "objetivo esencial del desarrollo de la educación la transmisión y el enriquecimiento de los valores culturales y morales comunes, en los que el individuo y la sociedad han de asentar su identidad y su dignidad (Pérez, 2005, p. 27).

Asimismo, en la convención relativa a la lucha contra la discriminación en la esfera de la enseñanza se establecen los mecanismos para 
hacer de la escuela un escenario libre de discriminación, en donde la diferencia no sea un obstáculo para el aprendizaje y de esta manera lograr que el proceso de enseñanza aprendizaje sea óptimo, democrático y ético (UNESCO, 1960).

En este marco, las directrices de las Naciones Unidas para la disminución de la violencia juvenil de 1990, vislumbran también le papel de la educación como escenario mediante el cual los jóvenes pueden adquirir los valores y las competencias necesarias y suficientes para alejarse de las prácticas delictivas como una forma de subsistencia o como un hábito internalizado (Naciones Unidas, 1990).

Tal y como se ha podido apreciar, las convenciones, directrices y tratados en materia de derechos humanos, expedidos desde la segunda mitad del siglo XX, independientemente del campo al que hagan mención, siempre aluden a la educación como uno de los escenarios sobre el que los Estados deben encaminar sus políticas para el cumplimiento efectivo de dichos convenios.

Asimismo, es pertinente mencionar la trascendencia que tiene el que aspectos como la etnicidad, la cultura - en relación con las comunidades indígenas- así como los tratados y disposiciones en materia de violencia contra la mujer, se hayan incorporado en dichos tratados, en tanto estos temas no eran considerados importantes o por lo menos decisivos en otros momentos históricos ${ }^{127}$.

La incorporación de los temas mencionados en tratados sobre derechos humanos, pueden entenderse a partir de la comprensión del derecho como un campo en el que la lucha siempre está abierta, es decir, como un escenario de confrontación en donde se cristalizan las demandas de los grupos sub alternos o históricamente invisivilizados.

Por lo cual, podría afirmarse que un ordenamiento jurídico, para el caso particular los tratados en materia de derechos humanos "Si se lo considera en perspectiva histórica, puede tener en su fase inicial un función innovadora y progresista [...] aunque posteriormente esa

127 Por ejemplo el rol que se asignaban a la mujer en declaración de los derechos del hombre, así como el desconocimiento y subvaloración de gramáticas de la dignidad humana diferentes a la occidental (Cf. De Sousa, 2014). 
función se torne conservadora en la medida en que se limite a garantizar la reproducción social (Giménez, 1989, p. 85).

Esta visión, implica que el derecho no es un discurso al servicio de los intereses del capitalismo, sino, en tanto la lucha por el capital cultural de dicho campo siempre está abierta, éste puede incorporar medidas que pueden considerarse como progresistas en determinado momento, aunque con el transcurrir del tiempo éstas pueden llegar a ser conservadoras.

Para ilustrar dicha afirmación, autores como De Sousa (2014; Cf, 1995; 2009; 2014b) son contundentes al exponer como el discurso de los derechos humanos, a pesar de haber incorporado algunos aspectos que en su momento pudieron considerarse en su momento como progresistas, poco a poco "se ha ido ajustando a ajustado a las políticas liberales, al desarrollo capitalista y a sus diversas metamorfosis (liberal, socialdemócrata, fordista, posfordista, fordista periférica, corporativa, estatal, neoliberal, etc. ) y también a un colonialismo metamorfoseado (neocolonialismo, colonialismo interno, racismo, trabajo análogo a la esclavitud, xenofobia, islamofobia, políticas de inmigración represivas, etc.) (p. 29).

De otro lado, es hasta el Plan de Viena que se fijan unos objetivos puntuales respecto a la educación en derechos humanos. Estos

abarcan la evaluación de necesidades y el diseño de estrategias para la inclusión de la educación en derechos humanos en todos los ámbitos educativos, formales e informales; la creación de programas para la educación en derechos humanos en el Plan nacional de educación en derechos humanos ámbito internacional, nacional y local; el desarrollo de materiales didácticos; el fortalecimiento de los medios de difusión en la educación de los derechos humanos y la difusión mundial de la Declaración Universal de Derechos Humanos (Ministerio de educación Nacional, 2009, p. 24)

Seguidamente, la Asamblea General de las Naciones Unidas proclamó el periodo 1995 - 2004 como el decenio de las Naciones Unidas para la educación en la esfera de los derechos humanos y acogió el 
programa de acción para el decenio del Secretario General de la ONU (Ministerio de educación, 2009, p. 26).

Los objetivos establecidos, fijados en el artículo 10 del documento eran:

a. La evaluación de las necesidades y la formulación de estrategias eficaces para el fomento de la educación en la esfera de los derechos humanos en todos los niveles de enseñanza, en la capacitación profesional y en la enseñanza académica y no académica; b. El establecimiento y fortalecimiento de programas y capacidades para la educación en la esfera de los derechos humanos en los planos internacional, regional, nacional y local;

c. El desarrollo coordinado de los materiales didácticos para la enseñanza de los derechos humanos;

d. El fortalecimiento de la función y la capacidad de los medios de difusión en el fomento de la educación en la esfera de los derechos humanos;

e. La difusión mundial de la Declaración Universal de Derechos Humanos en el mayor número posible de idiomas y en otras formas apropiadas para los diversos niveles de instrucción y para las personas discapacitadas (Ministerio de educación, 2009, p. 26).

En este estado de cosas, se establece en el año 2004 el Programa Mundial de Educación en Derechos Humanos, el cual se divide en tres etapas proyectadas desde al año 2005 hasta el 2019. La primera etapa estuvo encaminada a la enseñanza de los derechos humanos en primaria y secundaria; la segunda tuvo como objetivo centrarse en la enseñanza de los derechos humanos en la educación y "programas de capacitación sobre derechos humanos para maestros y educadores, funcionarios públicos, fuerzas del orden y personal militar a todos los niveles" (Naciones Unidas, 2017) y la tercera etapa tuvo como fin el reforzamiento de lo establecido en las dos primeras etapas, además de contemplar la educación en derechos humanos en periodistas y profesionales de medios de comunicación (Naciones Unidas, 2017). 
Ahora bien, en lo que concierne al ordenamiento jurídico sobre educación en derechos humanos en Colombia, éste tiene se sustentó en la constitución de 1991, más específicamente en el artículo 67 de la misma, en donde se expone que

La educación es un derecho de la persona y un servicio público que tiene una función social; con ella se busca el acceso al conocimiento, a la ciencia, a la técnica, y a los demás bienes y valores de la cultura. La educación formará al colombiano en el respeto a los derechos humanos, a la paz y a la democracia; y en la práctica del trabajo y la recreación, para el mejoramiento cultural, científico, tecnológico y para la protección del ambiente (Constitución política de Colombia, 2013, p. 32).

Sin embargo, en la Ley General de educación de 115/1994, en tanto que instrumento jurídico de mayor trascendencia en lo que a educación se refiere en Colombia, en donde se exponen los lineamientos y normas en materia educativa, no se hace alusión directa a la educación en derechos humanos ni como una asignatura o área de conocimiento, más bien lo que se encuentra allí son una serie de aspectos que pueden considerarse como componentes de la educación en derechos humanos.

Muestra de ello es el artículo 5 referido a los fines de la educación, en donde se expone como uno de éstos "La formación en el respeto a la vida y a los demás derechos humanos, a la paz a los principios democráticos, de convivencia, pluralismo, justicia, solidaridad y equidad, así como en el ejercicio de la tolerancia y la libertad" también se alude a la formación para la participación ciudadana entendida como, "la formación para facilitar la participación de todos en las decisiones que los afectan en la vida económica, política, administrativa y cultural de la Nación (Ministerio de educación Nacional, 2003, p. 52).

Asimismo, pueden encontrarse elementos relacionados a la educación en derechos humanos en el acápite relacionado a los objetivos comunes a todos los niveles en la educación formal, en donde se establecen como objetivos:

a) Formar la personalidad y la capacidad de asumir con responsabilidad y autonomía sus derechos y deberes; B) Proporcionar una 
sólida formación ética y moral y fomentar la práctica del respeto a los derechos humanos. c) Fomentar en la institución educativa, prácticas democráticas para el aprendizaje de los principios y valores de la participación y organización ciudadana y estimular la autonomía y la responsabilidad (Ministerio de educación Nacional, 2003, p. 56).

De igual forma, en lo que respecta a las áreas de enseñanza obligatoria, tanto para secundaria como para primaria se encuentra la educación en ética y valores, la cual deriva de los objetivos específicos para la enseñanza primaria y secundaria, en donde uno de estos es “a) La formación de los valores fundamentales para la convivencia en una sociedad democrática, participativa y pluralista” (p. 61).

De otro lado, se encuentra el decreto 1860 de 1994, el cual reglamenta parcialmente la ley115/1994

en los aspectos pedagógicos y organizativos generales e introduce una propuesta de construcción de proyectos pedagógicos en el sistema escolar que abre la posibilidad de realizar los proyectos de educación para la sexualidad, la educación en derechos humanos y la educación ambiental (Ministerio de educación Nacional, 2009, p. 32).

Casi una década después, en al año 2003, se incluye en el Plan de Desarrollo la denominada revolución educativa, en la cual se estableció que el gobierno nacional en coordinación con la Defensoría del Pueblo, promoverá en los establecimientos educativos el desarrollo de las competencias ciudadanas que incluya la formación, el respeto y la práctica de los derechos humanos.

Asimismo, en el año 2006, en el Plan decenal de educación también se establecen elementos referidos a la educación en derechos humanos, logrando de esta manera ir sentando las bases en materia institucional para la consolidación de la educación en derechos humanos en la educación formal.

Si bien aún no se contaba con un marco institucional sobre la educación en derechos humanos, si se había logrado avanzar considerablemente en la materia, en tanto ya se contaba con 
un considerable grupo de formadores; (ii) la existencia de redes de educadores y promotores de derechos humanos; (iii) la presencia de grupos de investigadores y de especialistas en el campo conceptual en materia de EDH; (iv) la producción de textos y materiales pedagógicos para la enseñanza de los derechos humanos; y (v) proyectos escolares, barriales, comunales e institucionales en dicho ámbito (Ministerio de educacion Nacional 2009, p 35)

En este marco, una de las experiencias más significativas en materia de educación en derechos humanos fue el Programa Nacional de capacitación de personeros municipales, en el cual participaron la procuraduría, la Defensoría del Pueblo y el Alto Comisionado de las Naciones Unidas para los derechos Humanos. Dicho programa buscó

fortalecer la labor de promoción y de divulgación de derechos humanos de los personeros municipales propiciando una reflexión sobre la construcción de sujetos de derechos, que comprende la revisión y la significación en la práctica de la defensa y la protección de los derechos humanos (Ministerio de educación Nacional, 2009, p. 36).

A la par con este programa se implementó también el proyecto conocido como "Red Nacional de Promotores de Derechos humanos" que tuvo como fin

promover una ética ciudadana fundada en los derechos humanos como condición esencial para la construcción de una cultura democrática de paz. La idea fue planteada como una forma de gestión concertada entre el Estado y la sociedad, con el propósito de dar apertura a acuerdos para el diseño de propuestas que permitan el empoderamiento ciudadano y crear una cultura de ejercicio y de defensa de los derechos humanos (Ministerio de educación Nacional, 2009, p. 36). 
Luego de estas experiencias y los avances en materia de educación en derechos humanos en diferentes niveles, se estableció el Planedh, (Plan Nacional de Educación en Derechos Humanos), en donde se fijaron los conceptos orientadores, el plan operativo y los criterios que en adelante iban a orientar la educación en derechos humanos en Colombia en el marco de un Estado social de derecho. En este sentido El Planedh,

adopta los principios establecidos en el marco del Estado Social de Derecho, respecto de lo cual ha dicho la Corte Constitucional que la dignidad humana “...es el presupuesto esencial de la consagración y efectividad del entero sistema de derechos y garantías contemplado en la Constitución (y se la considera) como principio fundante del Estado, que tiene valor absoluto no susceptible de ser limitado ni relativizado bajo ninguna circunstancia." (Ministerio de educación Nacional, 2009, p. 69).

Asimismo, los componentes centrales del Planedh, teniendo en cuenta lo expuesto hasta el momento, serían la formación de sujetos de derechos, la consolidación de un Estado Social de Derecho y la construcción de una cultura de derechos humanos (Ministerio de educación Nacional, 2009, p. 71).

En síntesis, educar en derechos humanos tendrá como fin la formación de sujetos autónomos y libres, capaces de construir conocimiento y realizar acciones de transformación desde su propia historia. Así como promover una cultura de los derechos humanos basada en relaciones equitativas e incluyentes y que involucre el diseño de ambientes y relaciones educativas democráticas (Ministerio de educación Nacional, 2009, p. 79).

Finalmente, en el marco de los acuerdos de paz firmados en el año 2016 por el Gobierno y las Fuerzas Armadas Revolucionarias de Colombia FARC, se implementó la Cátedra de Paz, la cual se soporta jurídicamente en la ley 1732 de 2014. Allí se establece dicha cátedra como área obligatoria en todos los colegios del país. Esta iniciativa tiene como 
finalidad ser un "espacio para el aprendizaje, la reflexión y el diálogo sobre la cultura de la paz y el desarrollo sostenible que contribuya al bienestar general y el mejoramiento de la calidad de vida de la población (Decreto 1038 de 2015).

En suma, la educación en derechos humanos, en lo que al ordenamiento jurídico se refiere, ha logrado amplios avances tanto en el ámbito nacional como internacional. En el contexto internacional, el programa mundial para la Educación en Derechos Humanos es la base para la implementación de políticas y planes de educación en los Estados, allí se establecen tanto los lineamientos teóricos como las herramientas metodológicas y pedagógicas, lo que sin duda es un avance significativo en la materia.

Por su parte, en lo que respecta al plano nacional, el Planedh y la cátedra de paz, son los mecanismos de mayor trascendencia en lo que a educación en derechos humanos se refiere, en la medida en que propenden por la consolidación de un sujeto de derechos, ético, crítico y respetuoso de la diferencia, en el marco de una apuesta pedagógica y no simplemente instructiva o memorística.

De otra parte en lo que concierne propiamente al discurso jurídico en materia de derechos humanos, particularmente en lo que a educación se refiere, se puede afirmar que la noción de educación a la que allí se alude, está referida a un proceso pedagógico en donde el sujeto, en tanto que agente empoderado a nivel político, cuenta con la posibilidad de agenciar su entorno a partir de la interiorización de una serie de valores y hábitos, los cuales derivan de un discurso sustentado en una filosofía liberal occidental en la que priman los derechos civiles y políticos, por sobre los derechos sociales, económicos y culturales.

\section{La educación en derechos humanos en la historia reciente de Colombia: de la apertura económica a los acuerdos de paz}

Si bien es hasta el año 2006 que se cuenta con un Plan Nacional de Educación en Derechos Humanos, es necesario reconocer el contexto social en el que se fue configurando y fraguando el discurso sobre 
la EDH en Colombia, en donde factores como el conflicto armado, la apertura económica, la constitución de 1991, el movimiento pedagógico, la seguridad democrática, los acercamientos entre el Estado Colombiano y las guerrillas, así como las políticas en materia de seguridad en el mundo luego de la caída del muro de Berlín y posteriormente los atentados del 11 de septiembre, influenciaron no solamente el discurso sobre los derechos humanos, sino, además, fueron de gran importancia en la estructuración de los planes y políticas en materia de EDH tanto en Colombia como en el resto del mundo.

En este marco, en el presente apartado se lleva a cabo una aproximación al contexto socio político de finales de los años ochenta hasta la implementación de la cátedra de paz en el marco de las negociaciones del Estado colombiano con la guerrilla de las Farc, con el fin de contar con un marco que permita comprender el contexto en el que se fue configurando el discurso sobre la EDH en Colombia y su institucionalización.

Ahora bien, antes de entrar en el tema de la educación en derechos humanos en el periodo explicitado, resulta pertinente realizar una breve aproximación histórica al contexto latinoamericano así como al Colombiano de los años ochenta, con el fin de identificar aquellos momentos que incidieron en que el discurso acerca de los derechos humanos fuera adquiriendo fuerza y posicionándose como un tema de agenda política en los gobiernos de la región.

Luego de la culminación de las dictaduras del cono sur en las que se implementó la Doctrina de Seguridad Nacional, se inició un proceso de transición democrática en donde se empezó a considerar que la "educación en derecho debía convertirse en pilar fundamental en los procesos de (re) democratización de las sociedades que se habían visto afectadas por violaciones sistemáticas a los derechos humanos" (Beltrán, s.f, p. 41).

Por ende, la preocupación primordial eran los derechos civiles y políticos desde una mirada normativa - jurídica en donde predominaba una mirada racional y fraccionada respecto a la educación en derechos humano. Es decir, ésta se entendía como la instrucción sobre los mecanismos y el procedimiento jurídico normativo requerido para la denuncia de violaciones a los derechos humano (Magendzo, 2009). 
Seguidamente, en los años noventa, los Estados latinoamericanos mostraron un mayor interés por el tema de la educación en derechos humanos, el cual se plasmó en "la incorporación legal del tema al currículo de educación formal, incluyéndose en la materia de Ciencias Sociales" (Beltrán, s.f, p. 41).

Asimismo, la Educación en derechos humanos también incursionó en el campo de la investigación académica, incorporándose así como un tema de interés en la investigación social. La temática de la educación en derechos humanos trascendió al mundo universitario, de tal modo que se crearon institutos especializados: Instituto Peruano de Educación en Derechos Humanos y Paz, Instituto de Derechos Humanos en Argentina, Cursos Interdisciplinario de Derechos Humanos de la Academia mexicana de Derechos Humanos (Beltrán, s.f, p. 41).

En sintonía con los cambios mencionados en materia de educación en derechos humanos en América Latina, en el ámbito internacional se estaba considerando la EDH como un tema de agenda política de los Estados por lo que con la proclamación del decenio de la educación en derechos humanos por la Naciones Unidas, se esperaba que durante los gobiernos llevaran a cabo políticas y proyectos en la materia.

Ahora bien, en Colombia el tema de la Educación en Derechos Humanos empezó a adquirir importancia desde finales de la década de los setenta, particularmente en el marco del Estatuto de Seguridad de Turbay, caracterizado por la implementación de políticas represivas hacia sectores políticos, movimientos estudiantiles, periodistas, líderes sociales, etc... lo que sin lugar a dudas desencadenó en reiteradas violaciones a los derechos humanos ${ }^{128}$.

Estos acontecimientos posibilitaron la emergencia de formas de educación popular en donde los derechos humanos eran un componente fundamental. Además, dichas iniciativas solían sustentarse en

128 La aplicación del Estatuto de seguridad es considerada como un "remedo de ocupación militar del Estado, [...] con burdas detenciones indiscriminadas y torturas a personas de grupos sindicales, organizaciones populares e intelectuales considerados de izquierda (Leal, 1994, p. 55). 
la teología de la liberación y la IAP Investigación acción participativa como marcos ideológicos ${ }^{129}$ que orientaba el accionar de las mismas ${ }^{130}$.

De igual forma, el movimiento pedagógico ${ }^{131}$ conformado en 1982, tuvo un rol preponderante en lo que al sentido de la educación se refiere, en la medida en que desde sus propuestas se logró poner en cuestionamiento algunos elementos estructurales de la educación referidos a la pedagogía, los contenidos, la didáctica, la formación del maestro, entre otros temas de relevancia en la educación colombiana.

No obstante, es hasta la última década del siglo XX que se empieza a considerar el tema de la Educación en Derechos Humanos como un componente central para la preservación de la dignidad humana, en el marco de una re estructuración del orden mundial derivado de la caída del muro de Berlín, en donde la democracia liberal capitalista puede considerarse como el modelo triunfador.

Ante este estado de cosas, Colombia al igual que los demás países latinoamericanos a finales del siglo XX se encontraban en un proceso de transición que radicaba principalmente en la adopción de medidas en materia económica fijada en el consenso de Washington, conocida como el ajuste estructural, fundamentalismo de mercado o el Neoliberalismo.

Luego de la constitución de 1991, en el marco de la consolidación del Estado Social de Derecho, la Educación en Derechos Humanos se posiciona como un tema de agenda pública, lo cual se evidenció en

129 Además de la IAP y la teología de la liberación estas iniciativas se amparaban en la pedagogía de la liberación de Freire, mediante la cual se buscaba empoderar a la comunidad a partir del reconocimiento de su condición de oprimido. Cabe enunciar además que en la pedagogía Freireana, el rol del docente se limita a la mediación y no a la imposición o adoctrinamiento.

130 Entre la experiencia que es posible destacar en cuanto a educación popular y derechos humanos, se encuentran la red de educación popular de mujeres y educación feminista, la cual buscaba reconfigurar el rol de la mujer a partir de las desigualdades de género (Salcedo, 2017, p. 10).

131 Las propuestas establecidas por el movimiento pedagógico lograron incidir en la constitución de 1991 y posteriormente en la ley general de educación de 1994 (Jaimes, 2016). 
proyectos llevados a cabo por ONGs y organizaciones de base, aunque para la época no se contaba con un plan de orden nacional en la materia.

Para esta misma época, durante el gobierno de César Gaviria, se llevó a cabo una re- estructuración de la estrategia de seguridad nacional en Colombia en la cual ya no solamente se contemplaba la lucha contra el comunismo y el paramilitarismo, sino también otras formas de violencia, entre las que se encontraban aquellas producidas por el Estado en cooperación con grupos al margen de la ley. Dicha concepción implicó el posicionamiento de los DDHH como discurso y como política en la estrategia de seguridad nacional en Colombia (Leal, 1994; Vargas, 2010).

Asimismo, con la Constitución de 1991 se fortaleció la concepción del Estado Social de Derecho, la cual fomentó y promulgó aspectos como los derechos de las minorías étnicas, el establecimiento de unas mínimas condiciones para las poblaciones marginales y la posibilidad de ejercer y reclamar los derechos mediante los mecanismos de participación.

De otra parte, en 1994 se logra la construcción de la ley general de educación en la que se le dio un orden y una estructura al tema educativo en Colombia. Sin embargo, la educación en derechos humanos en dicha ley no estaba claramente definida.

Luego, durante el gobierno de Andrés Pastrana se implementó el Plan Colombia, el cual no solamente estaba enfocado en la contención militar del narcotráfico, sino además tenía como uno de sus componente el tema de los derechos humanos, al cual según Tokatlián (2001) se destinó un presupuesto de 51 millones de dólares.

De igual forma, la Unión Europea al igual los Estados Unidos, también tuvo una participación considerable en cuanto al fomento, defensa y reconocimiento de los derechos humanos, aportando "105 millones de euros para el periodo 2000-2006 como forma de apoyo institucional al proceso de paz y con el fin de alcanzar la defensa de los derechos humanos, la protección ambiental y la sustitución de cultivos ilícitos” (Tokatlián, 2001, p. 139).

De lo anterior es posible abducir que el tema de los derechos humanos en Colombia, más concretamente la educación sobre éstos, no 
ha sido un tema de opinión pública de mayor importancia, - por lo menos hasta antes de la promulgación del Planedh - debido principalmente a que todo lo relacionado con los derechos humanos ha sido interpretado bajo la perspectiva del conflicto armado ${ }^{132}$.

Dicha situación ha conllevado a que "El cumplimiento de los tratados en materia de derechos humanos en Colombia se complejice" en la medida en que "injusticias como el acceso a la salud, la violencia intrafamiliar, trabajo digno, entre otros han sido ocultados por la dinámica del conflicto armado (Salcedo, 2017, p. 25).

Si bien en Colombia el conflicto armado aún continuaba siendo un tema central en la agenda política, con la llegada de Álvaro Uribe al poder en el año 2002, éste dejó de ser considerado como tal en tanto ya no se aludía a dichos grupos como guerrilleros, grupos insurgentes o movimientos de liberación, sino se les asignó la categoría de grupos terroristas, lo cual se debió a la reconfiguración del discurso de seguridad nacional en el mundo luego de la caída del muro de Berlín.

Es decir, para occidente, luego de la caída del muro de Berlín se consideró que el comunismo había sido derrotado por la democracia liberal por lo que en adelante los enemigos a combatir ya no serían los movimientos de liberación sino grupos terroristas de características sustancialmente distintas ${ }^{133}$.

Esto influenció de manera significativa el discurso de la EDH en tanto en adelante la filosofía sobre la que se sustentaría dicho discurso sería el liberalismo democrático occidental en donde el prototipo de sujeto a formar sería aquel que mediante la interiorización de los

132 En relación con la naturaleza del conflicto armado colombiano, cabe acotar que para autores como Leal (1994), "La violencia política estimuló el desborde de los conflictos sociales, al crear en forma progresiva un ambiente propicio para reproducirlos y desbordarlos en diversas formas de violencia. Esas otras violencias, (social, de paramilitares, del narcotráfico, delincuencia común organizada y circunstancial) se han vuelto más importantes cuantitativamente que las de naturaleza política” (p. 45).

133 Algo que ayudó a legitimar la posición del Estado frente a los grupos insurgentes ahora considerados como terroristas, fue el hecho de que éstos habían perdido gran parte de su base popular debido a mecanismos como el secuestro, los carros bomba y el narcotráfico. 
hábitos y prácticas democráticas lograra ajustarse al modelo de gobernabilidad occidental y de esta manera no representara una amenaza para la estabilidad del sistema social.

Es por esto que, con la llegada del nuevo milenio, en el marco de una re estructuración del discurso de seguridad en el ámbito internacional debido a la trascendencia de los atentados del 11 de septiembre ${ }^{134}$, la educación en derechos humanos ya contaba con una respaldo jurídico internacional, y además se implementaron en Colombia el programa de capacitación a personeros municipales así como el proyecto "red de promotores de derechos humanos, lo que sin lugar a dudas da cuenta del posicionamiento y la importancia que ha adquirido la educación en derechos humanos en Colombia.

Tal es la importancia que adquirió la educación en derechos humanos con la entrada del nuevo milenio, que para el año 2006 ya se contaba con un Plan Nacional de educación en derechos humanos PLANEDH, en donde se fijaban las pautas, los lineamientos y los componentes que debía tener la educación en derechos humanos en la educación formal, informal y no formal en Colombia.

Sin embargo, según informes de organizaciones de derechos humanos tales como el colectivo de abogados José Alvear Restrepo y el Observatorio de derechos humanos y violencia política del Cinep, durante la primera década del nuevo milenio, las violaciones a los derechos humanos tuvieron un incremento sustancial en determinados momentos.

Particularmente fenómenos como los falsos positivos, masacres, desplazamiento y persecución a líderes políticos han venido presentándose con cierta regularidad ${ }^{135}$.

134 Luego de los atentados del 11 de septiembre se reconfigura la concepción de enemigo interno en tanto ahora se habla es de de terrorismo de alcance global, conformado por redes transnacionales de grupos terroristas y no movimientos de liberación o guerrillas. (Vargas, 2010) (Cf, Beck, 2003).

135 Según el colectivo de abogados José Alvear Restrepo, "Durante el primer gobierno de Álvaro Uribe Vélez se evidenciaron irregularidades en capturas y procesos jurídicos hacia población civil, además de acciones represivas tales como "capturas fundamentadas en testimonios de reinsertados y/o red de informantes mediante el ofrecimiento de dádivas, presiones o amenazas, entre 


\section{Conclusiones}

En suma, si bien la educación en derechos humanos en Colombia cuenta con un sustento jurídico, teórico e institucional, esta no ha logrado trascender, principalmente en el ámbito práctico, a las comunidades menos favorecidas o en condición de vulnerabilidad, lo cual es posible evidenciarlo en los indicadores de violencia juvenil en las áreas urbanas y el aumento de familias en condición de pobreza extrema en ciertas regiones del país, entre muchos otros aspectos.

De otra parte, si bien la educación en derechos humanos busca formar sujetos críticos, conscientes y activos en el ejercicio de sus derechos y deberes, ésta sigue enmarcándose en un proyecto educativo donde la prioridad es formar sujetos útiles al modelo económico neoliberal consumista, en términos de Carazzone, (2009), "La educación de hoy es una educación de mercado, al servicio del mantenimiento de un status quo que continúa, en la era de la globalización, privatizando la riqueza, cada vez más en pocas manos" (p. 4).

Lo cual implica cuestionarse si la EDH en lugar de empoderar al sujeto como un agente de cambio, lo que hace es reproducir las estructuras sociales tal y como lo plantea Bourdieu (1995) en tanto ésta se encuentra sometida a las dinámicas de libre mercado, las cuales en la contemporaneidad han colonizado el mundo de la vida además de volverse determinantes en la política e incluso en la cultura.

Además, vale la pena mencionar algunos aspectos que se consideran relevantes en el proceso de fortalecimiento de la Línea de Educación en Derechos Humanos y Formación Ciudadana y tienen que ver con el tipo de democracia que está imperando en las instituciones educativas, dado que es allí en donde se pretende que los sujetos encarnen y adopten los principios de la democracia como parte de su forma de vida, así como lo atinente a la formación del profesor para el aprendizaje en el

otras (Corporación colectivo de abogados José Alvear Restrepo, 2004, citado en Galindo, 2005, p. 523). 
marco de la Educación en Derechos Humanos, la Educación Ambiental y el desarrollo de la practicas pedagógicas en esta área.

\section{Referencias bibliográficas}

Beck, U. (2003). Sobre el terrorismo y la guerra. Barcelona: Paidós.

Beltrán, M. (s.f) La importancia de la educación en derechos humanos. Especial referencia a América Latina. Dehuidela, 37-48.

Bourdieu, P y Passeron, J. (1995). La reproducción: elementos para una teoría del sistema de enseñanza. México: Fontamara.

Bourdieu, P. (1989). Social space and symbolic power. Sociological Theory. $7(1), 14-25$.

Braudel, F. et al. (1988). El Mediterráneo. Madrid: Espasa/Calpe.

Carazzone, C. (2009). Educar en y para los Derechos Humanos. Congreso Internazionale Sistema Prevventivo e Diritti Umani. (Ed.) Roma

Castillo, J. (2012). Sociología de la educación. México: Red Tercer Milenio S.C.

Constitución política de Colombia. (2013). Bogotá D.C: Editorial Centauros.

De Sousa, B. (2014). Derechos Humanos, democracia y Desarrollo. Bogotá. D.C: Dejusticia.

Durkheim, E. (1979). Educación y sociología. Bogotá: D.C: Editorial linotipo.

Espinel, O. (2013). Educación en derechos humanos. Esbozo de una lectura biopolítica. Revista Colombiana de Educación, (65), 101-122.

Giménez, G. (1989). Poder, Estado y discurso. Perspectivas sociológicas y semiológicas del discurso político - jurídico. México: Universidad Nacional Autónoma de México.

Giroux A. Henry, Teorías de la reproducción y la resistencia en la nueva sociología de la educación: un análisis crítico, en Cuadernos políticos, No. 44, México, Era, 1995.

Habermas, J. (1987). Teoría de la acción comunicativa. T (II). Crítica de la razón funcionalista. Madrid: Taurus.

Hevia, R. (s.f). El derecho a la educación en Derechos Humanos en el contexto internacional. Revista Latinoamericana de Educación inclusiva, 4(2), 24-39 
Jaimes, A. (2016). El derecho a la educación en Colombia desde la perspectiva de los derechos humanos. Revista Principia Iuris. 13(26), 243-260.

Leal, F. (1994). El oficio de la Guerra. La seguridad nacional en Colombia. Bogotá: Tercer mundo editores - IEPRI Universidad Nacional de Colombia.

Leal, F. (2001). Plan Colombia: orígenes, desarrollos y proyección regional. Íconos (10), 80-86.

Leis, R. (2005). La educación popular en derechos humanos y la construcción del sujeto democrático. Decisio. (10), 39-45.

Magendzo, A y Pavéz J. (2015). Desarrollo de la educación en derechos humanos en América Latina, en: Educación en derechos humanos: una propuesta para educar desde la perspectiva controversial. México D.F: Comisión de derechos humanos del Distrito Federal.

Magendzo, A. (2009). Pensamiento e ideas fuerza de la educación en Derechos Humanos en Iberoamérica. UNESCO/OEI.

Ministerio de Educación Nacional, Defensoría del Pueblo y Programa Presidencial para los Derechos Humanos y el Derecho Internacional Humanitario. (2009). Plan Nacional de Educación en Derechos Humanos. Bogotá D.C

Ministerio de educación Nacional. (2003). Nueva Ley General de educación. Bogotá: Momo ediciones.

Naciones Unidas. (1965). Convención Internacional sobre la Eliminación de todas las Formas de Discriminación Racial. Consultado el 28 de marzo de 2017. Recuperado de http://www.ohchr.org/SP/ProfessionalInterest/ Pages/CERD.aspx

Naciones Unidas. (1984). Convención contra la Tortura y Otros Tratos o Penas Crueles, Inhumanos o Degradantes. Consultado el 28 de marzo de 2017. Recuperado de http://www.ohchr.org/SP/ProfessionalInterest/Pages/CAT.aspx

Naciones Unidas. (1989). Convenio 169 de la OIT. Consultado el 28 de marzo de 2017. Recuperado de http://www.cdi.gob.mx/transparencia/ convenio169_oit.pdf

Naciones Unidas. (1990). Directrices de las Naciones Unidas para la prevención de la delincuencia juvenil (Directrices de Riad). Consultado el 28 de marzo de 2017. Recuperado de http://www.ohchr.org/SP/ProfessionalInterest/Pages/PreventionOfJuvenileDelinquency.aspx 
Naciones Unidas. (1996). Convención Interamericana para Prevenir, Sancionar y Erradicar la Violencia contra la Mujer "Convención de Belém do Pará". Consultado el 28 de marzo de 2017. Recuperado de https://www. unicef.org/argentina/spanish/ar_insumos_ConvencionBelem.pdf

Naciones Unidas. (2005). Programa mundial para la educación en derechos humanos. Consultado el 28 de marzo de 2017. Recuperado de http://www. ohchr.org/SP/Issues/Education/EducationTraining/Pages/Programme.aspx

OEA. (1948). Declaración Americana de los derechos y deberes del hombre. Consultado el 28 de marzo de 2017. Recuperado de http://www.oas.org/ es/cidh/mandato/Basicos/declaracion.asp

OEA. (1988). Protocolo adicional a la convención americana sobre derechos humanos en materia de derechos económicos, sociales y culturales "protocolo de San Salvador. Consultado el 28 de marzo de 2017. Recuperado de http://www.oas.org/juridico/spanish/Tratados/a-52.html

OEA. (1999). Convención interamericana para la eliminación de todas las formas de discriminación contra las personas con discapacidad. Consultado el 28 de marzo de 2017. Recuperado de http://www.oas.org/juridico/spanish/tratados/a-65.html.

ONU. (1948). Declaración Universal de los Derechos Humanos.

Pérez, G. (2005). Derechos Humanos y Educación Social. Revista de Educación. (336), 19-39

Salcedo, F. (2017). Educación en derechos humanos: el discurso de los profesores en Colombia. 1994-2015. (Tesis de Meastría). Universidad Santo Tomás. Bogotá.

Sánchez, A. (2013). Seguridad Nacional y Derechos Humanos. México: Universidad Nacional Autónoma de México/ Acatlán.

Sánchez, L.Y. (2014). La Educación Social: Una Apuesta desde el que Hacer del Trabajador Social (Tesis de Maestría). Universidad de San Buenaventura. Cali. Colombia. Universidad La Gran Colombia. Armenia. Colombia.

Téllez, U. (2002). Pierre Bourdieu. Conceptos básicos y construcción socio educativa. Bogotá: Universidad pedagógica nacional.

Teubner, G y Bourdieu, P. (2000). La fuerza del derecho. Bogotá: Siglo del hombre editores. Facultad de derecho de la Universidad de los Andes. Ediciones Uniandes. Instituto Pensar.

Tokatlian, Juan Gabriel. (2001). Colombia, el Plan Colombia y la región andina ¿Implosión o concertación? Nueva Sociedad, 173, 126 - 143. 
UNESCO. (1960). Convención relativa a la Lucha contra las Discriminaciones en la Esfera de la Enseñanza 1960. Consultado el 28 de marzo de 2017. Recuperado de http://portal.unesco.org/es/ev.php-URL_ID=12949\&URL_ DO=DO_TOPIC\&URL_SECTION=201.html.

Vargas, A. (2010). Las fuerzas armadas en el conflicto colombiano. Antecedentes y perspectivas. Medellín: La Carreta editores.

Villaseñor, I. (2015). La democracia y los derechos humanos: una relación compleja. Foro internacional. 55(4), 1115-1138. 



\title{
Instituciones en la defensa jurídica internacional del Estado $^{136}$
}

\author{
Sandra Milena Molina Peláez ${ }^{137}$
}

\section{Introducción}

- 1 incumplimiento de los compromisos del Estado en materia de Cderechos humanos, generó la necesidad de crear un sistema de defensa jurídica internacional a través de la creación de una política pública (Consejo Nacional de Política Económica, 2003). En su implementación, la diversidad de temáticas y de entidades, obligó a acudir a un sistema de articulación, procurando una defensa única orientada a satisfacer los requerimientos internacionales. No obstante en el desarrollo, se visibiliza un nuevo problema, que es la pugna de intereses propios de cada entidad.

136 Articulo resultado producto de investigación del proyecto denominado "Procesos de exigibilidad y justiciabilidad de los Derechos Humanos y el Derecho Internacional Humanitario, en el contexto nacional e internacional." Adscrito al grupo de investigación Sociohumanistico Categoría A en Colciencias de la Facultad de Derecho de la Universidad Santo Tomás Bogotá.

137 Abogada de la Universidad Externado de Colombia, Especializada en Derecho Internacional Público, Universidad Paris II Pantheon- Assas, con estudios de Maestría en Gobierno y Políticas Publicas, Universidad Externado de Colombia. Docente Maestría de Derechos Humanos y Derecho Internacional Humanitario de la Universidad Santo Tomás - Sede Bogotá. Email.Smmp1975@yahoo.fr 
En el desarrollo de la defensa internacional del Estado varias entidades del engranaje institucional se encuentran involucradas, aunque de diferentes maneras. Se han creado algunos grupos de trabajo en función de garantizar una adecuada defensa. Existen entidades que coordinan, y otras que vigilan, otras que se encuentran involucradas porque fueron sus agentes quienes generaron las posibles responsabilidades internacionales y ahora procuran defender sus intereses que han sido afectados por las demandas. Adicionalmente existen personas contratadas externamente para asesorar y asumir la agencia por el Estado en dichos procesos. Por encima de toda la estructura y desde el mandato de la Constitución se especifica que está en cabeza del Ejecutivo, la dirección de las relaciones exteriores; de lo cual se desprende que también es el Ejecutivo quien se encarga de la defensa internacional.

Artículo 189. Corresponde al Presidente de la República como Jefe de Estado, Jefe de Gobierno y Suprema Autoridad Administrativa: (...) 2. Dirigir las relaciones internacionales. Nombrar a los agentes diplomáticos y consulares, recibir a los agentes respectivos y celebrar con otros Estados y entidades de derecho internacional tratados o convenios que se someterán a la aprobación del Congreso.

El Ejecutivo es quien formula la política exterior, sin perjuicio de las otras autoridades que desarrollan funciones relacionadas con la agenda exterior del Estado. En primer lugar encontramos las referencias que hace la misma Constitución Política sobre la función del Congreso de la República (art. 150.16), relacionada con la aprobación de tratados internacionales, así como la función de la Corte Constitucional relacionada con el control de constitucionalidad frente a los tratados y leyes aprobatorias de tratados (art. 241. 10).

La Comisión Asesora de Relaciones Exteriores (art. 225 C.P) se cita sólo cuando el Presidente lo considera necesario, para apoyarlo técnicamente en las más altas decisiones de política internacional. Esta comisión la conforman ex presidentes y ex cancilleres de la República. No obstante, el Presidente decide en que momento convocarla y sus decisiones son secretas. Vale la pena resaltar que las decisiones están 
a cargo del Ejecutivo y es el quien responde políticamente. La defensa jurídica internacional, se adelanta en varias áreas, lo cual obligatoriamente hace que se incluyan más autoridades dentro del panorama.

\section{Origen de la defensa jurídica del Estado en Colombia}

Luego de los primeros fallos de la Corte Interamericana de Derechos Humanos se perfiló la necesidad de comenzar a trabajar en la línea de defensa en su momento denominada Defensa Legal del Estado (Centro Dejusticia, 2005). A partir de esta fecha se expidieron numerosos decretos y leyes, que se relacionaban directamente con dicha defensa. Uno de los objetivos de esta campaña, fue controlar el desgaste fiscal de las demandas en materia de derechos humanos contra Colombia, especialmente ante el Sistema Interamericano (Mejía, 2007) y posteriormente dicho Conpes requirió de un nuevo documento que permitiera un crédito internacional para cubrir económicamente la defensa (Consejo Nacional de Politica Economica y Social, 2012). Desde entonces todos los gobiernos han trabajado por la defensa jurídica del Estado incluyendo la defensa internacional.

\section{GRAFICA 1}

Legislación colombiana relacionada con

la defensa jurídica internacional del Estado

\begin{tabular}{|l|l|l|}
\hline NORMA & AÑO & FUNCION \\
\hline Ley 288 & 1996 & $\begin{array}{l}\text { Por medio de la cual se establecen instrumentos } \\
\text { para la indemnización de perjuicio a las víctimas } \\
\text { de violaciones de derechos humanos en virtud de lo } \\
\text { dispuesto por determinados órganos internacionales } \\
\text { de Derechos Humanos. }\end{array}$ \\
\hline Ley 446 & 1998 & $\begin{array}{l}\text { Se consideran mecanismos alternativos de } \\
\text { controversias. }\end{array}$ \\
\hline $\begin{array}{l}\text { Decreto } \\
1890\end{array}$ & 1999 & $\begin{array}{l}\text { Creó la Dirección de Defensa Judicial de la Nación } \\
\text { dentro del Ministerio de Justicia y Derecho, para } \\
\text { encausar estrategias de defensa de la Nación. Trabajo } \\
\text { en conjunto con la Presidencia de la Republica. }\end{array}$ \\
\hline
\end{tabular}




\begin{tabular}{|c|c|c|}
\hline $\begin{array}{l}\text { Decreto } \\
1214\end{array}$ & 2000 & Sobre los Comités de Conciliación. \\
\hline $\begin{array}{l}\text { Ley } 678 \\
2001\end{array}$ & 2001 & $\begin{array}{l}\text { Sobre la acción de repetición frente a servidores } \\
\text { públicos, en demandas contra el Estado. }\end{array}$ \\
\hline Ley 790 & 2002 & $\begin{array}{l}\text { Mediante la cual se reorganizó la administración } \\
\text { pública. Se fusionó el Ministerio del Interior y de } \\
\text { Justicia, dando especial impulso a la Dirección de } \\
\text { Defensa del Estado. }\end{array}$ \\
\hline $\begin{array}{l}\text { Decreto Ley } \\
200\end{array}$ & 2003 & $\begin{array}{l}\text { Que establece cada una de las funciones del Ministeric } \\
\text { del Interior y de Justicia del entonces. Y se habla } \\
\text { por primera vez de defensa judicial internacional del } \\
\text { Estado, refiriéndose a lo relacionado con Derechos } \\
\text { Humanos. }\end{array}$ \\
\hline Ley 790 & 2002 & $\begin{array}{l}\text { Fortalecimiento Dirección de Defensa. Creación de } \\
\text { LITIGOB }\end{array}$ \\
\hline $\begin{array}{l}\text { CONPES } \\
3250\end{array}$ & 2003 & $\begin{array}{l}\text { Política Pública que pretendió Aumentar la capacidad } \\
\text { del Estado para prevenir y enfrentar el Daño } \\
\text { antijurídico. }\end{array}$ \\
\hline Ley 812 & 2003 & Fortalecimiento a la Política Única de Defensa Judicial \\
\hline Ley 819 & 2003 & $\begin{array}{l}\text { Normas relacionadas con la Ley Orgánica del } \\
\text { Presupuesto, para vigilar la transparencia fiscal. }\end{array}$ \\
\hline \begin{tabular}{|l|} 
Directiva \\
presidencial \\
01
\end{tabular} & 2004 & $\begin{array}{l}\text { Reporte de información litigiosa desde las entidades al } \\
\text { Ministerio del Interior }\end{array}$ \\
\hline \begin{tabular}{|l|} 
Directiva \\
Presidencial \\
02 \\
\end{tabular} & 2005 & $\begin{array}{l}\text { Creación del Grupo Técnico Interinstitucional GOI, en } \\
\text { desarrollo del CONPES } 3250\end{array}$ \\
\hline $\begin{array}{l}\text { Decreto } \\
4530\end{array}$ & 2008 & $\begin{array}{l}\text { Por el cual se modifica la estructura del Ministerio del } \\
\text { Interior y de Justicia. }\end{array}$ \\
\hline $\begin{array}{l}\text { Decreto } \\
3355\end{array}$ & 2009 & $\begin{array}{l}\text { Estructura y funcionamiento del Ministerio de } \\
\text { Relaciones Exteriores. Art. } 8 \text { funciones de la Dirección } \\
\text { de Asuntos Jurídicos Internacionales. }\end{array}$ \\
\hline $\begin{array}{l}\text { Decreto Ley } \\
4085\end{array}$ & 2011 & $\begin{array}{l}\text { Mediante el cual se crea la Agencia Nacional de } \\
\text { Defensa, objetivos y estructura. }\end{array}$ \\
\hline Ley 1437 & 2011 & $\begin{array}{l}\text { Código de procedimiento administrativo. Las } \\
\text { entidades deben valorar sus pasivos contingentes. }\end{array}$ \\
\hline
\end{tabular}




\begin{tabular}{|l|l|l|}
\hline Conpes 3722 & 2012 & $\begin{array}{l}\text { Para contratar un empréstito externo con la banca } \\
\text { multilateral hasta por la suma de us\$10 millones o su } \\
\text { equivalente en otras monedas destinado a financiar el } \\
\text { programa de fortalecimiento de la Defensa Jurídica } \\
\text { del Estado }\end{array}$ \\
\hline
\end{tabular}

(Gráfica de elaboración propia)

El ente coordinador en materia de defensa, fue el Ministerio del Interior y de Justicia que se encontraba bajo la supervisión de la Secretaría Jurídica de la Presidencia de la República.

Como se explicó antes, la responsabilidad internacional del Estado surge cuando este no cumple sus compromisos internacionales, compromisos que surgen de cualquiera de las normas internacionales como lo son el incumplimiento de tratados internacionales (en cualquier materia), incumplimiento de principios de derecho internacional (ej. soberanía territorial), costumbre internacional (ej. normas de derecho internacional humanitario), entre otras.

En este sentido, dentro de los ámbitos de responsabilidad internacional del Estado colombiano, las situaciones que han generado mayor ni el de responsabilidad han sido las violaciones a compromisos en materia de derechos humanos. En el planteamiento de la política publica, no se asumió la defensa internacional del Estado caso Nicaragua vs. Colombia, ante la Corte Internacional de Justicia (por causa del tratado internacional de 1928), ni otras áreas de defensa como la defensa ante la OMC ante el mecanismo de solución de controversias, por incumplimiento al tratado constitutivo de la organización cuyo objeto es la preservación del libre comercio), o incluso ante el Tribunal Andino de Justicia (cumplimiento e incumplimiento del Acuerdo de Cartagena y sus acuerdos derivados). La Corte Penal Internacional convoca al Estado para que este informe sobre su examen preliminar, esta Corte estudia la responsabilidad individual de las personas como criminales internacionales. Es decir, la responsabilidad no recae sobre el Estado sino sobre los individuos. Valga la pena aclarar entonces, que en el momento en el que se entregó la misión a la Dirección de Defensa del Ministerio del Interior, la defensa internacional en materia de derechos humanos ante el Sistema Interamericano de Protección 
de Derechos Humanos, surgió como una labor excepcional, es decir como una consecuencia de las demandas internas sobre responsabilidad del Estado, entre otras contra el Ministerio de Defensa por las acciones de la Fuerza Pública.

\section{GRAFICA 2}

Instituciones involucradas directamente en la defensa

\begin{tabular}{|c|c|c|}
\hline $\begin{array}{l}\text { Ministerio del } \\
\text { Interior y de } \\
\text { Justicia }\end{array}$ & $\begin{array}{l}\text { Dirección de } \\
\text { Defensa del } \\
\text { Estado }\end{array}$ & $\begin{array}{l}\text { Crear y supervisar el centro de información } \\
\text { sobre los procesos. }\end{array}$ \\
\hline & $\begin{array}{l}\text { Dirección } \\
\text { de Asuntos } \\
\text { Jurídicos } \\
\text { Internacionales }\end{array}$ & $\begin{array}{l}\text { Supervisó dos demandas } \\
1 . \quad \text { Sea Search vr. Colombia en Estados } \\
\text { Unidos. } \\
2 . \quad \text { Ecuador vr. Colombia ante la Corte } \\
\text { Internacional de Justicia. }\end{array}$ \\
\hline \multirow[t]{2}{*}{$\begin{array}{l}\text { Ministerio de } \\
\text { Relaciones } \\
\text { Exteriores }\end{array}$} & $\begin{array}{l}\text { Dirección } \\
\text { de Derechos } \\
\text { Humanos y } \\
\text { DIH }\end{array}$ & $\begin{array}{l}\text { Defensa ante el Sistema Interamericano, de } \\
\text { todas las demandas hasta la fecha. } \\
\text { Así como la atención a los requerimientos } \\
\text { de las organizaciones internacionales, como } \\
\text { control político no judicial, en diferentes temas }\end{array}$ \\
\hline & $\begin{array}{l}\text { Dirección de } \\
\text { Soberanía } \\
\text { y Asuntos } \\
\text { Fronterizos }\end{array}$ & $\begin{array}{l}\text { Supervisar las demandas ante la Corte } \\
\text { Internacional de Justicia: } \\
\text { 1. } \quad \text { Nicaragua vs. Colombia } \\
2 . \quad \text { Ecuador vs. Colombia }\end{array}$ \\
\hline $\begin{array}{l}\text { Ministerio de } \\
\text { Defensa }\end{array}$ & $\begin{array}{l}\text { Dirección } \\
\text { de Derechos } \\
\text { Humanos }\end{array}$ & $\begin{array}{l}\text { Defensa del Estado: Fortalecimiento de la } \\
\text { participación del Ministerio de Defensa y la } \\
\text { Fuerza Pública en los grupos de defensa del } \\
\text { Estado en derechos humanos. }\end{array}$ \\
\hline $\begin{array}{l}\text { Ministerio } \\
\text { de Comercio } \\
\text { Industria y } \\
\text { Turismo }\end{array}$ & $\begin{array}{l}\text { Oficina de } \\
\text { Asuntos } \\
\text { Legales } \\
\text { Internos }\end{array}$ & $\begin{array}{l}\text { Actuar, representando al país en los foros y } \\
\text { organismos internacionales sobre política, } \\
\text { normas y otros aspectos en comercio } \\
\text { internacional. Esa Oficina ha adelantado la } \\
\text { representación, frente al Tribunal de Justicia } \\
\text { de la Comunidad Andina de Naciones así } \\
\text { como, frente a la Organización Mundial del } \\
\text { Comercio y otros foros internacionales cuando } \\
\text { ha querido. }\end{array}$ \\
\hline
\end{tabular}




\begin{tabular}{|c|c|c|}
\hline $\begin{array}{l}\text { Agencia de } \\
\text { Defensa } \\
\text { Jurídica del } \\
\text { Estado }\end{array}$ & $\begin{array}{l}\text { Desde mayo } \\
2013\end{array}$ & $\begin{array}{l}\text { Diseño de estrategias, planes y acciones } \\
\text { dirigidos a dar cumplimiento a las políticas } \\
\text { de defensa jurídica de la Nación y del Estado } \\
\text { definidas por el Gobierno Nacional; la } \\
\text { formulación, evaluación y difusión de las } \\
\text { políticas en materia de prevención de las } \\
\text { conductas antijurídicas por parte de servidores } \\
\text { y entidades públicas, del daño antijurídico } \\
\text { y la extensión de sus efectos, y la dirección, } \\
\text { coordinación y ejecución de las acciones que } \\
\text { aseguren la adecuada implementación de } \\
\text { las mismas, para la defensa de los intereses } \\
\text { litigiosos de la Nación. }\end{array}$ \\
\hline $\begin{array}{l}\text { Ministerio } \\
\text { de Hacienda } \\
\text { y Crédito } \\
\text { Público }\end{array}$ & $\begin{array}{l}\text { Dirección General } \\
\text { de Crédito } \\
\text { Público y Tesoro } \\
\text { Nacional - } \\
\text { División de Pasivos } \\
\text { Contingentes del } \\
\text { Ministerio }\end{array}$ & $\begin{array}{l}\text { La Directiva Presidencial No. } 01 \text { de } 2004 \text {, } \\
\text { designó a la Dirección, como responsable de } \\
\text { hacer seguimiento al CONPES } 3250 .\end{array}$ \\
\hline $\begin{array}{l}\text { Departamento } \\
\text { Nacional de } \\
\text { Planeación } \\
\text { DNP }\end{array}$ & & $\begin{array}{l}\text { Lidera y orienta la formulación del Plan } \\
\text { Nacional de Desarrollo, hace seguimiento de los } \\
\text { recursos de inversión dirigidos al logro de los } \\
\text { objetivos de mediano y largo plazo, y orienta, } \\
\text { formula, monitorea, evalúa y hace seguimiento } \\
\text { a las políticas, planes, programas y proyectos } \\
\text { para el desarrollo económico, social y ambiental } \\
\text { del país, a través de un trabajo interinstitucional } \\
\text { coordinado con las entidades del orden nacional } \\
\text { y territorial, con sentido de responsabilidad } \\
\text { frente a la ciudadanía. }\end{array}$ \\
\hline $\begin{array}{l}\text { Auditoría } \\
\text { General de la } \\
\text { República }\end{array}$ & & $\begin{array}{l}\text { Optimiza la oportunidad, el recaudo y mejora } \\
\text { la calidad de los procesos de responsabilidad } \\
\text { fiscal, sancionatorios y de jurisdicción coactiva } \\
\text { y promover otros medios para la prevención o } \\
\text { resarcimiento del daño", de la mano este del } \\
\text { otro objetivo estratégico } 3.3 \text { "Propender por } \\
\text { la efectividad del control fiscal y la prevención } \\
\text { del daño antijurídico a través de las acciones } \\
\text { complementarias de otros instrumentos legales } \\
\text { e institucionales". }\end{array}$ \\
\hline $\begin{array}{l}\text { Contraloría } \\
\text { General de la } \\
\text { Republica }\end{array}$ & & $\begin{array}{l}\text { Trabaja por la prevención del daño antijurídico } \\
\text { y la gestión eficiente y efectiva de la defensa } \\
\text { jurídica de los intereses estatales. }\end{array}$ \\
\hline
\end{tabular}

Grafica de elaboración propia, información obtenida de derechos de petición 2011 - 2012. 


\section{Actores directos en la defensa juridica Ministerio del Interior y de Justicia (hoy Ministerio de Justicia)}

En vista del creciente pasivo contingente del Estado, se creó en el año 2000 la Dirección de Defensa Jurídica dentro del Ministerio del Interior, encargada de coordinar la defensa del Estado.

En el Plan Nacional de Desarrollo 2003-2006 "Hacia un Estado Comunitario" de la primera administración Uribe-Vélez, se previó el fortalecimiento del servicio de justicia, buscando defender de forma eficaz al estado en los procesos de los cuales haga parte. En la misma línea surge el CONPES 3250 de 2003 Líneas de Acción para el fortalecimiento de la defensa legal de la nación y para la valoración de pasivos contingentes. El seguimiento del mismo, estaría a cargo de los Ministerios: del Interior y de Justicia, y Hacienda. La labor de la Dirección no era fijar estrategias de defensa ni lineamientos de una política de defensa integral. Su labor consistió en crear y supervisar el centro de información sobre los procesos.

(...) esta Dirección solo ejerce funciones de administración de la información litigiosa reportada por las entidades de la Administración Pública Nacional. Así mismo no contamos con las estadísticas de los procesos, sino con la información de las demandas que reportaron las entidades del orden nacional (...) (Derecho de Petición Dirección de Defensa Jurídica del Estado, 2010).

La información manejada por el entonces Ministerio del Interior y de Justicia, consistió en una información juiciosa, y detallada de los procesos contra el Estado colombiano. Poco a poco la información fue evolucionando hasta contar con una buena base de datos de los procesos -LITIGOB, en donde se recogió información sobre las demandas contra el Estado colombiano. Dicha Dirección subsistió durante los dos gobiernos de Álvaro Uribe Vélez. Dentro de las 163 entidades demandadas para el año 2010 (antes de trasladar su función a la Agencia de Defensa del Estado), se encontró que además de las demandas en el sector de protección social, el Ministerio de Defensa ocupaba un lugar predominante, ya que contemplaba el mayor número de demandas, 
bien fundamentadas en su contra y con buena calidad probatoria según establece la base de datos de las demandas. Es decir las más susceptibles de ser perdidas por el Estado colombiano (Derecho de Petición Dirección de Defensa Jurídica del Estado, 2010).

La información sobre los procesos consistía en los siguientes datos: número del proceso, acción (donde casualmente no se encuentran las acciones a nivel internacional), valor de las pretensiones, demandante, situación que genera la demanda, jueces de conocimiento e instancia etc.; claramente la finalidad de esta información era lograr una política de conciliación de contingentes judiciales o al menos anticipar los valores de las contingencias, para mitigar la situación fiscal que generaba el alto número de demandas del Estado.

No obstante, dentro del documento enviado por la Dirección de Defensa, la información sobre los pasivos contingentes a cargo del Ministerio de Relaciones Exteriores no se encontraba categorizada. Según los datos manejados por la Dirección de Defensa, las demandas relacionadas se encuentran entremezcladas entre las demandas institucionales (Fondo Rotatorio, despidos, extradiciones, inmunidades, etc.) y las demandas que esta entidad atiende pero que originan responsabilidad internacional del Estado, que son conocidas por tribunales internacionales (ante organizaciones internacionales) y tribunales extranjeros (ante otros Estados). A partir de la información, no pudo consolidarse un escenario sobre los procesos sobre la responsabilidad internacional del Estado, ya que no están bien identificados.

En conclusión el Ministerio del Interior fue el primero en actuar cuando se detectó la alarma que estaban generando las contingencias en contra de la Nación. Su función fue la de gestionar y administrar el pago de las mismas. En este sistema las demandas internacionales no se encontraban contempladas ni discriminadas.

\section{Ministerio de Relaciones Exteriores}

A través de la Dirección de Derechos Humanos y DIH Dirección de Asuntos Jurídicos Internacionales; y Dirección de Soberanía Territorial y Desarrollo Fronterizo. 
El Ministerio ha incorporado la función de adelantar la defensa internacional del Estado, en los decretos que establecen el funcionamiento interno del Ministerio. En el Decreto 3355 de 2009 se estableció como función de la Dirección de Asuntos Jurídicos Internacionales la de:

Artículo $8^{\circ}$ : Atender cuando le sea solicitado por el Ministro, la defensa jurídica internacional de los intereses del Estado colombiano en coordinación con las dependencias del Ministerio y las entidades estatales correspondientes.

\section{Dirección de Derechos Humanos y DIH}

La defensa internacional del Estado ante el Sistema Interamericano de Derechos Humanos y otras instancias internacionales de derechos humanos, la adelanta esta Dirección. Desde la conformación de la Corte Interamericana de Derechos Humanos y las primeras peticiones contra Colombia la función de la Dirección de Derechos Humanos comenzó a incrementarse, con aproximadamente cinco funcionarios debió replantear su estrategia. El caso Diecinueve comerciantes dispara las reparaciones por responsabilidad en derechos humanos del Estado ( Corte Interamericana Derechos Humanos, 2004). En el 2005 se expidió la Directiva Presidencial No. 02, que creo el Grupo Técnico Interinstitucional GOI, compuesto por dos funcionarios del Ministerio de Defensa Nacional, dos funcionarios del Ministerio de Relaciones Exteriores, dos funcionarios del Ministerio del Interior y de Justicia, un funcionario del Ejercito Nacional, un funcionario de la Policía Nacional y un funcionario del Programa Presidencial de Derechos Humanos y Derecho Internacional Humanitario (Derecho de Petición Dirección de Defensa Jurídica del Estado, 2010).

El Grupo GOI se constituyó como de carácter permanente y se conformó por funcionarios y contratistas de dedicación exclusiva. Este grupo tuvo asiento en la Dirección de Derechos Humanos de la Cancillería y en este sentido cumplieron la función de defensa exclusiva hasta mayo del 2013, técnicamente bajo instrucciones de dicha Dirección. No obstante cada entidad tuvo a su cargo el pago y remuneración de sus funcionarios y contratistas de acuerdo con los 
salarios establecidos a nivel interno. (Derecho de Petición en Defensa Internacional del Estado, 2011).

Desde la Dirección de Derechos Humanos de la Cancillería, este grupo interdisciplinario, con diversos enfoques, preparó la defensa ante el Sistema Interamericano, de todas las demandas que ha recibido Colombia hasta la fecha.

Sin perjuicio de lo anterior, esta Dirección ha tenido la labor de atención a los requerimientos de las organizaciones internacionales, estas solicitudes configuran la labor de las diferentes organizaciones de supervisión a los cumplimientos de los estados en los varios compromisos que adquieren con la comunidad internacional, en diferentes temas. No configura esto un control de tipo judicial.

Existen seis comités que supervisan el cumplimiento de los Estados en relación con estos tratados. Los organismos internacionales ante los Cuales Colombia presenta informe sobre control político internacional son:

\section{GRAFICA 3}

Organismos internacionales ante los Cuales Colombia presenta informe sobre control político internacional

\begin{tabular}{|l|l|}
\hline COMITÉ / SISTEMA & $\begin{array}{l}\text { PERIODICIDAD EN LA } \\
\text { PRESENTACIÓN DE } \\
\text { INFORMES }\end{array}$ \\
\hline $\begin{array}{l}\text { Comité para la Eliminación de la } \\
\text { Discriminación Racial - ONU }\end{array}$ & \\
\hline Comité de Derechos Humanos - ONU & \\
\hline $\begin{array}{l}\text { Comité de Derechos Económicos, Sociales y } \\
\text { Culturales -. ONU }\end{array}$ & \\
\hline Comité Contra la Tortura -ONU & \\
\hline $\begin{array}{l}\text { Comité para la Eliminación de Todas las } \\
\text { Formas de Discriminación Contra La Mujer } \\
- \text { ONU }\end{array}$ & \\
\hline Comité de los Derechos del Niño - ONU & \\
\hline $\begin{array}{l}\text { Comité de Protección de los Derechos de Todos } \\
\text { los Trabajadores Migrantes y de Sus Familiares. }\end{array}$ & \\
\hline $\begin{array}{l}\text { Depositario en Convención para la de } \\
\text { Prohibición del Empleo, Almacenamiento, } \\
\text { Producción y Transferencia de Minas } \\
\text { Antipersonal y sobre su Destrucción. }\end{array}$ & Anual \\
\hline
\end{tabular}




\begin{tabular}{|l|l|}
\hline $\begin{array}{l}\text { Depositario Protocolo II de la anterior } \\
\text { Convención sobre Ciertas Armas }\end{array}$ & Anual \\
Convencionales. & \\
\hline $\begin{array}{l}\text { Programa de Acción de las Naciones Unidas } \\
\text { para Prevenir, Combatir y Eliminar el Tráfico } \\
\text { Ilícito de Armas Pequeñas y Ligeras. }\end{array}$ & Bianual \\
\hline $\begin{array}{l}\text { Comité Consultivo de la Convención } \\
\text { Interamericana contra el Tráfico Ilícito de } \\
\text { Armas de Fuego, Municiones, Explosivos y } \\
\text { otros Materiales Relacionados }\end{array}$ & \\
\hline $\begin{array}{l}\text { Depositario para la Convención sobre la } \\
\text { Prohibición y el Almacenamiento de Armas } \\
\text { Bacteriológicas y sobre su destrucción. }\end{array}$ & \\
\hline $\begin{array}{l}\text { Depositario para el Tratado para la } \\
\text { Proscripción de las Armas Nucleares en } \\
\text { América Latina y el Caribe. Tratado de } \\
\text { Tlatelolco. - OPANAL }\end{array}$ & \\
\hline $\begin{array}{l}\text { Depositario para la Convención sobre la } \\
\text { Prohibición del Desarrollo de la Producción } \\
\text { el Almacenamiento y el Empleo de Armas } \\
\text { Químicas y sobre su destrucción - OPAQ }\end{array}$ & \\
\hline $\begin{array}{l}\text { Depositario para el Acuerdo entre Colombia y } \\
\text { el Organismo Internacional de Energía Atómica } \\
\text { para la aplicación de Salvaguardas en relación } \\
\text { con el Tratado para la Proscripción de las } \\
\text { Armas Nucleares en América Latina -OIEA }\end{array}$ & \\
\hline $\begin{array}{l}\text { Oficina de las Naciones Unidas contra la Droga } \\
\text { y el Delito - ONUDD }\end{array}$ & Anual - trimestral \\
\hline $\begin{array}{l}\text { CICAD Comisión Interamericana para el } \\
\text { Control del Abuso de las Drogas }\end{array}$ & Bianuales \\
\hline
\end{tabular}

Gráfica de elaboración propia. Fuente, Derechos de petición, 2012.

Adicionalmente, de los informes hacia los Comités, el Consejo de Derechos Humanos de las Naciones Unidas estableció el mecanismo para analizar el cumplimiento en materia de Derechos Humanos: Examen Periódico Universal EPU, que se presenta cada cuatro años, Colombia presentó el Informe por primera vez en septiembre de 2008. Estos informes requieren de un trabajo juicioso y en cooperación de varias instancias nacionales.

En este sentido, la Dirección de Derechos Humanos cuenta con una labor de coordinación y elaboración de la defensa jurídica internacional 
del Estado que viene adelantando hace más de diez años. Coordina la información entre las diferentes entidades para la defensa ante los sistemas internacionales.

Además de la gestión adelantada en materia litigiosa y temática de la Dirección, en Materia de Derechos Humanos, se cuenta con la gestión en ciertos temas en defensa internacional a cargo de la Dirección de Asuntos Jurídicos Internacionales.

\section{Dirección de Asuntos Jurídicos Internacionales}

Esta Dirección supervisa la defensa en las siguientes dos demandas:

1Sea Search Armada vs. el Estado de Colombia: ante la Corte

Distrital del Distrito de Columbia de los Estados Unidos de América.

Colombia fue demandada el 7 de diciembre de 2010 por la Empresa Sea Search Armada, en el sentido de que el fallo de la Corte Suprema de Justicia configura un título de propiedad al declarar que la empresa es propietaria del $50 \%$ de los tesoros que se encuentren en naufragio y que el Estado le ha impedido a la empresa ejercer este derecho. Sus pretensiones ascienden a diecisiete mil millones de dólares. El 24 de octubre de 2011, dicha Corte profirió un fallo donde acogió favorablemente los argumentos de la defensa de Colombia, con relación a la improcedencia de la acción judicial y la prescripción de dicha acción. Recientemente se acaba de emitir el fallo confirmando la primera instancia, a favor de Colombia.

2.Demanda presentada por Ecuador vs. Colombia: la demanda se presenta el 31 de marzo de 2008 a causa de las campañas de fumigaciones con químicos herbicidas, realizadas por el Estado Colombiano. La demanda fue conciliada en la Corte Internacional de Justicia, a través de un acuerdo entre Ecuador y Colombia del 2013. (Acuerdo entre la República del Ecuador y la Republica de Colombia, para la solución de la controversia existente en la Corte Internacional de Justicia, relativa a la erradicación de cultivos ilícitos cerca de la frontera con Ecuador, 2013) 
Es importante aclarar, que el Gobierno consideró pertinente conciliar esta demanda ya que el fallo se produciría en el 2013( solo un año después del fallo desfavorable caso Nicaragua) y que según la expectativa era muy probable tener un fallo contrario a las intenciones del Estado. Por lo anterior, Colombia celebra este acuerdo como un mecanismo alternativo para la solución de esta controversia y de la demanda formulada por Ecuador en el Sistema Interamericano por la muerte de Francisco Aisalla en el bombardeo transfronterizo al campamento de Raúl Reyes guerrillero de las FARC en Ecuador. Dicho acuerdo se celebró debiendo Colombia pagar quince millones de dólares para conciliar las demandas.

\section{Dirección de Soberanía Territorial y Desarrollo Fronterizo}

En esta Dirección se encuentra el Grupo Interno de Trabajo en Asuntos ante la Corte Internacional de Justicia, que se encargó del Diferendo territorial Nicaragua vs. Colombia. El proceso inició en diciembre de 2001, el 24 de diciembre 2007 se produjo el fallo sobe excepciones preliminares, y el diecinueve de noviembre de 2012 se produjo fallo desfavorable para nuestro país. Esta Dirección también tuvo a su cargo en conjunto con la Dirección de Asuntos Jurídicos, la defensa en la controversia contra Ecuador a causa de las fumigaciones aéreas adelantadas por Colombia en zona de frontera iniciada en 2008, resuelta en el 2013 con la firma del Acuerdo que concilio las demandas con Ecuador.

El grupo de defensa lo componen funcionarios de dicha Dirección del Ministerio que han trabajado de manera estable, durante mucho tiempo; además los agentes son personas de muy alto perfil dentro del gobierno colombiano (ex cancilleres con la mejor trayectoria). Así mismo, se contrataron abogados externos que apoyaran la defensa. Este grupo ha trabajado privadamente en la defensa sin otras funciones. Se resalta que, su única misión fue la defensa en dos procesos ante la Corte Internacional, no participó en otros procesos.

En conclusión el Ministerio de Relaciones Exteriores, en sus diferentes Direcciones contempla las funciones de defensa internacional de Colombia en diferentes áreas, algunas más activas que otras pero siempre en función de defender los intereses de la Nación. Si bien los 
sistemas ante quienes se defiende a Colombia son diferentes, llama la atención que las experiencias de cada oficina puede sugerir sinergias y emplear estrategias comunes que resalten la destreza ante los tribunales.

\section{Ministerio de Defensa}

La Política Integral en materia de Derechos Humanos y DIH- 2008, al igual que la normatividad interna en el sector Defensa, promovió la participación activa del Ministerio, en la defensa jurídica internacional. En la Política se define la visión integral de promoción y respeto a los derechos humanos, y fija tres propósitos: Sincronización en enseñanza y capacitación de Derechos Humanos y DIH; adecuación en medios de instrucción frente a los DH y a las necesidades de la Fuerza Pública, y la integración de las capacidades de la Fuerza Pública, para asegurar el cumplimiento de sus obligaciones.

En 1994 se creó la Oficina de DH, y se replicó el modelo en las Fuerzas, con el fin de optimizar la coordinación de la materia. Esta Oficina fue determinante en la Política Integral, ya que fue allí de donde se coordinó además la generación de mecanismos de garantía el derecho a la Defensa de los miembros de la Fuerza Pública, así como de fortalecer la calidad y cantidad de los defensores técnicos. Se previó la conciliación administrativa. Esta es precisamente una de las cinco líneas de acción de la Política Integral de Derechos Humanos.

(...)Linea Defensa:

- Defensa Técnica: creación de un fondo para la protección del derecho de defensa de los miembros de la Fuerza Pública, por hechos relacionados con la ejecución de operaciones militares o policiales.

- Defensa del Estado: Fortalecimiento de la participación del Ministerio de Defensa y la Fuerza Pública en los grupos de defensa del Estado.

- Conciliación administrativa: Consolidación del mecanismo de la conciliación administrativa para reparar de forma directa daños patrimoniales causados como consecuencia de la ejecución de una operación, desincentivando el escalonamiento de conflictos que sin la debida atención podrían llegar a instancias judiciales. (...)

(Política Integral en Derechos Humanos 2008) 
Como se dijo antes, miembros del sector participarían en conjunto con las otras entidades involucradas en la defensa dentro de los procesos jurídicos a nivel interno y a nivel internacional. El Grupo Operativo Interinstitucional cuenta con la representación del sector defensa. De nueve funcionarios inicialmente contemplados 5 son de instituciones civiles como Interior y Justicia, Cancillería y Programa Presidencial y los otros cuatro son del Sector Defensa (Ministerio dos, uno Ejercito y unos Policía). Los coordinadores del grupo interinstitucional que están bajo la Dirección de Derechos Humanos de la Cancillería, han sido enviados por del Ministerio de Defensa. Adicionalmente, existen abogados externos sugeridos por el Ministerio de Defensa, con trayectoria cercana a este Ministerio, que han prestado sus servicios en la defensa internacional. Lo anterior es apenas lógico en cuanto es el sector defensa el que ha originado la mayoría de las controversias objeto de demanda internacional. Además, dentro del conflicto interno, quien da cuenta del desarrollo de los procedimientos de DIH es la Fuerza Pública colombiana.

Es de anotar que el Ministerio de Defensa explica además su actuación en medio de los procedimientos y operativos de la Fuerza Pública. La defensa es internacional pero para el Ministerio es importante defender también sus actuaciones en los casos que han generado controversia internacional.

\section{Ministerio de Comercio Industria y Turismo (Oficina de Asuntos Legales Internos)}

Este Ministerio actúa en ejercicio de las atribuciones otorgadas mediante sus decretos internos de funcionamiento. El Decreto 210 de 2003 numeral 16 le permite actuar, representando al país en los foros y organismos internacionales sobre política, normas y otros aspectos en comercio internacional. Esa Oficina ha adelantado la representación, frente al Tribunal de Justicia de la Comunidad Andina de Naciones así como, frente a la Organización Mundial del Comercio y otros foros internacionales cuando ha querido. Frente al Órgano de Solución de Diferencias de la Organización Mundial del Comercio ha representado al país en derecho del comercio internacional y en 
las obligaciones derivadas del Acuerdo de Cartagena y Tratado de Creación del Tribunal Andino de Justicia de la Comunidad Andina. Actualmente acompaña los procedimientos derivados del Tratado de Libre Comercio Colombia Estados Unidos. Se ha trabajado en colaboración activa con el Ministerio de Relaciones Exteriores, pero siempre bajo la instrucción del Presidente de la República como Director de las Relaciones Exteriores del País. (Derecho de Petición en Defensa Internacional del Estado, 2011)

Para esa fecha, Colombia ha sido convocada al Órgano de Solución de Diferencias de la OMC en las siguientes oportunidades:

a. Diferencia DS181 "Colombia-Medida de salvaguardia a las importaciones de filamentos lisos de poliéster procedentes de Tailandia” en ese caso se llegó a un acuerdo con Tailandia y la medida de salvaguardia fue retirada.

b. Diferencia DS348 "Colombia-Medidas aduaneras sobre la importación de determinadas mercancías procedentes de Panamá. Las partes llegaron a un acuerdo en esa materia y el proceso terminó.

c. Diferencia DS 366 "Colombia - Precios indicativos y restricciones de los puertos de entrada" El Informe del Grupo Especial en el caso pertinente le recomendó a Colombia poner sus medidas de conformidad con la Normativa OMC. Colombia implementó estas recomendaciones mediante el Decreto 111 de 2010 y actualmente ha cumplido con las recomendaciones del Grupo Especial.

Las consecuencias económicas, no recaen sobre el Estado colombiano sino directamente sobre el comercio y puede afectar a particulares que son actores en este sector. Frente a los procesos dentro de la Comunidad Andina de Naciones, las solicitudes se presentan a través de la Secretaria de la Comunidad, quien emite un dictamen sobre su opinión en el estado de incumplimiento y fija unos plazos para que el Estado se ponga al día en sus compromisos. En caso de que no se haga, se pasa a la etapa judicial ante el Tribunal Andino de Justicia.

Según la Oficina de Asuntos Legales del Ministerio, se identificó un impacto positivo en las defensas judiciales, ya que para el momento de la consulta, solo en acciones de incumplimiento ante el Tribunal Andino Colombia fue requerido en 26 oportunidades dentro de las cuales sólo en 7 procesos se emitieron fallos en contra. Se 
aclara que en buena parte de los casos se logra conjurar el proceso judicial o legal a través de la vía diplomática, por lo mismo en estos casos no hay proceso (Derecho de Petición Defensa Internacional del Estado, 2011).

La labor del Ministerio de Comercio se enfoca más en la explicación de algunos procedimientos administrativos que pueden impedir un buen desarrollo del comercio internacional.

\section{Fiscalía General de la Nación y Auditoria General de la República}

Desde octubre de 2001, se lanzó una Circular Conjunta dirigida a los contralores y fiscales, sobre la "Constitución como Parte Civil en los Procesos Penales”. La Circular reconoce como justificación de su expedición “(...) el alarmante monto de demandas y condenas contra el Estado, el grave detrimento patrimonial, y la escasa recuperación de los recursos del erario (...), advierte también que se están adelantando gestiones al interior de las entidades públicas, procurando una debida defensa judicial de la Nación y políticas de prevención del daño antijurídico. (Dirección Nacional de Fiscalías y Auditoría General, 2010),

Se retoma lo dispuesto en las leyes 190 de 1995, y 610 del 2000 así como la ley 600 del mismo año. En estas normas se prevé que le corresponde a las entidades públicas, a sus representantes legales y a los entes de control participar en los procesos penales, de forma facultativa en algunos pero obligatoria en otros. Dentro de las obligaciones se contempla que los fiscales deben informar sobre a respectiva investigación a los representantes legales de las entidades afectadas y también a las Contralorías para que se exijan el cumplimiento de dicha obligación. Se requiere también a las contralorías para que puedan constituirse como parte civil en los procesos penales.

Si bien la Fiscalía no pertenece a la rama ejecutiva, no se puede desconocer que en todos los fallos en contra de Colombia en materia de derechos humanos se resalta la debilidad del Estado en materia de justicia. La Fiscalía podría implementar mejores dinámicas para evitar así la responsabilidad internacional del Estado. 
Todas las instituciones mencionadas anteriormente tienen una labor de participación directa ya que desde su área temática y teniendo presente la serie de compromisos internacionales que va adquiriendo el Estado colombiano, tienen a cargo su defensa jurídica.

\section{Instituciones técnicas}

\section{Ministerio de Hacienda y Crédito Público}

La Directiva Presidencial No. 01 de 2004, designó a la Dirección General de Crédito Público y Tesoro Nacional - División de Pasivos Contingentes del Ministerio, como responsable de hacer seguimiento al CONPES 3250. La principal tarea de este Ministerio es recoger la información sobre los pasivos contingentes y la creación de un sistema metodológico de seguimiento. Este Ministerio no hace ningún tipo de asignación de recursos para efectos de la defensa internacional del Estado (pago a defensores). (Derecho de Petición en Defensa Internacional del Estado, 2011).

A partir del año 2004 se reportaron pasivos contingentes originados por sentencias y conciliaciones dentro del Marco Fiscal de Mediano Plazo. Su identificación y metodologías de valoración se han ido perfeccionando. Para la vigencia del 2006 se creó el rubro de fallos Corte Interamericana de Derechos Humanos, con el fin de distribuirle a las diferentes entidades del Estado los recursos para hacer los pagos por las condenas, para apropiaciones de recursos por año. En este sentido, como muestra para el año 2010 se apropiaron recursos por \$ 41.733.120.000, dentro de este monto se previó el pago para las publicaciones de los fallos por las condenas de Jesús María Valle Jaramillo, Manuel Cepeda; y reparaciones por razón de los fallos sobre masacre de Ituango y Familiares de Manuel Cepeda (como complementó al fallo interno).

Se ha adelantado un importante esfuerzo para crear una metodología adecuada para la valoración del pasivo contingente por la actividad litigiosa, teniendo en cuenta tanto los datos históricos, como las expectativas de fallo, suministradas por los apoderados en contra de la Nación (Derecho de Petición Defensa Internacional del Estado, 2010). 
Cabe resaltar que se adelantó una labor interesante en cuanto a la consolidación de una base de datos en conjunto con el Ministerio del Interior y de Justicia en el cual se reportan todas las demandas al Estado. Como se mencionó antes, las demandas internacionales por violaciones de derechos humanos, no se encuentran documentadas de manera específica en la base de datos LITIGOB, por lo cual se confunden con las demandas según sector (ej. Ministerio de Defensa).

Se advierte que los gastos son fiscales inciertos, pues dependen de una condición futura. Las indemnizaciones son realizadas por cada una de las entidades demandadas, por lo cual estas entidades incluyen en sus presupuestos anuales una apropiación para el pago de sentencias. Las jurisdicciones frente a las cuales se reportan los rubros son: la ordinaria (administra los procesos civiles, laborales y penales), administrativa, constitucional, cortes internacionales (dictámenes y fallos). El Ministerio de Hacienda y Crédito Público, ha identificado al Ministerio de Defensa Nacional como quien más pagos reporta por razones de defensa jurídica del Estado.

En conclusión su función consiste en provisionar los montos que deben pagarse por razón de las contingencias judiciales, no participan en la defensa pero deben conocer de la situación para poder provisional los pagos.

\section{Departamento Nacional de Planeación DNP}

El Departamento Nacional de Planeación es un organismo técnico asesor del Gobierno Nacional, que lidera y orienta la formulación del Plan Nacional de Desarrollo, hace seguimiento de los recursos de inversión dirigidos al logro de los objetivos de mediano y largo plazo, y orienta, formula, monitorea, evalúa y hace seguimiento a las políticas, planes, programas y proyectos para el desarrollo económico, social y ambiental del país, a través de un trabajo interinstitucional coordinado con las entidades del orden nacional y territorial, con sentido de responsabilidad frente a la ciudadanía. (Departamento Nacional de Planeación, 2013).

En su labor de participar en la elaboración de una política pública, el DNP advierte que luego de su creación, se adelanta el seguimiento 
y la evaluación de la misma. Para el caso del CONPES 3250, el seguimiento, provee información sobre el progreso de una política pública y comparar los avances logrados frente a las metas propuestas; también se ha encaminado a la acción correctiva y a establecer la responsabilidad de los ejecutores y sus resultados. La evaluación consiste en una valoración de la causalidad entre una intervención del Estado y sus efectos para determinar su efectividad y sostenibilidad. Según el DNP el gobierno no ha realizado ninguna evaluación estratégica específica, sobre impacto del proceso, costo beneficio; pues esta se enmarca en el programa de Renovación de la Administración Pública- PRAP, el cual tiene un alcance mucho más amplio, en tanto que propone dos tipos de estrategia: Una vertical que se encamino a la reorganización de la institucionalidad sectorial y la otra transversal dirigida a los procesos estructurales necesarios para el correcto funcionamiento de la Administración Pública, comunes a todos los sectores (Derecho de Petición - DNP, 2010).

Es importante recordar que las cuatro líneas de acción propuestas en dicho CONPES fueron:

1. Diseño de los modelos de gestión para las áreas de apoyo jurídico de las entidades del sector nacional.

2. Diseño e implementación del sistema de recaudo de información para la defensa judicial del Estado y la valoración de Pasivos Contingentes.

3. Diseño del Plan para la Capacitación

4. Propuestas normativas para la sostenibilidad institucional del Programa de Defensa Legal del Estado.

Frente a la primera línea el Ministerio del Interior y de Justicia comenzó su ejecución desde 2006, pero el DNP solo se limitó al seguimiento presupuestal y al acompañamiento en los Comités Técnicos, que discutieron los productos de las consultorías sobre:

a. La evaluación critica de la estructura sistemas de coordinación, actividades de prevención del daño antijurídico y la organización y estructura de 40 entidades de la administración pública nacional.

b. El diseño del modelo de gestión, que abarca aspectos como estructura organizacional, institucionalidad necesaria para la implementación, definición de macro procesos y formulación de indicadores de 
gestión para cada uno de los frentes: asesoría, defensa, contratación y producción normativa bajo la metodología balanced scorecard.

c. Definición en el nivel central de la instancia encargada de la gestión jurídica, y las relaciones de tipo funcional con diversos entes de apoyo como el Ministerio de Hacienda, el Archivo General de la Nación, Comisión Intersectorial de Contratación Pública entre otras.

d. Implementación de un piloto en cuatro entidades (incluidas las entidades cabeza de sector) de los sectores administrativos Interior y Justicia y el sector Agricultura y Desarrollo Rural.

Para la segunda línea, la actividad del Departamento se enfocó en el seguimiento presupuestal y acompañamiento en dos etapas.

a. Creación del "Sistema de Pleitos de la Nación", con recursos de donación y posteriormente, con recursos provenientes de crédito externo que fueron canalizados a través del proyecto de inversión “Apoyo a la estrategia jurídica de la administración pública nacional PRAP, cuyo principal insumo fue la información reportada por las entidades y luego las actualizaciones vía web, por las oficinas jurídicas.

Implementación del LITIGOB y la formulación de las alternativas para la generación de economías de escala con otras iniciativas relacionadas como la propuesta de creación de un Sistema Único de Información Normativa (SUIN).

La función del Departamento de Planeación Nacional es muy importante porque objetivamente puede formular y planear la solución a una problemática determinada, además con la inyección de recursos y no perdiendo de vista el interés general del Estado.

\section{Instituciones de control}

\section{Auditoría General de la República}

La Auditoría General dentro del Plan Estratégico 2009 - 2011, "Fortaleza del Control Fiscal”, adoptó como objetivo institucional número 3. "optimizar la oportunidad, el recaudo y mejorar la calidad de los procesos de responsabilidad fiscal, sancionatorios y de jurisdicción coactiva y promover otros medios para la prevención o resarcimiento del daño", de la mano este del otro objetivo estratégico 3.3 
"Propender por la efectividad del control fiscal y la prevención del daño antijurídico a través de las acciones complementarias de otros instrumentos legales e institucionales". La Auditoria ha diseñado una política de prevención del daño antijurídico con las Contralorías vigilando el formato de Controversias Judiciales, en cuanto a la intervención de estas en los procesos judiciales en defensa del patrimonio público.

La Auditoria también inició un proceso de acompañamiento conjunto con la Fiscalía General de la Nación desde 2010, con el que se insta a los entes de control a constituirse como parte civil o como víctimas en procesos penales, en pro de la protección del patrimonio público.

\section{Contraloría General de la República}

En el documento de "Seguimiento a la Problemática de las Demandas contra el Estado" (Contraloría Delegada Sector Defensa, Justicia y Seguridad, 2010), la Contraloría advierte que viene trabajando por la prevención del daño antijurídico y la gestión eficiente y efectiva de la defensa jurídica de los intereses estatales. Según la institución, las causas de las demandas son variadas y tienen que ver directamente con las funciones o responsabilidades inherentes al Estado, cuando los agentes fallan al servicio por acción u omisión, por presunta violación al ordenamiento jurídico y por controversias contractuales entre otras.

Una de las misiones que se resaltó fue la creación del Fondo de Contingencias, creado por la ley 448 de 1998, cuyo objeto es atender las obligaciones contingentes de las entidades estatales que determine el gobierno. En el 2003, la ley 819 señaló que estos pasivos contingentes deben ir incluidos en el Marco Fiscal de Mediano Plazo, con el fin de conocer la realidad problemática y entender cómo funciona, como riesgo a la sostenibilidad fiscal. La idea fue incluirlos al igual que se hace con los créditos y con las obras de infraestructura. En este caso, se incluye desde que la entidad es demandada y teniendo en cuenta cada una de las etapas, hasta el fallo definitivo.

Con la Directiva Presidencial 02 de 2003, se impulsa la utilización de los mecanismos alternativos de solución de conflictos entre la Nación y entidades descentralizadas. Figuraban demandas incluso 
por parte de las personas jurídicas de derecho público, a pesar de que se espera la colaboración conjunta con el Estado e incluso el uso de mecanismos de autocomposición con el fin de evitar la congestión judicial. La Contraloría encontró que la conciliación prejudicial en lo contencioso administrativo, no ha sido satisfactoria. Para el 2010, se radicaron 75.423 solicitudes de conciliación, de las cuales admitieron $63.677(84 \%)$, de las cuales realizaron $51.942(82 \%)$. De este monto se concilió finalmente 3.354 (6\%) y sin acuerdo se registran 48.588 (94\%). Adicionalmente se debe tener presente que la finalidad de atenuar el impacto fiscal, evitando que se demande al Estado, y contribuir a la descongestión, no ha sido alcanzada.

Asimismo la Contraloría advirtió que las entidades no habían contemplado en sus registros contables los procesos y las contingencias, debidamente en las cuentas que corresponden.

(...) aún es incierto el número total de procesos, estado jurídico en que se encuentran y posible valor de las condenas, por lo tanto no se conoce la dimensión real de la problemática, ni es posible estimar los recursos presupuestales que deberán destinarse a cubrir los pagos por este concepto.(...) (Contraloría Delegada Sector Defensa, Justicia y Seguridad, 2010).

Para diciembre de 2009, las pretensiones de las demandas contra el Estado ascendieron a $\$ 754.7$ (cuentas de orden Litigios $\$ 741.6$ y provisión para contingencias \$13.1). Esto además de las sentencias ejecutadas que quedaron pendientes de pago que fueron $\$ 1.4$ billones. Del orden nacional, las pretensiones fueron $\$ 728$ billones $(96 \%)$ y en el Territorial $\$ 26.7$ billones (4\%).

Según los aspectos presupuestales revisados por la Contraloría, el sector demandado más representativo es Defensa, Justicia y Seguridad; luego es el sector Infraestructura. Lo preocupante es que existe tendencia creciente. Por lo anterior se recomendó revisar y reorientar las políticas de promoción y respeto de los derechos humanos para evitar daños antijurídicos que son los que generan las demandas.

Un aspecto delicado es que también se puede los recursos del presupuesto, con recursos de crédito como Títulos de Tesorería - TES clase $\mathrm{B}$, lo cual incrementa los costos por concepto de intereses. 


\section{Hallazgos de la Contraloría}

Las entidades no cuentan con el estudio de riesgo jurídico que les permita tomar medidas efectivas frente a las responsabilidades contingentes, no se ha formalizado su procedimiento con valor técnico para evaluar las contingencias judiciales. Los archivos de los procesos no se encuentran organizados de acuerdo con las actuaciones para poder hacer seguimiento y control. Los procesos encuentran deficiencias en su gestión: contestación de las demandas, interposición de recursos, aporte y solicitud de pruebas, términos, alegatos. La "Relación de procesos" Judiciales en los Estados Contables de las entidades, presenta diferencias, lo cual es una falla de coordinación en las áreas contable y jurídica y presenta incertidumbre en el Balance General de la Nación.

Por estos hallazgos, la Contraloría sugirió la creación de una entidad (Abogacía General del Estado) con el fin de que se dicten desde allí las políticas en materia de defensa de los intereses del Estado, controle la información de los procesos y represente al Estado en casos específicos.

\section{Agencia de defensa jurídica del Estado}

La multiplicidad de instituciones involucradas, y la diversidad de intereses que defienden, visibilizaron la necesidad de constituir un ente coordinador, imparcial para la defensa jurídica internacional del Estado.

Con el cambio de gobierno, el nuevo mandatario dejó clara su intención de seguir trabajando en procura de disminuir los contingentes judiciales. El Plan de Desarrollo Prosperidad para todos 2011, establece en su capítulo quinto, lo relacionado con la Consolidación de la Paz. En este capítulo desarrolla tres componentes: la seguridad, orden público y seguridad ciudadana; Justicia, y Derechos Humanos; Derecho Internacional Humanitario; y Justicia transicional. El Plan de Desarrollo advierte de la necesidad de crear una Agencia de Defensa Jurídica del Estado, que utilice los mecanismos alternativos de solución de controversias para descongestionar la Rama Judicial. 
(...) A pesar de los esfuerzos se la Rama Judicial por descongestionar los despachos, esa situación continua impactando de manera negativa la prestación del servicio, y en especial, la celeridad de los procesos.Asimismo, el aumento de acciones y omisiones de las autoridades públicas continúan generando pleitos contra el Estado, que hoy superan los 170.252 procesos con las consecuencias patrimoniales que implica la indemnización de daños antijurídicos a los ciudadanos ante tribunales nacionales e internacionales. Los esfuerzos realizados resultan insuficientes para enfrentar la problemática descrita y para garantizar el cumplimiento de la ley, la seguridad jurídica y la confianza en el ciudadano. (...)

(...) e. Prevención del daño antijurídico (defensa judicial del Estado) Se requiere contar con una Abogacía General del Estado resistente a la corrupción, compuesta por un personal que cumpla los modelos de competencias comportamentales y funcionales de la gestión jurídica pública encargados de diseñar, ejecutar y controlar políticas estructurales y transversales en temas relacionados con la defensa de los intereses del Estado. Entre éstos, el desarrollo de un sistema de administración del riesgo jurídico que reduzca las acciones y omisiones que vulneran los derechos y bienes de los ciudadanos, la promoción de la conciliación extrajudicial, el arbitramento y demás mecanismos alternos que solucionen los conflictos en los que se involucran entidades estatales, la defensa articulada del Estado en tribunales nacionales e internacionales que garanticen el cumplimiento de la ley, la seguridad jurídica y la confianza ciudadana.(...)

En noviembre de 2011 se expidió el Decreto 4085, mediante el cual se creó la Agencia de Defensa Jurídica del Estado.

ARTÍCULO 20. OBJETIVO. La Agencia tendrá como objetivo el diseño de estrategias, planes y acciones dirigidos a dar cumplimiento a las políticas de defensa jurídica de la Nación y del Estado definidas por el Gobierno Nacional; la formulación, evaluación y difusión de las políticas en materia de prevención de las conductas antijurídicas por parte de servidores y entidades públicas, 
del daño antijurídico y la extensión de sus efectos, y la dirección, coordinación y ejecución de las acciones que aseguren la adecuada implementación de las mismas, para la defensa de los intereses litigiosos de la Nación.

PARÁGRAFO. Para efectos este decreto, entiéndase por intereses litigiosos de la Nación, los siguientes:

a) Aquellos en los cuates esté comprometida una entidad de la Administración Pública del orden nacional por ser parte en un proceso.

b) Aquellos relacionados con procesos en los cuales haya sido demandado un acto proferido por una autoridad pública o un órgano estatal del orden nacional, tales como leyes y actos administrativos, así como aquellos procesos en los cuales se controvierta su interpretación o aplicación.

c) Aquellos relacionados con procesos en los cuales se controvierta una conducta de un servidor público del orden nacional.

d) Aquellos relacionados con procesos en el orden regional o internacional en los cuales hava sido demandada la Nación.

e) Los demás que determine el Consejo Directivo de esta Agencia dentro de los lineamientos y prioridades señalados por el Gobierno Nacional. (Subrayado nuestro)

A comienzos de 2012 se designó a Fernando Carrillo como Director de la entidad y a su cargo, la obligación de enfrentar los más de 260.000 procesos instaurados contra el Estado, con pretensiones económicas por cerca de 1.000 billones de pesos (Portafolio, 2012). El Director designado advirtió al diario Portafolio en enero de 2012 que "Hay una fragmentación de la defensa del Estado alrededor de las 228 entidades públicas, por lo menos las de orden nacional".

La revista Semana en su edición del 6 de febrero del 2012, señaló que (...) las cifras (a las que se enfrenta Colombia) son aterradoras. En juego hay 1.028.000.000.000.000 de pesos. Esto equivaldría a unos 500.000 millones de dólares. Esta cifra corresponde a más de dos veces 
el Producto Interno Bruto de Colombia, que es más de 500 billones de pesos al año (...). En otras palabras, si las demandas que hoy cursan contra la nación prosperan, cada colombiano tendría que pagar, hipotéticamente, 22 millones de pesos (...) (Semana, 2012)

Se advirtió en esta entrevista que, en las entidades demandadas se perdían el $73 \%$ de los casos. Mientras que en Chile y Brasil de se pierden el $23.5 \%$ y el 55, $2 \%$ respectivamente. En el 2003 se pagaron unos 180.000 millones de pesos, en el 2006, 500.000 millones y para el 2012 se espera pagar casi 1 billón de pesos; casi la mitad de lo que se recauda al año por impuesto de guerra. Adicionalmente, en la entrevista con la revista Semana, se señala que con la creación de la Agencia, no se espera reemplazar a los 4.700 abogados que defienden los procesos de la Nación, sino fortalecer la información para tomar decisiones, crear una artillería única de defensa en instancias nacionales e internacionales. (Semana, 2012)

\section{GRAFICA 4}

Porcentaje de demandas que pierden los Estados

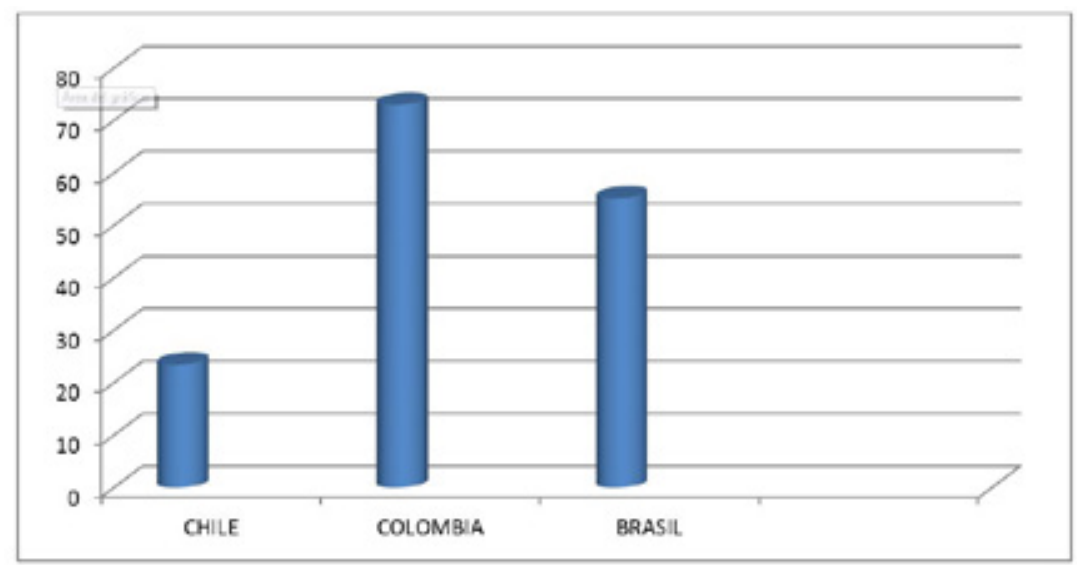

Recuperado de Semana, 2012. 


\section{GRAFICA 5}

Montos que se han pagado por condenas al Estado colombiano

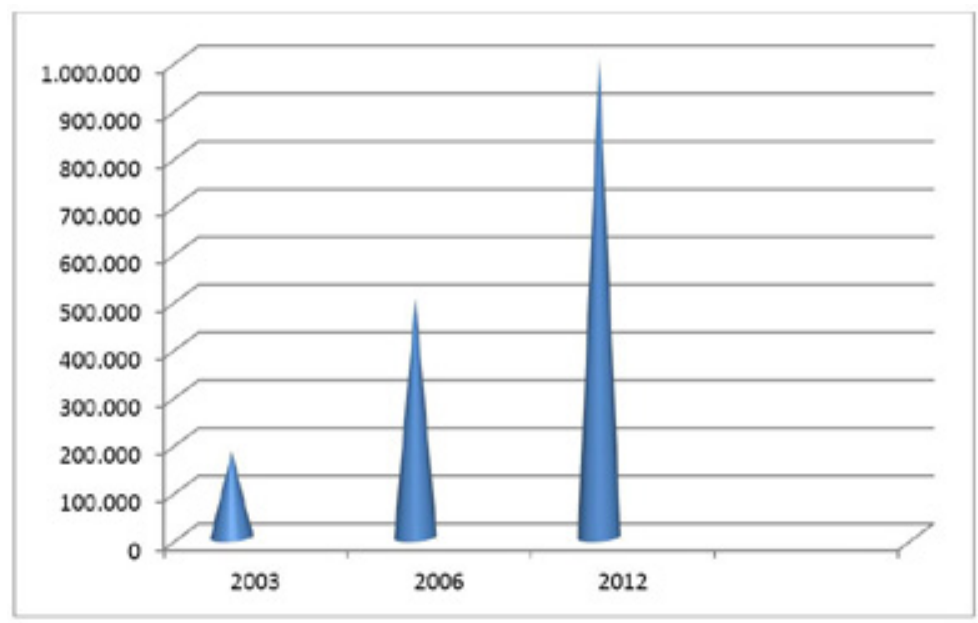

*Cifras en millones de pesos para el 2012. Recuperado de Semana, 2012

Según se ve en las gráficas, Colombia es el país que más demandas pierde en relación con Chile y Brasil, de igual forma se evidencia que los montos de las pretensiones que ha pagado Colombia también se encuentran en acenso.

Explica Carrillo que el Distrito en administración de Antanas Mockus creó el Sistema de Procesos Judiciales de Distrito Capital que en una sola entidad unificó los procesos y logró revertir la cifra de pagos por contingente judicial en el 2004 pago 244 millones de dólares y en el 2010 sólo 32 millones de dólares. (Semana, 2012).

La Agencia tiene funciones relacionadas con la formulación, evaluación y aplicación y difusión de las políticas relacionadas con la defensa, y prevención del daño antijurídico. Asimismo, coordina la defensa jurídica del Estado y asumirá la representación judicial del Estado en los procesos internos o internacionales, en los cuales estén en juego los intereses del mismo según los criterios que establece la ley. La ley otorgó a la Agencia un verdadero rol de coordinación, pero también de formulación de lineamientos y políticas en la defensa jurídica del Estado. 
La función de defensa jurídica del Estado se originó en el entonces Ministerio del Interior y de Justicia, y se desempeñó allí por más de una década teniendo como principal fruto, la consolidación de una base de datos, que contiene la información de las pretensiones litigiosas, de todas las entidades a nivel nacional. Esta base de datos, permitió tomar decisiones frente a la posibilidad de mecanismos alternativos para solucionar controversias como la conciliación, capacitar a los abogados encargados de la defensa del Estado en las diferentes entidades, consolidar protocolos para responder a demandas sobre las mismas temáticas, pero lo más importante consolidar los valores de las pretensiones en contra del Estado.

En el año 2011, dicha dirección se conformó en la Agencia para la Defensa Jurídica del Estado, una Unidad Administrativa Especial adscrita al Ministerio de Justicia y del Derecho, y que hace parte de la Rama Ejecutiva. Cuenta con un rol más amplio del que tenía la antigua Dirección de Defensa; en el que se consideran como funciones: la formulación, aplicación y divulgación la política pública de defensa jurídica del Estado; la coordinación de la defensa nacional e internacional del Estado y la representación judicial del mismo en ciertos procesos.

El proceso de creación de la Agencia se llevó a cabo con la colaboración del Banco Interamericano de Desarrollo y un equipo del gobierno. Su creación se anunció así:

(...) incrementará el número de casos conciliados, ahorrara costos y contingencias de largos procesos, tendrá a su cargo controlar y coordinar los casos adelantados ante organismos y tribunales internacionales, como la Corte Interamericana de Derechos Humanos o la Corte Internacional de Justicia de La Haya, entre otras; y realizara el ordenamiento y sistematización de la información disponible de todos los casos adelantados en contra de la Nación (...)

(...) será una Agencia moderna, innovadora, con gran apoyo en las tecnologias de la información, que recoja las buenas experiencias internacionales y evite dificultades ya experimentadas tanto a nivel interno, como a nivel internacional”, expresó (el Presidente) Santos.(...) (Departamento Nacional de Planeación, 2011) 
Advierte que la Agencia tendrá tres direcciones: Defensa Jurídica, Políticas y Estrategias en Defensa Jurídica, y Gestión de la Información. No obstante, no quedo claro el panorama específico en materia de defensa internacional del Estado, pues aún no se cuenta con un equipo especial dentro de la Agencia que desarrolle la defensa internacional, adicionalmente la normatividad, no deja muy clara la función que desempeña el Ministerio de Relaciones Exteriores.

El rol de la Agencia en los procesos judiciales ante organismos internacionales o extranjeros, le informó que de conformidad con el artículo 6, numeral 3, literales (iii) y (iv) del Decreto 4085 de 2011, la Entidad tiene como funciones " coordinar o asumir la defensa jurídica del Estado en los procesos que se adelanten ante organismos y jueces internacionales o extranjeros, de conformidad con los tratados y acuerdos que regulen la materia” y " apoyar al Ministerio de Comercio Industria y Turismo en la Defensa de las controversias comerciales internacionales del Estado colombiano y en los procesos que se adelanten en instancias internacionales en relación con las obligaciones contenidas en tratados internacionales en materia de inversión.

La agencia coordina la defensa jurídica internacional, pero con un importante soporte institucional. No obstante no existe una interinstitucionalidad preestablecida o fija sino que el asunto determina la autoridad o institución que deba estar presente en la gestión de defensa para el caso concreto. Por lo pronto la Agencia no ha asumido totalmente la coordinación de la defensa internacional, aun la asume el Ministerio de Relaciones Exteriores.

En respuesta a un derecho de petición enviado a la Agencia, la misma señaló que no existe línea o política general para determinar la procedencia de soluciones amistosas o mecanismos alternativos de solución de conflictos internacionales. La Agencia reconoce que esta es una de las funciones que se asumirán en el futuro. A la pregunta de cuánto ascienden las pretensiones en demandas internacionales, la Agencia manifestó no tener establecidos los rubros pecuniarios. (Derecho de Petición Agencia Nacional de Defensa Jurídica del Estado, 2012) 


\section{A modo de conclusión...}

Por razones del conflicto interno y la situación de violencia generaliza$\mathrm{da}$ fueron varias las instituciones que debieron adaptarse para responder ante la comunidad internacional en la defensa jurídica del Estado.

Algunas instituciones enfrentan directamente la labor de defenderlo y de otra parte encontramos otras instituciones que aportan técnicamente y hacen control fiscal en materia de contingencias judiciales.

Si bien ha sido un esfuerzo notable que ha evolucionado con el tiempo, al que se la ha invertido recursos económicos, humanos e incluso algunas propuestas para su mejor desarrollo, la articulación de entidades no se evidencia tan simple como se creyera en tan solo defender los intereses de la nación a nivel internacional.

Algunas de las instituciones para adelantar su labor requieren de la cooperación de las otras para que les suministren insumos con el fin de poder explicar internacionalmente la actuación del Estado. Para otras entidades se confunden los intereses de la misma entidad frente a los intereses estatales impidiendo una misma voz en la defensa de Colombia.

Para la mayoría de las entidades el problema es eminentemente económico de cómo se provisionan las contingencias judiciales. En este sentido, la defensa jurídica internacional cuenta con múltiples variables y en algunos casos enfrenta las diferencias de los intereses de cada institución desconociendo el interés primordial que es la defensa jurídica del Estado, no la defensa de los intereses de cada institución. Por lo tanto, pareciera que no ha articulado muy bien el panorama de responsabilidad internacional.

La Agencia de Defensa Jurídica se proyecto como el ente que asumiría dicha defensa pero en la marcha mantuvo solo su función de coordinación y parte de la defensa técnica continua en las instituciones. Para Ostrom (2005) todas las entidades deben articularse para que el Estado obtenga su objetivo. El error es caes en defender a una institución desconociendo el interés general de la nación.

La constitución advierte que Colombia es un Estado unitario y sus políticas deben procurar el bienestar general. Toda política pública debe tener un objetivo central que es tan importante como la formulación 
del problema de la política. El objetivo sirve de brújula para señalar el fin que se quiere alcanzar.

Cada institución se crea para trabajar en un objetivo, en algunos casos estos se pueden cruzar, para lo cual se creó la Agencia que con el paso del tiempo ha madurado su propio objetivo el cual es el de coordinar de manera imparcial la defensa jurídica del Estado. Después de algunos años de funcionamiento, la entidad entendió que su rol era el de coordinar - conciliar y mediar entre las instituciones buscando un beneficio superior estatal.

La Agencia ha servido para la coordinación, mediación y conciliación y aporta neutralidad en medio del de los objetivos particulares de las entidades que se encuentran.

Pero es fundamental comprender que si bien a nivel internacional, la defensa de los derechos humanos es lo que visibiliza la problemática, son varios los frentes que Colombia debe atender en respuesta a sus compromisos internacionales, y es claro como no todos fueron contemplados en la política Conpes.

No obstante, la presente investigación toma solo la defensa en derechos humanos, como estudio ya que solo en este frente se presentan falencias que responden a un diseño no muy ajustado dentro de la política pública.

\section{Referencias bibliográficas}

Agencia Nacional de Defensa Jurídica del Estado (26 DE octubre de 2016). Derecho de Petición No. 20168001831622. Bogotá.

Centro Dejusticia, (2005) ¿justicia mediante litigio? Reparación y extracción en las demandas laborales y extracontractuales en contra del Estado. Informe final presentado al Ministerio del Interior y Justicia.

Congreso de la República de Colombia. (2011) Decreto Ley 4085 de 2011, por la cual se establecen los objetivos y estructura de la Agencia Nacional de Defensa Jurídica del Estado. Bogotá: Diario Oficial 48240 del 1 de noviembre de 2011.

Consejo de Defensa Jurídica del Estado. "Ministerio de Justicia y de Derechos Humanos Perú". https://www.minjus.gob.pe/defensa-del-estado/ (acceso febrero de 2017). 
Consejo Nacional de Política Económica y Social. (2003) Documento CONPES 3250. Bogotá.

Consejo Nacional de Política Económica y Social. (29 de marzo de 2012) Documento CONPES 3722. Bogotá.

Constitución Política de Colombia (1991). Bogotá: Legis,.

Correa, María Victoria. (18 de marzo de 2016) "El controversial 'no' de Santos a la Corte Internacional de La Haya”. El Colombiano, Sección Colombia. Sitio Web http://www.elcolombiano.com/colombia/ el-controversial-no-de-santos-a-la-corte-de-la-haya-XA3772725

Corte Interamericana de Derechos Humanos. (5 de julio de 2004) . Caso 19 Comerciantes vs. Colombia. Fondo, Reparaciones y Costas. Sentencia C-109.

Derecho de Petición - DNP, SJ- 2010420693171 (Departamento Nacional de Planeación 4 de octubre de 2010).

Derecho de Petición Agencia Nacional de Defensa Jurídica del Estado, U.A.E.A.N.D.J.E 02 (Agencia Nacional de Defensa Jurídica del Estado 21 de diciembre de 2012).

Derecho de Petición Defensa Internacional del Estado, 6001 (Ministerio de Hacienda y Crédito Público 30 de septiembre de 2010).

Derecho de Petición Defensa Internacional del Estado, OALI 014 (Ministerio de Comercio, Industria y Turismo 04 de febrero de 2011).

Derecho de Petición Defensa Internacional del Estado, OALI 014 (Ministerio de Comercio, Industria y Turismo 04 de febrero de 2011).

Derecho de Petición Dirección de Defensa Jurídica del Estado, OF110- 35202DIL- 0352 (Ministerio del Interior y de Justicia 29 de septiembre de 2010).

Derecho de Petición en Defensa Internacional del Estado, DIDHD/GOI No 10001/0451 (Dirección de Derechos Humanos y DIH 21 de febrero de 2011).

Derecho de Petición en Defensa Internacional del Estado, OALI-002 (Oficina de Asuntos Legales Internacionales 3 de enero de 2011).

Lenoir, Remy. (1964) ."Groupes de pression et groupes consensuels. Contribution a un analyse de la formation du droit". Actes de la Recherche en Ciences Sociales. 
López, J. y Parra, F. (2010). El análisis del desarrollo institucional (IAD) de Elinor Oström. En A.N. Roth (Ed.), Enfoques para el análisis de las políticas públicas (p-97-122). Bogotá: Universidad Nacional de Colombia.

Molano, Andrés. (21 de noviembre de 2013 ). "Acuerdo ente Colombia y Ecuador: Glifosato, secretos y contradicciones”. razonpublica.com. Sección Política y Gobierno.. Sitio Web: http://www.razonpublica.com/index.php/ politica-y-gobierno-temas-27/7144-el-acuerdo-entre-colombia-y-ecuador-glifosato,-secretos-y-contradicciones.html

Oström, E. (2005). Understanding institucional diversity. Michigan: Princeton.

Patiño Aroca, Ricardo y María Ángela Holguín. (9 septiembre de 2013) Acuerdo entre la República del Ecuador y la Republica de Colombia, para la solución de la controversia existente en la Corte Internacional de Justicia, relativa a la erradicación de cultivos ilícitos cerca de la frontera con Ecuador.

Presidencia de la Republica. "LITIGOB”. http://wp.presidencia.gov.co/sitios/ dapre/oci/ Paginas/litigob.aspx

Jordana, J. (1995). El análisis de los policy networks: ¿una perspectiva sobre la relación entre las políticas públicas y el Estado? Gestión y Análisis de Políticas Públicas, 3, 77-90. Recuperado de goo.gl/IPGv8N

PandioleauJ. (1982). L'Etat au concret. Politiques et management public, vol. $1, n^{\circ} 2,1983,107-110$.

Portafolio. (27 de 01 de 2012). Agencia de Defensa Jurídica protegerá al Estado de demandas. Recuperado el 27 de 01 de 2012, de Portafolio.co: www.portafolio.co

Semana. (2012). 1.000 billones de pesos. Semana, 20 - 24.

Roth, A.-N. (2009). Políticas Públicas. Bogotá. 


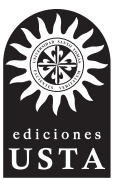

Esta obra se editó en Ediciones USTA, Departamento Editorial de la Universidad Santo Tomás. Se usó papel propalcote de 300 gramos para la carátula y papel bond beige de 75 gramos para páginas internas.

Tipografía de la familia Sabón. 2018 